\title{
The January 17, 1994 Northridge Earthquake: Effects on Selected Industrial Facilities and Lifelines
}

Mark W. Eli

Stanley C. Sommer

Thomas R. Roche

Kelly L. Merz

February 1995

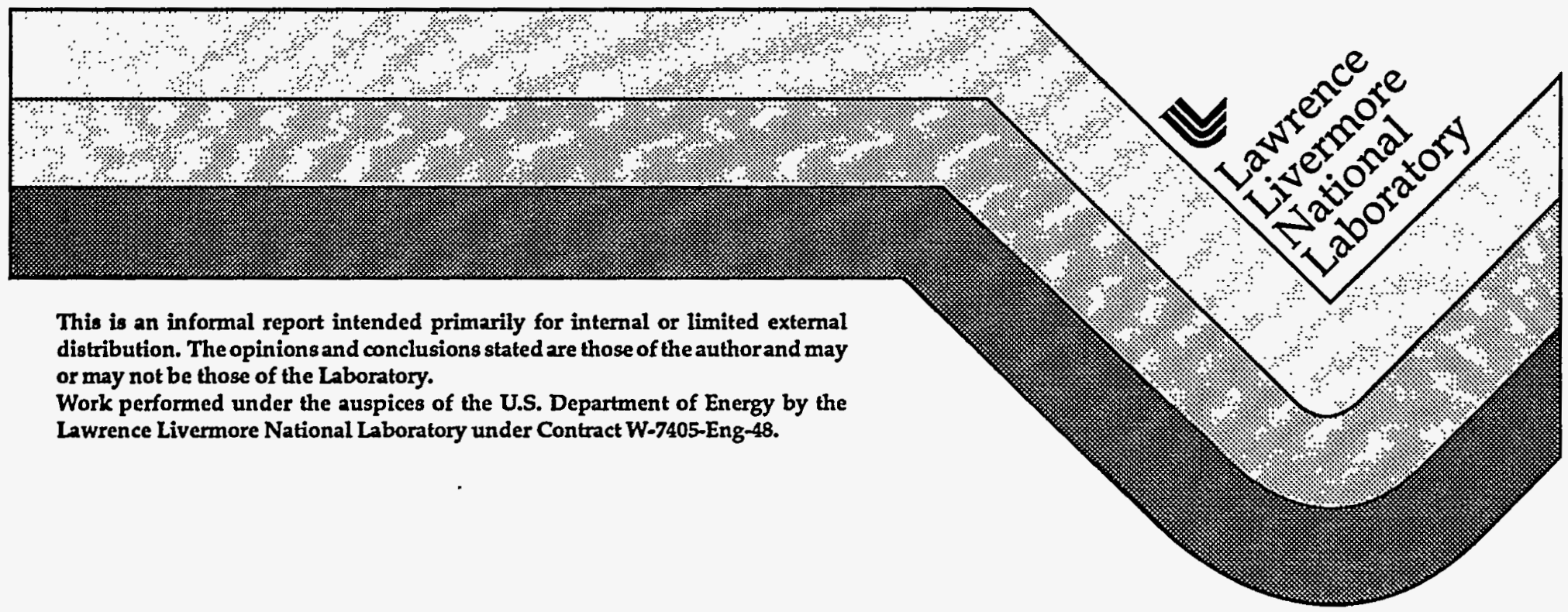

DISTAIBUTION OF THIS DOCUMENT IS UNLIMITED Gt 


\section{DISCLAIMER}

This document was prepared as an account of work sponsored by an agency of the United States Government. Neither the United States Government nor the University of California nor any of their employees, makes any warranty, express or implied, or assumes any legal liability or responsibility for the accuracy, completeness, or usefulness of any information, apparatus, product, or process disclosed, or represents that its use would not infringe privately owned rights. Reference herein to any specific commercial product, process, or. service by trade name, trademark, manufacturer, or otherwise, does not necessarily constitute or imply its endorsement, recommendation, or favoring by the United States Government or the University of California. The views and opinions of authors expressed herein do not necessarily state or reflect those of the United States Government or the University of California, and shall not be used for advertising or product endorsement purposes.

This report has been reproduced directly from the best available copy.

Available to DOE and DOE contractors from the Office of Scientific and Technical Information P.O. Box 62, Oak Ridge, TN 37831

Prices available from (615) 576-8401, FTS 626-8401

Available to the public from the

National Technical Information Service

U.S. Department of Commerce

5285 Port Royal Rd.

Springfield, VA 22161 


\section{DISCLAIMER}

Portions of this document may be illegible in electronic image products. Images are produced from the best available original document. 


\title{
The January 17, 1994 Northridge Earthquake: Effects on Selected Industrial Facilities and Lifelines
}

\author{
Prepared by: \\ Mark W. Eli and Stanley C. Sommer \\ Lawrence Livermore National Laboratory \\ Thomas R. Roche and Kelly L. Merz \\ EQE International \\ Sponsored by: \\ United States Department of Energy \\ United States Nuclear Regulatory Commission \\ In Conjunction With: \\ Electric Power Research Institute
}

February 1995

DISTRIBUTION OF THIS DOCUMENT IS UNLIMITED

$\mathrm{BH}$ 


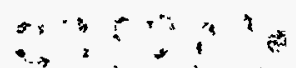

$\because: 2$ 


\section{TABLE OF CONTENTS}

1. INTRODUCTION .......................................................... $\frac{\text { Page }}{1-1}$

1.1 Mitigating the Effects of Earthquakes.................................... 1-4

1.2 Types of Damage Caused by the Earthquake ............................. 1-6

1.3 References........................................................... 1-28

2. DESCRIPTION OF THE EARTHQUAKE.............................................. 2-1

2.1 Geologic Setting...................................................... 2-1

$2.2 \quad$ Historic Seismicity ................................................... $2-4$

$2.3 \quad$ Strong Motion ....................................................... 2-4

$2.4 \quad$ References.......................................................... 2-20

3. ELECTRIC POWER SYSTEMS.......................................................... 3-1

3.1 Electric Power System Response................................................... 3-1

3.2 Electric Power Generation....................................................... $3-4$

3.2.1 Valley Generating Station ........................................ $3-4$

3.2.2 Burbank Power Plant .......................................... 3-9

3.2.3 Glendale Power Plant......................................... $3-10$

3.2.4 Pasadena Power Plant ........................................... $3-12$

3.2.5 Ventura Coast Plants............................................. 3-16

3.2.6 Southern Los Angeles Plants ................................... 3-16

3.3 Electric Power Transmission...................................................... 3-17

$3.4 \quad$ References............................................................ $3-21$

4. INDUSTRIAL FACILITIES .............................................. 4-1

4.1 Cogeneration Facilities............................................................ 4-4

4.1.1 AES Placerita .................................................. 4 4-4

4.1.2 ARCO Placerita................................................. 4-9

4.1.3 Pitchess Honor Ranch ........................................... 4-12

4.1.4 Olive View Cogeneration Plant .................................. 4-17

4.2 Hospital Support Systems..................................................... 4-20

4.2.1 St. John's Hospital, Santa Monica................................ 4-22

4.2.2 Northridge Hospital and Medical Center, Northridge.................... 4-26

4.2.3 Olive View Hospital, Sylmar .................................... 4-29

4.2.4 Veterans' Administration Hospital \& Medical Center, Sepulveda..... 4-29 


\section{TABLE OF CONTENTS (CONTINUED)}

Page

4. INDUSTRIAL FACILITIES (Continued)

4.2.5 Holy Cross Medical Center, Mission Hills............................... 4-32

4.2.6 Indian Hills Hospital, Mission Hills ............................. 4-32

4.2.7 Granada Hills Community Hospital, Granada Hills ................ 4-38

4.3 Miscellaneous Industrial Facilities.............................................. 4-38

4.3.1 Data Processing Center ......................................... 4-40

4.3.2 Anheuser-Busch Los Angeles, California Plant .................... 4-42

4.3.3 Sand \& Gravel Plant ......................................... $4-45$

4.4 Seismic Base Isolated Facilities.................................................... 4-45

4.4.1 Los Angeles County Fire Command and Control Facility.............. 4-47

4.4.2 USC University Hospital............................................... 4-53

$4.5 \quad$ Research Facilities..................................................... 4-58

4.5.1 California State University at Northridge................................ 4-58

4.5.2 Energy Technology Engineering Center......................... 4-63

4.6 Emergency Power Systems .......................................... 4-65

$4.7 \quad$ References............................................................ 4-66

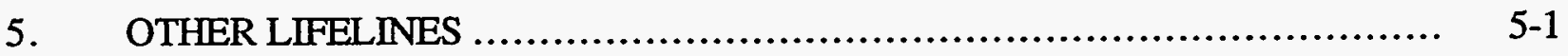

$5.1 \quad$ Water Systems.................................................... $5-1$

5.1.1 Los Angeles Department of Water and Power (LADWP) ............ 5-1

5.1.2 Los Angeles Aqueduct Filtration Plant - Van Norman Complex ...... 5-7

5.1 .3 Joseph Jensen Filtration Plant .................................. $5-9$

5.1.4 Response of Other Systems .................................. $5-14$

5.2 Telecommunications ................................................ $5-16$

$5.3 \quad$ Natural Gas Systems..................................................... 5-22

5.3.1 Southern California Gas Company (SoCalGas) ................... 5-22

5.3.2 Aliso Canyon Gas Storage Facility.................................... 5-29

$5.4 \quad$ Freeway Structures.......................................................... $5-30$

5.4.1 SR 14/I-5 Separation \& Overhead..................................... 5-30

5.4.2 I-5 at Gavin Canyon Undercrossing ............................ $5-34$

5.4.3 SR-118 at Mission-Gothic Undercrossing ........................ 5-39

5.4.4 I-10 at La Cienega-Venice Undercrossing.............................. 5-39

5.4.5 Interaction of Lifelines at Highway Bridges ...................... 5-48 


\section{TABLE OF CONTENTS (CONTINUED)}

Page

5. OTHER LIFELINES (Continued)

$5.5 \quad$ References............................................................. $5-50$

6. OBSERVATIONS AND CONCLUSIONS.............................................. 6-1

6.1 General ............................................................... 6-1

6.2 Structures, Systems, and Components ................................... 6-3

6.2 .1 Buildings .................................................... $6-3$

6.2.2 Nonstructural Components of Buildings ........................... 6-5

6.2.3 Mechanical and Electrical Equipment ............................ 6-5

6.2.4 Electric Power Systems and Substation Components.................... 6. 6-6

6.2.5 Water and Natural Gas Systems and Piping ........................ 6-7

6.2 .6 Tanks ........................................................ $6-9$

6.2 .7 Emergency Power............................................ $6-9$

6.2.8 Transportation Systems and Freeway Structures.................... 6-10

6.3 Action Items............................................................ 6-12

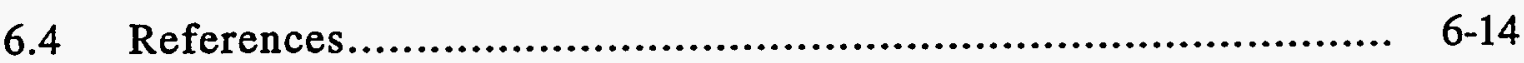




\section{ACKNOWLEDGMENTS}

The authors thank the following organizations and people who provided information and technical assistance for the preparation of this report.

- AES Placerita - Paul Burger

- Anheuser-Busch Companies

- California State University at Northridge - Ron Nelson, Environmental Department

- Energy Technology Engineering Center - Bob Jetter, Engineering Department

- Fluor Daniel, Inc. - Robert Bachman

- Government Information Service - Mark Williams

- Los Angeles County Fire Command and Control Facility - Dennis Martin, Facilities Complex Manager

- Los Angeles Department of Water and Power - Melvin Blevens, Watermaster of Upper Los Angeles River Area; Gil Grace, Sylmar Operations; Scott Munson, Field Operations Engineer; Mitchell Sakado, Waterworks Engineer; Kenneth Salsman, Engineering and Operations; Charles Serazio, Rinaldi Plant Superintendent; Ron Tognazzini, Seismic Manager

- Metropolitan Water District of Southern California - A. Alfi, Pipeline Engineering; Bill Pecsi, Joseph Jensen Filtration Plant; John Shama, Pipeline Engineering

- Northridge Hospital and Medical Center - Robert Henson, Director of Facilities

- Olive View Hospital - Tom Day, Director for Facilities; Ron French, Assistant Director for Facilities; Pat Horner, Steamfitter

- Rocketdyne Canoga Park Facility - Dick Wilson

- Southern California Edison - Ron Brown, Pardee Substation Station Chief; Dennis Ostrom, Seismic Manager; Carl Todd, Regional Manager

- State of California Governor's Office of Emergency Services - Brigitte Rehorn, Protocol Officer; Mike Sunderson 
- State of California Department of Conservation, Division of Mines and Geology - Anthony Shakal, Program Manager

- St. John's Hospital and Health Center - Satoshi Nitta, Assistant Director Construction

- Technical Council on Lifeline Earthquake Engineering - Mark Pickett, University of Toledo; Anshel Schiff, Precision Measurement Instruments

- USC University Hospital - David Zastrow, Chief Engineer

- Veterans' Administration Hospital in Sepulveda - Ad Amador; Ron Foster, Facilities Engineering; Ed Safdie

In addition, the authors thank Tong Ly and Brandy Stout of EQE International who provided editorial assistance in the preparation of the September 30, 1994 draft of this report.

The financial support of the following organizations and the technical review by the people listed at those organizations is greatly appreciated.

- Electric Power Research Institute - Robert Kassawara, Program Manager

- U.S. Nuclear Regulatory Commission - Roger Kenneally, RES

- U.S. Department of Energy - James Hill, EH-34

- U.S. Department of Energy - Jeffrey Kimball, DP-31

The authors thank Robert Murray of LLNL for providing management and technical assistance for the preparation of this report. Sections of the report were written by the following authors:

- $\quad$ Mark Eli, LLNL - Sections 1., 1.1, 1.2, 2., 2.1, 2.2, 4.2, 4.5, 4.6, 5., 5.4, 6.2, 6.3

- Kelly Merz, EQE - Sections 2.3, 3.1, 3.2, 3.3, 4.1

- Thomas Roche, EQE - Sections 2.3, 3., 3.1, 3.2, 3.3, 4., 4.1, 4.3

- Stanley Sommer, LLNL - Sections 1., 1.1, 1.2, 4.4, 4.5, 5.1, 5.3, 6.1, 6.2, 6.3

- $\quad$ Masoud Zadeh, EQE - Section 5.2 


\section{FOREWORD}

Revision 0 of this report is being published in February 1995 to closely mark the one-year anniversary of the Northridge Earthquake. A September 1994 Draft version of the report was reviewed by DOE and NRC, and many of the review comments are incorporated into Revision 0. While this revision of the report is not entirely complete, it is being made available for comment, review, and evaluation. Since the report was written by several authors, sections of the report have slightly different styles.

Several sections of Revision 0 are not complete, but are planned to be completed in Revision 1. The primary unfinished section is Section 3.3 on Electric Power Transmission. Other sections of Revision 0, such as Section 4.5.2 on the Energy Technology Engineering Center and 3.2 on Electric Power Generation, will be enhanced with further detailed information as it becomes available. In addition, further data, including processed response spectra for investigated facilities and cataloging of relay performance, will be added to Revision 1 depending upon investigation support. While Revision 0 of this report is being published by LLNL, Revision 1 is planned to be published by EPRI. The anticipated release date for Revision 1 is December 1995.

Unfortunately, the one-year anniversary of the Northridge Earthquake was also marked by the devastating Hyogo-Ken Nanbu (or Hanshin-Awaji) Earthquake in Kobe, Japan. As compared to the Northridge Earthquake, there were many more deaths, collapsed structures, destroyed lifelines, and fires following the Kobe Earthquake. Lessons from the Kobe Earthquake will both reemphasize topics discussed in this report and provide further issues to be addressed when designing and retrofitting structures, systems, and components for seismic strong motion. 


\section{INTRODUCTION}

On January 17, 1994, at 4:31 AM (PST), an earthquake with moment magnitude ( $\left.\mathrm{M}_{\mathrm{W}}\right) 6.7$ struck the Northridge area of metropolitan Los Angeles, California. It was one of the largest earthquakes to occur within a heavily populated area in the United States since the 1906 San Francisco Earthquake. The 1994 Northridge Earthquake has caused roughly $\$ 15-30$ billion in damage and has been estimated to have one of the highest amounts of insured losses due to a natural disaster in U.S. history. These large losses are due to the considerable damage to the built environment, such as industrial facilities, lifelines, commercial centers, and residential buildings. Damage consequences included collapsed buildings, loss of electric power to large portions of the city of Los Angeles, closure of major freeways due to collapsed freeway structures, and disrupted water and natural gas service. In addition, there was a substantial amount of nonstructural damage, such as water damage and contents destroyed by overturning or falling from shelves or cabinets, which caused closure of several hospitals and other facilities.

Fortunately, the number of deaths and injuries during the earthquake were limited by its timing, which was early in the morning and on the Federal holiday in honor of Dr. Martin Luther King Jr. Many nonresidential buildings were empty, and traffic on the Los Angeles freeways was relatively light. Nearly 60 deaths were attributed to the earthquake. In addition, about 1500 people sustained major injuries during the event, and about 16,000 people were treated and quickly released by hospitals [ref 1.0-1]. Approximately 100,000 people were temporarily or permanently displaced from their dwellings.

The epicenter of the earthquake is located about 20 miles northwest of downtown Los Angeles as shown in Figure 1.0-1. The main shock occurred on a relatively unknown blind thrust fault near the Frew and Santa Susana Faults. Similar to the 1971 San Fernando Earthquake which had an epicenter within 10 miles of Northridge, the Northridge Earthquake was characterized by reverse faulting and caused relatively high vertical accelerations. Several instruments within 15 miles of the epicenter recorded accelerations approaching $1.0 \mathrm{~g}$ in the horizontal and vertical directions. Areas of relatively strong ground motion included communities near Northridge, Van Nuys, Sylmar, Santa Clarita, and Santa Monica. Since there were many strong-motion instruments in the earthquake-affected region, many strong-motion recordings were obtained. These recordings provide an unprecedented opportunity to correlate recorded accelerations with the observed performance of structures. 


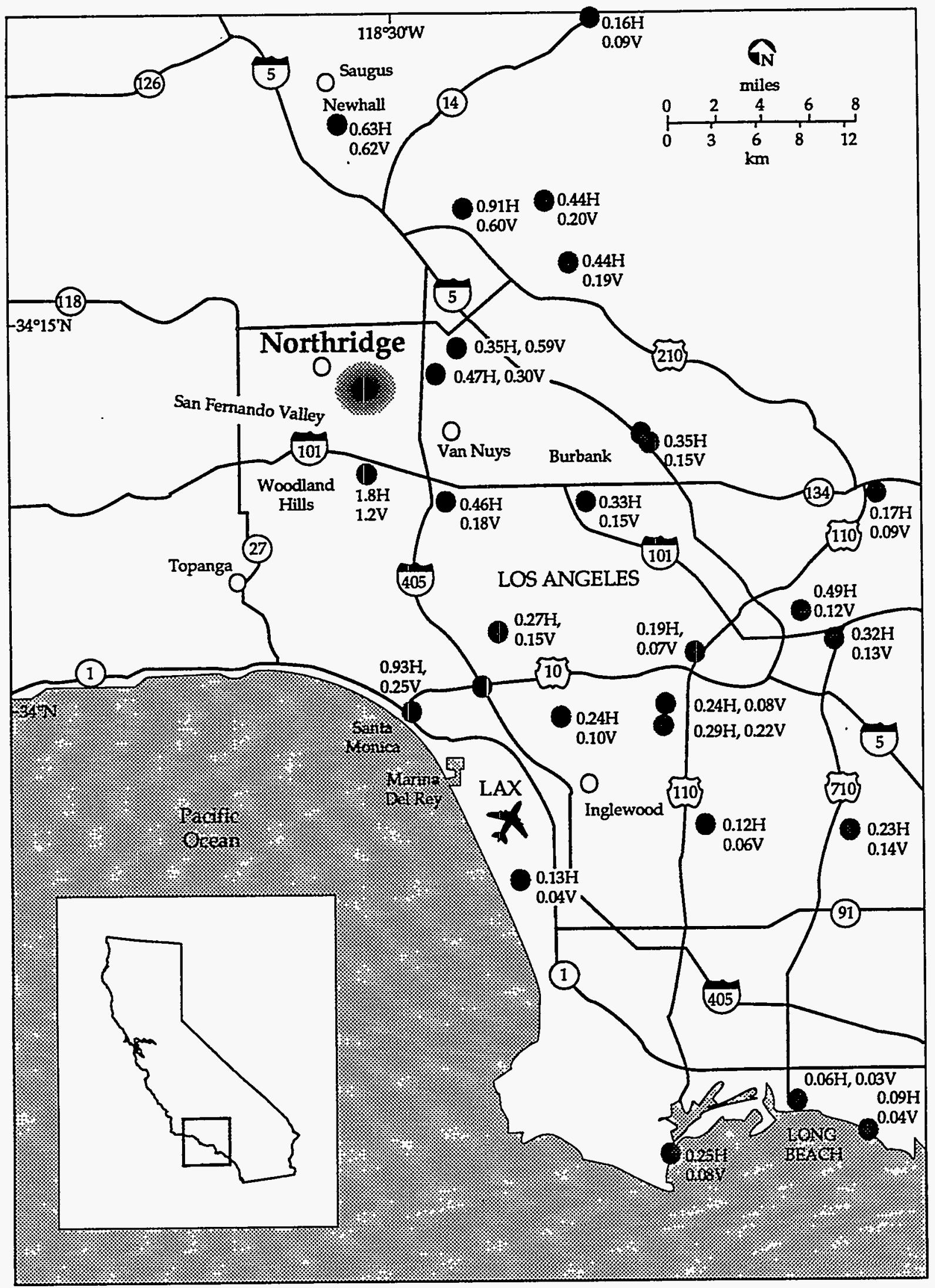

Figure 1.0-1 Based on the "Fifth Quick Report on CSMIP Strong-Motion Data from the Northridge/San Fernando Valley Earthquake of January 17, 1994," Report OSMS 94-05, California Strong Motion Instrumentation Program (CSMIP), January 25, 1994. Selected CSMIP stations that recorded the Northridge earthquake are shown as $\bigcirc$. The earthquake epicenter is denoted by , and peak horizontal and vertical acceleration values are shown. 
Since the Northridge Earthquake occurred in a highly populated and industrialized area, numerous types of structures, systems, and components (SSCs) experienced the seismic event. Many of these SSCs are similar to those found in nuclear power plants and in Department of Energy (DOE) facilities. To observe and document the effects of the earthquake on industrial facilities and lifelines, teams from Lawrence Livermore National Laboratory (LLNL) and from EQE International traveled to the epicentral region immediately following the seismic event. On several subsequent occasions, teams from LLNL and EQE were joined by members of the Nuclear Regulatory Commission (NRC), DOE, and the Electric Power Research Institute (EPRI) to conduct more detailed investigations. The observations made during these investigations, along with supplemental documentation, are the bases of information in this report.

This report provides a general overview of earthquake-caused damage to lifelines, freeway structures, and commercial buildings. However, the emphasis of the report is on the performance of structures and equipment in industrial facilities similar to those found in nuclear power plants, other electric power generation and transmission facilities, and DOE facilities. While these facilities may not have the identical SSCs as those discussed in the report, the engineering trends discovered about the seismic performance of the SSCs can be directly applicable. For most facilities discussed in the report, an attempt is made to provide an overall description of the facility, estimates of recorded accelerations, dimensions and ratings of damaged SSCs, potential interaction issues, and lessons about the performance of the SSCs in the facility. The lessons learned from the Northridge and previous earthquakes greatly aid efforts by DOE, NRC, and EPRI to mitigate the effects of earthquakes on industrial facilities and lifelines.

After introductory information in Chapter 1, Chapter 2 gives a general description of the seismological and geological aspects of the earthquake. Chapter 3 discusses the performance of electric power syštems, including power generation and transmission. In Chapter 4, many different types of industrial facilities including cogeneration facilities, hospital support systems, seismic base isolated facilities, and research facilities are discussed. Chapter 5 provides descriptions of the performance of lifeline systems such as water systems, telecommunications, natural gas systems, petrochemical systems, and freeway structures. Finally, Chapter 6 summarizes the detailed information in the report with overall observations and conclusions. Considerable efforts were made to validate the accuracy of the information in this report. As new information is uncovered about the earthquake, some of the details provided in this report will need to be updated to reflect the new data. However, the general trends and conclusions provided in Chapter 6 should remain valid. 


\subsection{MITIGATING THE EFFECTS OF EARTHQUAKES}

The main purpose of this report is to disseminate information about the effects of the Northridge Earthquake on industrial facilities and lifelines in order to develop effective seismic mitigation methodologies. The study discussed in this report focuses on electric power facilities, which were heavily shaken and damaged by the earthquake, and on industrial facilities and lifelines containing equipment and structures of relevance to DOE, NRC, and EPRI. It is part of a series of postearthquake investigations which have been conducted since the 1971 San Fernando Earthquake. For the first time, the observations and conclusions from investigations conducted for DOE, NRC, and EPRI are combined into a joint report. These observations and conclusions emphasize that while most of the damage caused by the Northridge Earthquake is repairable, much of it could have been avoided with proper seismic design practices and implementation and with effective seismic planning. Many studies have shown that the costs of repairing or replacing earthquake-damaged SSCs exceed those associated with implementing appropriate seismic design and planning procedures before the earthquake.

Since 1975, DOE has had an applied program to plan for and respond to natural phenomena hazards including earthquakes, extreme winds, hurricanes, floods, lightning, and volcanoes. The program has the following four mission areas: development of policy, requirements, and standards; technical support, research, and development; technology transfer; and participation in walkdowns and design reviews. An important element of this program has been the translation of post-earthquake observations into practical lessons for the DOE community. This report on the Northridge Earthquake provides valuable data for the development of seismic mitigation strategies for new and existing facilities within DOE.

DOE currently has an extensive program which uses experience data from past seismic events and testing programs to establish screening criteria for evaluating existing SSCs. Items which pass the screening criteria are accepted without detailed analysis or further testing. In addition, the program emphasizes the use of facility walkdowns as a means of identifying and fixing deficiencies of the most critical systems and components in an expedient manner. This experience-based screening evaluation methodology is expected to demonstrate sufficient safety margins in accordance with DOE criteria and to have implementation costs which are much less than the alternative options of analysis and testing. Information gathered from the Northridge Earthquake will greatly enhance the experience database.

Since 1979, the NRC has supported research associated with post-earthquake investigations. The scope of the research includes the impact a particular seismic event had on facilities that contained 
SSCs similar to those found in nuclear power plants. SSCs that survived well during the earthquake motions and also those that failed are investigated. These investigations provide insights and data used by the NRC staff to verify calculation assumptions, benchmark computer codes, and identify failure modes and levels used in seismic probabilistic risk assessments and seismic margin evaluations.

In 1985, EPRI began post-earthquake investigations to study the effects of interest to the electric power industry. Following the procedure of previous investigations, information was collected on the effects of the Northridge Earthquake to structures and equipment installations representative of modern power plants and substations. A particular emphasis was placed on gathering data on earthquake effects to equipment representative of critical systems in nuclear power plants.

The efforts by DOE, NRC, and EPRI to use earthquake experience data to evaluate the performance of SSCs has enhanced ongoing efforts within the nuclear power industry. As part of the Unresolved Safety Issue A-46 program (Verification of Seismic Adequacy of Equipment in Operating Plants), selected facilities provide earthquake experience data for the Seismic Qualification Utility Group (SQUG) 20 Classes of active electrical and mechanical equipment. Many of the selected facilities which experienced the 1971 San Fernando Earthquake also were affected by the 1994 Northridge Earthquake. The data and observations from the Northridge Earthquake will provide valuable information to augment the SQUG database for future applications of the database. As new and replacement equipment, or NARE, issues are explored, the 1994 Northridge Earthquake may help to yield useful data for future seismic evaluations.

Information gained from ongoing investigations of the 1994 Northridge Earthquake also has potential to benefit the development of criteria and procedures for seismic qualification of equipment that will be installed in Advanced Light Water Reactor (ALWR) plants. Performance of particular equipment classes and distribution systems in this earthquake can add to the database being assembled for the ALWR First-of-a-Kind Engineering, or FOAKE, Project on Equipment Seismic Qualification. 


\subsection{TYPES OF DAMAGE CAUSED BY THE EARTHQUAKE}

As a result of several strong-motion instrumentation programs, the region affected by the Northridge Earthquake contains a large number of strong-motion recordings. Instruments for these recordings were located in the free-field, at the ground level of buildings, and on floors of multi-story buildings. As shown in Figure 1.0-1 and discussed in several sections of this report, records indicate that the peak ground accelerations were much larger than the design values for many facilities. While many modern structures were designed with appropriate ductile details to accommodate these relatively large accelerations, numerous types of structures experienced nonductile performance leading to damage or collapse. In addition, the vertical accelerations were comparable to the horizontal accelerations in some cases and these relatively high vertical accelerations may have contributed to some of the failures in the epicentral region.

The relatively large ground motions during the Northridge Earthquake caused several types of structural damage. In general, nonductile reinforced concrete frame structures did not perform well. A considerable number of buildings with poor and nonductile structural details suffered significant damage including collapse. Examples of structural details which did not perform well included soft first stories, inadequate connections in precast structures, tilt-up wall to roof connections, and unreinforced masonry shear walls. Surprisingly, there was also considerable damage to steel special moment-resisting-frames (SMRFs). Even though no steel moment-frame buildings collapsed, observed connection failures were not expected by most of the structural engineering practitioners.

An example of a nonductile reinforced concrete frame building which collapsed is the Kaiser Permanente Medical Office Building. As shown in Figures 1.2-1 to 1.2-3, all of the columns failed just above the second floor. Located about 2 miles east of the epicenter, the Kaiser Permanente Building was a multistory frame with reinforced brick shear walls on its north and south faces. Poor beam-to-column details and lack of shear walls on the east and west faces contributed to the collapse. Since the north-south component of the earthquake appeared to dominate as discussed in Chapter 2 of this report, the massive east-west shear walls at each end of the building contributed little strength for resistance to the north-south component of the lateral load on the structure. Another nonductile reinforced concrete frame which collapsed was the Bullock's Department Store at the Northridge Fashion Center. It appeared that the concrete waffle slab on the second floor was not securely tied to the columns. This lack of connection allowed the floor to collapse as shown in Figures 1.2-4 and 1.2-5. 


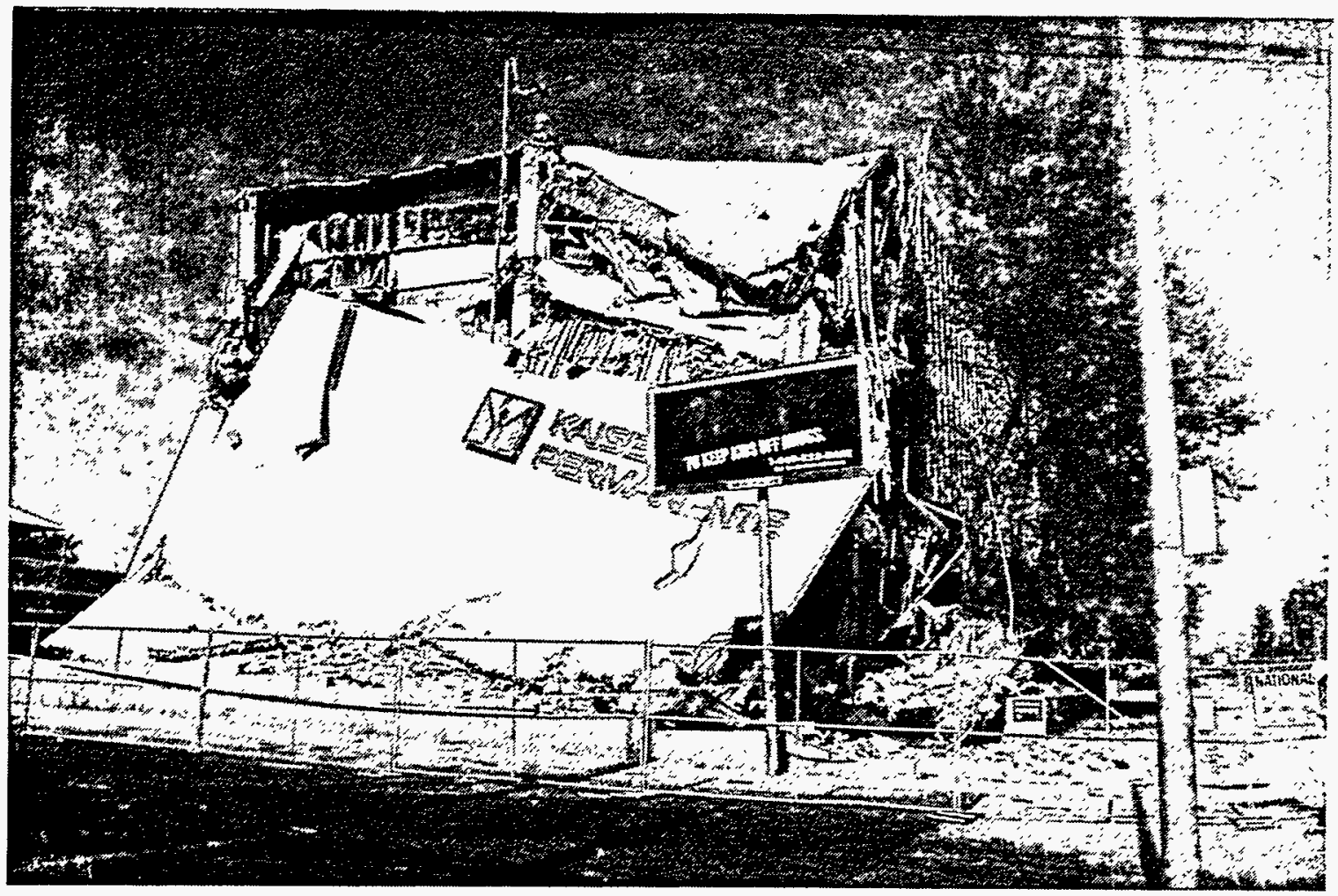

Figure 1.2-1: An example of a concrete-frame building which collapsed is the Kaiser Permanente Medical Office Building.

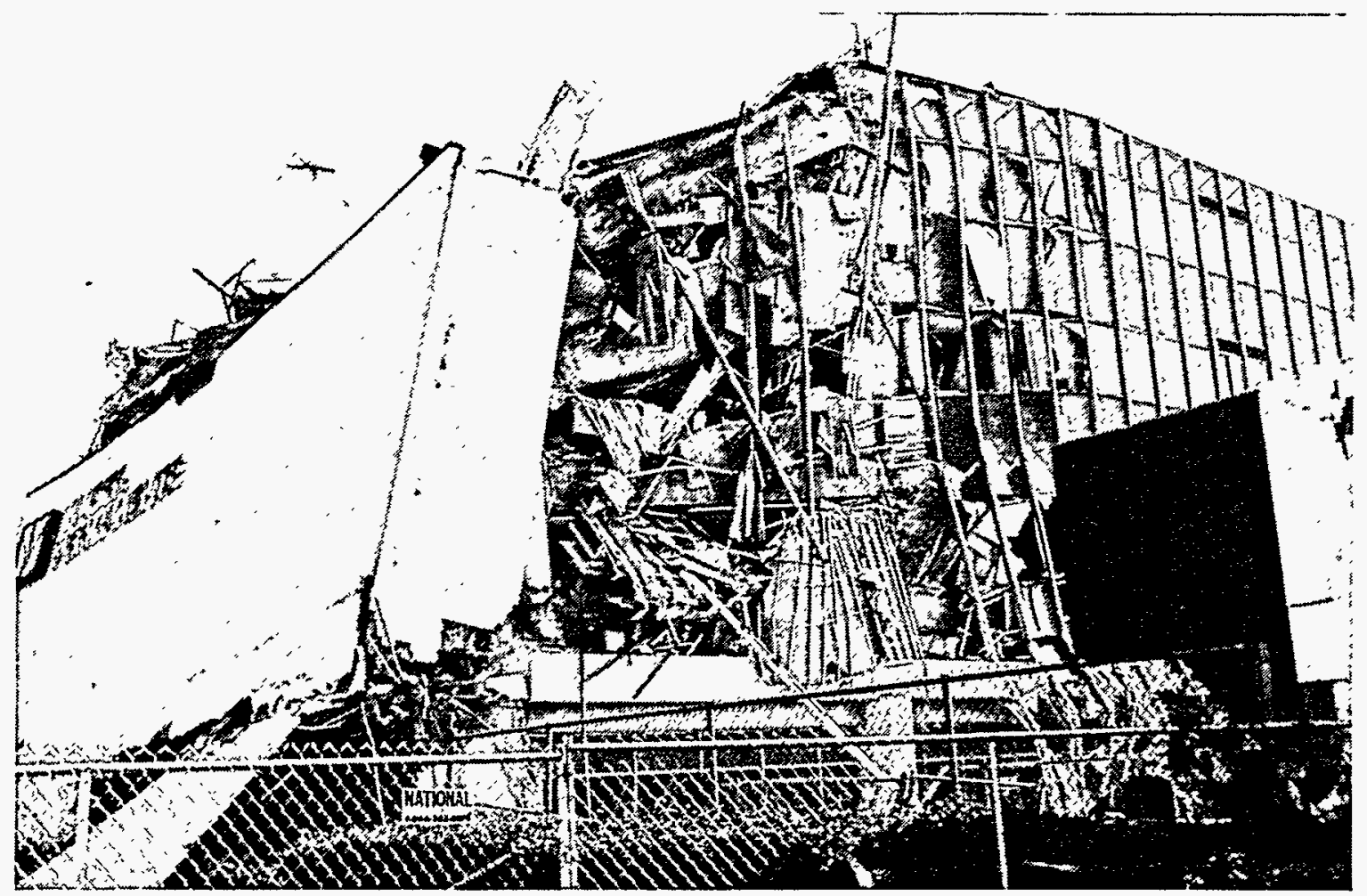

Figure 1.2-2: View from the NW corner of the collapsed Kaiser Permanente Medical Office Building. 


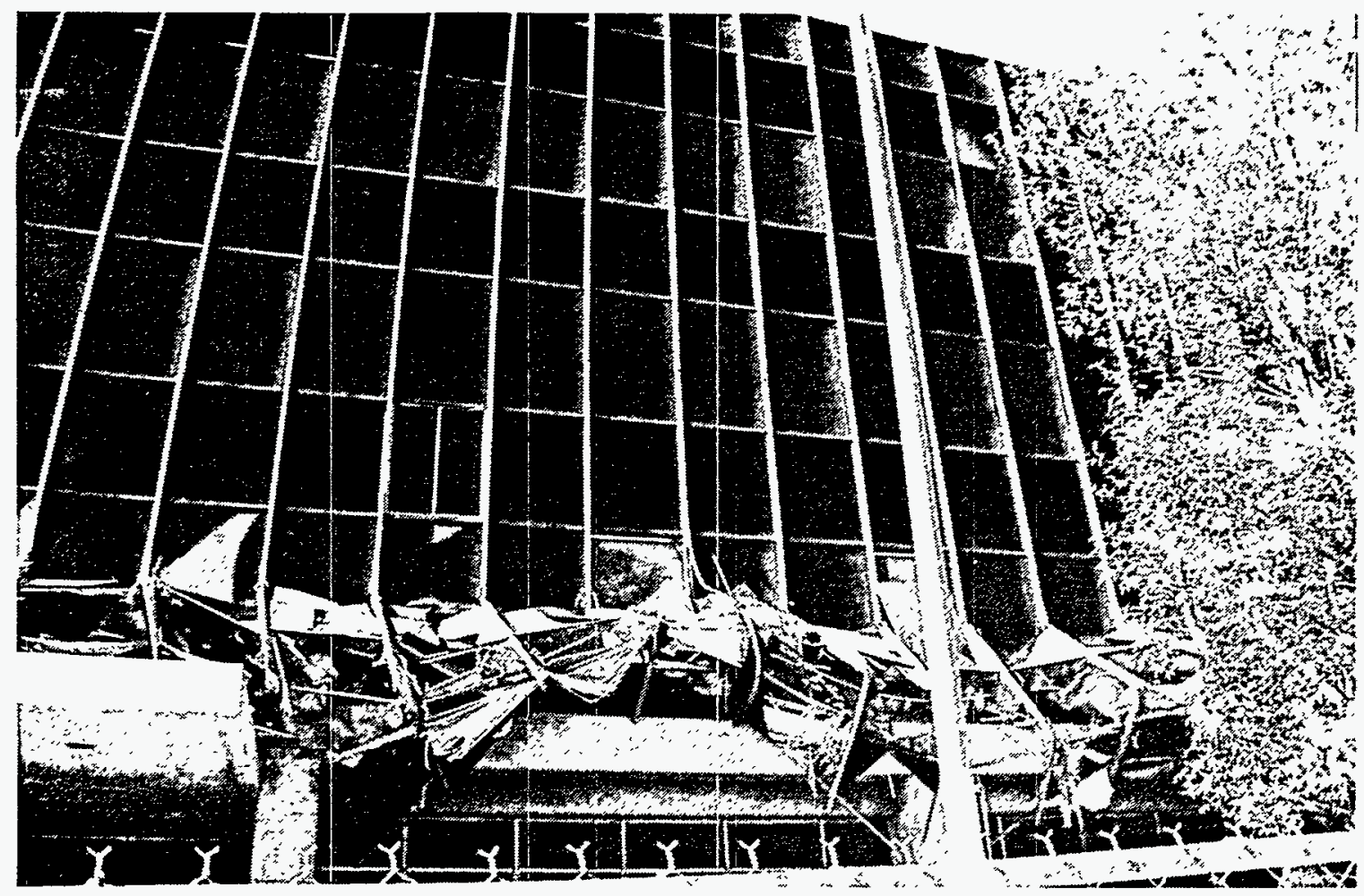

Figure 1.2-3: Close-up view of the collapsed second story of the Kaiser Permanente Medical Office Building. All of the columns had failed just above the second floor.

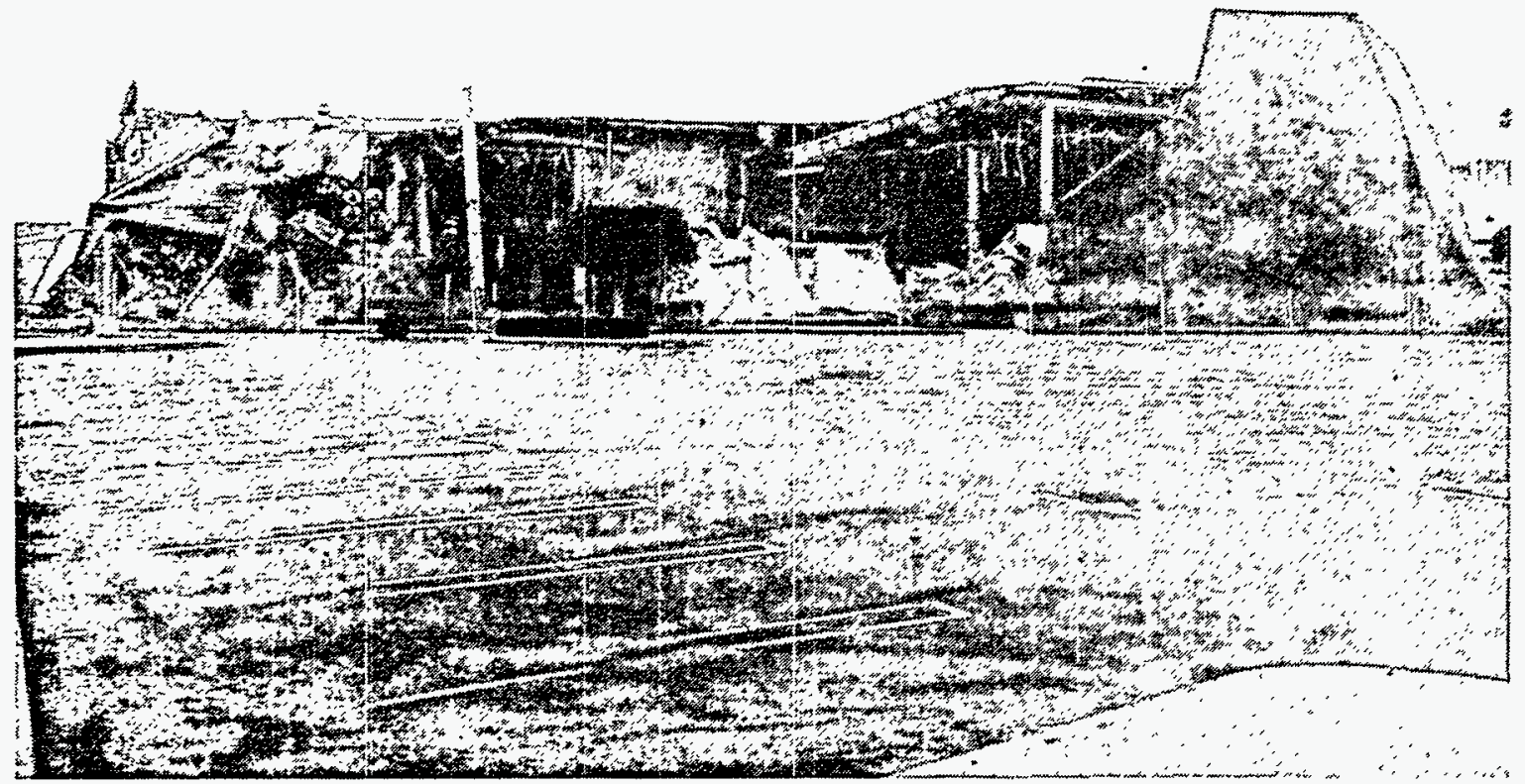

Figure 1.2-4: Bullock's Department Store at Northridge Fashion Center was another nonductile reinforced concrete frame structure that performed poorly. 
xə[duos quəunrede

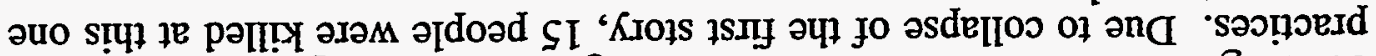

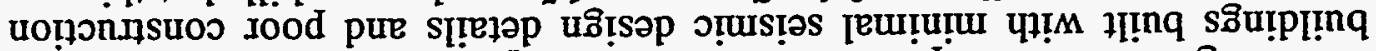

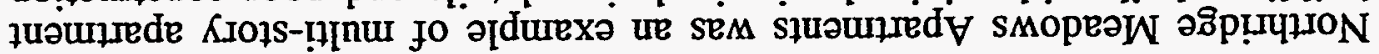

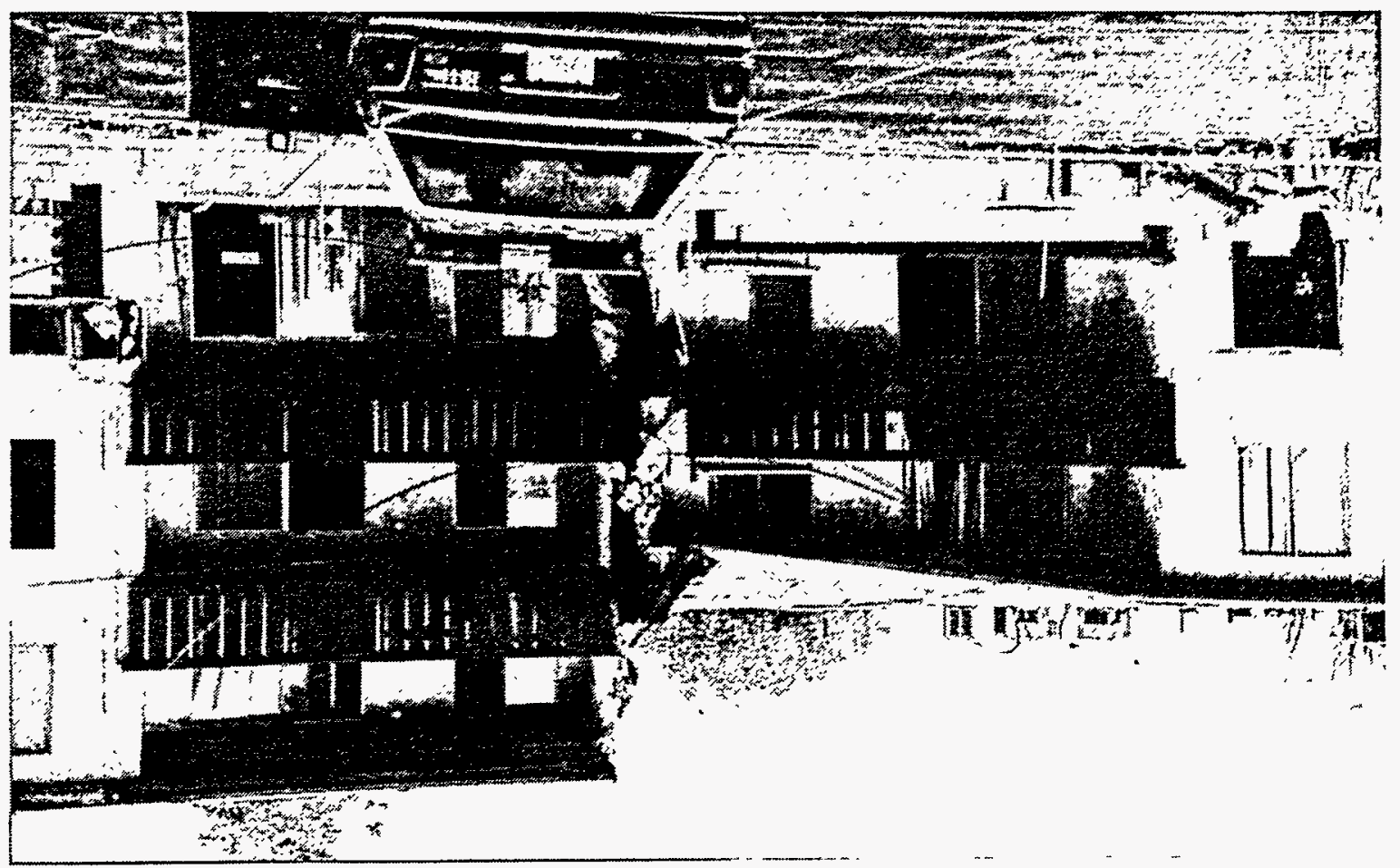

•əsde

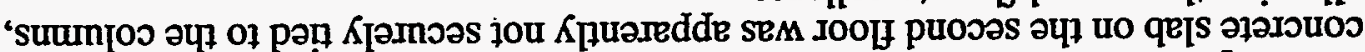

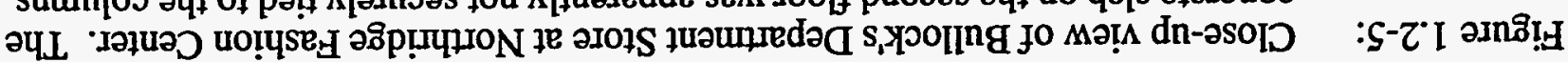

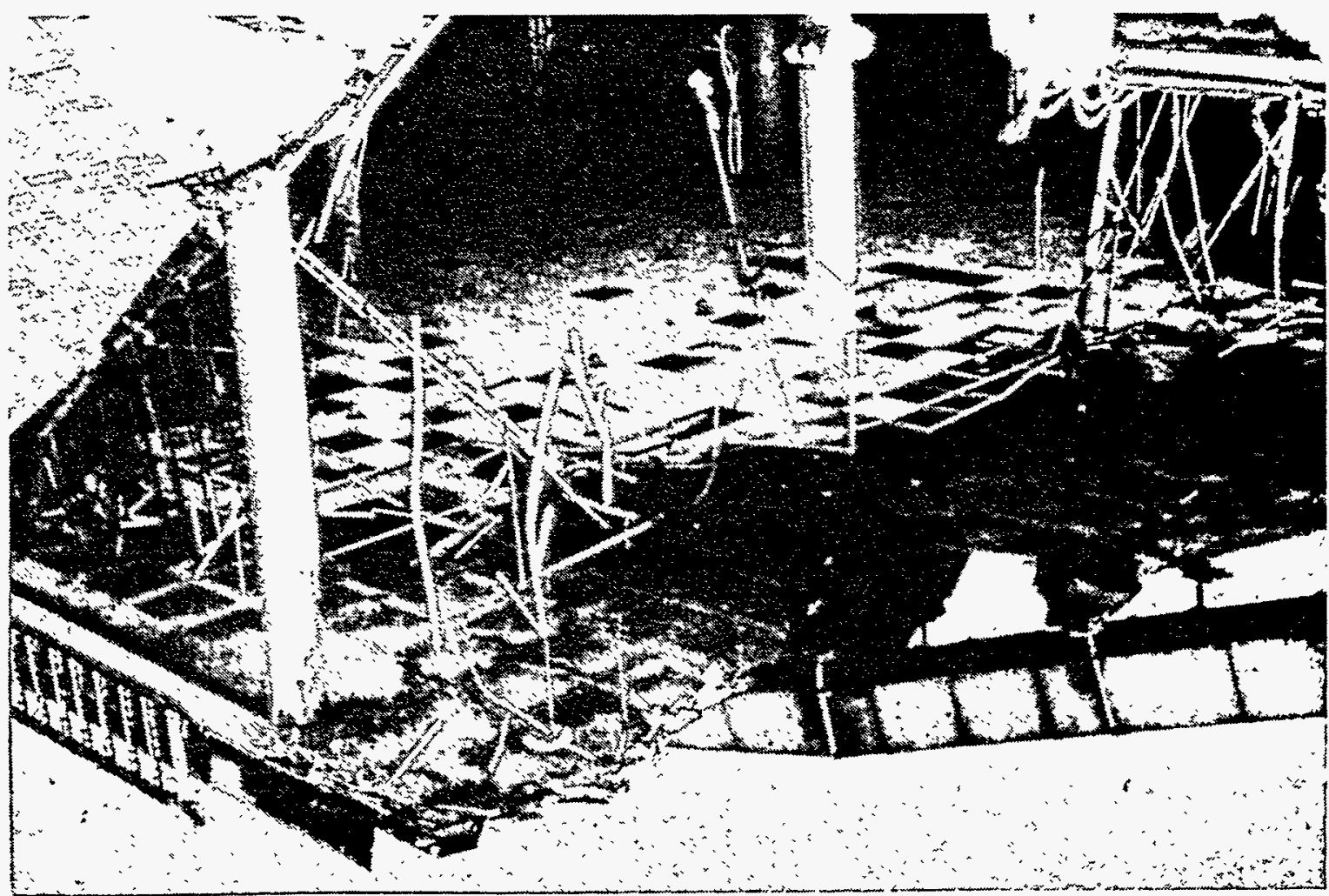


There were many severely damaged apartment buildings, especially those with parking garages on the first floor. These buildings were constructed as dwellings-over-garages. This building type typically does not perform well during earthquakes due to the inadequate horizontal shear capacity in the first floor and nonductile connections. Lack of good seismic design details and use of poor construction practices contributed to the collapse of the first story at the Northridge Meadows Apartments in Northridge as shown in Figure 1.2-6. Fifteen people were killed at this one apartment complex due to the earthquake.

The Northridge Earthquake caused eight parking garages to partially or totally collapse and caused damage to numerous other parking garages. Most of these parking garages were precast concrete structures with poor construction details and inadequate lateral-load resisting systems. Figures 1.2-7 and 1.2-8 show the collapsed parking garage at the Northridge Fashion Center. Even though this structure was constructed in the early 1990 s, it lacked adequate connection details to withstand the strong motion of the Northridge Earthquake. Another modern parking structure which collapsed during the earthquake was located at the California State University at Northridge (CSUN), shown in Figure 1.2-9. The CSUN structure had been designed as an exterior ductile frame with a nonductile interior structure. The short columns between the ramps and adjacent floors failed because they attracted loads which were higher than their intended capacities. In addition, the short development length of rebar between each column and the floor diaphragm did not provide sufficient resistance for the seismic strong motion. Both the Fashion Center and CSUN structures were located within 2 miles of the epicenter.

As has been typical in past earthquakes, unreinforced masonry (URM) buildings did not perform well. Figure 1.2-10 shows evidence of large diagonal cracks in the masonry wall of a URM building in Santa Monica. An out-of-plane-bending failure in a URM building is shown in Figure 1.2-11. Throughout the epicentral region, there were also widespread occurrences of typical earthquake damage including broken glass, fallen chimneys, and fallen poorly reinforced block walls as shown in Figure 1.2-12.

An area which is currently generating a lot of research is the damage to steel moment frame buildings. This research is focusing on welded-flange, bolted-web connections of steel beams to steel columns. An example of this type of connection is shown in Figure 1.2-13. During the Northridge Earthquake, an unexpected number of connections in steel buildings with this connection detail experienced brittle failures. Most of the buildings with these failures had been designed as SMRF buildings and with connections that met the ductile detailing provisions of the current building code [ref 1.2-3]. 


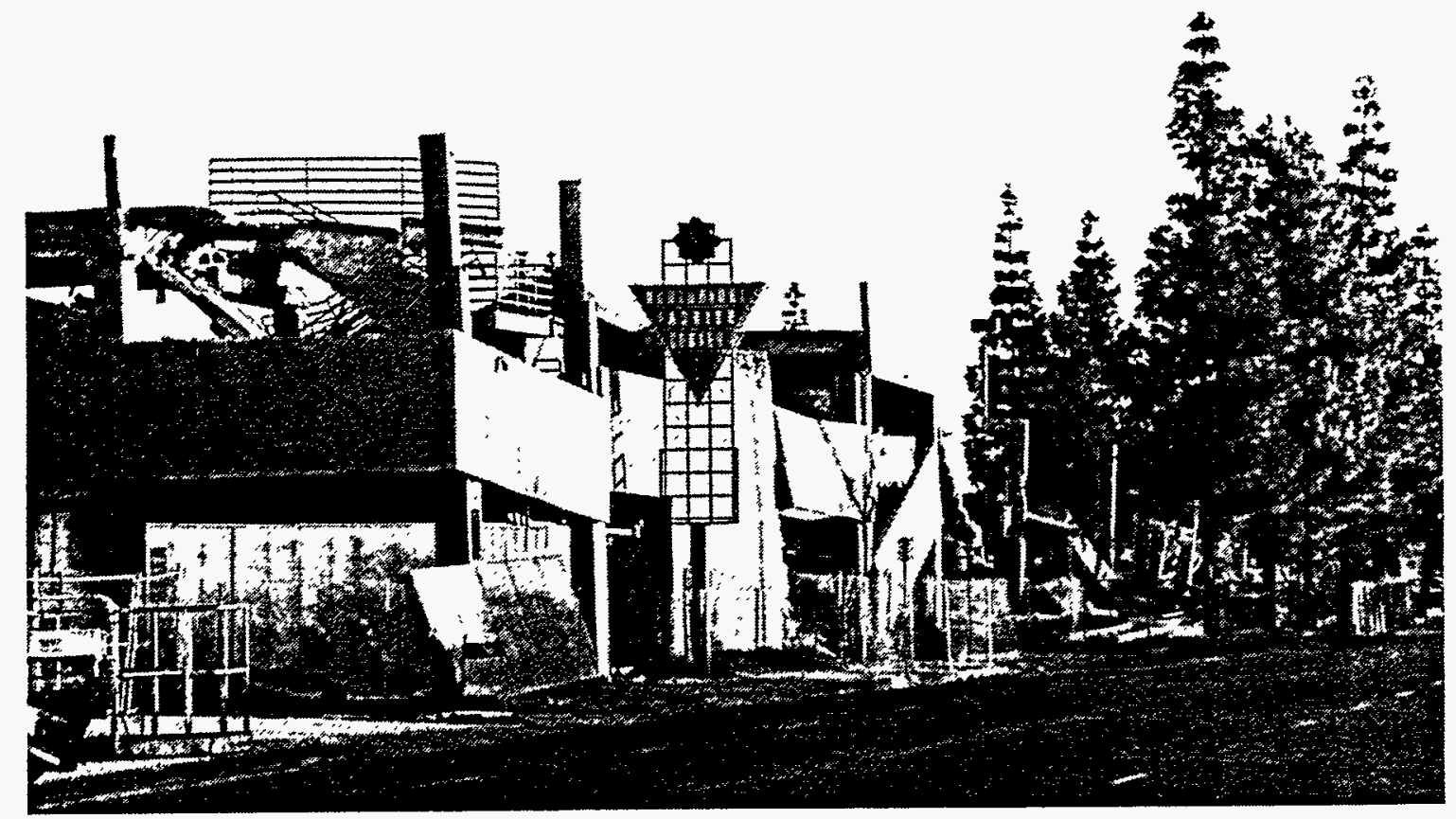

Figure 1.2-7: The concrete parking garage collapsed at the Northridge Fashion Center. A man working in a street sweeper was pinned underneath the collapsed structure for about nine hours until he was rescued.

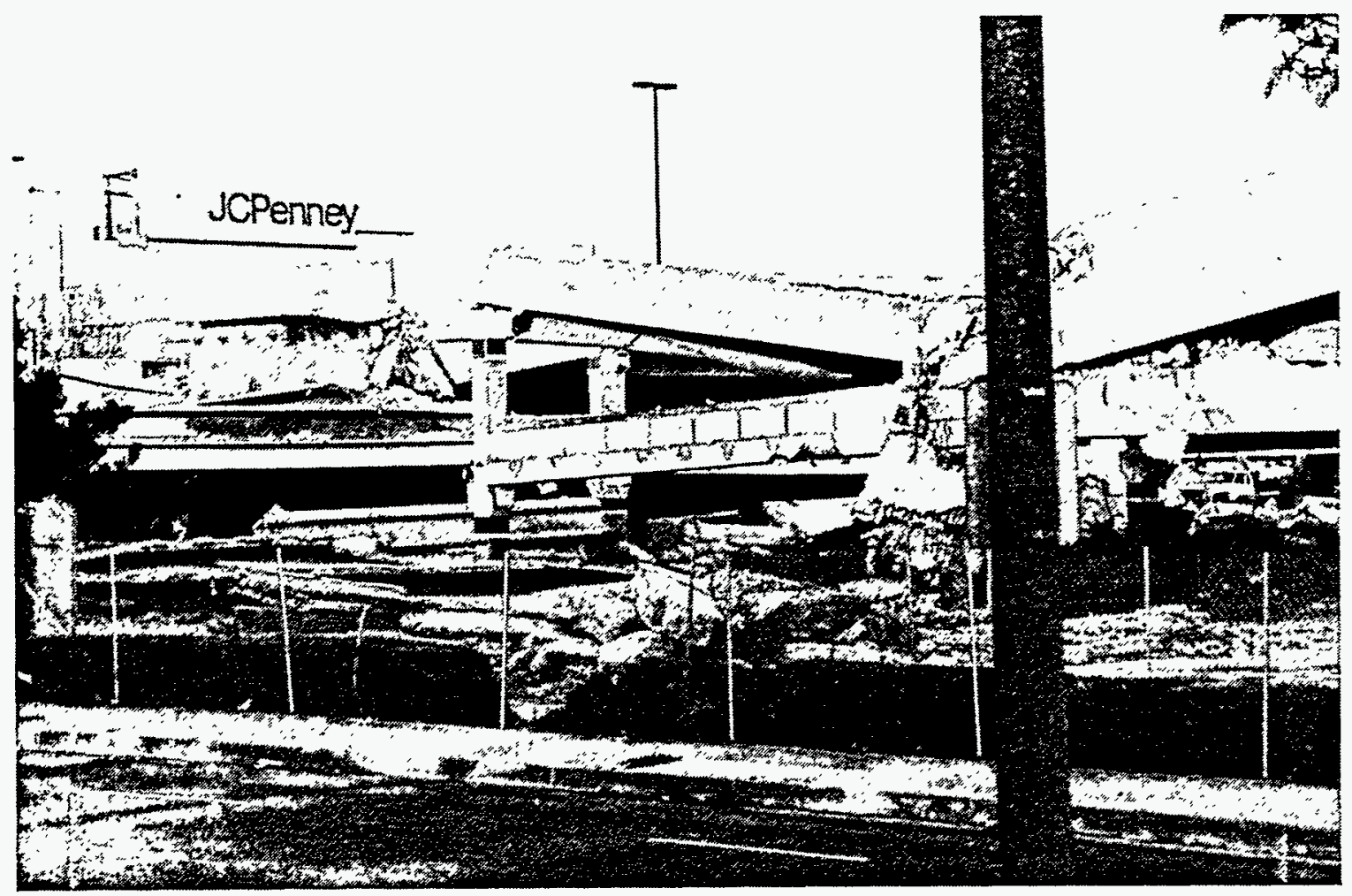

Figure 1.2-8: Another view of the concrete parking garage that collapsed at the Northridge Fashion Center. Poor connection details and lack of adequate lateral-load resisting systems led to severe damage to or failure of many parking garages in the earthquake-affected area. 


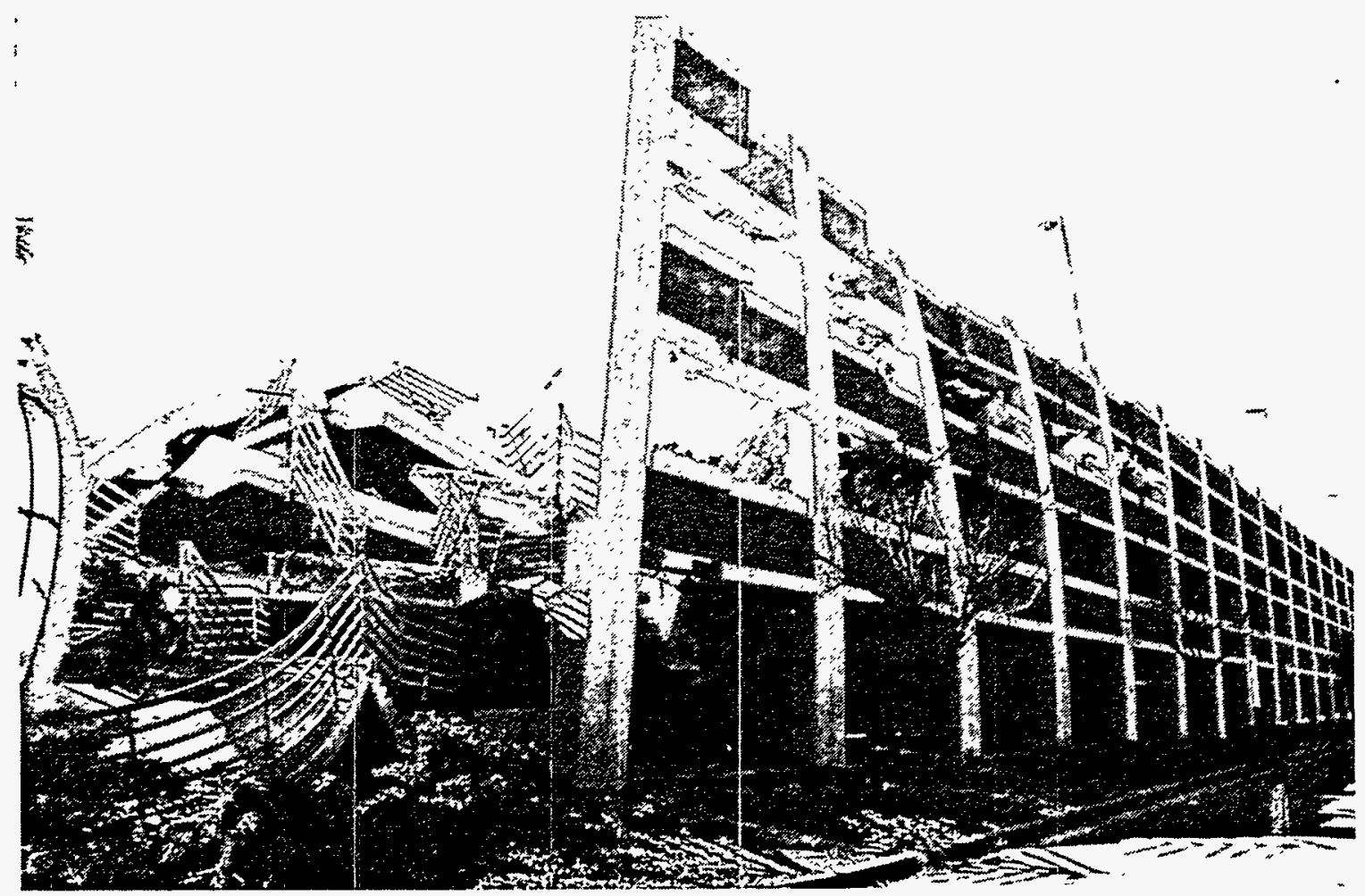

Figure 1.2-9: Collapsed parking structure at California State University at Northridge.

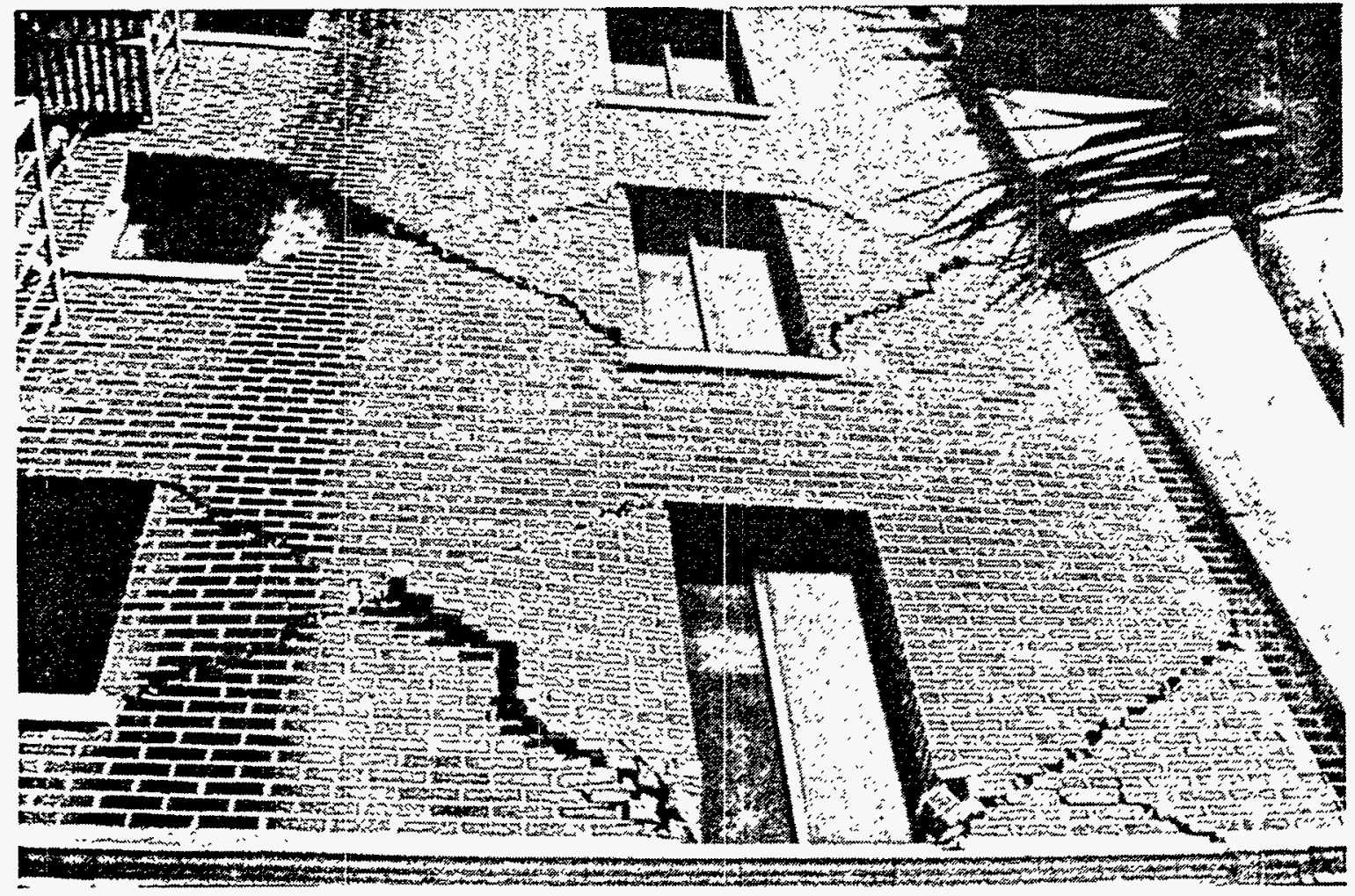

Figure 1.2-10: Large diagonal cracks in unreinforced masonry cladding (one-wythe thickness) over a reinforced concrete frame in an L-shaped apartment building in Santa Monica [ref 1.2-1]. 


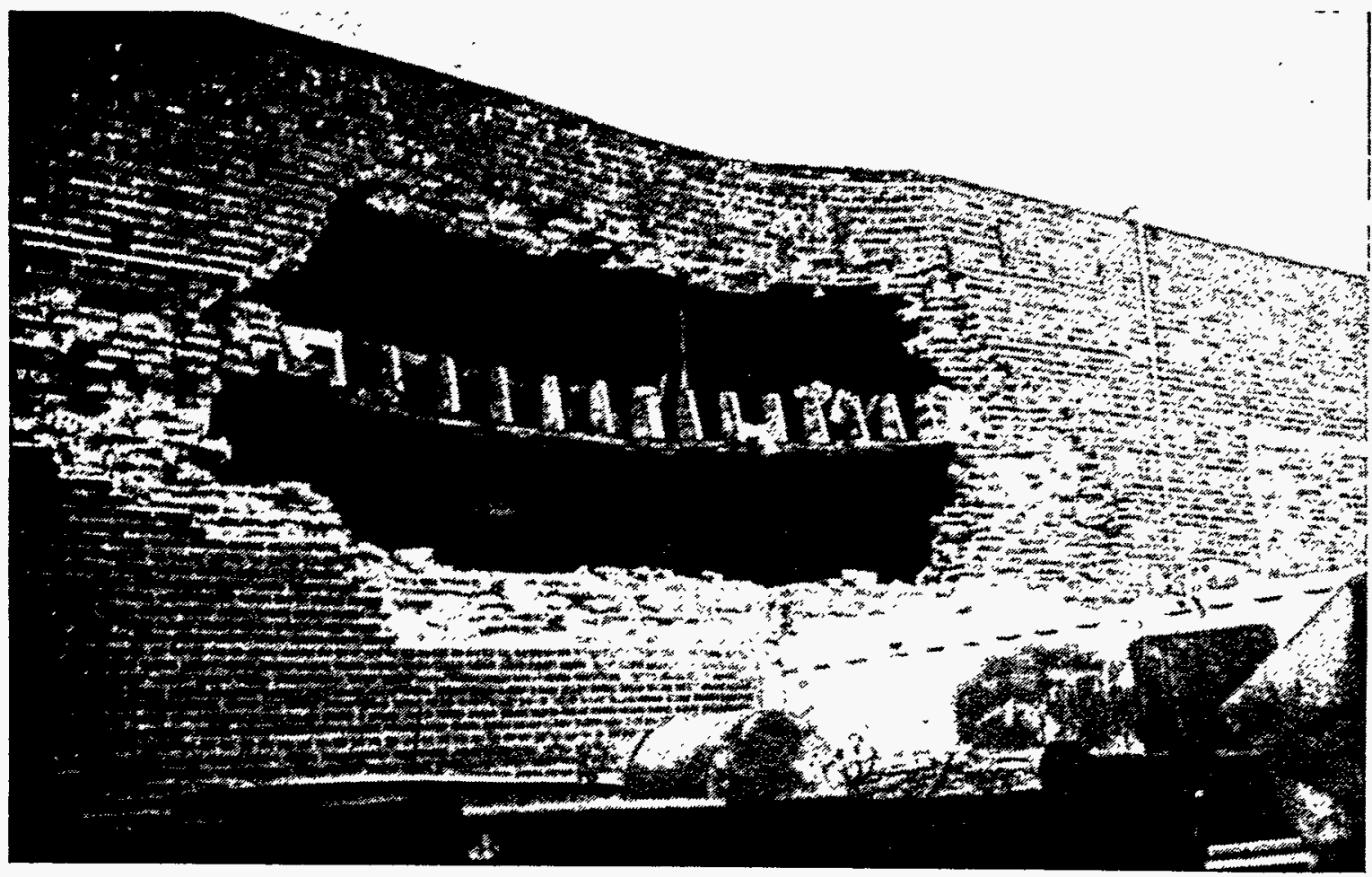

Figure 1.2-11: This two-story commercial unreinforced masonry building on Venice Blvd. in Santa Monica had been previously retrofit with diaphragm ties. Bearing walls were constructed of three wythes of bricks. Ties were placed through upper diaphragm only. Damage observed to be due to out-ofplane bending of the side wall [ref 1.2-1].

Figure 1.2-12: Typical poorly reinforced concrete block wall that collapsed in the San Fernando Valley area. Note that there was no grout in the cells that had rebar, and that any rebar used did not have adequate overlapping splices.

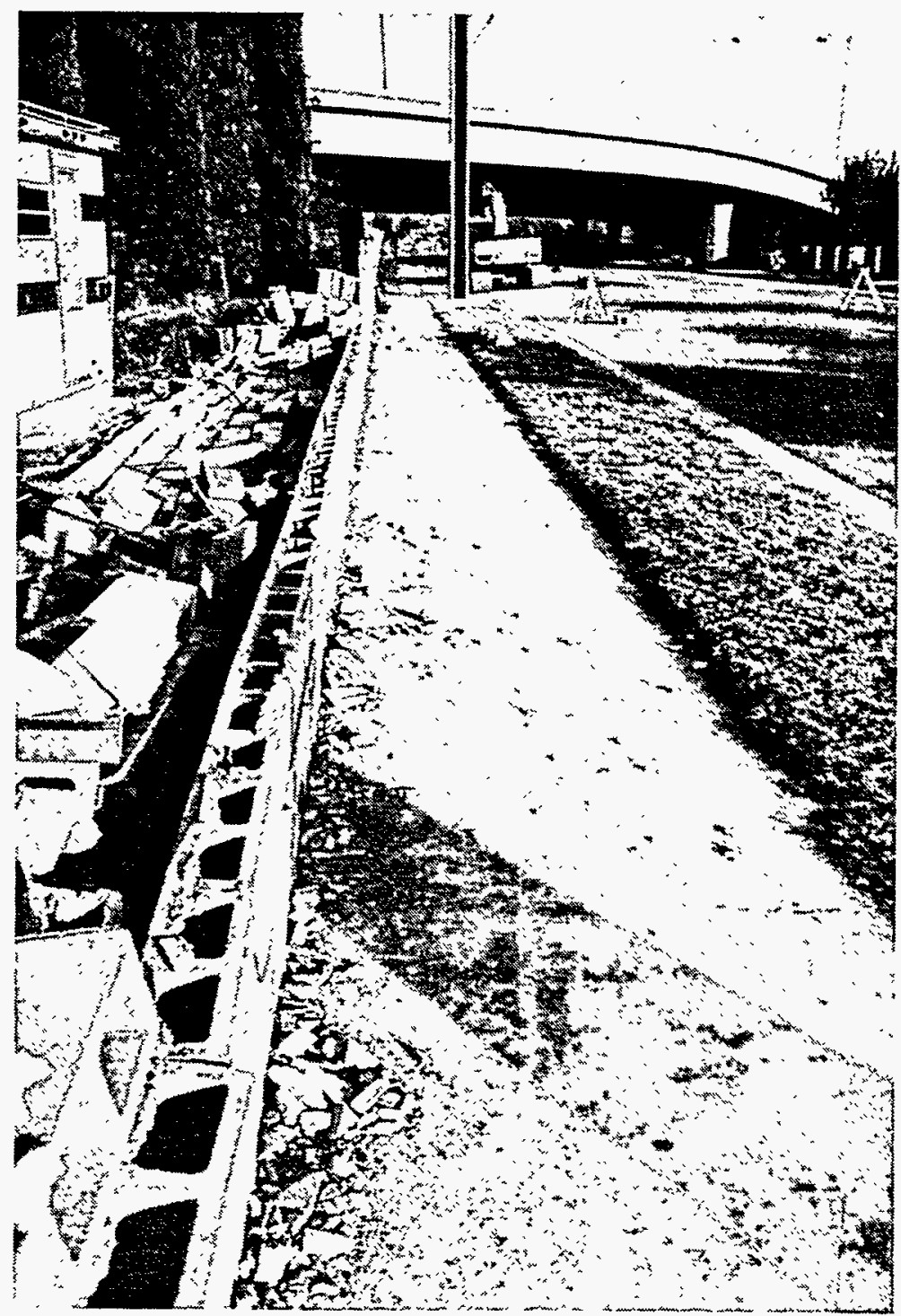




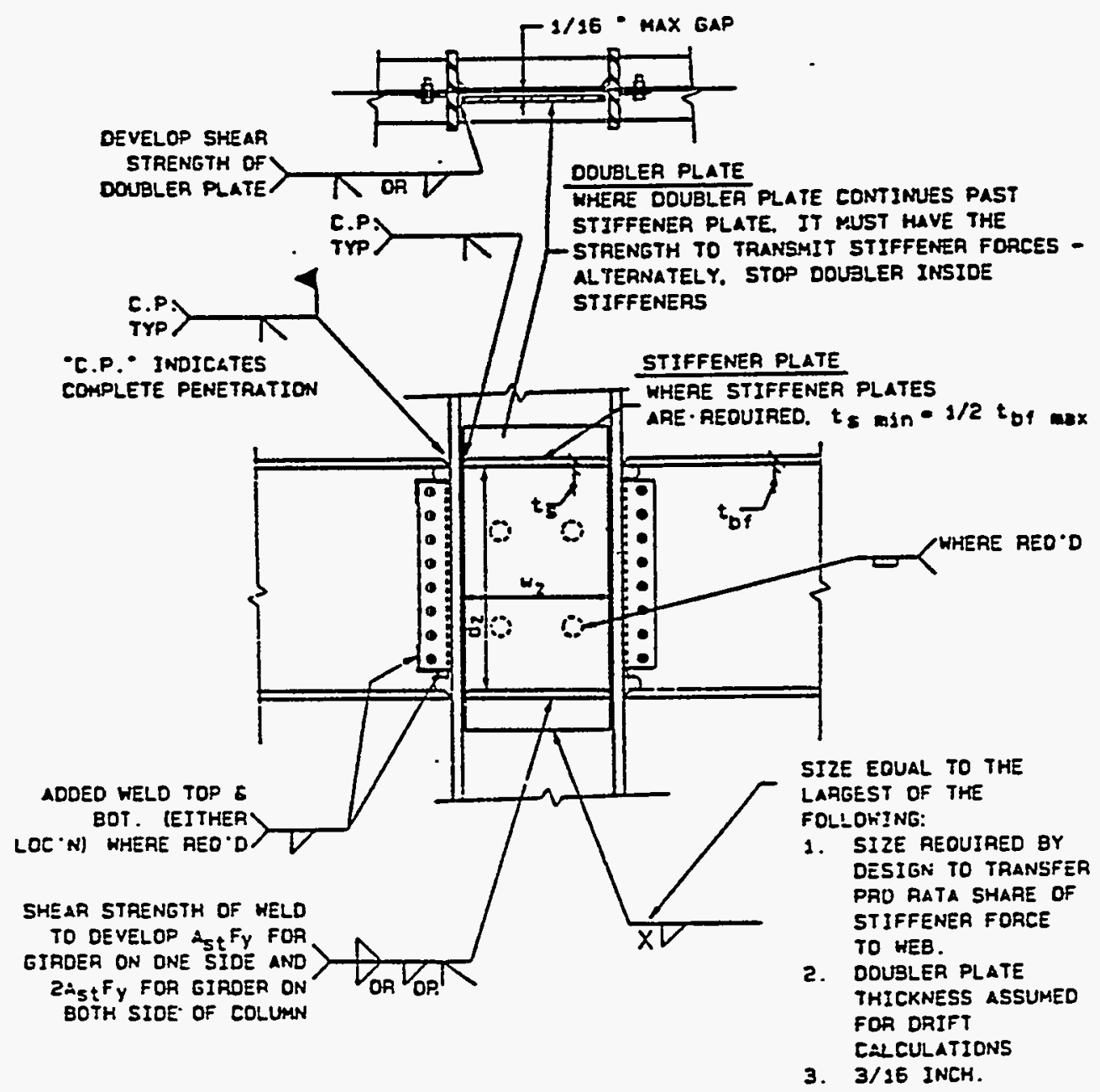

Figure 1.2-13: Special moment-resisting-frame (SMRF) girder-to-column flange detail [ref 1.22] which should not be used until further recommendations are made by the structural engineering community. 
Several weeks after the earthquake, less than 10 damaged SMRF buildings had been identified due to difficulties with inspections. Visual inspections of the steel SMRFs were hampered by architectural finishes, fireproofing, access limitations, and interior utilities. After careful inspections, several failure modes were identified in the SMRF connections. The most common mode was a fracture which initiated in the weld of the girder bottom flange. As shown in Figures 1.2-14 and 1.2-15, the fracture typically passed through the weld or the adjacent heat-affected material. The crack, in many cases, initiated at the base of the back-up bar. In several extreme cases, the crack passed through the weld, the adjacent column flange, and into the column web. Examples of weld failures in steel structures are shown in Figures 1.2-16 and 1.2-17. In Figure 1.2-16, lack of fusion between the backup bar under the beam flange and the column created a crack which may have initiated the fracture. The bolts shown in the figure were replaced after being sheared off when the beam flange connection broke [ref 1.2-5]. While SMRFs with connection failures met life safety objectives by not collapsing, the damage significantly reduced the capacity of the structural system.

By the end of 1994, over 100 steel SMRF buildings were identified as needing repair. The extent of the damage caused a building code abatement in California for steel SMRFs with the connection detail shown in Figure 1.2-13. In addition, the topic has had a widespread impact on design details, material specifications, and welding procedures for both steel moment-frame and steel braced-frame structures. Adding to the concerns about these connections was the discovery that many cracks were in rejectable welds that had incipient root cracks and that the locations of connection failures were not predictable or obvious. To address the performance of steel SMRFs during the Northridge Earthquake, the SAC Joint Venture was formed with representatives from the Structural Engineers Association of California, the Applied Technology Council, and the California Universities for Research in Earthquake Engineering. SAC has developed three advisories and will be developing interim guidelines for the design, evaluation, and retrofit of steel SMRF buildings.

During the Northridge Earthquake, a large number of lifeline systems were affected. On the morning of the earthquake, approximately 2 million customers in the Los Angeles area lost electric power. In addition, power was disrupted for 600,000 customers in nearby cities along interconnected power grids such that 150,000 customers in Idaho lost power for three hours [ref 1.2-7]. Pipeline distribution systems carrying water, gas, and liquid fuels all suffered failures, and many of which were attributed to permanent ground deformations. Transportation was also disrupted by the failure of structures along four major highways, Interstate (I) 5, State Route (SR) $14, \mathrm{I}-10$, and SR-118. 


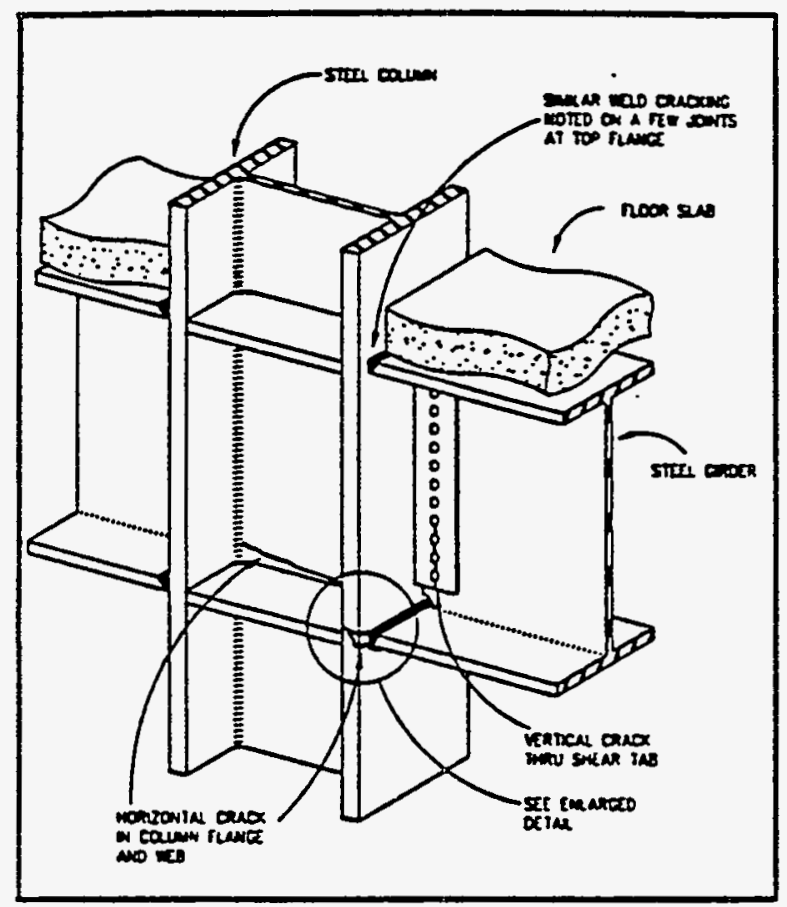

Figure 1.2-14: Typical damage to welded-flange, bolted-web connections of steel beams to steel columns in moment-frame buildings [ref 1.2-4].

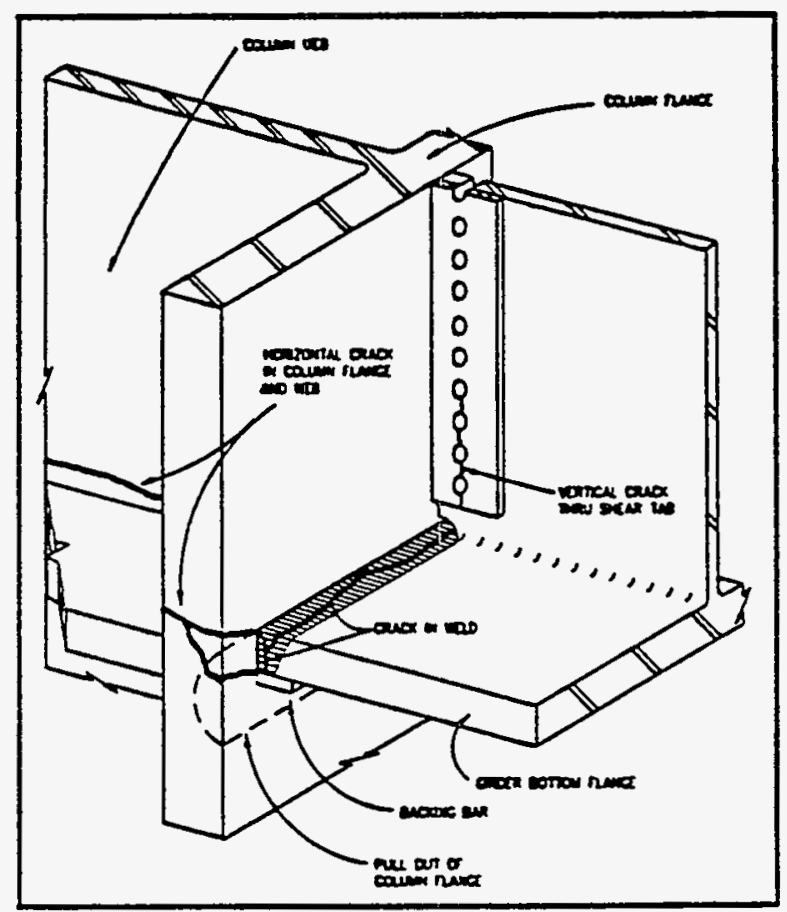

Figure 1.2-15: Enlarged detail of welded-flange, bolted-web connection damage [ref 1.2-4]. 


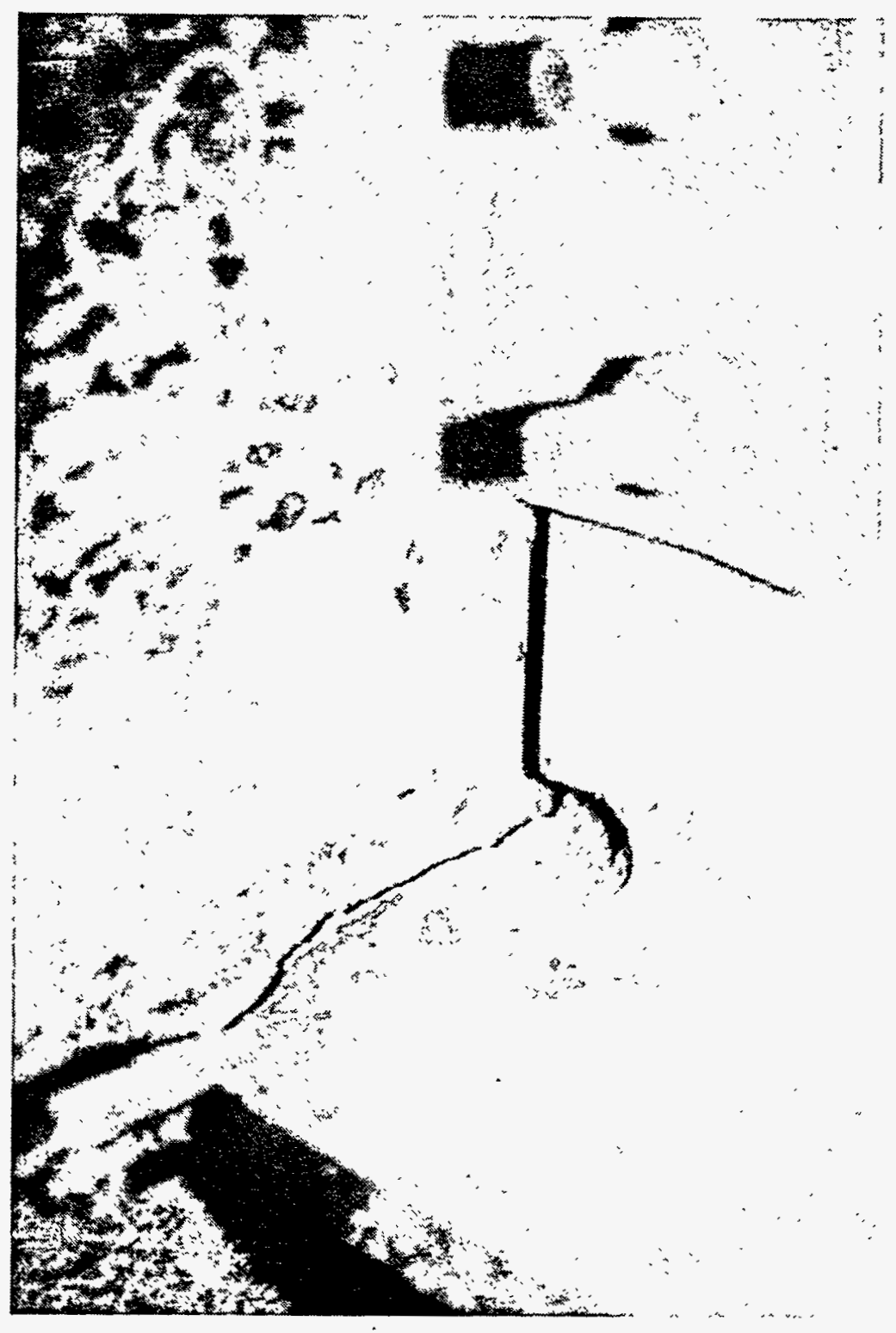

Figure 1.2-16: Close-up photo of typical failure of welded-flange, bolted-web connection of steel beams to steel columns in moment-frame buildings. The most common fracture resulted in the severing of a beam flange from a column flange and passed through the weld or through the adjacent heat-affected material. Note that the bolts were replaced after being sheared off when the beam flange connection broke [ref 1.2-5]. 
$\cdot[9$

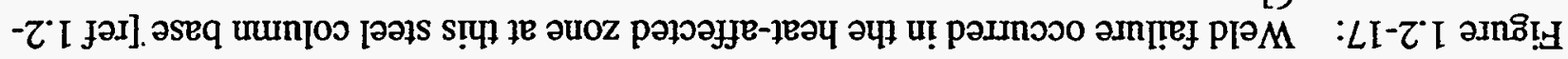

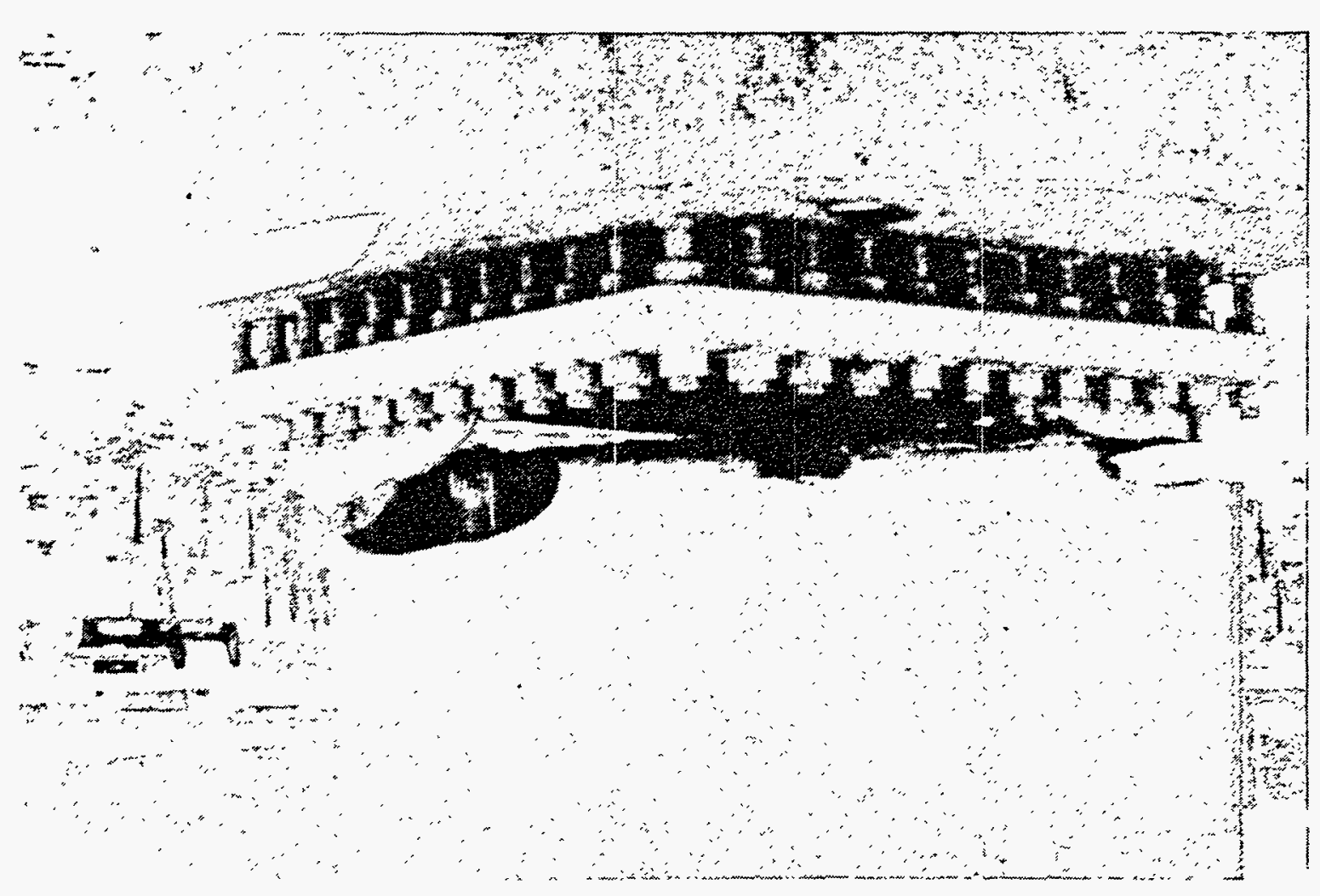


The freeway structures for SR-118 over San Fernando Mission and Gothic Streets were severely damaged by the earthquake. Figure 1.2-18 shows one of the bridge columns which lost core confinement of the concrete and thereby lost its capacity to support the bridge deck. At the I-5 and SR-14 interchanges, connection structures for SR-14 to I-5 had short column and abutment damage which led to unhinging and collapse of the bridge spans, as shown in Figure 1.2-19. Near these collapsed structures, electric power and water systems sustained damage. Figure 1.2-20a shows repair efforts to a large transformer at an electric power substation. The earthquake caused the bushing in the transformer to rock and become damaged. Other examples of damage at electric power substations are shown in Figures 1.2-20b and 1.2-20c. Near these substations, the earthquake caused several large-diameter water mains to rupture which led to local flooding problems. Further detailed information about the performance of many lifeline systems is included throughout this report.

In addition to damage to structures and lifelines, there was considerable nonstructural damage throughout the epicentral region. Building inventory loss and contents damage were a common problem. The large seismically-induced motions caused contents to fall off shelves, nonstructural items to fall on contents, and support racks for the contents to fail because of inadequate design details. As shown in Figures 1.2-21 to 1.2-23, typical nonstructural interior damage included overturned cabinets, fallen lights, and dislodged ceiling tiles. At some locations, the interior damage caused the facilities to close. Mechanical systems within structures were also damaged as shown in Figures 1.2-24 to 1.2-25. The air handler unit shown in the figures had failed vibration isolators that lacked seismic bumpers. This report contains information on other mechanical systems which were affected by the earthquake.

While there was significant damage following the Northridge Earthquake, acceleration records indicate that many SSCs experienced motion which exceeded their design values. In most cases, properly designed, detailed, and constructed SSCs suffered minimal damage and remained functional during the earthquake. The majority of buildings, lifelines, and equipment designed and built using mid-1970s or later seismic requirements had good structural performance. Details, such as flexible connections and seismic bumpers for vibration isolators respectively shown in Figures 1.2-26 and 1.2-27, contributed to many SSCs sustaining no damage.

With all the damage and problems associated with the Northridge Earthquake, the local, state, and Federal agencies moved quickly to aid people affected by the event. The Los Angeles metropolitan area was extremely fortunate that the event occurred early in the morning on a holiday. As stated in References 1.2-9 and 1.2-10, this earthquake was another "wake-up call" reminding us of the importance of preparing for earthquakes and for retrofitting SSCs that are not seismically safe. 
The earthquake could have occurred mid-day with many more businesses open and more traffic on the freeways. With the significant amount of seismic sources in the area, the epicenter of the earthquake could also have been under a more densely populated and industrialized portion of Los Angeles. In addition, the earthquake could have had a larger magnitude and the duration of strong shaking could have been longer. If any of these factors had been true, the death and damage toll could have been much greater than that experienced on January 17, 1994. 


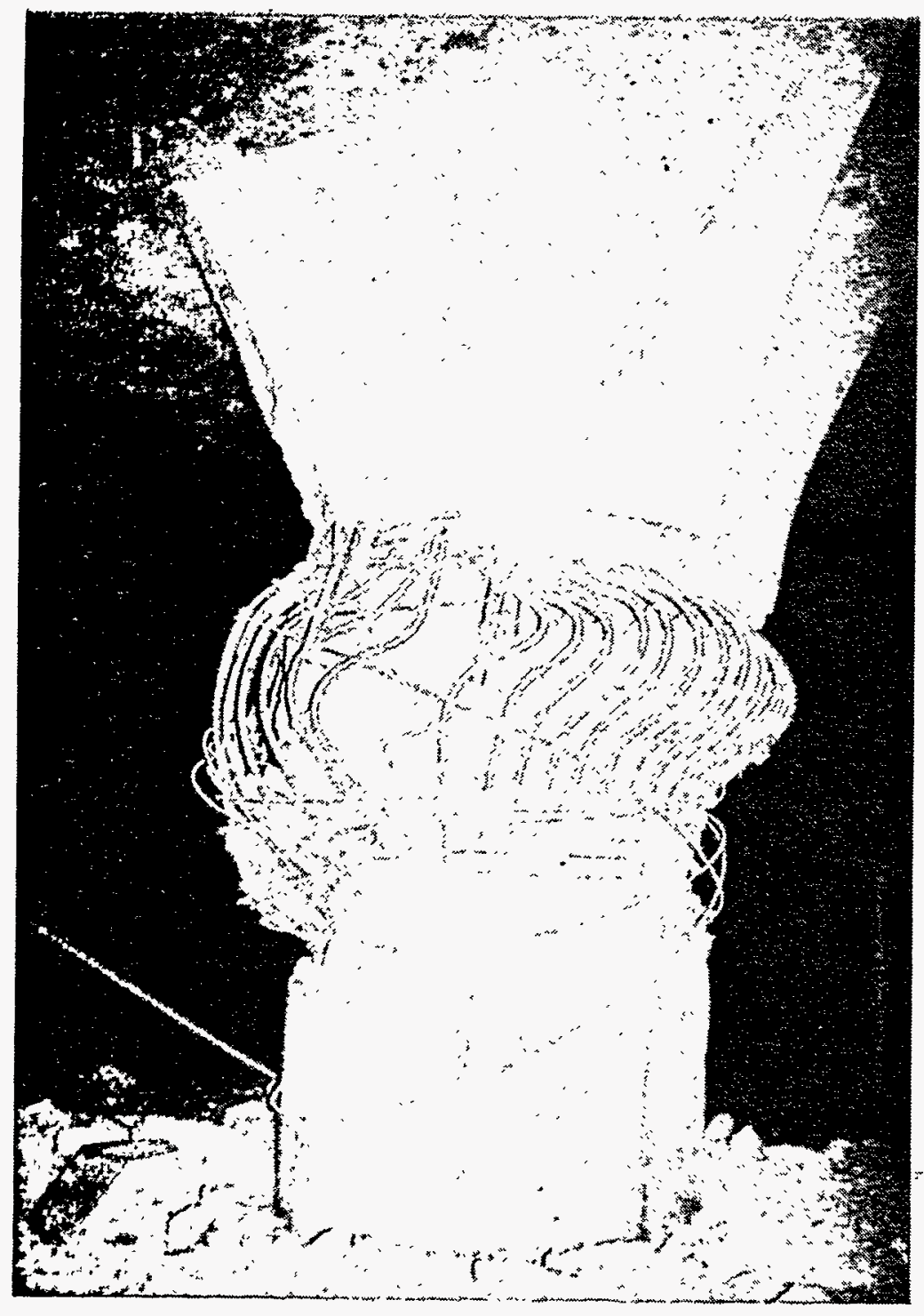

Figure 1.2-18: Damaged column at SR-118 at MissionGothic Undercrossing.

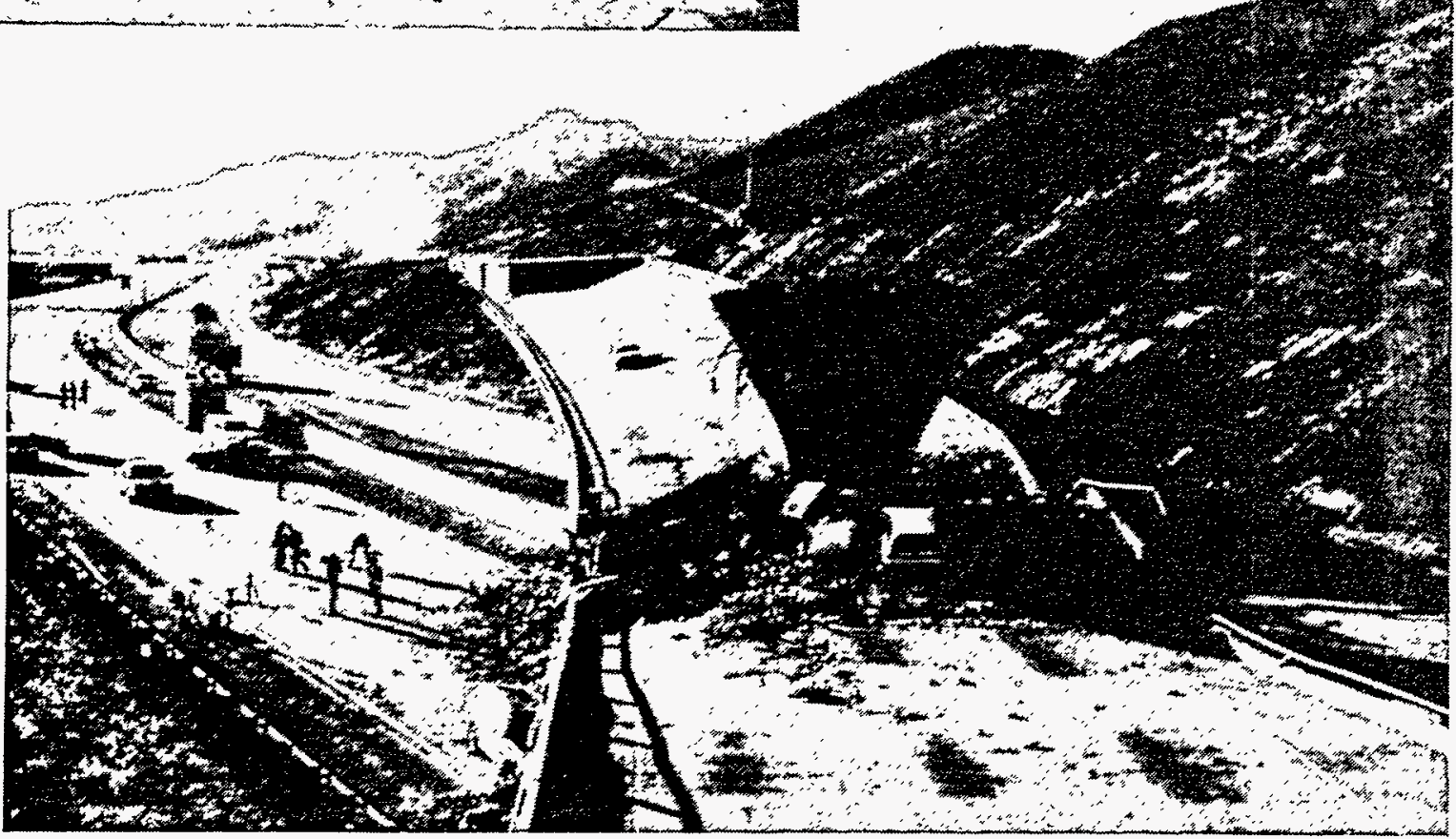

Figure 1.2-19: Collapse of I-5/SR-14 Separation and Overhead [ref 1.2-5]. 


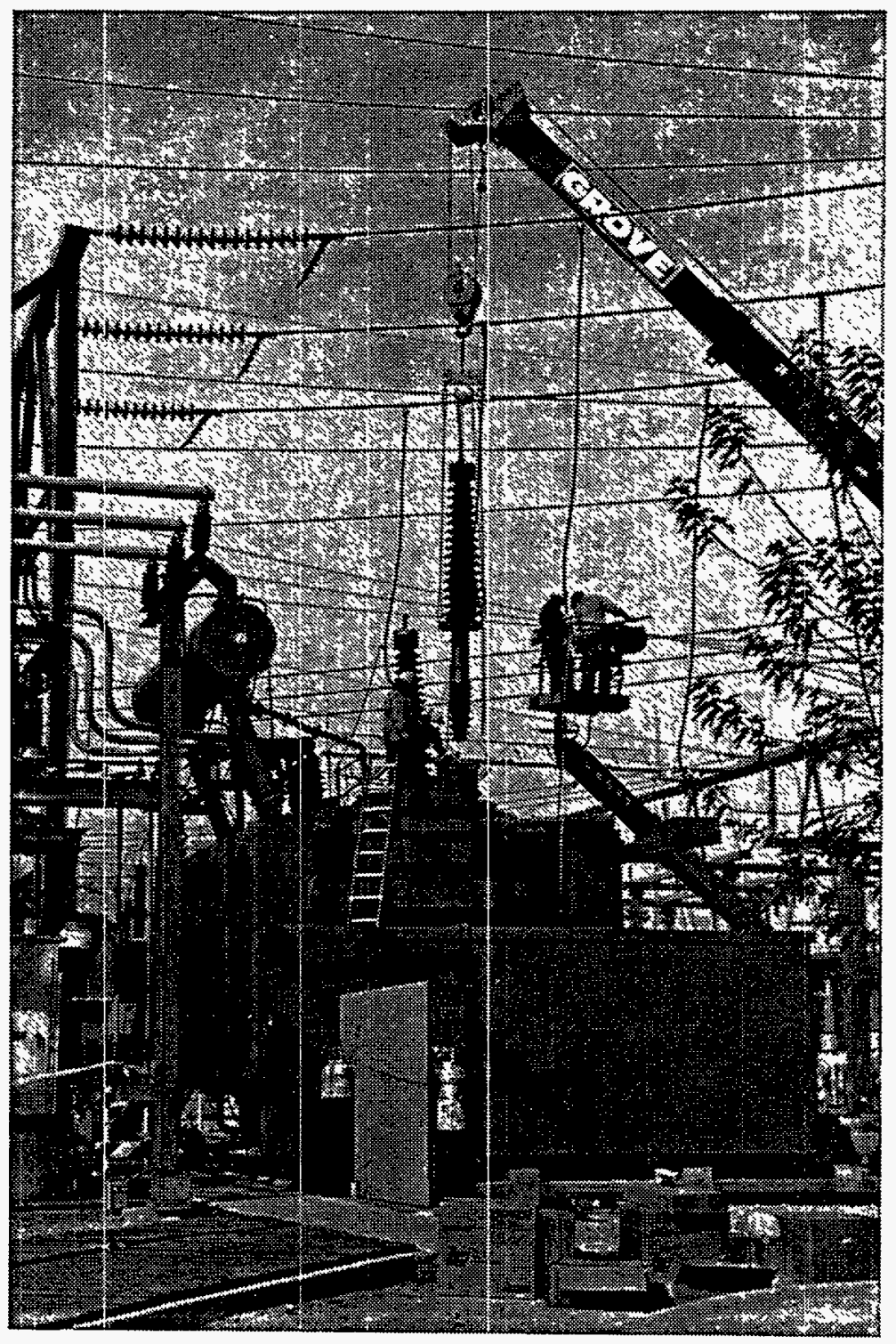

Figure 1.2-20a: Replacement of transformer bushing component at an electric power substation [ref 1.2-8]. 


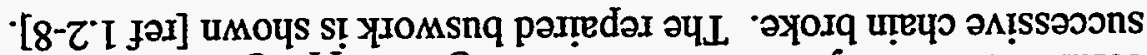

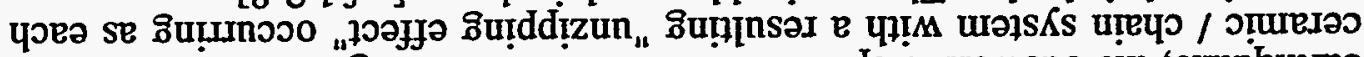

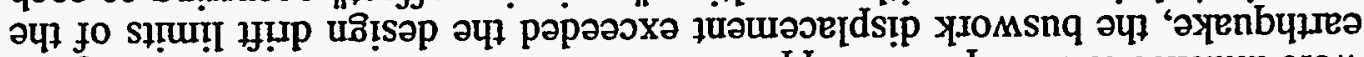

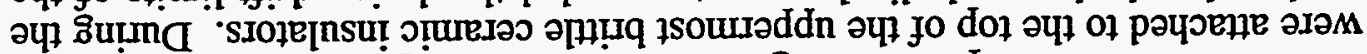

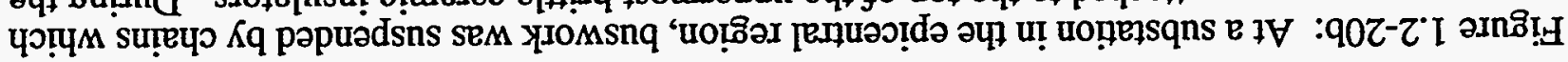

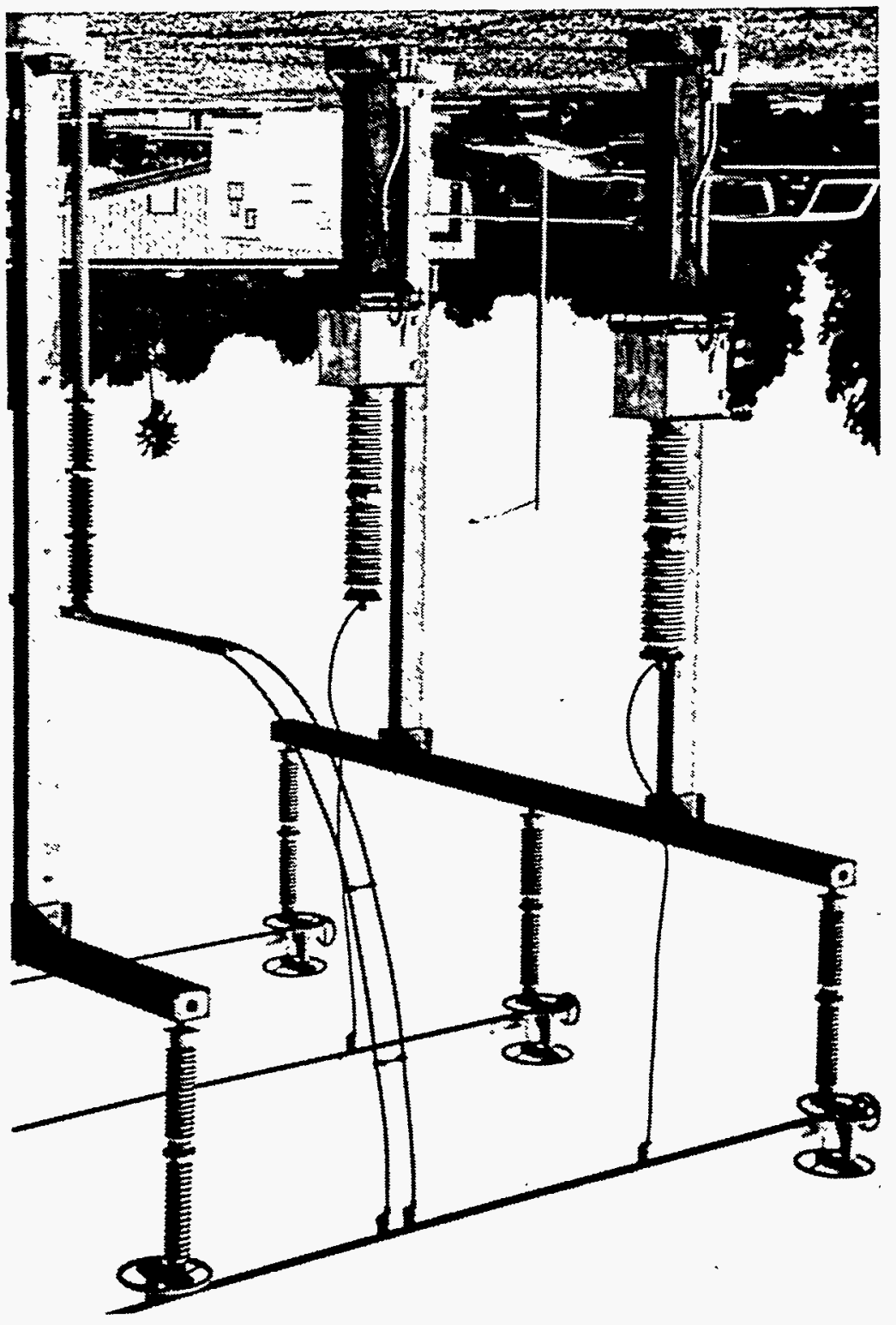




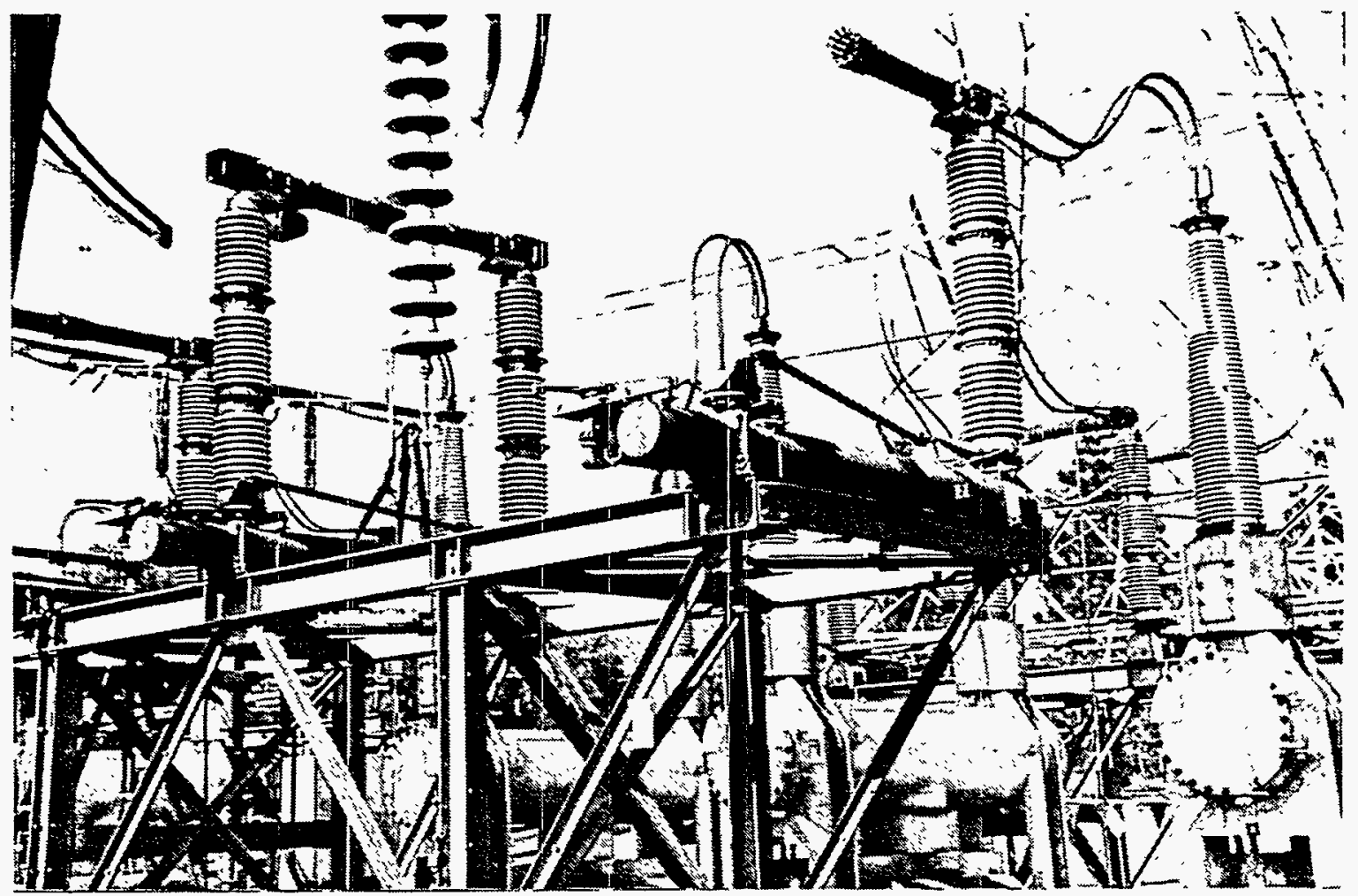

Figure 1.2-20c: A brittle ceramic column of the disconnect switch shown above fractured at its base during the earthquake. Fortunately, there was sufficient slack in the bus between the damaged disconnect switch and the nearby dead tank circuit breakers to prevent seismic interaction damage. As expected, the dead tank circuit breakers performed well during the earthquake [ref 1.2-8].

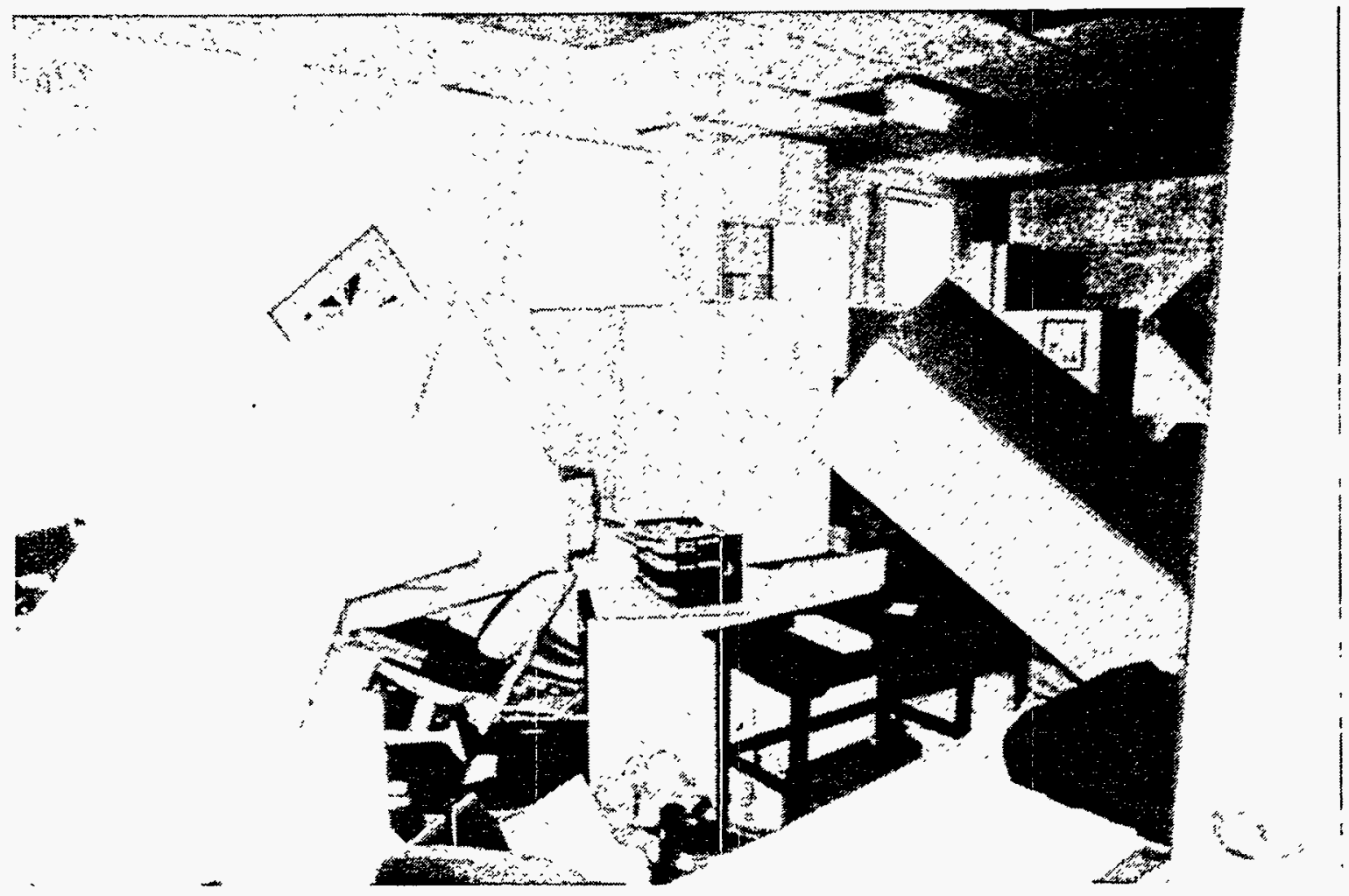

Figure 1.2-21: Typical nonstructural interior damage which caused a hospital to close [ref 1.2-5]. 


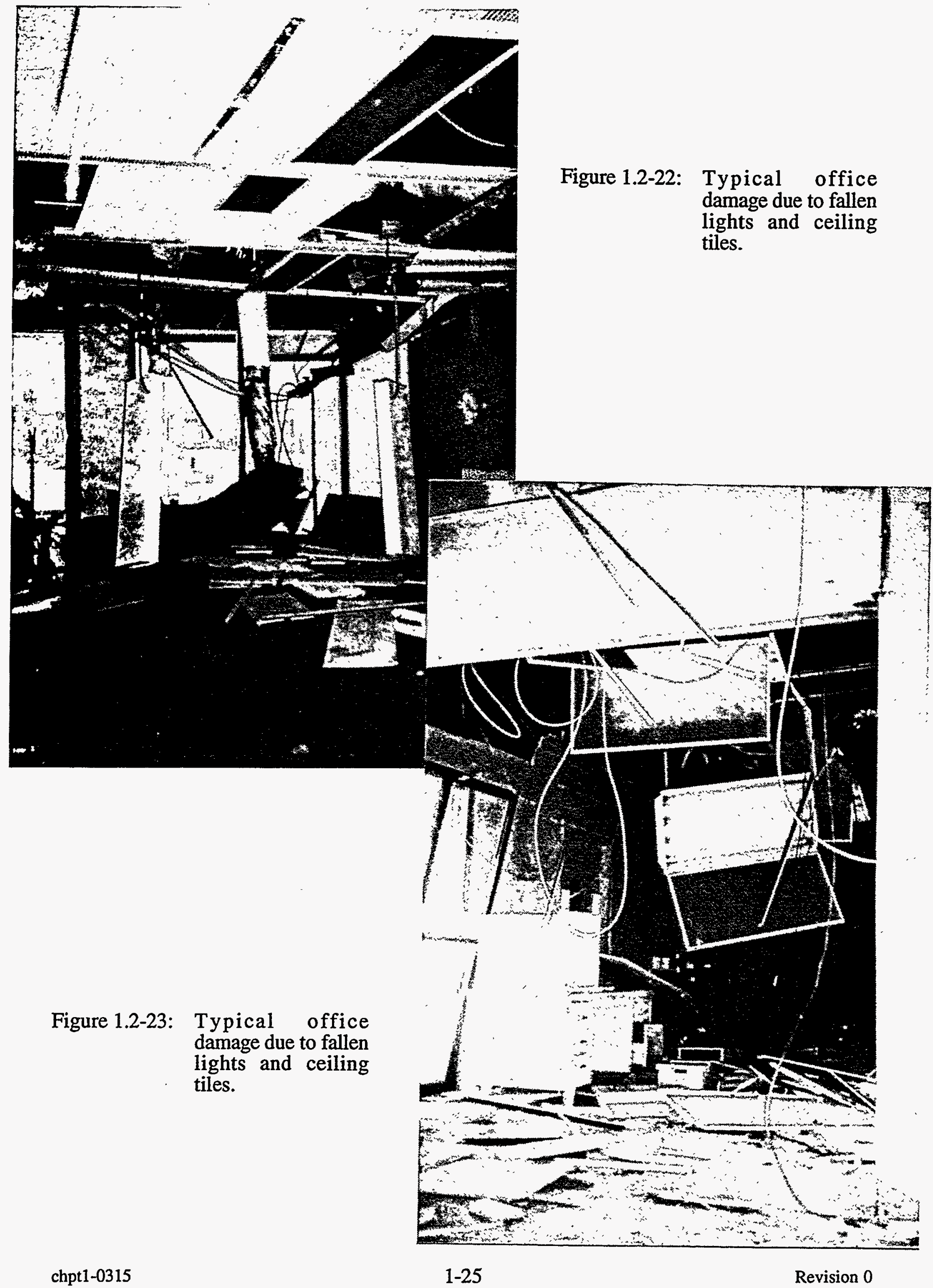




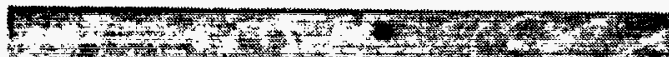

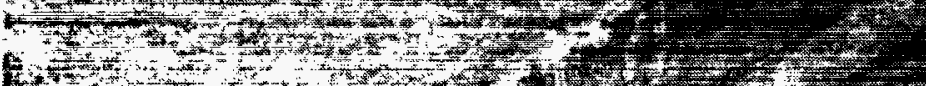

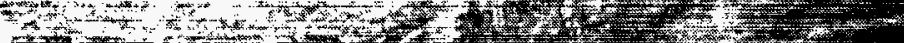

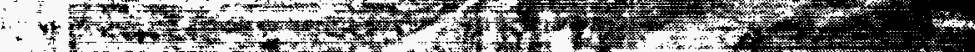

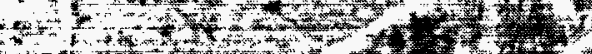

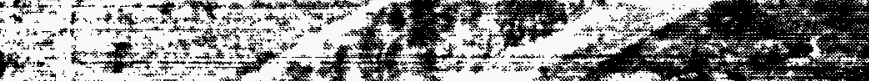

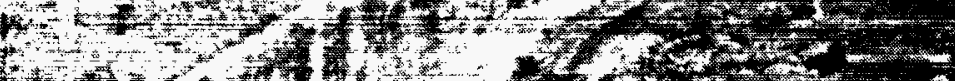

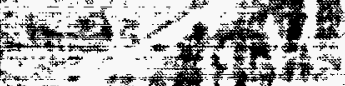

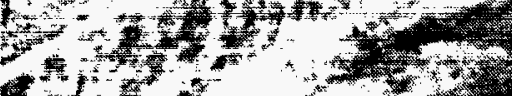

8

8
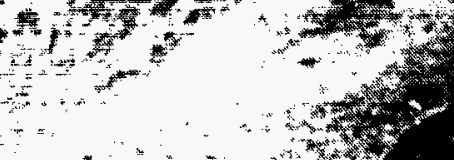$$
\text { . * * * }
$$
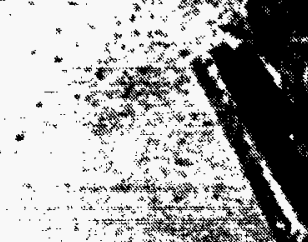

$a^{2}+1+2$

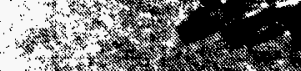

$+3$

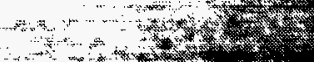

(1) $y^{3}-4$

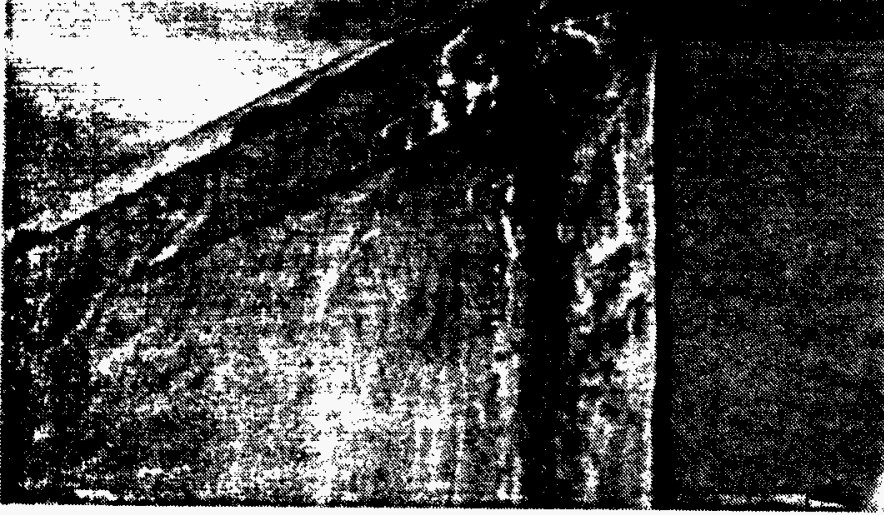

-sıədurnq

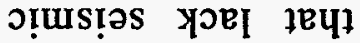

S.IOJejos! uoIfeIqIA

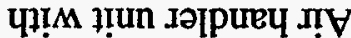

:†て-で I วInoิ!H -sıədunq ग̣usţəs

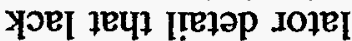

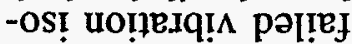

4lIM IIUn JəIPURY

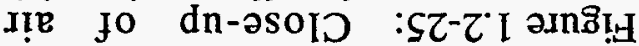

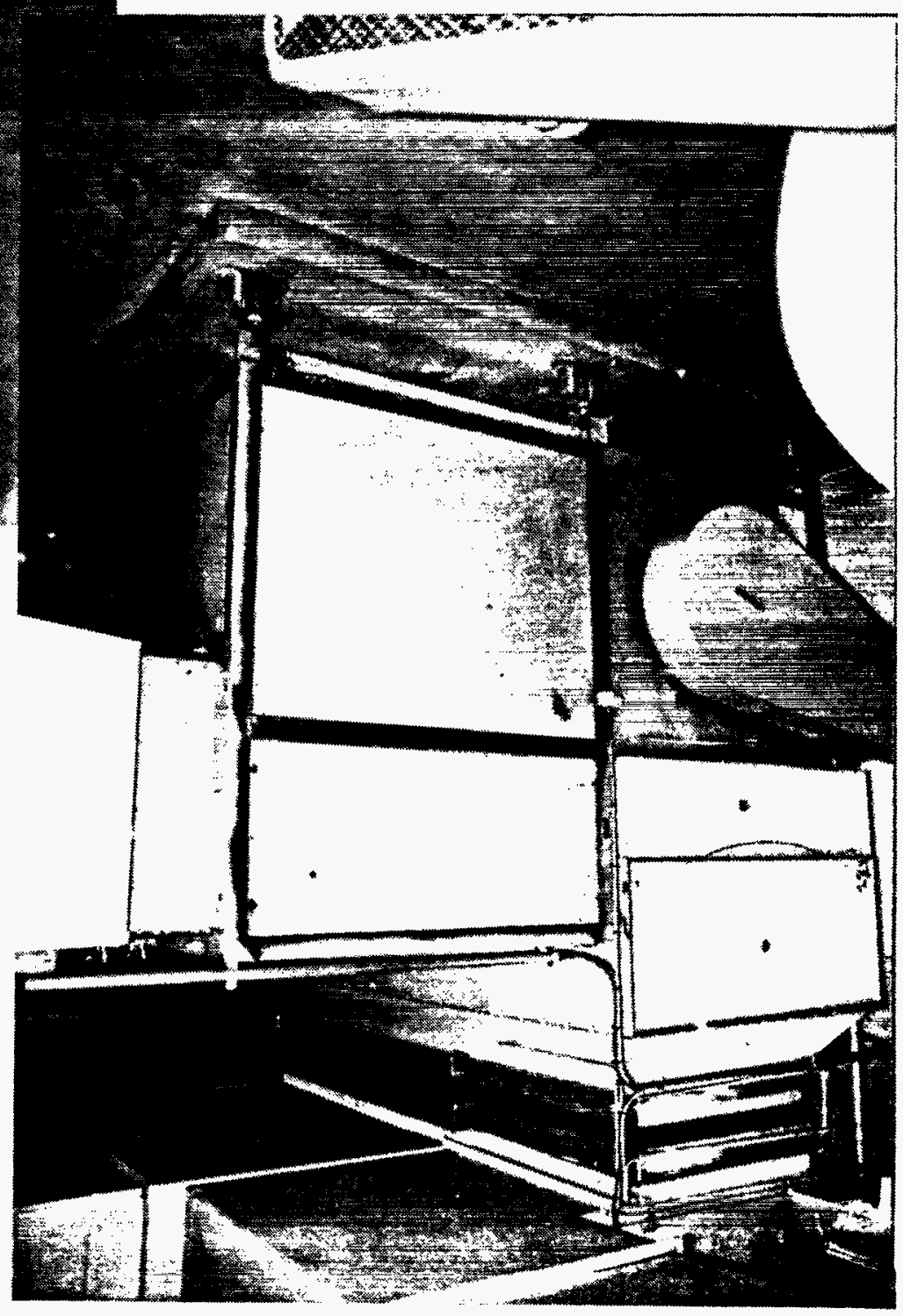




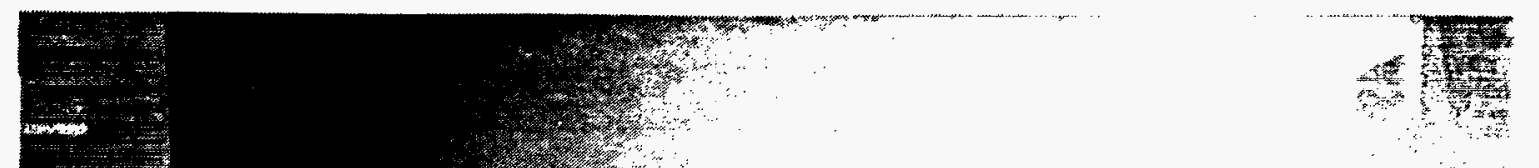

Figure 1.2-26: The flexible connection on the attached piping of this large water tank accommodated the relative motion of the tank and piping.

Figure 1.2-27: This engine / generator set is mounted on a common skid with vibration isolators that have seismic bumpers. 


\subsection{REFERENCES}

1.0-1 Todd, D., et. al., 1994 Northridge Earthquake - Performance of Structures, Lifelines, and Fire Protection Systems, NIST Special Publication 862, ICSSC TR14, United States Department of Commerce Technology Administration, National Institute of Standards and Technology, May 1994.

1.0-2 State of California Department of Conservation, Division of Mines and Geology, Fifth Quick Report on CSMIP Strong-Motion Data from the Northridge / San Fernando Valley Earthquake of January 17, 1994, Report OSMS 94-05, January 25, 1994.

1.2-1 Earthquake Engineering Research Center (EERC), "Seismological and Engineering Aspects of the January 17, 1994 Northridge Earthquake: Abridged Slide Set", University of California at Berkeley, 1994.

1.2-2 UCRL-CR-106554, Structural Concepts and Details for Seismic Design, Figure 4-27, Lawrence Livermore National Laboratory, 9/91.

1.2-3 Shipp, J., "Steel's Performance in the Northridge Earthquake", EQE Review, EQE International Inc., San Francisco, Fall 1994.

1.2-4 Degenkolb Engineers, "Damaged Steel Frame Buildings: The Big Surprise of the Northridge Earthquake", Events - Earthquake Reconnaissance News, June 1994.

1.2-5 Earthquake Engineering Research Institute (EERI), "Slides on the January 17, 1994, Northridge Earthquake".

1.2-6 Photograph provided by Southern California Edison.

1.2-7 Earthquake Engineering Research Institute (EERI), "Northridge Earthquake January 17, 1994 Preliminary Reconnaissance Report".

1.2-8 Photograph provided by Los Angeles Department of Water and Power.

1.2-9 Eli, M. and Sommer, S., "1994 Northridge Earthquake Damage Investigation", Phenomenal News - Natural Phenomena Hazards Newsletter, prepared by Lawrence Livermore National Laboratory for the United States Department of Energy, April 1994. 
1.2-10 Eli, M. and Sommer, S., "Update on 1994 Northridge Earthquake Damage Investigation", Phenomenal News - Natural Phenomena Hazards Newsletter, prepared by Lawrence Livermore National Laboratory for the United States Department of Energy, August 1994. 


\section{DESCRIPTION OF THE EARTHQUAKE}

On January 17, 1994, the Northridge Earthquake originated beneath the floor of the San Fernando Valley in Southern California. More than 10 major earthquakes have occurred in Southern California in the last 80 years. The Northridge Earthquake emanated from a hidden thrust fault which was not identified by most geologists. Some record of the fault was found on geophysical maps prepared by oil companies [ref 2.0-1]. The epicentral area was heavily instrumented prior to the main shock, resulting in many valuable strong-motion recordings of seismic data. From this information, seismic analyses and testing can be conducted on structures, systems, and components (SSCs) using the time histories and response spectra. This can provide a check on how well computer codes and the underlying assumptions predict the real performance of those SSCs in a major earthquake. Also, governing design and construction codes can be updated to incorporate new values for expected ground motion for the San Fernando Valley area.

\subsection{GEOLOGIC SETTING}

The San Fernando Valley is broadly elliptical, about $30 \mathrm{~km}$ long on its east-west axis and about 16 $\mathrm{km}$ wide. It is in a region that has repeatedly experienced moderate to large earthquakes (see Figure 2.1-1) [ref 2.1-1 \& 2.1-2]. The San Fernando Valley is bounded on the northeast by the Verdugo Mountains and the western San Gabriel Mountains, on the northwest by the Simi Hills and the Santa Susana Mountains, and on the south by the Santa Monica Mountains. The mountains have an east-west trend, which is consistent with being part of the Transverse Ranges. The ranges are actively deforming by folding and thrust-faulting in response to the north-southdirected compression that is occurring across the "big-bend" region of the San Andreas Fault (where the fault abruptly takes a more northerly course) [ref 2.1-1]. Numerous faults that have been active during the Quaternary have been identified in the area by surface mapping. These include the San Fernando fault, which ruptured during the 1971 San Fernando earthquake (see Figure 2.1-2). Other faults that do not extend to the surface are known to exist because of subsurface investigations, primarily for oil exploration. Mapping of these buried faults, which are referred to as "blind thrusts", is incomplete, and in many seismic hazard studies they have not been considered as potential sources of earthquakes [ref 2.1-2].

The San Fernando Valley is underlain by a thick fill of alluvium. This alluvium is underlain by thousands of meters of sediments, mostly of marine origin, which were deposited upon granite and metamorphic basement rocks [ref 2.1-1]. 


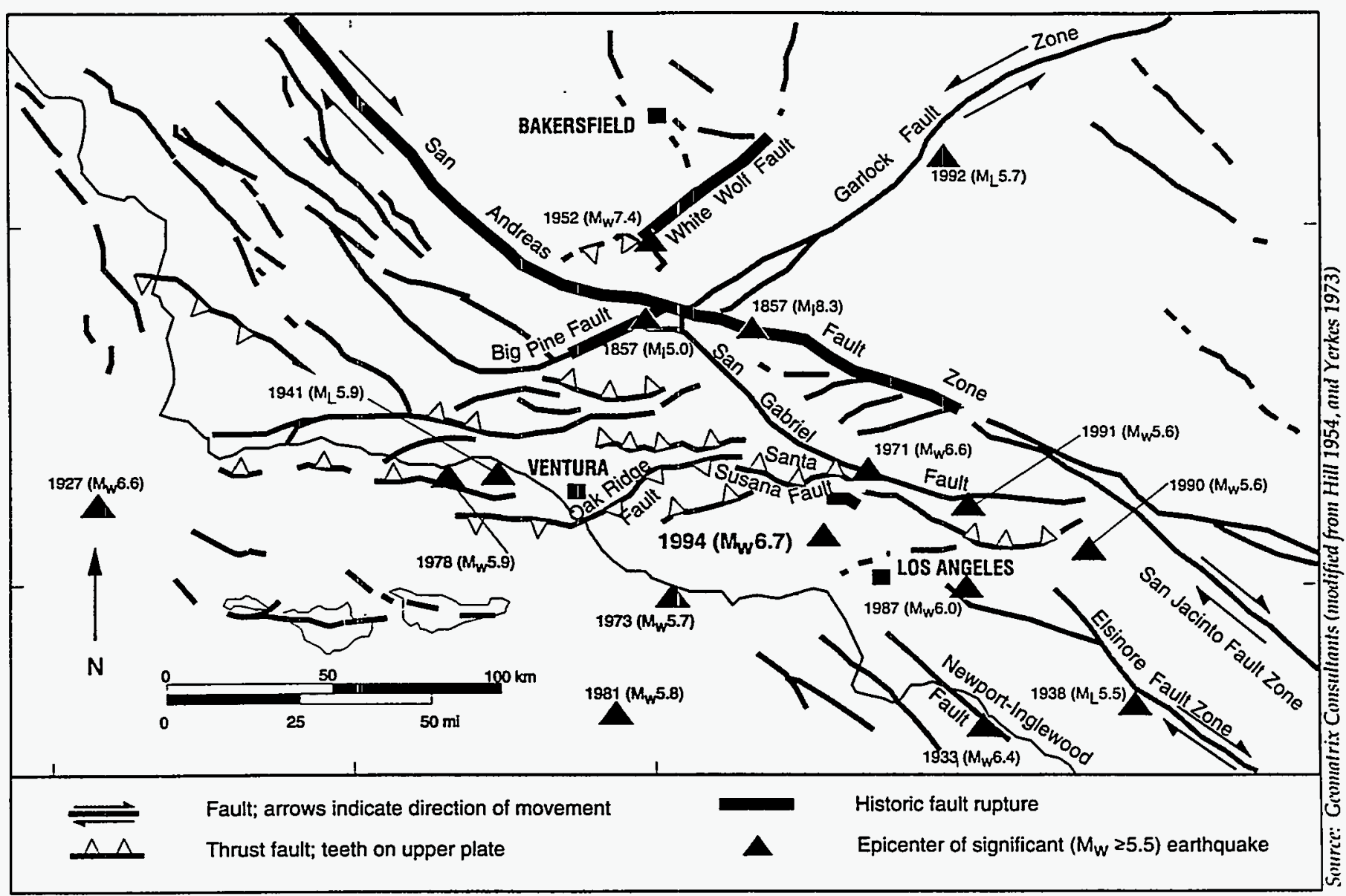

Figure 2.1-1: Major active faults and epicenters of significant historical earthquakes in Southern California [ref 2.1-1 \& 2.1-2]. 


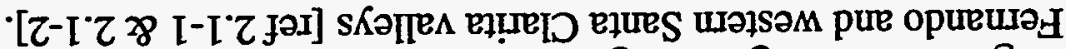

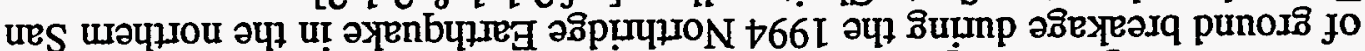

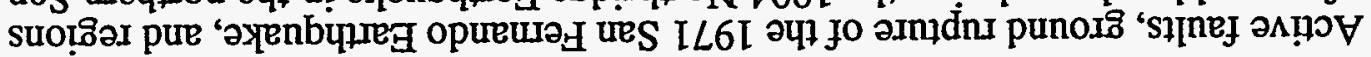

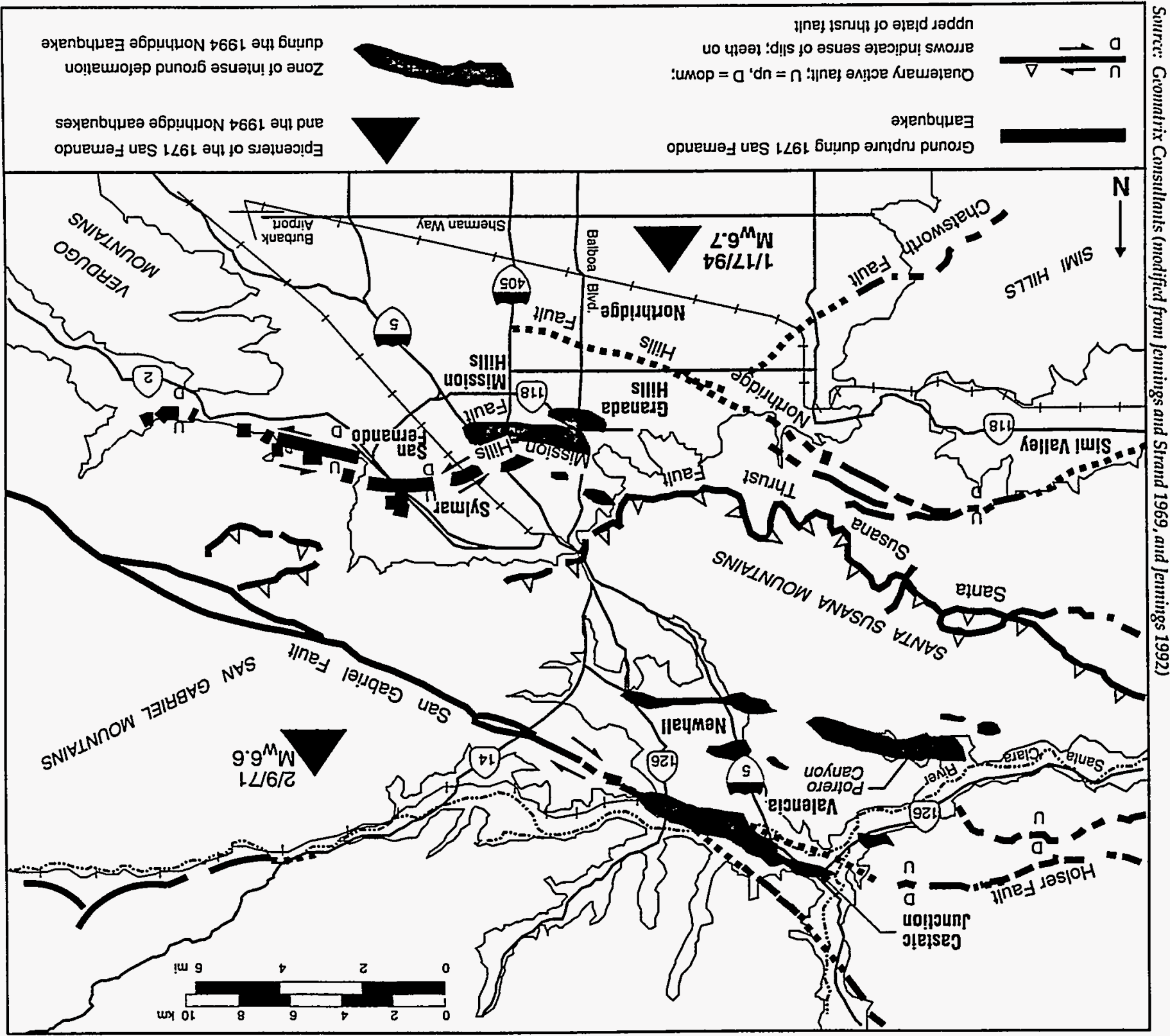




\subsection{HISTORIC SEISMICITY}

Reports from the California Institute of Technology and the U.S. Geological Survey indicate that the epicenter of the $M_{W} 6.7$ main shock occurred at a depth of approximately 18 to $20 \mathrm{~km}$ (see Figure 2.2-1). The main shock's focal mechanism and associated aftershocks indicate that thrusting occurred along a plane that dips $35^{\circ}$ to $45^{\circ}$ to the south-southwest. This is the opposite of the direction of thrusting from the 1971 San Fernando Earthquake [ref 2.2-1]. Aftershock activity was high; there were 13 aftershocks of magnitude greater than or equal to 4.0 between January 18 and 28. Although the level of aftershock activity had been high, the aftershock frequency decay was consistent with other larger California earthquakes. The pattern of aftershocks indicated that rupture occurred on a south-dipping plane at depths between approximately 5 and $18 \mathrm{~km}$. Above 5 $\mathrm{km}$, the seismicity pattern was more diffuse, possibly due to activity along one or more northdipping backthrusts [ref 2.2-2].

Northward directivity of energy was indicated by strong-motion recordings north of the event. As a result of slip on the causative fault, the San Fernando Valley may have moved north a few centimeters, closer to the city of Bakersfield [ref 2.2-2].

Research following the 1994 Northridge Earthquake and the 1992 Landers Earthquake has revealed the presence of a displacement pulse or "fling" [ref 2.2-4]. This displacement pulse is a near-field phenomenon which acts perpendicular to the direction of fault propagation. This type of pulse is of concern for structures with a low fundamental frequency.

Figure 2.2-2 shows the major Southern California earthquakes that have occurred in the 20th century [ref $2.2-5 \& 2.2-6]$.

\subsection{STRONG MOTION}

The damage to engineered structures during the Northridge Earthquake can be attributed primarily to earthquake-induced strong ground shaking. The strong ground motions from the Northridge Earthquake were recorded on many instruments within the Los Angeles area. Peak accelerations of free-field instruments approached $1.0 \mathrm{~g}$ in the near field area and decreased to $0.1 \mathrm{~g}$ at distances of about $50 \mathrm{~km}$. Strong-motion recordings were obtained from several accelerograph networks with significant instrument arrays in the southern California region. The California Division of Mines and Geology's Strong Motion Instrumentation Program (CSMIP) recovered 193 accelerograms from their network, the U.S. Geological Survey's National Strong Motion Program (NSMP) recovered approximately 150 accelerograms from their network, and the University of Southern 


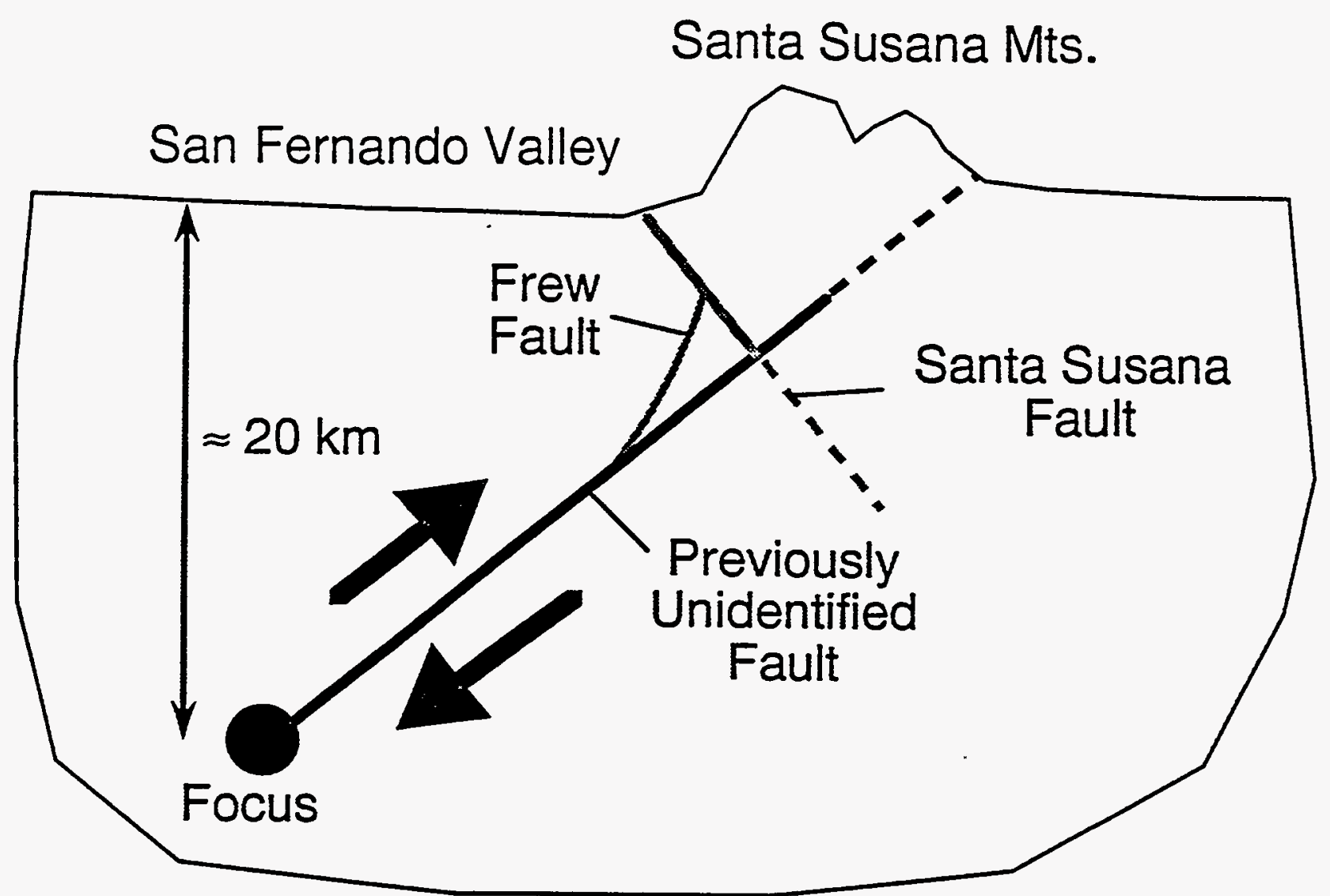

Source: EERC 1994

Figure 2.2-1: The main shock occurred on a previously unidentified "blind thrust" fault, near the Frew and Santa Susana faults (view of partial cross-section of the earth's crust, looking in northwesterly direction) [ref 2.2-1]. 


\section{Major Southem Califomia Earthquakes}

Earthquakes with magnitudes preater than 4.8

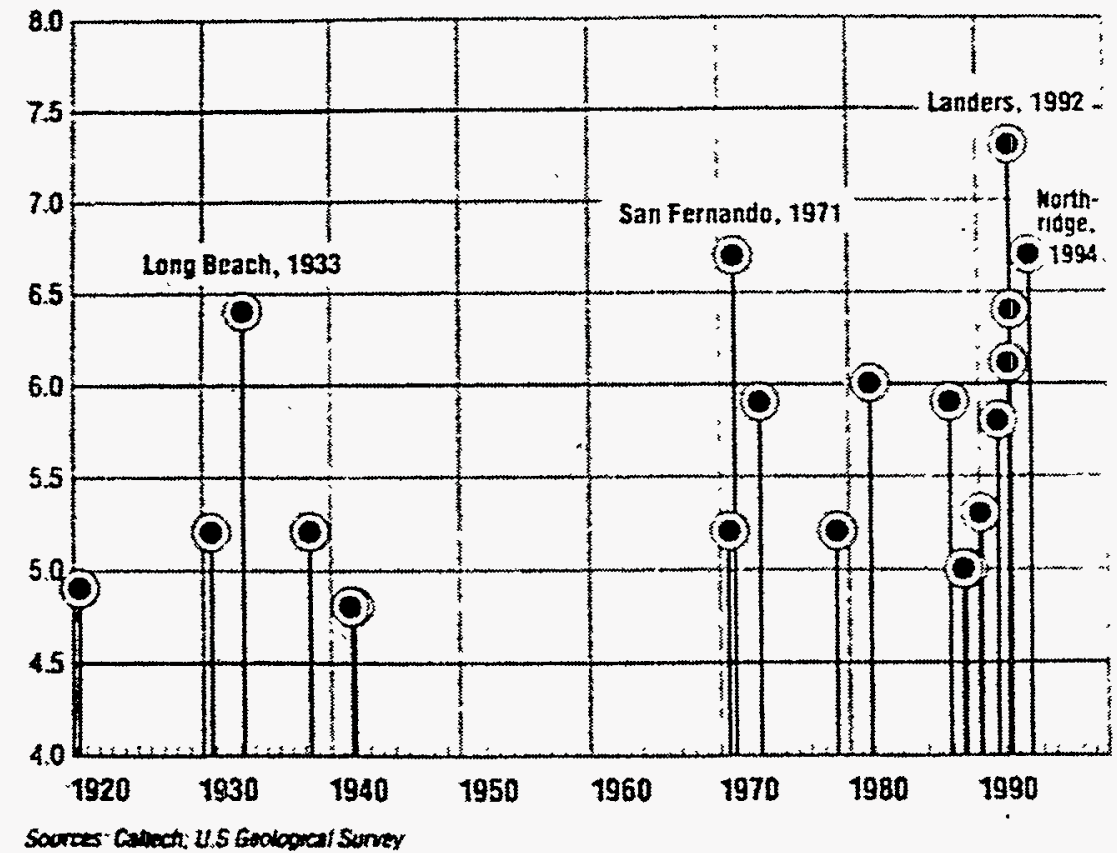

Soures Canch: U.S Goologorat Suntey

Figure 2.2-2: Major Southern California earthquakes that have occurred in the 20th century [ref 2.2-5 and 2.2-6]. 
California's Los Angeles Strong Motion Accelerograph Network (USC) recovered 65 accelerograms from their network. Additional recordings were also obtained from accelerographs owned by LADWP and SCE which are located at selected substations and generating plants. LADWP has 13 instrumented sites in the Los Angeles and Victorville areas which yielded 9 records of interest in the northern San Fernando Valley. SCE has 19 instrumented sites in southern California of which yielded several records of interest in the Palmdale, Santa Clarita, and Ventura areas Other facilities/building complexes also have owner supplied instruments which are still in the process of being identified and retrieved. Many structures ( $>6$ stories) have instruments as required by the Los Angeles City Building Code, however, due to a code change adopted in 1980 , they are only placed at the upper level or roof. Thus, ground motion for many of these sites is not available.

Preliminary contours of MMI were developed by (J. Dewey, 1994) by the USGS National Earthquake Information Center (NEIC) which are shown in Figure 2.3-1. Pockets of intensity IX occurred throughout the western San Fernando Valley and the Santa Clarita Valley, and isolated reports of IX were observed in the Santa Monica, West Los Angeles and West Hollywood areas. Intensity VIII was observed throughout the epicentral region and along the southern margins of the Santa Monica Mountains. Intensity VII extended as far northwest as Fillmore, as far east as Glendale, and as far southeast as Los Angeles. Since only power system facilities within the San Fernando and Santa Clarita valleys Intensity VIII were damaged by the earthquake, this report will focus on the ground motion within those areas. Areas of Santa Monica, north Culver City, and Hollywood also had Intensity VIII damage but power system facilities were not affected.

The location of selected strong ground motion measurements is shown in Figure 2.3-2. Average horizontal peak accelerations from the various networks are listed in Table 2.3-1. The use of the average of the two measured peak horizontal acceleration components is consistent with the procedure used in the SQUG and FOAKE programs. The average peak is believed to be a better estimator of strong ground motion amplitude than the often reported maximum peak acceleration. Only at a few stations did the peak vertical acceleration nearly equal or exceed the maximum horizontal component. The dominant motion was observed to be both northward and vertical from the epicenter. For this earthquake, epicentral distance does not seem to be an indicator of strong motion severity. The data indicate that most of the northwestern San Fernando Valley and the Santa Clarita Valley experienced average horizontal (and vertical) accelerations in excess of $0.5 \mathrm{~g}$. Maximum horizontal accelerations approaching $1 \mathrm{~g}$ were observed at a few stations in the northern part of the San Fernando Valley and at the CSMIP Tarzana site located $5 \mathrm{~km}$ from the epicenter at the base of the Santa Monica Mountains in the southern San Fernando Valley. The motion 


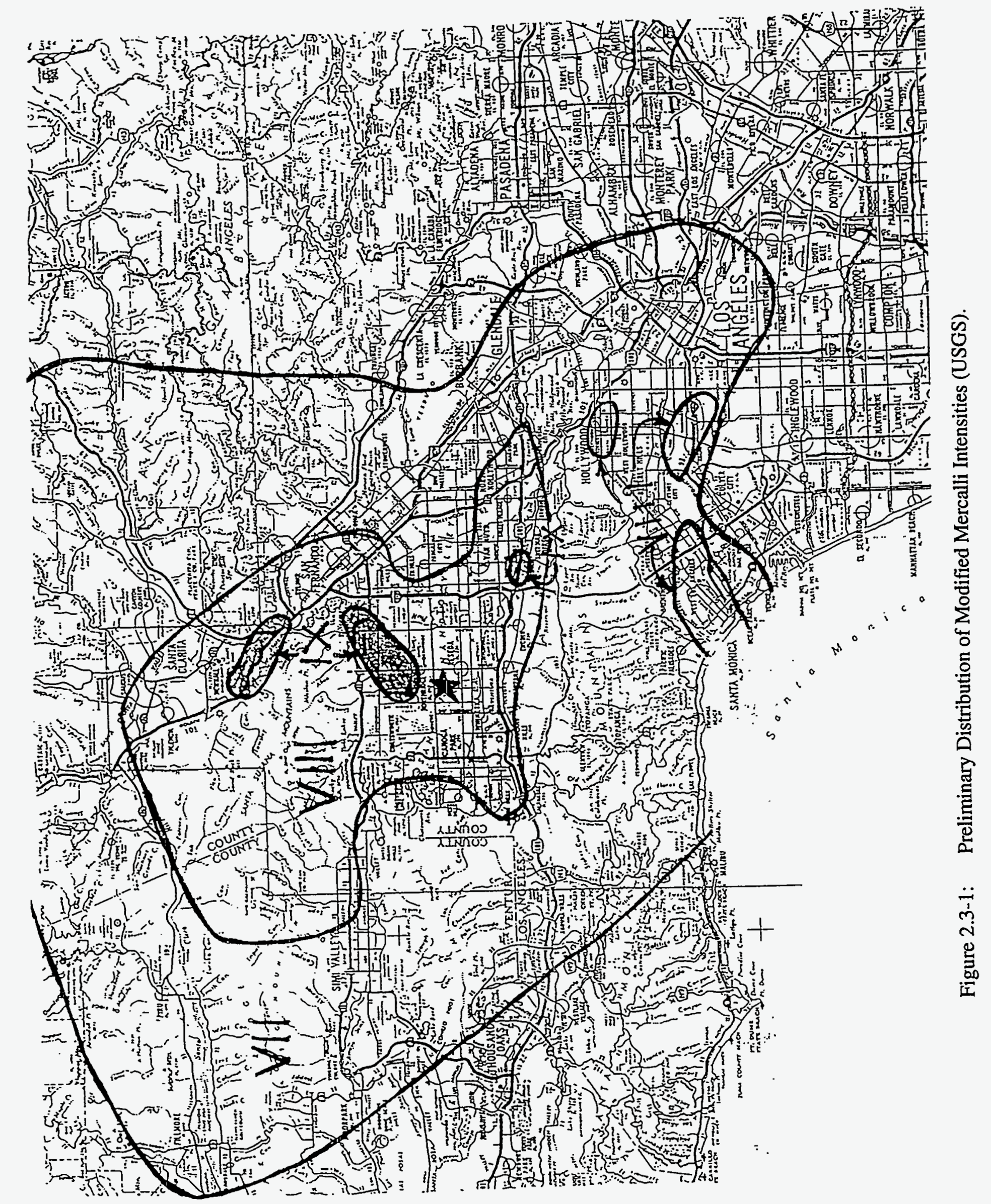

chpt2-0315 


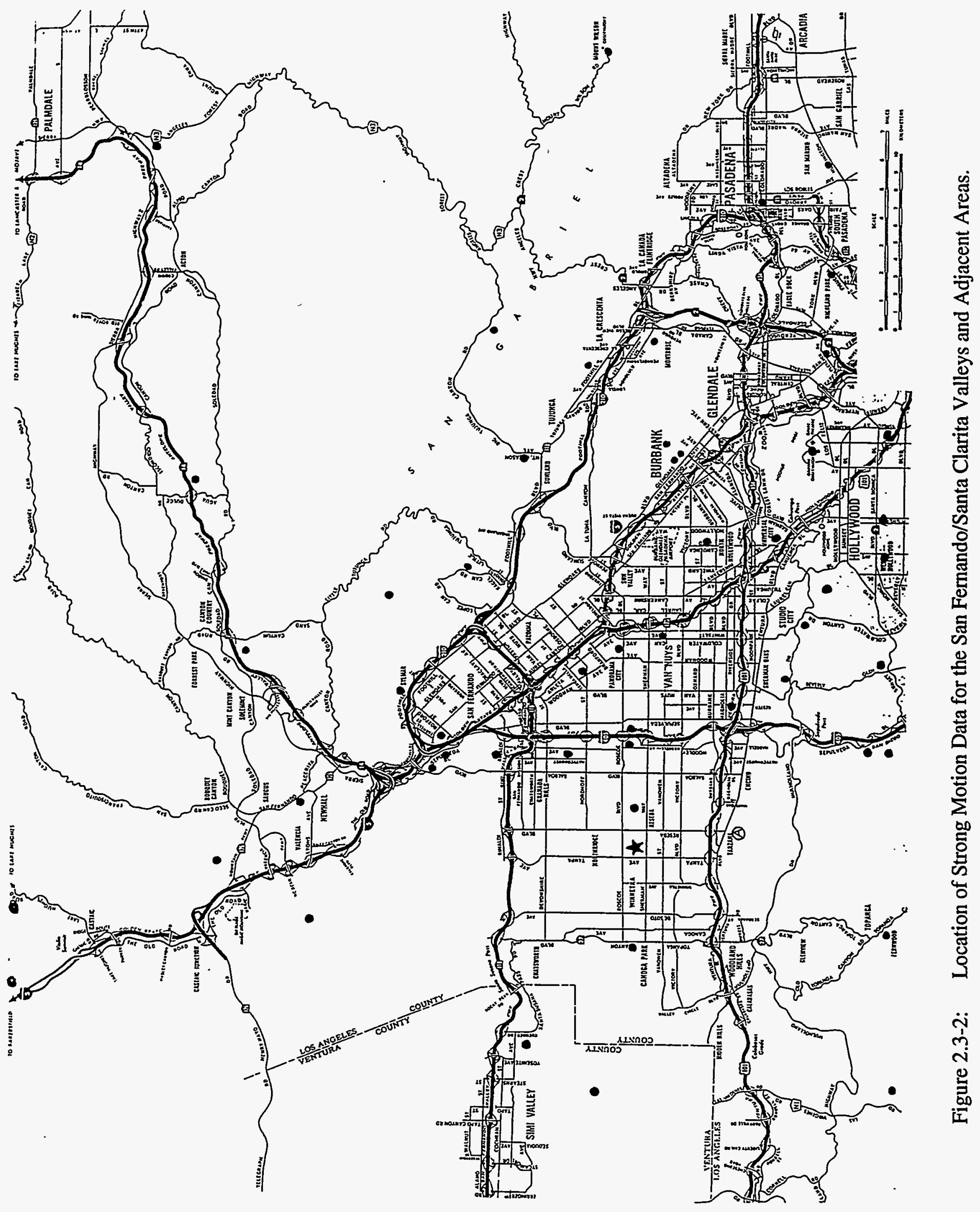


Table 2.3-1: Data Recovered From Selected Instrumentation Stations for the January 17, 1994 Northridge Earthquake

\begin{tabular}{|c|c|c|}
\hline $\begin{array}{l}\text { Station Name } \\
\text { (Organization) }\end{array}$ & $\begin{array}{l}\text { Epicentral } \\
\text { Distance* }\end{array}$ & $\begin{array}{l}\text { Average Horizontal Peak } \\
\text { Ground Acceleration (g) }\end{array}$ \\
\hline Reseda (USC) ** & $2 \mathrm{~km}$ & $0.49 \mathrm{~g}$ \\
\hline Canoga Park (USC) ** & $6 \mathrm{~km}$ & $0.42 \mathrm{~g}$ \\
\hline $\begin{array}{l}\text { Van Nuys (CSMIP) } \\
\text { 7-Story Hotel }\end{array}$ & $7 \mathrm{~km}$ & $0.43 \mathrm{~g}$ \\
\hline $\begin{array}{l}\text { Van Nuys (Owner) } \\
\text { Industrial Site }\end{array}$ & $7 \mathrm{~km}$ & $0.43 \mathrm{~g}$ \\
\hline Sepulveda VA Hospital (USGS/VA) & $8 \mathrm{~km}$ & $0.84 \mathrm{~g}$ \\
\hline Rinaldi Substation (LADWP) & $8 \mathrm{~km}$ & $0.66 \mathrm{~g}$ \\
\hline Sun Valley (USC) $* *$ & $9 \mathrm{~km}$ & $0.49 \mathrm{~g}$ \\
\hline $\begin{array}{l}\text { Sherman Oaks (CSMIP) } \\
\text { 13-Story Commercial Bldg. }\end{array}$ & $9 \mathrm{~km}$ & $0.33 \mathrm{~g}$ \\
\hline $\begin{array}{l}\text { Arleta (CSMIP) } \\
\text { Nordhoff Ave. Fire Station }\end{array}$ & $10 \mathrm{~km}$ & $0.33 \mathrm{~g}$ \\
\hline $\begin{array}{l}\text { Jensen Filter Plant (USGS/MWD) } \\
\text { Ground }\end{array}$ & $12 \mathrm{~km}$ & $0.77 \mathrm{~g}$ \\
\hline $\begin{array}{l}\text { Sylmar HVDC (LADWP) } \\
\text { Converter Station }\end{array}$ & $12 \mathrm{~km}$ & $0.75 \mathrm{~g}$ \\
\hline $\begin{array}{l}\text { Sylmar HVDC (LADWP) } \\
\text { Converter Station (East) }\end{array}$ & $13 \mathrm{~km}$ & $0.66 \mathrm{~g}$ \\
\hline Simi Valley (USC) ** & $13 \mathrm{~km}$ & $0.95 \mathrm{~g}$ \\
\hline $\begin{array}{l}\text { Sepulveda Canyon (USGS/MWD) } \\
\text { Spillway Building }\end{array}$ & $14 \mathrm{~km}$ & $0.35 \mathrm{~g}$ \\
\hline $\begin{array}{l}\text { Sylmar (CSMIP) } \\
\text { 6-Story County Hospital Free-Field }\end{array}$ & $16 \mathrm{~km}$ & $0.72 \mathrm{~g}$ \\
\hline Receiving Station East (LADWP) & $17 \mathrm{~km}$ & $0.45 \mathrm{~g}$ \\
\hline
\end{tabular}

* Based on Epicenter @ 34.21 N, 118.54 W.

** Peak Horizontal Acceleration. 
Table 2.3-1: Data Recovered From Selected Instrumentation Stations for the January 17, 1994 Northridge Earthquake

\begin{tabular}{|c|c|c|}
\hline $\begin{array}{l}\text { Station Name } \\
\text { (Organization) }\end{array}$ & $\begin{array}{l}\text { Epicentral } \\
\text { Distance* }\end{array}$ & $\begin{array}{l}\text { Average Horizontal Peak } \\
\text { Ground Acceleration (g) }\end{array}$ \\
\hline $\begin{array}{l}\text { Pacoima (CSMIP) } \\
\text { Kagel Canyon Fire Sta. \#74 }\end{array}$ & $18 \mathrm{~km}$ & $0.37 \mathrm{~g}$ \\
\hline $\begin{array}{l}\text { Pacoima Reservoir (CSMIP) } \\
\text { Pacoima Dam Downstream }\end{array}$ & $19 \mathrm{~km}$ & $0.42 \mathrm{~g}$ \\
\hline $\begin{array}{l}\text { North Hollywood (CSMIP) } \\
\text { 20-Story Hotel Base }\end{array}$ & $19 \mathrm{~km}$ & $0.23 \mathrm{~g}$ \\
\hline Pico Canyon (USC) $* *$ & $20 \mathrm{~km}$ & $0.44 \mathrm{~g}$ \\
\hline $\begin{array}{l}\text { Newhall (CSMIP) } \\
\text { LA County Fire Station }\end{array}$ & $20 \mathrm{~km}$ & $0.59 \mathrm{~g}$ \\
\hline $\begin{array}{l}\text { Burbank (CSMIP) } \\
\text { 10-Story Residential Bldg. Base }\end{array}$ & $21 \mathrm{~km}$ & $0.32 \mathrm{~g}$ \\
\hline $\begin{array}{l}\text { Burbank (CSMIP) } \\
\text { 6-Story Commercial Bldg. Base }\end{array}$ & $22 \mathrm{~km}$ & $0.27 \mathrm{~g}$ \\
\hline Canyon Country (USC) ** & $26 \mathrm{~km}$ & $0.46 \mathrm{~g}$ \\
\hline Pardee Substation (SCE) & $27 \mathrm{~km}$ & $0.45 \mathrm{~g}$ \\
\hline Vasquez Rocks Park (CSMIP) & $37 \mathrm{~km}$ & $0.15 \mathrm{~g}$ \\
\hline \multicolumn{2}{|c|}{$\begin{array}{l}\text { Los Angeles (CSMIP) } \\
\text { 7-Story University Hospital (Base Isolated) }\end{array}$} & $0.35 \mathrm{~g}$ \\
\hline $\begin{array}{l}\text { Los Angeles/City Terrace (CSMI } \\
\text { Fire Command Control Bldg. (Bz }\end{array}$ & $\begin{array}{l}38 \mathrm{~km} \\
\text { lated) }\end{array}$ & $0.25 \mathrm{~g}$ \\
\hline $\begin{array}{l}\text { Castaic (CSMIP) } \\
\text { Old Ridge Route }\end{array}$ & $41 \mathrm{~km}$ & $0.54 \mathrm{~g}$ \\
\hline Lake Hugher \#9 (CSMIP) & $44 \mathrm{~km}$ & $0.19 \mathrm{~g}$ \\
\hline Vincent Substation (SCE) & $48 \mathrm{~km}$ & $0.15 \mathrm{~g}$ \\
\hline
\end{tabular}

* $\quad$ Based on Epicenter @ 34.21 N, 118.54 W.

** Peak Horizontal Acceleration. 
recorded at the Tarzana free-field site yield an average horizontal acceleration of $1.39 \mathrm{~g}$ which was totally inconsistent with the lack of structural damage and stored items immediately adjacent to the instrument site. The site and record are currently under extensive study and the general consensus is that this record should be considered as anomalous until final study conclusions are issued.

Maximum horizontal accelerations exceeding $0.5 \mathrm{~g}$ were also observed immediately south of the Santa Monica Mountains in the Santa Monica and West Hollywood areas. In contrast, these areas experienced relatively low vertical accelerations with values generally less than about $0.2 \mathrm{~g}$. The accelerations attenuated rapidly southeast of these areas as the seismic waves propagated into the Los Angeles Basin. Downtown Los Angeles experienced maximum horizontal accelerations of about 0.2 to $0.3 \mathrm{~g}$. The central and eastern sections of the Basin saw maximum horizontal accelerations of between 0.1 and $0.2 \mathrm{~g}$.

As of September 25, twenty-eight of the CSMIP ground station accelerograms and five of the instrumented structure records have been digitized and processed (Darragh and others, 1994). The corrected accelerations, velocities, displacements and response spectra for selected stations are included with this processing Processed records for the LADWP and SCE sites are also available. The USGS and USC records have not been digitized and processing of these records will be accomplished at a future date. The corrected accelerations have been used, when available, for the determination of the average horizontal peak accelerations listed in Table 2.3-1. Figures 2.3-3 and 2.3-4 show the recorded acceleration time histories for two of the north San Fernando and Santa Clarita valley sites. These recordings indicate that the duration of significant shaking lasted for approximately 10 seconds or less in the epicentral region.

Figures 2.3-5 through 2.3-9 show the computed response spectra (5\% damping) for several sites in the northern San Fernando valley and the Santa Clarita valley. As can be noted, several of the sites have considerable high frequency energy content. The SQUG Reference Spectrum is indicated on the plots for comparison. The spectra for the Pardee Substation, located in the northern Santa Clarita valley has a strong low-frequency component which is a local site effect. Liquefaction was observed at this site. 


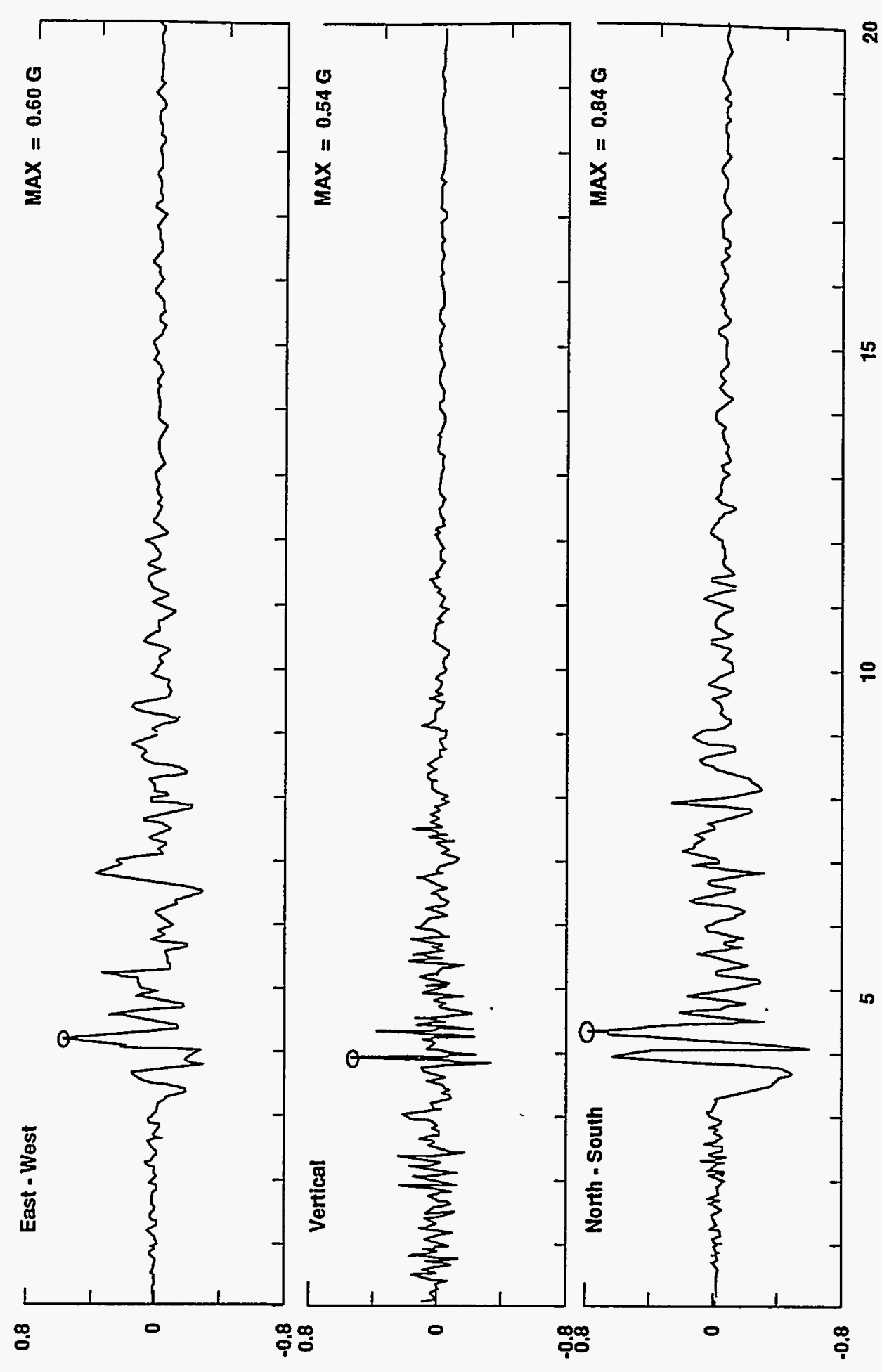

จ

हี่

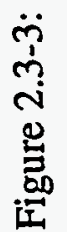

(פ) NOI $\forall \forall \exists 7 \exists O O \forall$ 


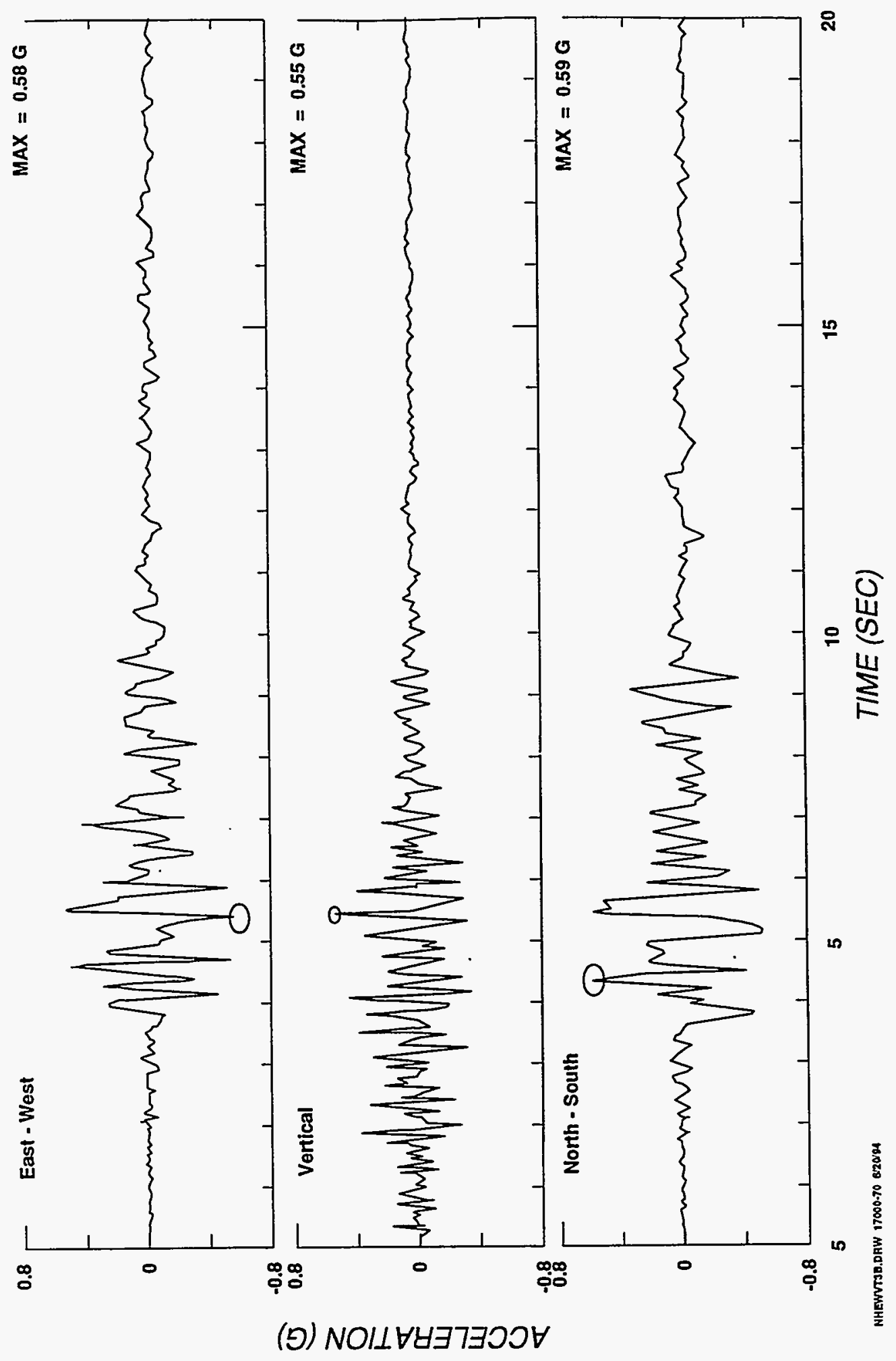

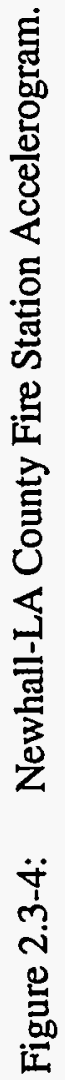




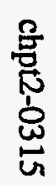

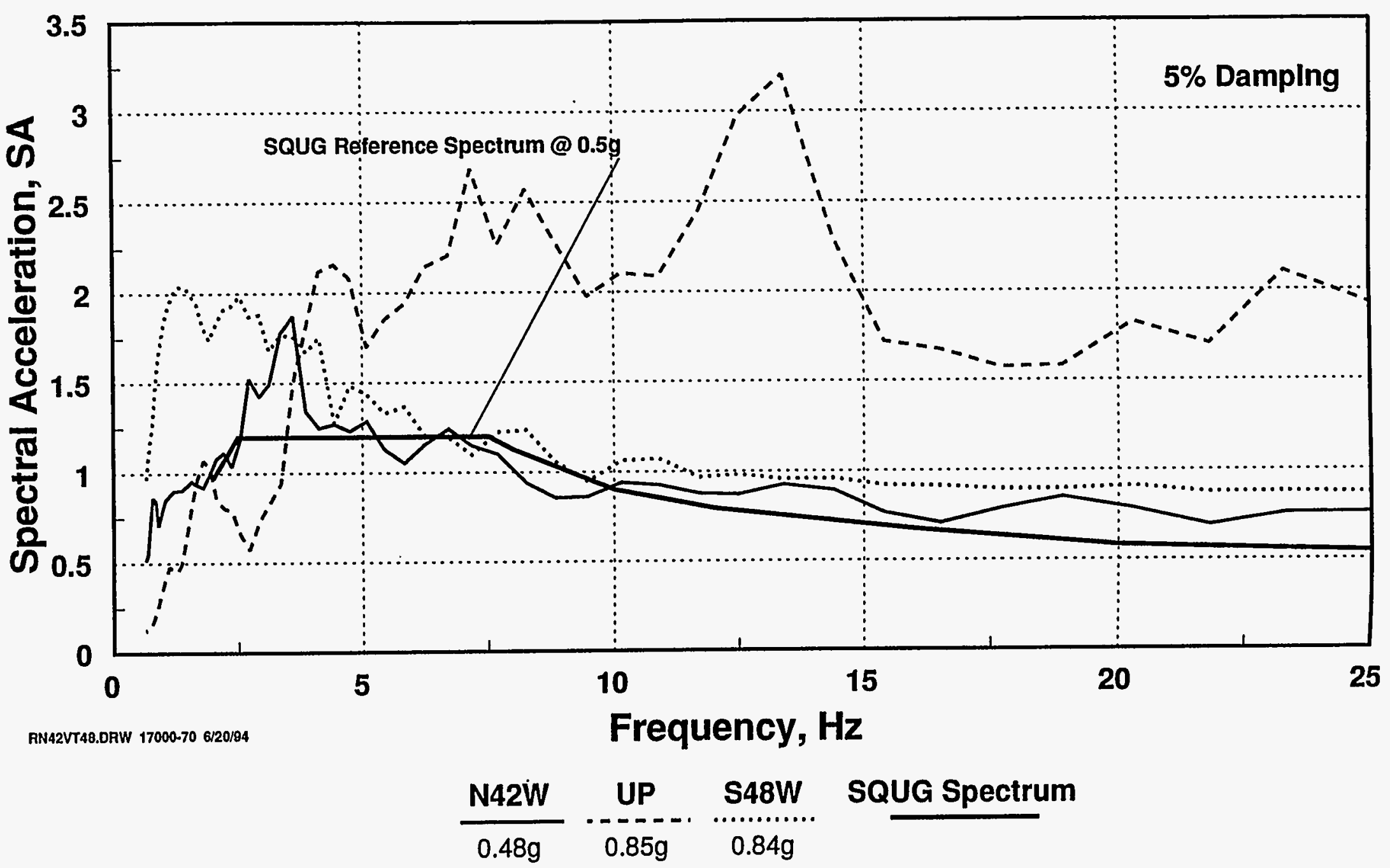

Figure 2.3-5: Rinaldi Receiving Station - Freefield Response Spectra. 


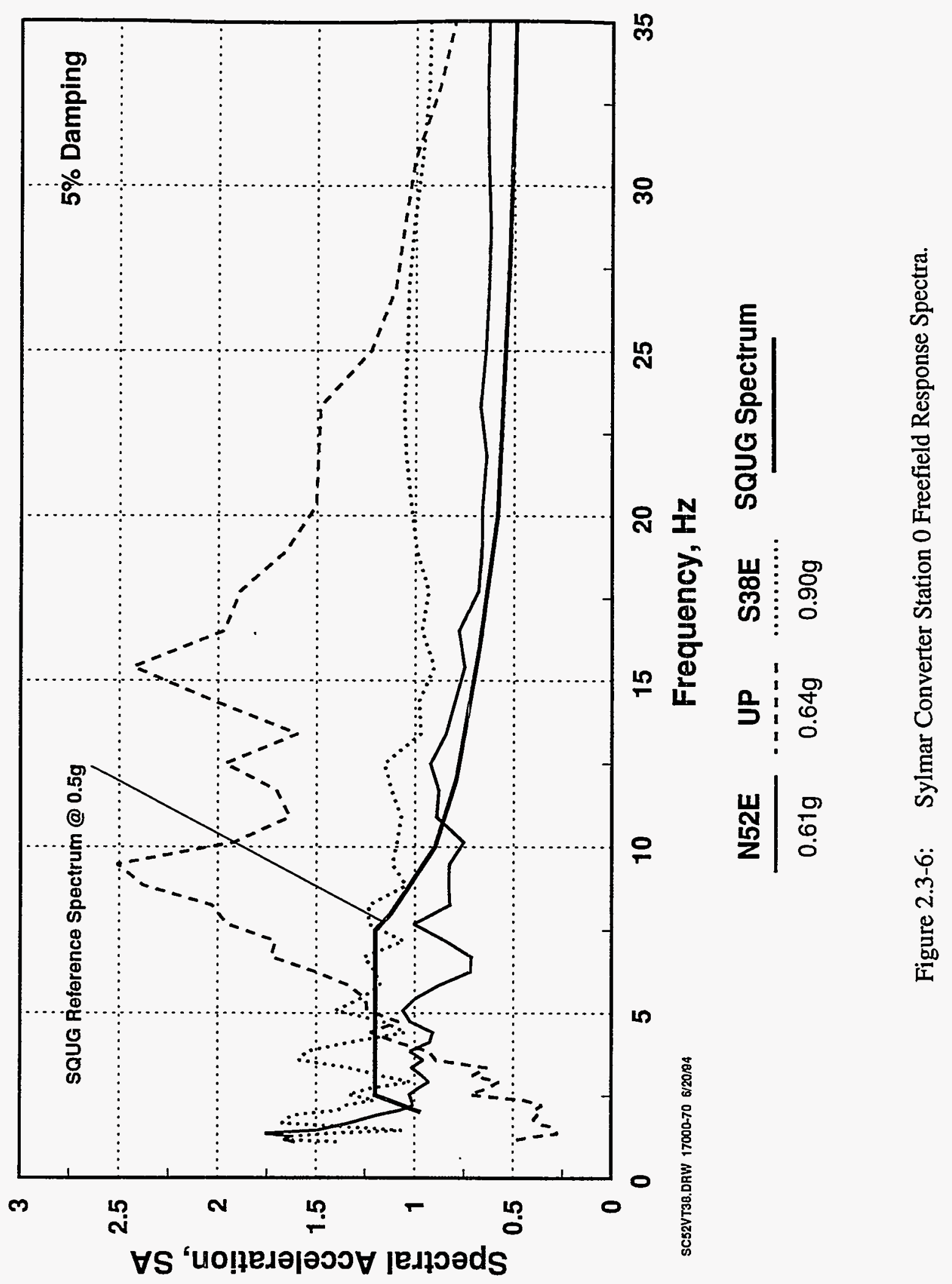




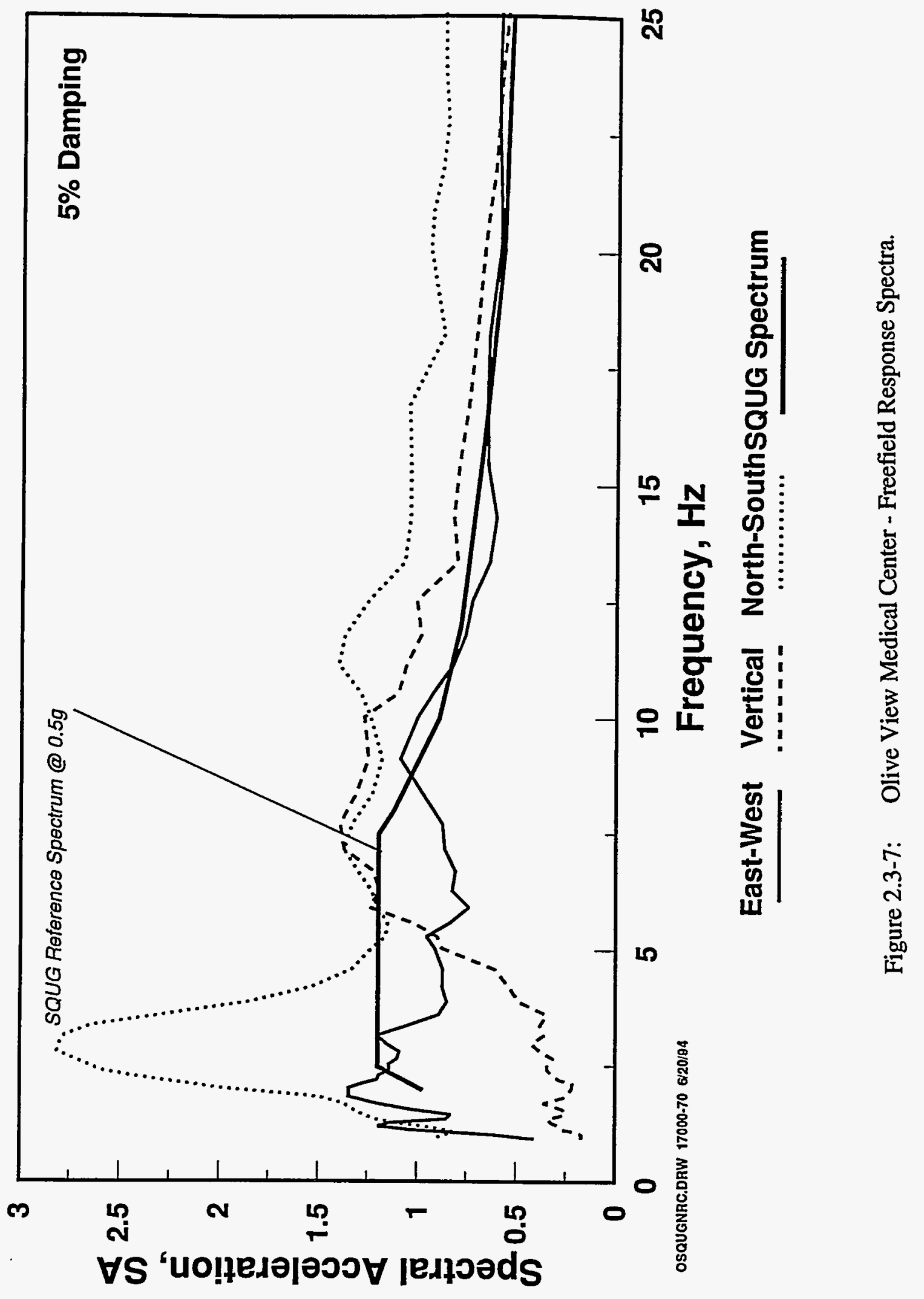




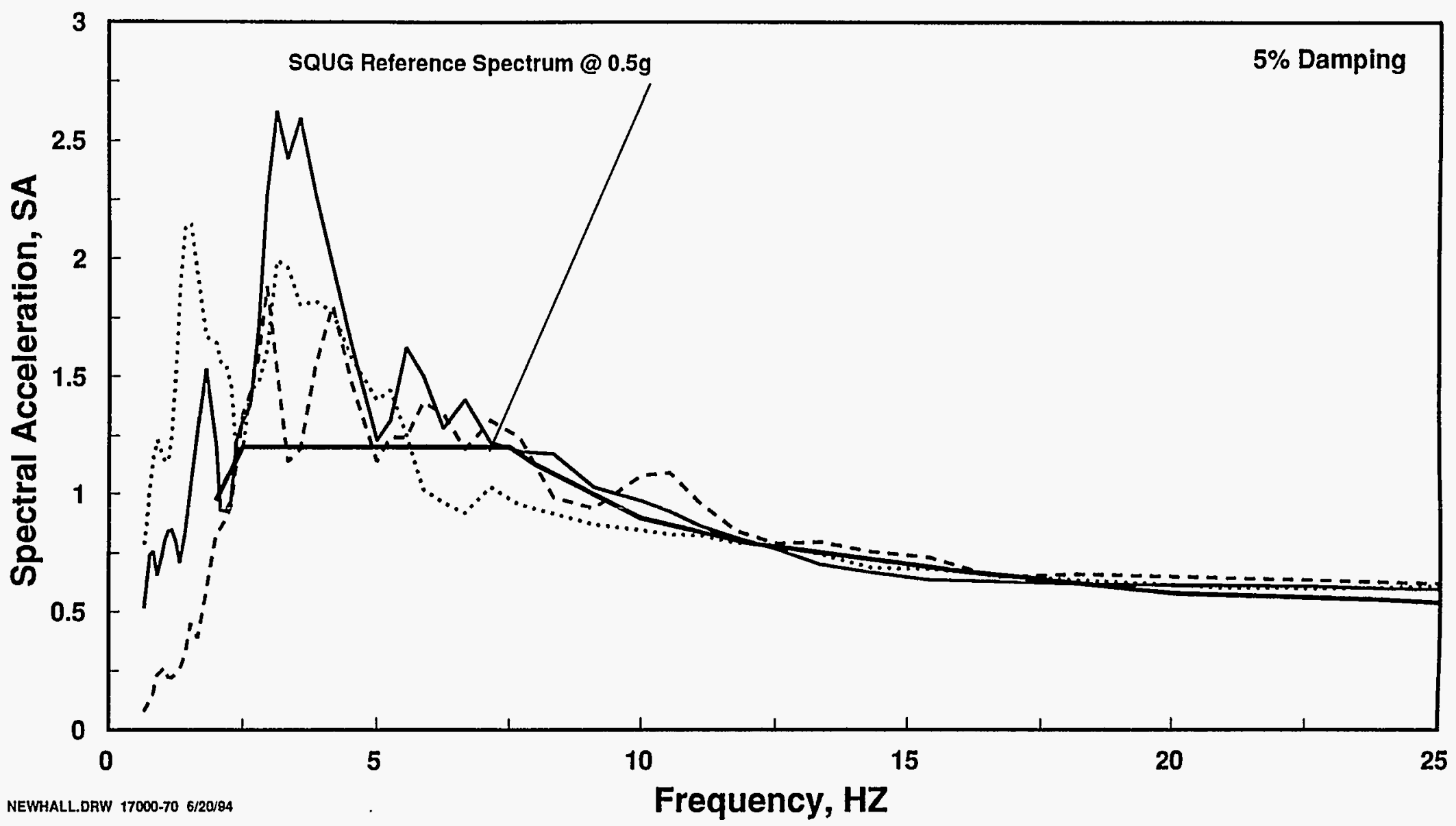

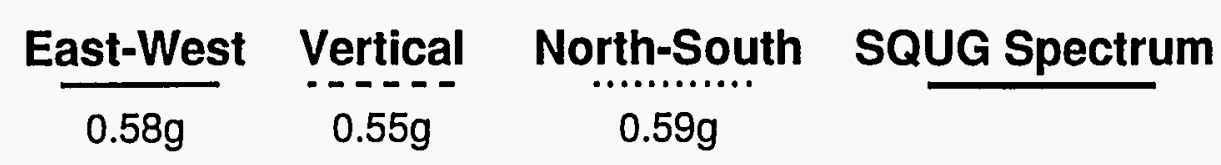

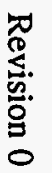

Figure 2.3-8: Newhall Fire Station - Response Spectra. 


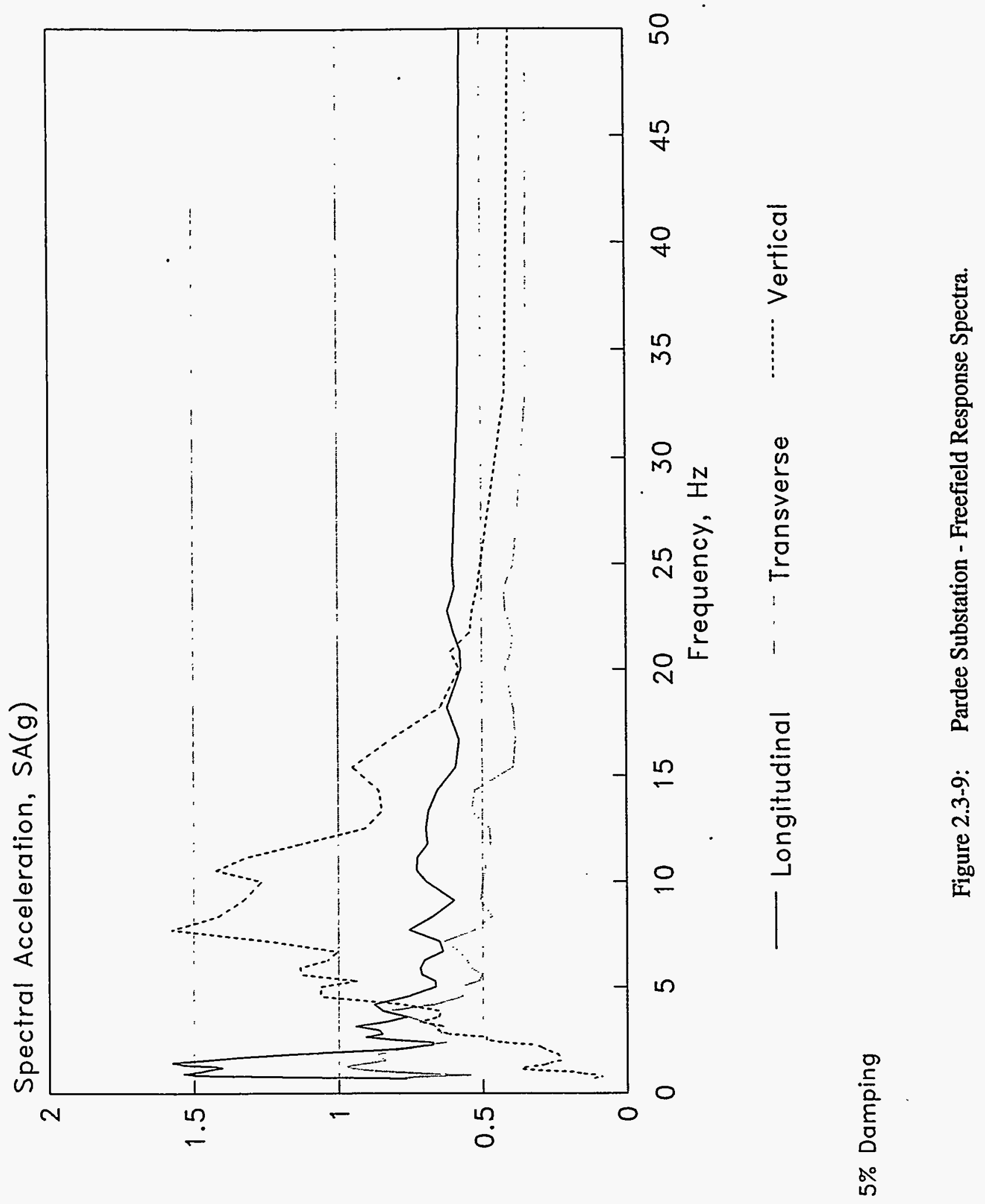




\subsection{REFERENCES}

2.0-1 Taylor, J.M., "Magnitude 6.7 Northridge Earthquake of January 17, 1994", SECY-94077, United Stated Nuclear Regulatory Commission, March 23, 1994.

2.1-1 EQE International, "The January 17, 1994 Northridge, CA Earthquake: An EQE Summary Report", March 19.94.

2.1-2 Geomatrix Consultants, "The January 17, 1994 Northridge Earthquake: Preliminary Assessments".

2.2-1 Earthquake Engineering Research Center, "Preliminary Report on the Seismological and Engineering Aspects of the January 17, 1994 Northridge Earthquake", College of Engineering, University of California at Berkeley, CA, Report UCB/EERC-94-01, January 1994.

2.2-2 EQE International, "The January 17, 1994 Northridge, CA Earthquake: An EQE Summary Report", March 1994.

2.2-3 Geomatrix Consultants, "The January 17, 1994 Northridge Earthquake: Preliminary Assessments".

2.2-4 Monastersky, R., "The Fatal Fling - A Maverick Earthquake Theory Spells Trouble for Tall Buildings", Science News, Vol. 145, No. 26, June 25, 1994.

2.2-5 Figure provided by California Institute of Technology, Pasadena, CA.

2.2-6 Figure provided by U.S. Geological Survey, Menlo Park, CA. 


\section{ELECTRIC POWER SYSTEMS}

About 2 million electric utility customers in the Los Angeles area awoke to power outages at 4:31 AM (PST) on Monday morning, January 17, 1994. Damage to substation apparatus supported by brittle porcelain insulators was the primary contributor to power outages throughout Los Angeles and surrounding areas, with black-outs reported in seven Western states, Mexico and Canada. Service was quickly restored with less than 75,000 customers without power the day following the event and virtually all service restored within 1 week. Electrical power system response, electric power generation and electric power transmission are discussed in the following sections.

\subsection{ELECTRIC POWER SYSTEM RESPONSE}

The electrical power system response to the Northridge Earthquake affected power to a wide diversity of users from the epicentral area through seven western states, Canada and Mexico. The following paragraphs discuss the system response from the global perspective of the Western States Coordinating Council (WSCC), to power outages in the epicentral area.

The WSCC is one of nine reliability councils that make up the North American Electric Reliability Council (NERC). The WSCC is composed of 76 electric systems in 14 western states, 2 Canadian provinces and the northern part of Baja California Norte. The interconnecting grid enhances system reliability and facilities inter-utility energy buying, selling and transportation. At the time of the earthquake, the southern region of the WSCC system was exporting electricity to the northern region. The flow of energy within the region varies dependent on factors such as time of day, season and annual precipitation. The availability of hydrogeneration in the Pacific Northwest is a significant factor.

Immediately preceding the earthquake, Northern California and the Pacific Northwest were importing about 2,000 MW from Southern California. About $800 \mathrm{MW}$ was transported via the $1,000 \mathrm{kV}$ DC Pacific Intertie with the remainder transported via three $500 \mathrm{kV}$ AC interconnections. Concurrently, about 1,700 MW of bulk electricity was transported to Southern California from Utah via the 1,000 kV DC Intermountain Interconnection. Figure 3.1-1 shows the major flows of energy preceding the earthquake. The remainder of the Los Angeles load came from local and remote generating stations.

Substation damage caused by the earthquake immediately shut down the $1,000 \mathrm{kV}$ DC Pacific Intertie and the three $500 \mathrm{kV}$ interconnections between southern and northern California (see 


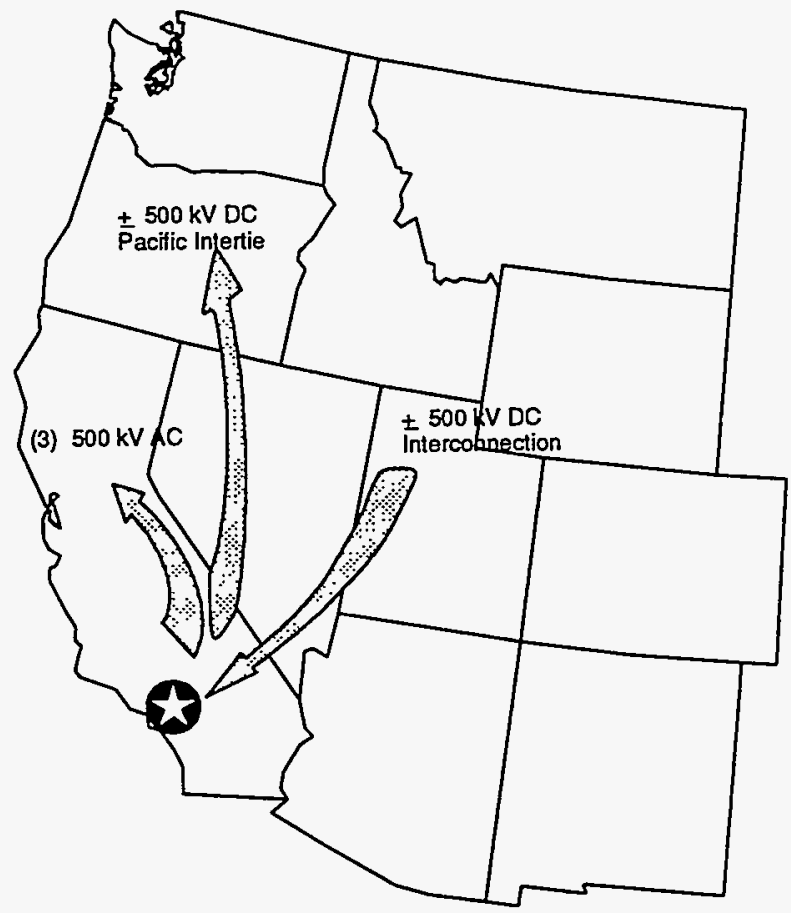

Figure 3.1-1: Major bulk power transmission preceding the Northridge Earthquake. Before the earthquake, the intermountain interconnection was carrying about 1,700 MW into the Los Angeles area. The Pacific intertie and three $500 \mathrm{kV}$ lines were carrying about 2,000 MW to Northern California and the Pacific Northwest.

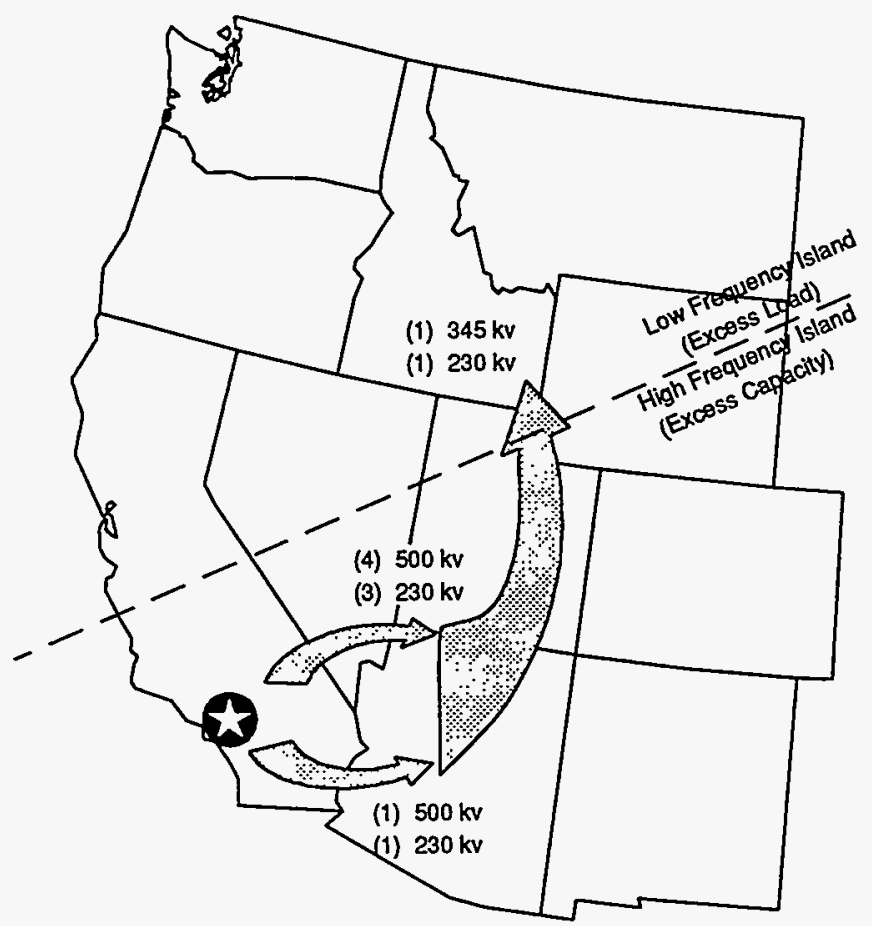

Figure 3.1-2: Following the earthquake, a 4,000 MW surge followed the path of least resistance through the southwest, tripping circuit breakers when the surge hit Southeast Idaho. This created two large islands, a Northwest low frequency island and a Southeast island high frequency. 
Section 3.3 for substation performance). Concurrently, substation damage and associated electrical transients resulted in the blackout of the entire City of Los Angeles.

The loss of transmission corridors to export the $2,000 \mathrm{MW}$ pre-earthquake surplus along with the loss of about 2,000 MW of Los Angeles load resulted in 4,000 MW surge. The surge traveled through the eastern part of the system, the path of least resistance. The transient tripped the 1,000 $\mathrm{kV}$ DC Intermountain Interconnection, causing the Intermountain Power Plant to attempt to convert the power to the AC system. The plant immediately tripped due to over-frequency. When the power surge reached South-East Idaho, the system was not synchronous. Circuit breakers then opened, creating two large islands: Southern California through South-East Idaho, and Northern California and the Pacific Northwest. Figure 3.1-2 shows the approximate break between the northern and southern islands.

The northwest island experienced higher energy demand than capacity, resulting in an underfrequency condition (less than $60 \mathrm{~Hz}$ ). The island then began shedding load in order to match capacity to demand in order to stabilize the system. Load shedding resulted in power outages in parts of Alberta, Northern California, British Columbia, Idaho, Montana, Northern Nevada, Oregon, and Washington. Power outages in the low frequency island were generally short duration.

The southwest island experienced an over-frequency condition (greater than $60 \mathrm{~Hz}$ ). Generating stations were tripped off-line to lower the frequency and stabilize the system. The high frequency island experienced power outages in parts of Arizona, Southern California, Colorado, Mexico, New Mexico, Utah, and Wyoming. Power outages outside of earthquake damaged areas were of short duration.

Electrical power systems in the affected areas are operated by the Los Angeles Department of Water and Power (LADWP) and Southern California Edison (SCE) as well as municipal utilities such as the cities of Burbank and Glendale. About 2 million customers were without power on the morning of the earthquake with the LADWP system completely blacked-out, for the first time in history. Resiliency of the power system and extraordinary efforts by utility personnel overcame the damage and restored service to most utility customers within a few hours, 93\% within 24 hours, and $99 \%$ of service restored within 3 days of the event. 


\subsection{ELECTRIC POWER GENERATION}

Electric power generating plants sustained relatively minor damage during the Northridge earthquake due to their inherent ruggedness and distance from the epicenter. The nearest power plant is located about $14 \mathrm{~km}$ east of the epicenter in a region of moderate ground motion compared to the much higher motion observed directly north and south of the epicenter.

Three electric generating facilities experienced enough ground motion to affect architectural features with isolated instances of equipment damage. Several other generating stations were not damaged, however, experienced ground motion levels sufficient to activate turbine trip vibration instrumentation. Additional stations within the Los Angeles Department of Water and Power (LADWP) and Southern California Edison (SCE) systems tripped off line due to fluctuations in the electrical grid.

The Valley Generating Station, Burbank Power Plant, and Glendale Power plant; operated by LADWP, the City of Burbank, and the City of Glendale, respectively; experienced moderate ground motion and sustained limited damage. The Pasadena Power Plant (City of Pasadena), Ventura coast plants (SCE) and southern LA plants (LADWP) were not physically damaged, however, were shutdown due to turbine vibration sensors and/or black-out of the local power grid. Some generation plants outside of Southern California were required to shut down in order to maintain the desired frequency of the western area power grid.

A summary of the performance of electric power generating stations follows. Facility locations are shown on Figure 3.2-1.

\subsubsection{Valley Generating Station}

Located closest to the epicenter, the Valley Generating Station includes four thermal generating plants; Unit 1 rated at $95,000 \mathrm{kw}$, Unit 2 rated at $99,000 \mathrm{kw}$, Unit 3 rated at $163,000 \mathrm{kw}$ and Unit 4 at $160,000 \mathrm{kw}$ (Figure 3.2.1-1). The first 2 units were placed in operation in 1954 then, after many years of service, placed in mothball status in 1994. Units $3 \& 4$ were placed in operation in 1955 and 1956, respectively, and in recent years were used only intermittently. Units $3 \& 4$ had not operated since November of 1993.

Valley Generating Station operational units produce power at $18.2 \mathrm{kV}$, stepped-up to $138 / 230 \mathrm{kV}$ for transmission and distribution throughout Los Angeles. 


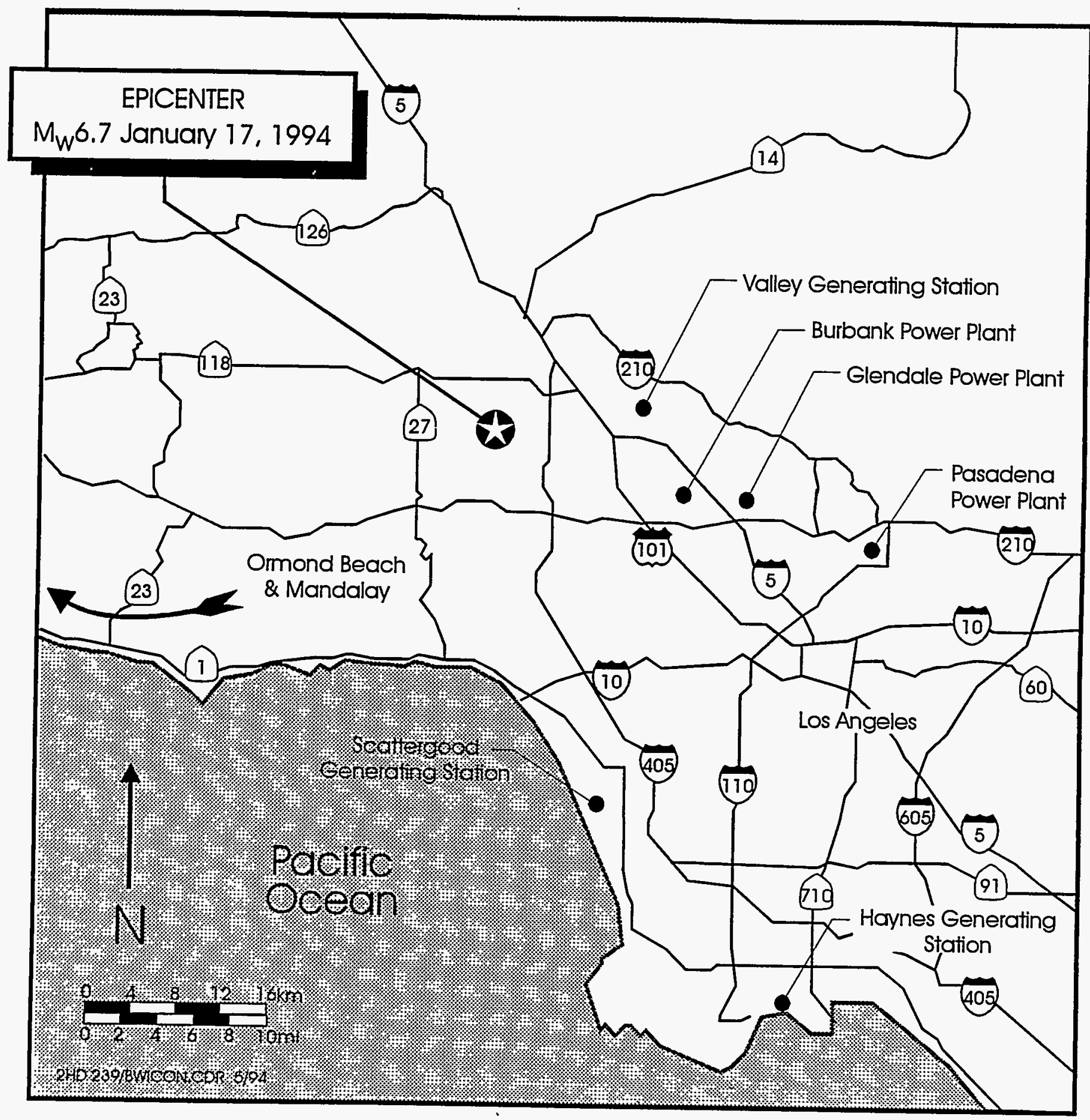

Figure 3.2-1: Electric power generating stations investigated following the Northridge Earthquake. 


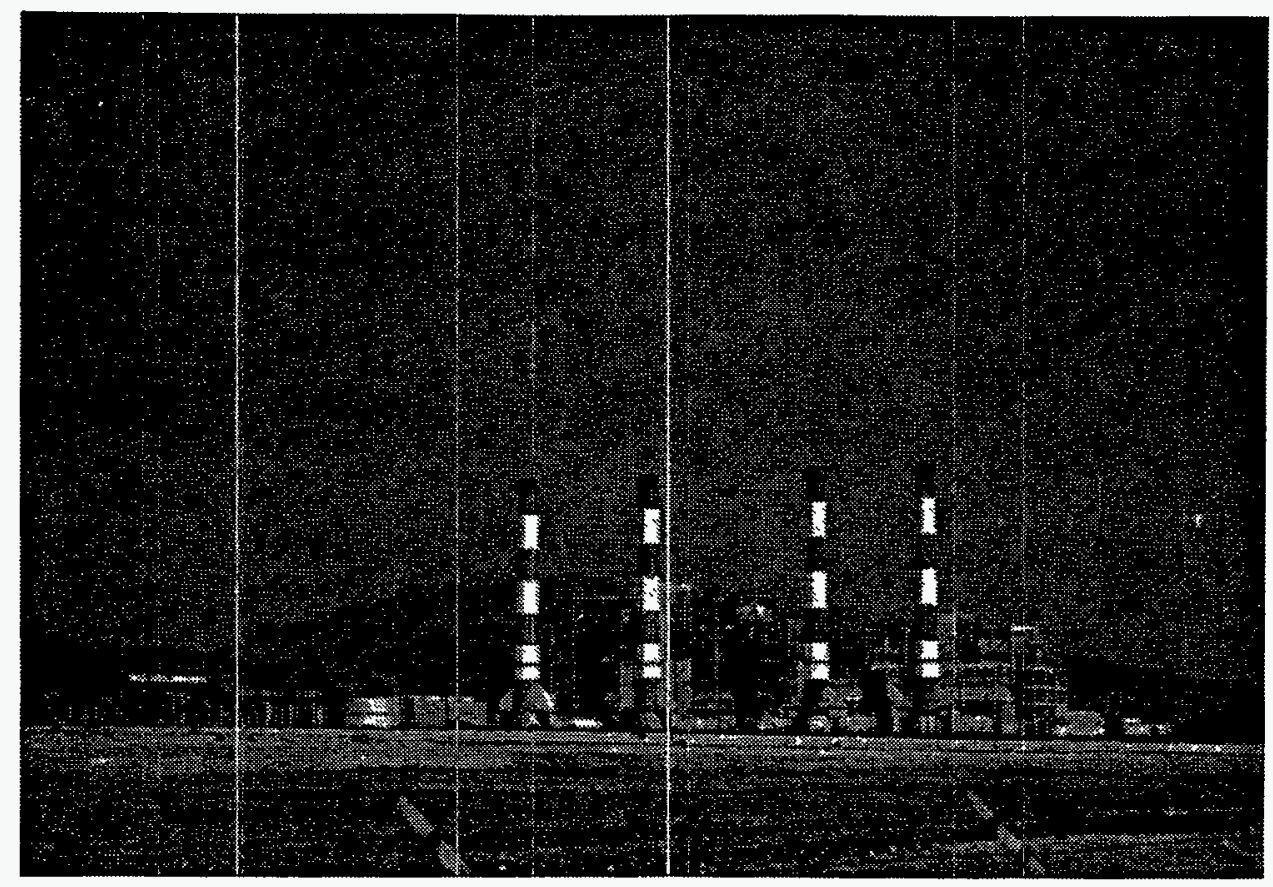

Figure 3.2.1-1: Valley Generating Station Units 1 through 4 from right to left. The facility is located at the foot of the Hansen Flood Control Basin about $14 \mathrm{~km}$ east of the Northridge Earthquake epicenter.

Figure 3.2.1-2: Mercury reservoir combustion air flow instruments (center) failed during the earthquake. Modern electronic transmitters (left) were installed to replace the much larger 1950 's vintage hardware.

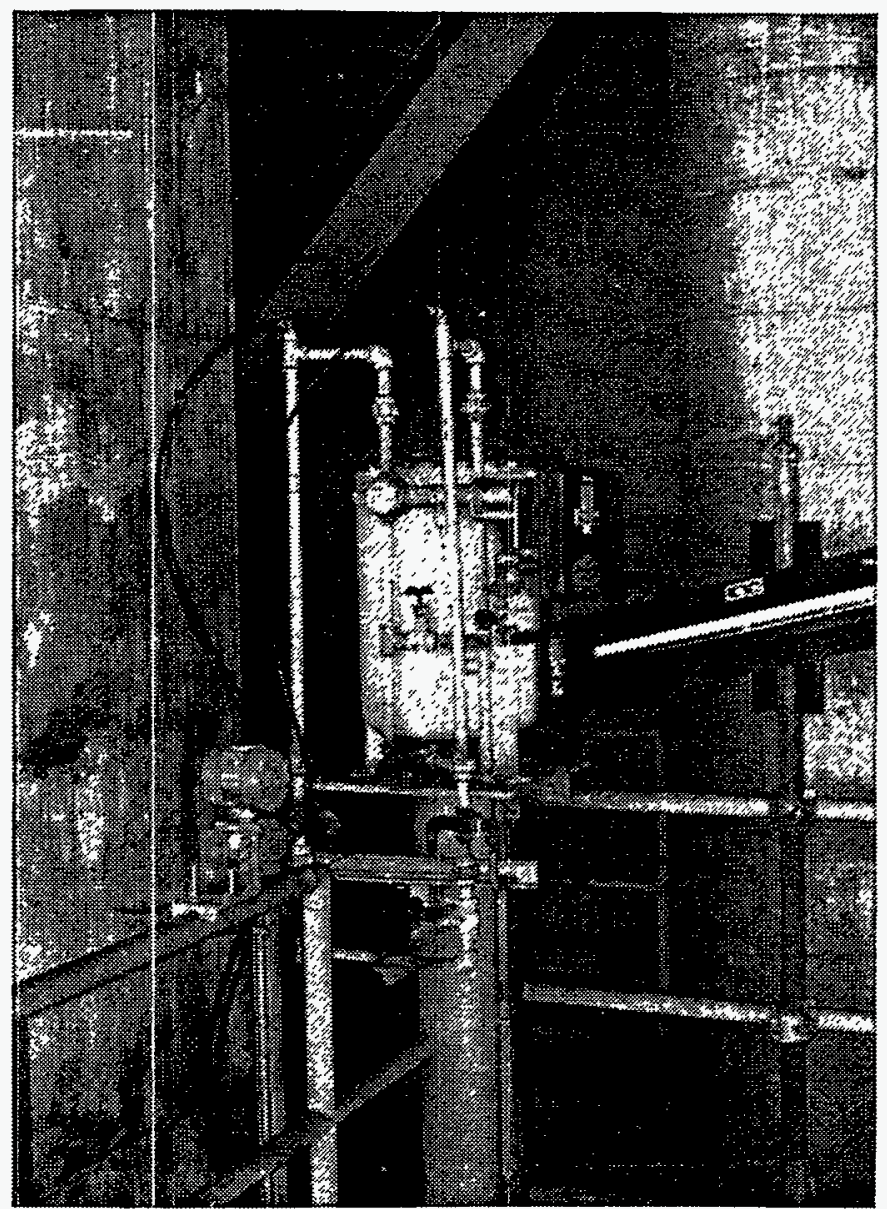

3-6

Revision 0 
Unit 3 was available on reserve shutdown and Unit 4 was unavailable due to a planned outage when the earthquake struck at 4:31 AM (PST). Plant power was immediately lost. Plants on reserve shutdown are in a cold condition and available to come on line, however, unlike plants in hot shutdown, it can take several hours to restart auxiliary systems, prepare the boiler for operations and generate steam.

The facility sustained minor damage such as cracks in steel struts, a twisted wide flange support, distorted exhaust duct insulation panels, damaged piping insulation, inoperable combustion air instruments and superficial damage to building elements. Numerous relays had to be reset prior to restart. The damage did not prevent plant start-up.

The combustion air flow instrument failures are virtually identical to failures experienced at the plant during the 1971 San Fernando Earthquake and at the Pasadena Power Plant during the 1987 Whittier and 1991 Sierra Madre Earthquakes. The large mercury reservoir displacer dislodges from its slip-fit into a mechanical lever. Modern electronic differential pressure instruments were installed rather than repair the existing hardware (Figure 3.2.1-2). Parts were available since replacement of mercury reservoir instruments was planned for the near future.

The plants were inspected and unit 4 placed on available standby status by 8:00 a.m.. Dispatchers requested units $3 \& 4$ to come on line and power was restored by $8: 10$ a.m.. Both units were on turning gear by $9: 30$ a.m., boilers lit by 11:30 a.m., turbines rolling on steam by 5:45 p.m. and synchronized to the system by approximately 10:00 p.m..

Upon restart, leakage in a 6 inch diameter welded steel condensate line was noticed (Figure 3.2.13). The leak occurred at the bottom of a butt-welded elbow in an area that is commonly prone to corrosion and erosion. The leak was small and did not prevent full operation of the plant.

Ultrasonic testing was performed several weeks later and wall thickness degradation due to erosion was determined to be the probable cause. A weld backing ring inside the pipe, used to align sections and facilitate full penetration welding, may have contributed to the erosion pattern. The shaking probably initiated a leak that would have developed in the near future regardless of the earthquake.

An 18 inch long temporary patch was welded to the line as a short term repair. The elbow and several feet of adjacent piping will be replaced when the plant is down for maintenance. Such repairs are common in fossil-fueled power plants. 


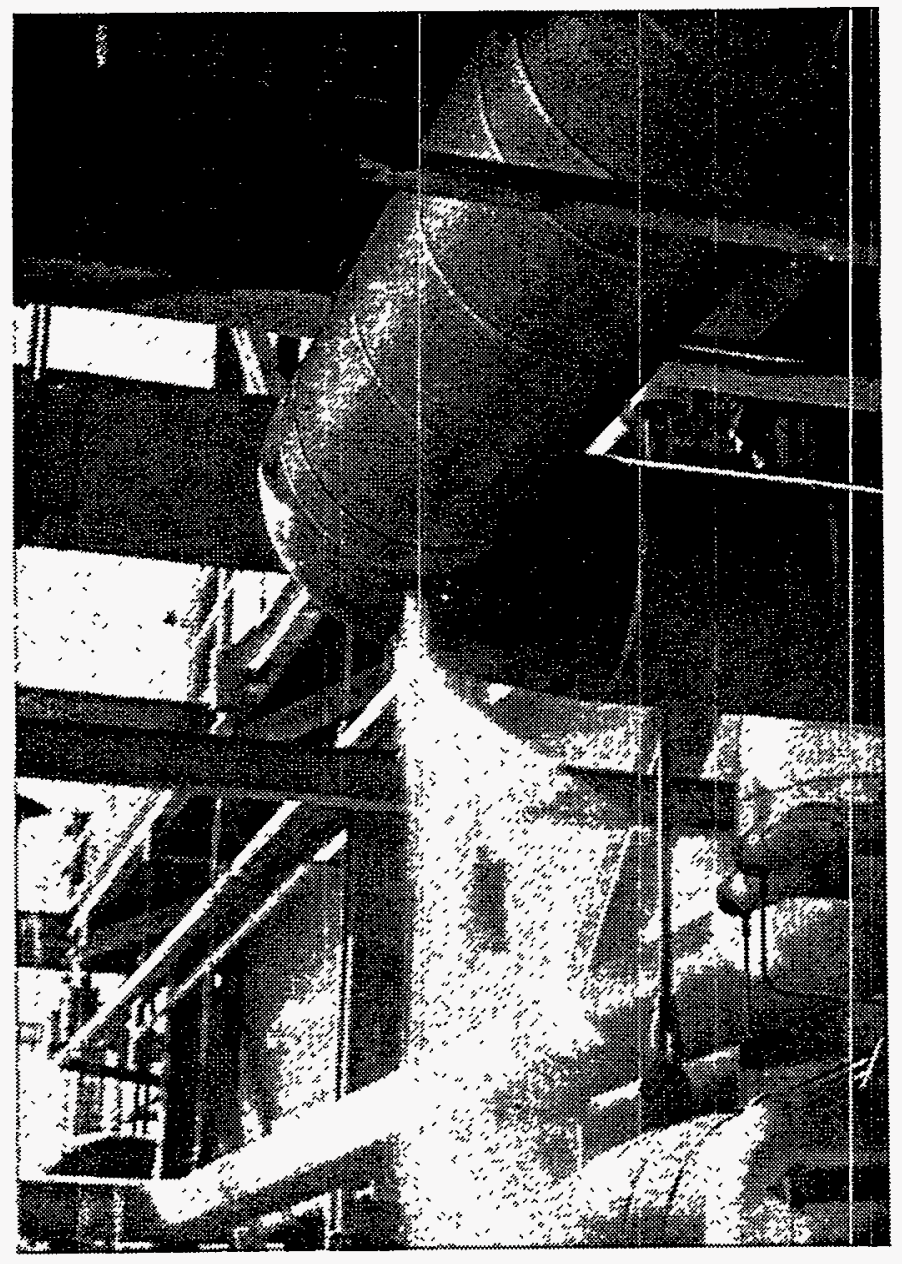

Figure 3.2.1-3: A leak developed in the elbow of a 6 inch diameter welded steel condensate line during postearthquake restart. The leak was the result of long term erosion and would have developed regardless of the earthquake.

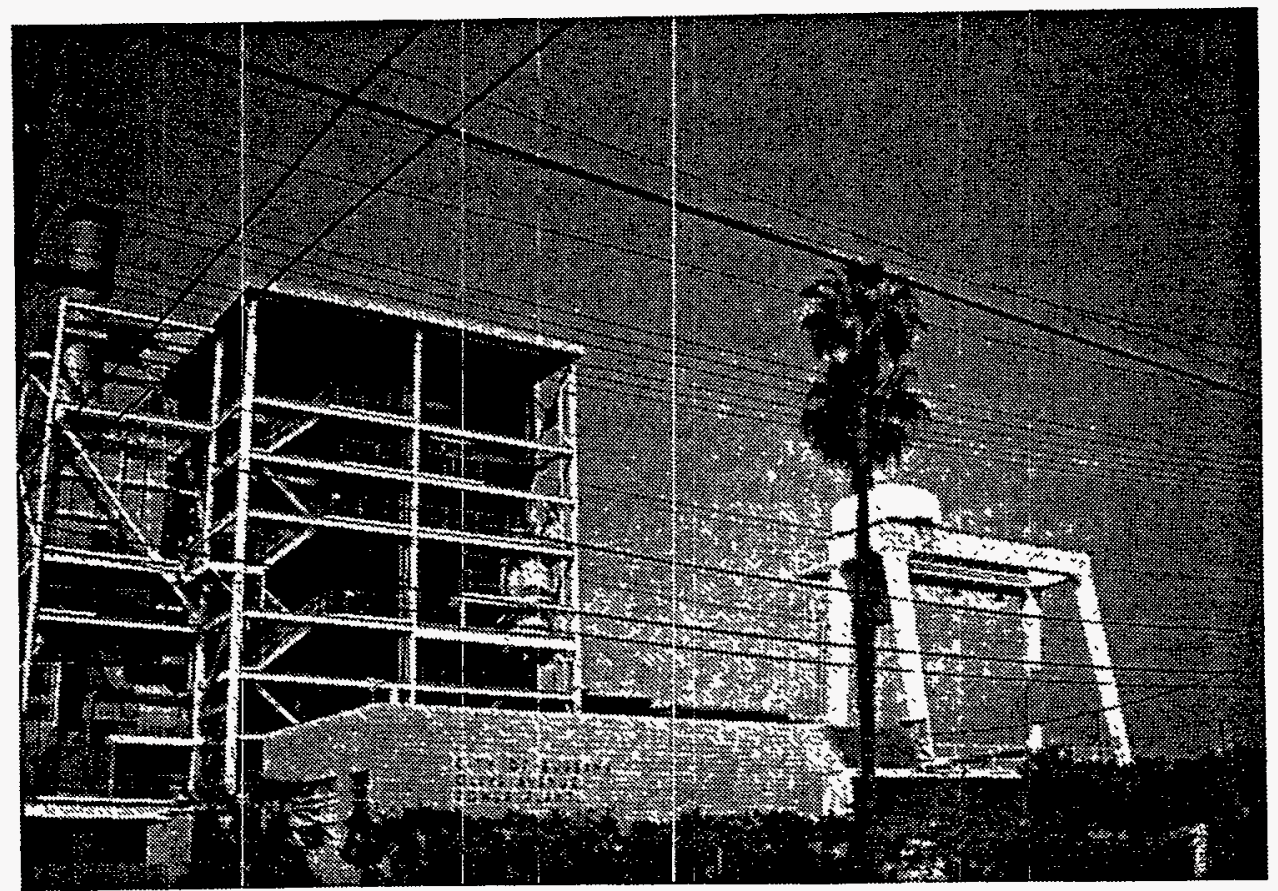

Figure 3.2.2-1: View of City of Burbank Power Plant, Olive Units. 
The plant was operating during the magnitude 5.1 aftershock on January 19, two days after the main shock. No significant physical damage was observed, however, Unit 4 tripped off-line due to relay actuation, indicating phase-to-phase and phase-to-ground faults. Facility personnel reviewed oscillographs and determined that the phase differentials did not occur. The shutdown can be attributed to earthquake induced relay chatter. Electro-mechanical protective relays of the differential-type have proven to be susceptible to chatter during past earthquakes.

Strong motion data from the California Strong Motion Instrumentation Program (CSMIP) includes 3 stations that form a rough triangle around the Valley Generating Station. The stations are:

(1) The Kagel Canyon Fire Station, located about $6 \mathrm{~km}$ north of the plant, recorded $0.44 \mathrm{~g}$ horizontal and $0.19 \mathrm{~g}$ vertical peak ground accelerations [ref 3.2-1]. The station is sited on Sandstone [ref 3.2-2].

(2) The Nordhoff Avenue Fire Station, located $5.5 \mathrm{~km}$ west of the plant recorded $0.35 \mathrm{~g}$ horizontal and $0.59 \mathrm{~g}$ vertical [ref $3.2-1]$. The station is sited on alluvium [ref 3.2-2].

(3) LADWP Receiving Station "E", located about $3.5 \mathrm{~km}$ south-east of the plant experienced maximum accelerations of $0.5 \mathrm{~g}$ horizontal and $0.36 \mathrm{~g}$ vertical [ref 3.2-3]. The station is sited on alluvium [ref 3.2-4].

Soil conditions at the generating station [5] and two of the adjacent CSMIP stations are alluvium.

The above records and damage assessments indicate that the facility experienced about the same level shaking as experienced during the 1971 San Fernando earthquake, approximately $0.4 \mathrm{~g}$ horizontal peak ground acceleration.

Valley Generating Station is not as efficient as newer units and was targeted for possible decommissioning in 1995. The positive performance during the Northridge earthquake and the availability of local generating capacity following the loss of long distance transmission capacity may influence the decision for continued operation.

\subsubsection{Burbank Power Plant}

The Burbank Power Plant consists of two facilities, the five unit Magnolia Plant and the four unit Olive Plant. Magnolia units 1 through 4 were constructed in the 1940's and early 1950's. Their capacities are 10,10,20, and $30 \mathrm{MW}$ respectively. Magnolia Unit 1 is no longer in service and Unit 2 is used for combined cycle with Olive Unit 4. Olive Units 1 and 2 were constructed in 1958 
and 1961 and have a capacity of $40 \mathrm{MW}$ and $55 \mathrm{MW}$ each (Figure 3.2.2-1). Magnolia Unit 5 and Olive Units 3 and 4 are gas turbines used for peaking and/or combined cycle operation.

At the time of the shock, Magnolia Unit 3 and Olive Unit 2 were operating at low load, Olive Unit 1 was in hot standby, Magnolia Unit 4 was shut down for maintenance, and none of the other units were operating. All units tripped off line because of lost auxiliaries. Subsequently, the gas turbine for Olive 3 was black-started which allowed Olive Unit 2 to be put on turning gear for cool down and allowed the other gas turbines to be brought on line. The restart of Magnolia Unit 3 was hindered by a sticky steam chest master valve and a broken $1 / 2$ inch condensate line. At approximately 11:30 a.m. an inadvertent trip of Olive Unit 3 caused lube oil to be sucked into the turbine. Although the oil was burned, it did not cause any damage, and the unit was put back into operation. Olive Unit 1 was brought on line at about 6:00 p.m. that evening.

Reported damage and failures were limited to a broken 3 inch diameter PVC line, spalling at a tank footing, a broken $1 / 2$ inch threaded gas line, failure of gantry crane bolts, and deformed restraining clips on a 12 ' diameter by $20^{\prime}$ high potable water tank.

The broken 3 inch diameter PVC buried piping was rigidly attached to the base of a 12' diameter by $24^{\prime}$ high fiberglass Deionized Water tank. The tank is restrained with bands but rocking of approximately 1-1/4 inch upward is indicated by scratches on the tank wall. The same line failed during the 1971 San Fernando Earthquake [ref 3.2-5].

Several 1-1/4 inch bolts connecting the base of the Magnolia Unit gantry crane to the rail wheel assemblies failed (Figures 3.2.2-2 and 3.2.2-3). The crane hoist is cantilevered from the frame structure approximately 60 feet above the connection. The crane did not disengage from the rails but was inoperable. The same failure occurred during the 1971 San Fernando Earthquake [ref 3.25].

The power plant is located $21 \mathrm{~km}$ from the epicenter, within $2 \mathrm{~km}$ of two CSMIP strong motion records. Instruments located on the ground floor of a 6-story office building located in Burbank recorded peak accelerations of $0.35 \mathrm{~g}$ horizontal and $0.15 \mathrm{~g}$ vertical [ref 3.2-1]. Instruments located on the ground floor of a 10-story residential building, also located in Burbank, recorded $0.35 \mathrm{~g}$ horizontal and $0.13 \mathrm{~g}$ vertical peak accelerations [ref 3.2-1].

\subsubsection{Glendale Power Plant}

The Glendale Power Plant is an electrical generating facility with five natural gas fired boilers (Units 1 through 5, at 20 to $44 \mathrm{MW}$ ) mounted in steel-frame boiler structures atop a deep concrete 


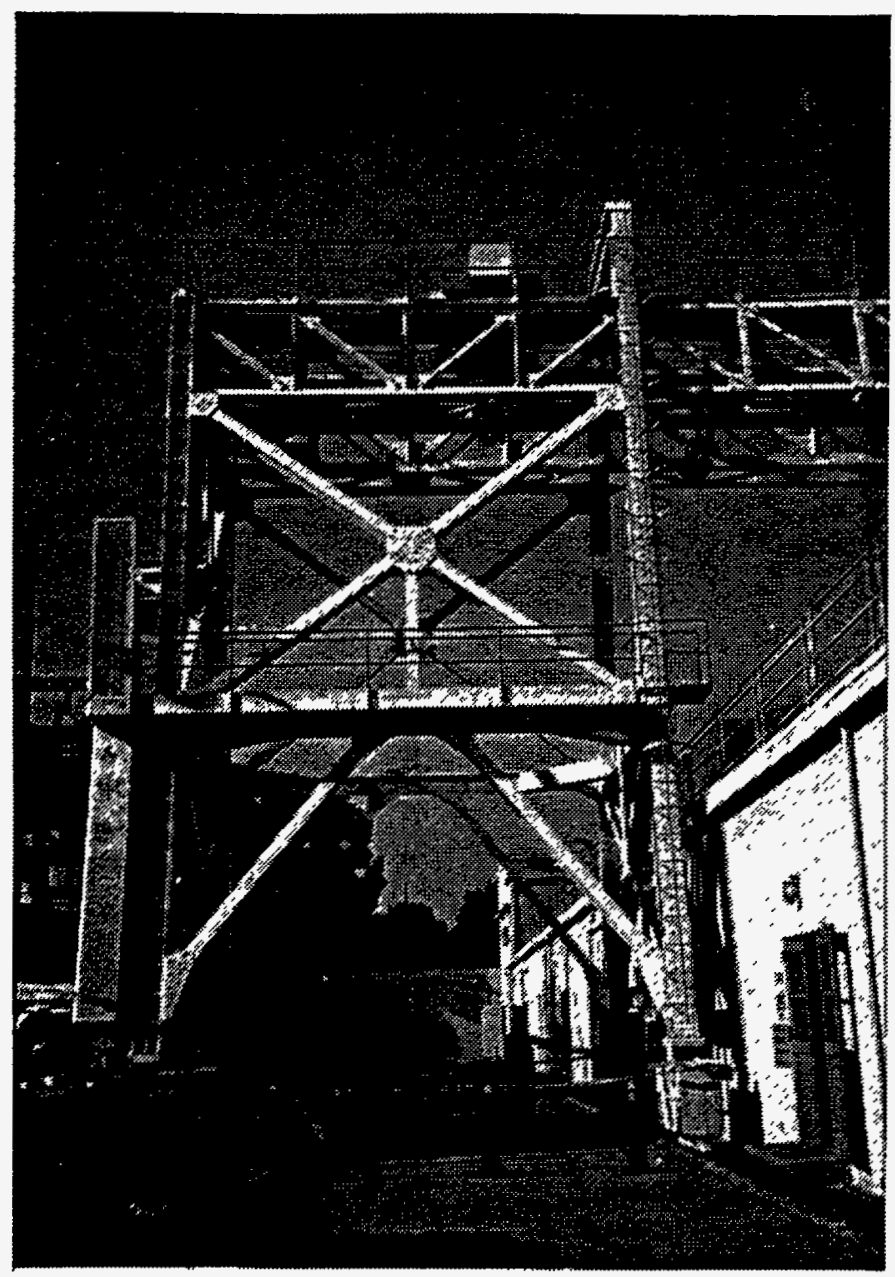

Figure 3.2.2-2: Several 1-1/4 inch bolts connecting the base of the Magnolia Unit gantry crane to the rail wheel assemblies failed.

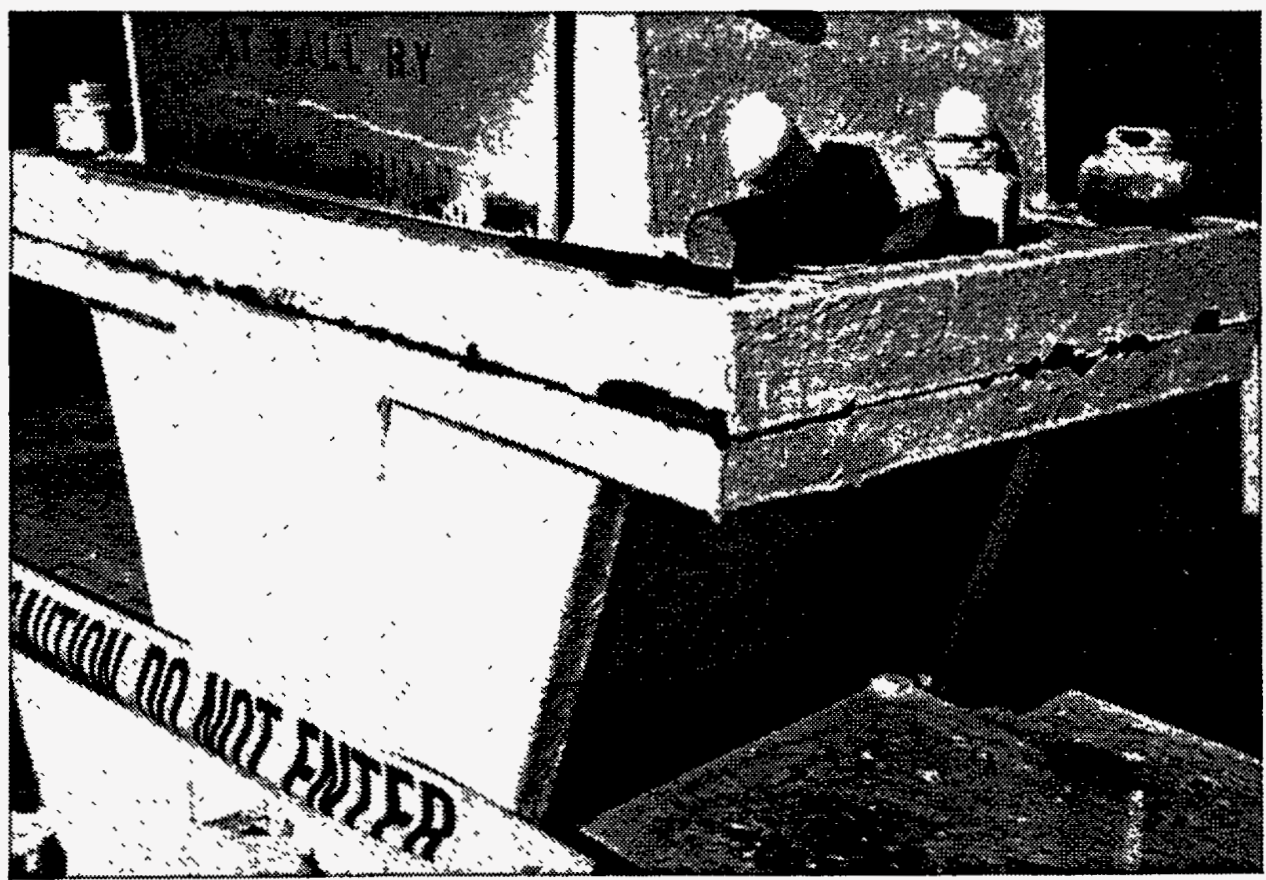

Figure 3.2.2-3: Close up of failed gantry crane bolts. Similar failures occurred during the 1971 San Fernando Earthquake. 
basement, all enclosed in a single metal-clad building, constructed between 1941 and 1964 (Figure 3.2.3-1). Several gas turbine generators are also located at the site (Units 6, 7, 8A, 8B and 8C) with a capacity of about $20 \mathrm{MW}$.

At the time of the earthquake, Units 2 and 5 were running at minimum load. Both Units tripped when the LADWP electrical system, which Glendale ties with, went black. Unit 7 was started up and was on line within an hour. City power was restored by 11:30 a.m. and all Units (except 5) were brought on line.

Reported damage and failures were limited to bearing damage on the Unit 5 turbine due to loss of $\mathrm{AC}$ power to the lube oil pump, leakage in two of five 24 inch diameter cooling tower risers and failure of a small copper line.

The Unit 5 turbine lube oil pump was not operable due to the loss of $\mathrm{AC}$ power. As the machine rolled down from the trip, it experienced a bearing rub and some oil was sucked into the turbine. Inspection of the turbine following the earthquake revealed that only the thrust bearing and one other bearing survived without damage.

Two out of five 24 inch diameter cooling tower inlet risers ruptured at the point where they come out of the ground (Figures 3.2.3-2 and 3.2.3-3). The other lines showed significant corrosion at the same location. The cement lined inlet lines reduce from 24 inch at the ground to 20 inch before a valve. The spiral welded steel pipe continues up about $30^{\prime}$ to flanged and supported connections at the top. Rupture was caused by displacement of the $50^{\prime}$ by $150^{\prime}$ by $40^{\prime}$ high cooling tower. The cooling tower remained in operation. Prior to the earthquake, there were plans to add concrete anchors at the bottom of the lines but they were not yet in place.

The Glendale Power Plant is located about $5 \mathrm{~km}$ south-east of the Burbank facility, about $25 \mathrm{~km}$ from the epicenter. Nearest strong motion records are the Burbank 10-story residential building CSMIP station and the United States Geological Survey (USGS) Griffith Observatory station. Instruments located on the ground floor of the 10-story residential building, located $5 \mathrm{~km}$ north of the plant, recorded peak accelerations of 0.35 horizontal and $0.13 \mathrm{~g}$ vertical [ref 3.2-1]. Peak ground accelerations recorded at the observatory, located about $5 \mathrm{~km}$ south-west of the plant, were $0.29 \mathrm{~g}$ horizontal and $0.15 \mathrm{~g}$ vertical [ref 3.2-6].

\subsubsection{Pasadena Power Plant}

The City of Pasadena operates three natural-gas-fired steam plants housed in adjoining open steelframe boiler structures (Figure 3.2.4-1) as well as a gas turbine unit used primarily for peaking 


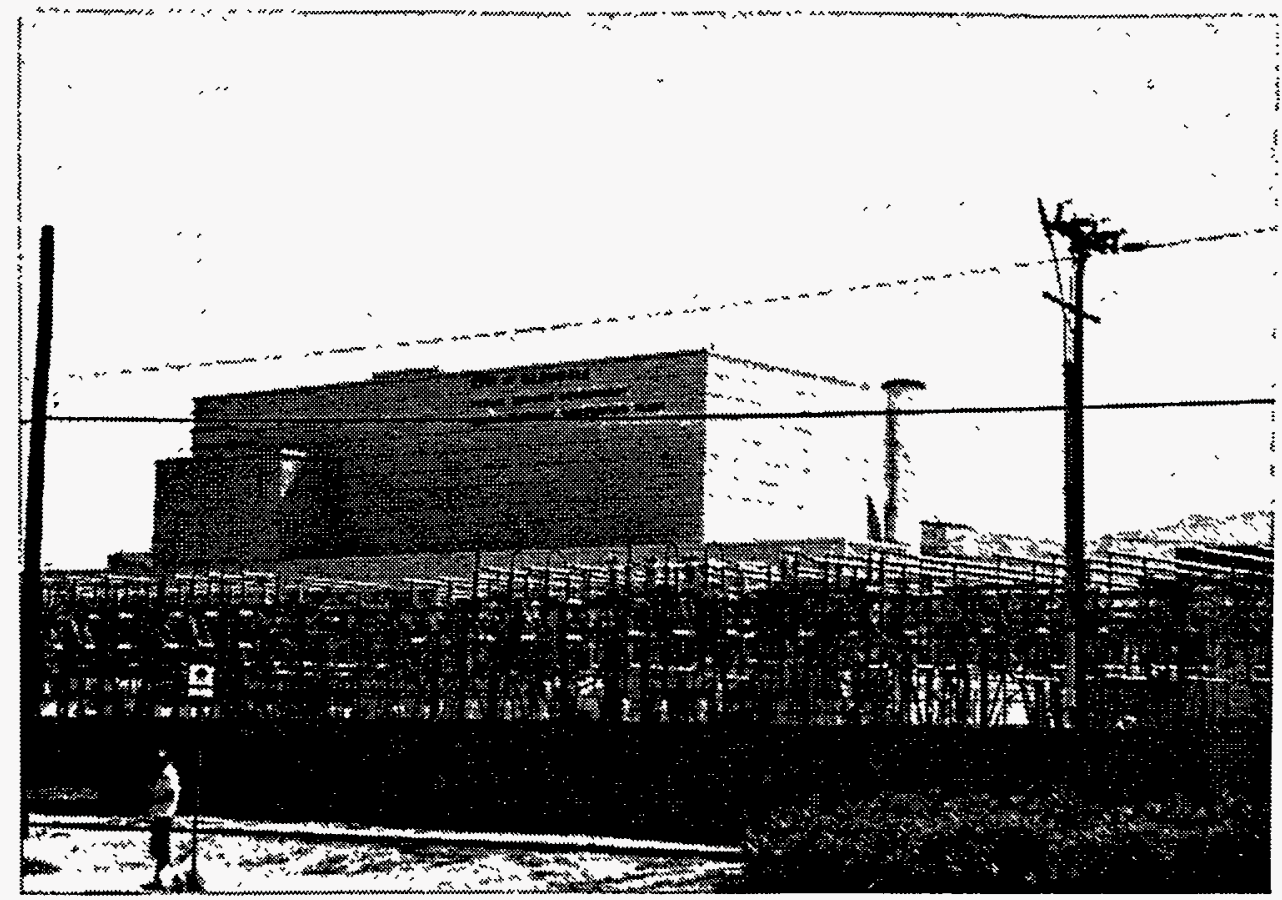

Figure 3.2.3-1: The City of Glendale steam electric plant includes five boilers, ranging in size from 20 to $44 \mathrm{MW}$, in a metal clad building.

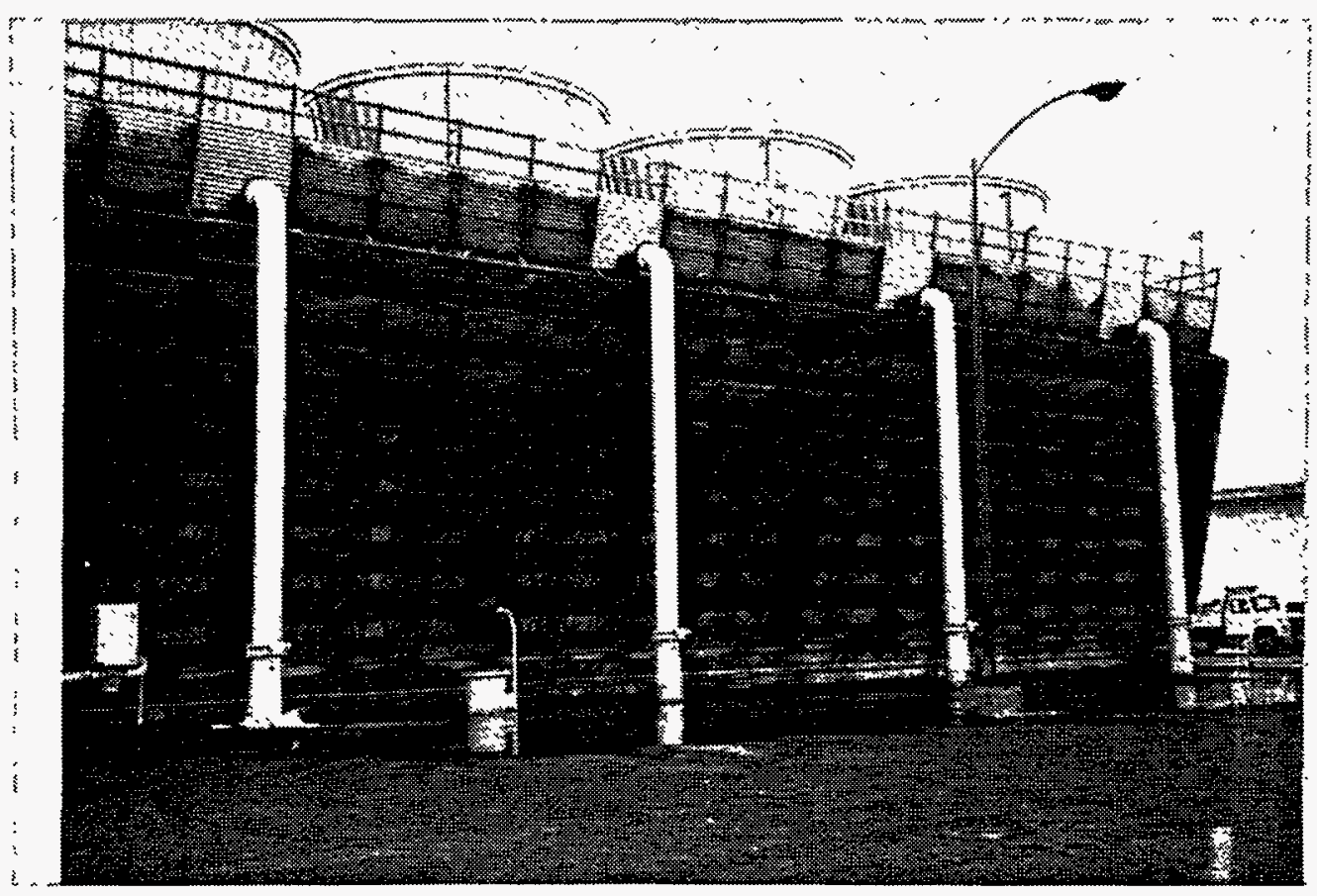

Figure 3.2.3-2: $50^{\prime}$ by $150^{\prime}$ by $40^{\prime}$ high cooling tower that displaced, resulting in the rupture of two of the 24 inch risers. 


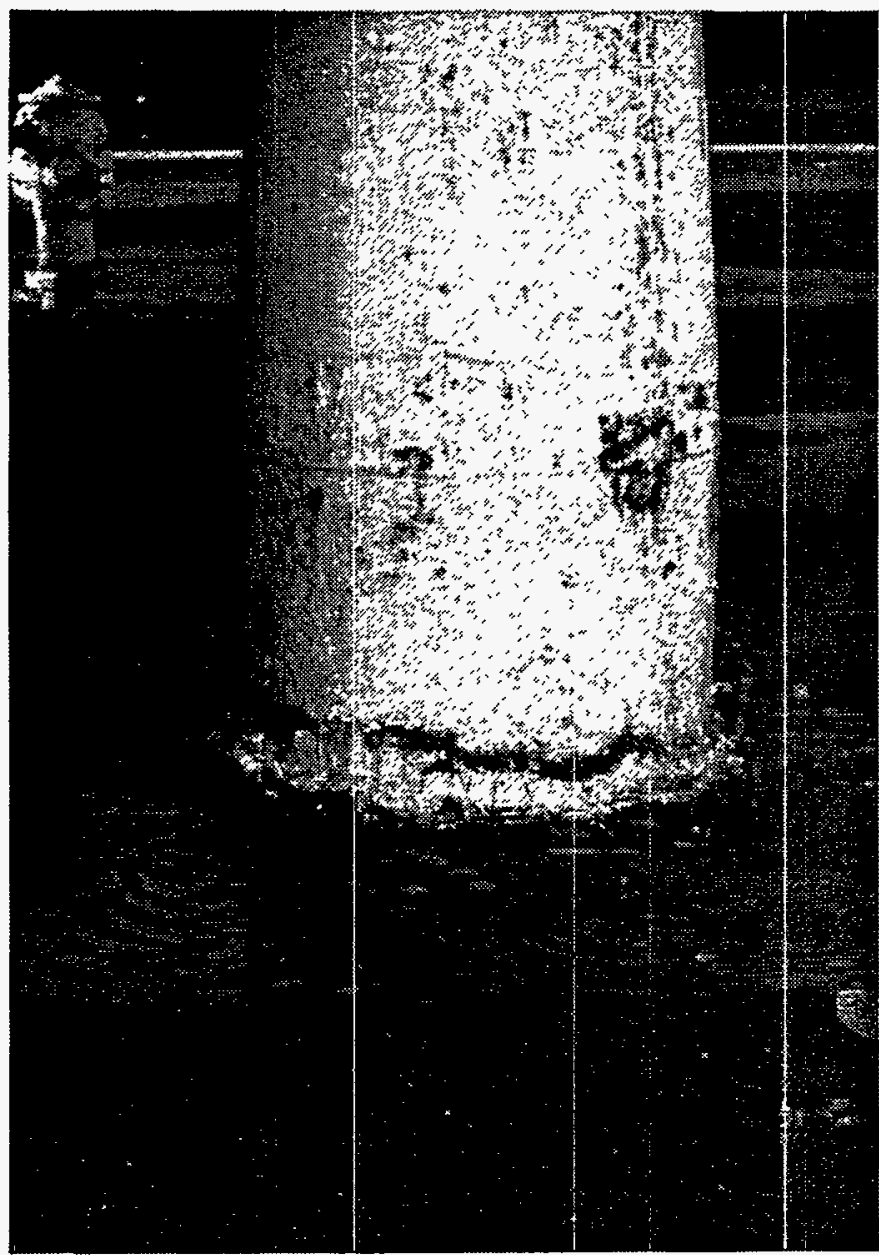

Figure 3.2.3-3: Failures occurred at grade level (before earthquake induced settlement) where corrosion from the standing water degraded the pipe.

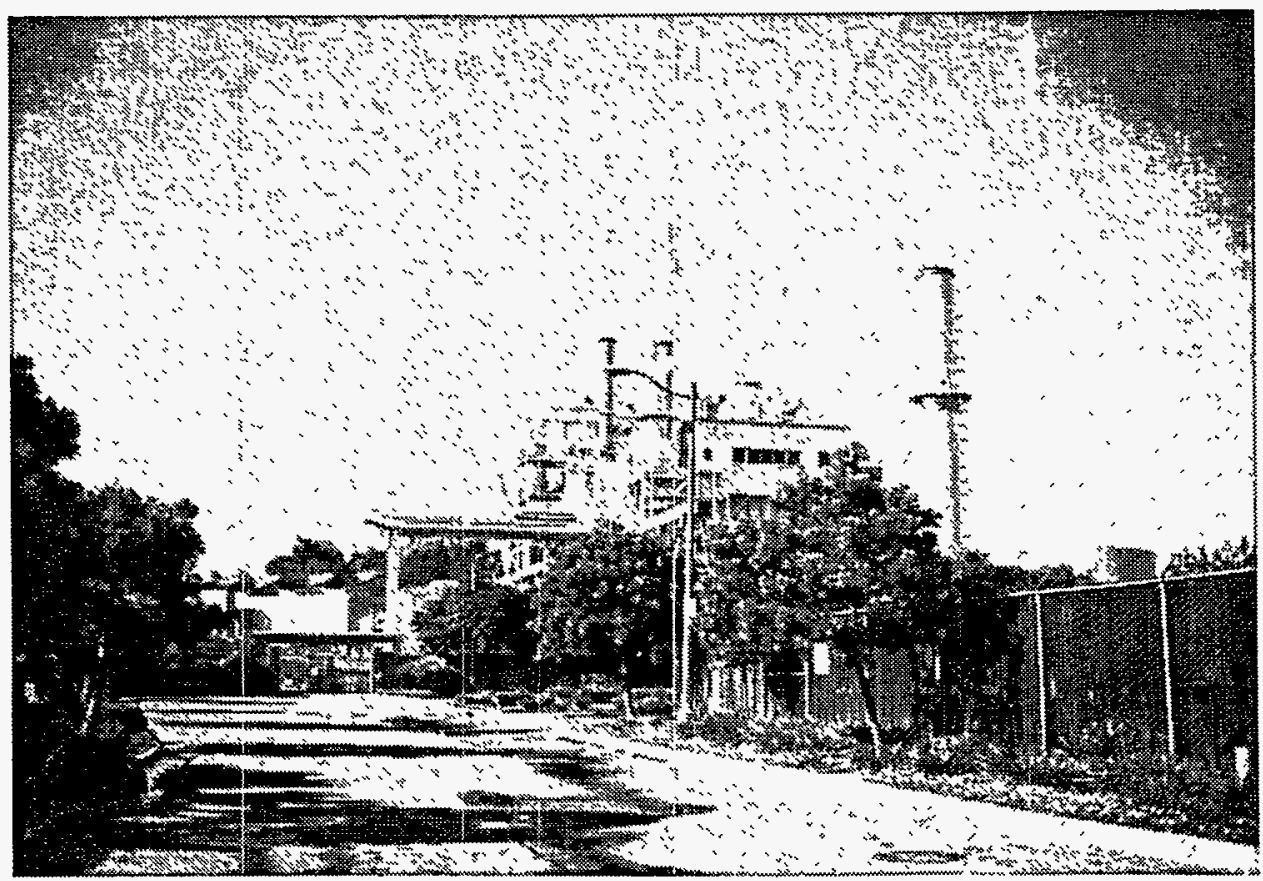

Figure 3.2.4-1: City of Pasadena $45 \mathrm{MW}$ steam generating plant. No significant damage was reported. 
purposes. Generating capacity of the steam plants ranges from 45 to $70 \mathrm{MW}$. The natural-gasfired combustion turbine capacity is $55 \mathrm{MW}$. Two smaller 1949 vintage steam plants housed in a nearby concrete building, the Glenarm plant, are no longer in service.

None of the plants were on-line when the early morning earthquake occurred due to low electricity demand and more efficient imported electricity. Energy was supplied via a $220 \mathrm{kV}$ intertie to the SCE grid. There was no significant damage to the power plants and units began to come on line within one half hour. Virtually all Pasadena Water and Power Department customers were provided with uninterrupted service during and following the event.

Several of the older buildings such as the 1940's vintage Glenarm building exhibited cracks in shear walls. Most of the cracking occurred during the 1991 Sierra Madre earthquake and worsened during the Northridge event.

The Northridge earthquake is the third significant event within the past seven years and the fourth since 1971 to affect the Pasadena plant. The San Marino Southwestern Academy CSMIP station, located $2 \mathrm{~km}$ from the plant and on similar soil conditions, recorded ground motion during the 1987 Whittier [ref 3.2-7], the 1991 Sierra Madre [ref 3.2-8] and the 1994 Northridge [ref 3.2-1] earthquakes. The $900 \mathrm{~S}$. Fremont USGS instrument, located $4.5 \mathrm{~km}$ from the plant, recorded ground motion during the 1971 San Fernando earthquake [ref 3.2-9] as well as the 1987 [ref 3.210] and 1994 [ref 3.2-6] events. Table 3.2.4-1 summarizes historical ground motion records near the plant.

Table 3.2.4-1: $\quad$ Pasadena Power Plant Ground Motion Records

\begin{tabular}{|l|l|l|l|l|l|l|}
\hline \multirow{2}{*}{ Earthquake } & \multicolumn{4}{|l|}{ Southwestern Academy } & \multicolumn{3}{l|}{900 S. Fremont } \\
\cline { 2 - 7 } & E-W & up & N-S & E-W & up & N-S \\
\hline 1994 & $0.12 \mathrm{~g}$ & $0.09 \mathrm{~g}$ & $0.16 \mathrm{~g}$ & $0.19 \mathrm{~g}$ & $0.10 \mathrm{~g}$ & $0.13 \mathrm{~g}$ \\
\hline 1991 & $0.19 \mathrm{~g}$ & $0.15 \mathrm{~g}$ & $0.19 \mathrm{~g}$ & N/A & N/A & N/A \\
\hline 1987 & $0.14 \mathrm{~g}$ & $0.14 \mathrm{~g}$ & $0.19 \mathrm{~g}$ & $0.30 \mathrm{~g}$ & $0.19 \mathrm{~g}$ & $0.26 \mathrm{~g}$ \\
\hline 1971 & N/A & N/A & N/A & $0.13 \mathrm{~g}$ & $0.09 \mathrm{~g}$ & $0.11 \mathrm{~g}$ \\
\hline
\end{tabular}

The Pasadena Power plant has demonstrated inherent ruggedness sufficient to withstand multiple events with peak horizontal ground accelerations of 0.1 to $0.3 \mathrm{~g}$. Experience in responding to these events will help prepare the City of Pasadena for the inevitable larger events. 


\section{2 .5 Ventura Coast Plants}

SCE operates two large generating stations located on the Ventura coast that were not significantly affected by the shaking. Ormond Beach and Mandalay tripped off-line due to damage at the Pardee substation. The Goleta plant, a $47 \mathrm{MW}$ gas turbine plant located north of Ormond Beach near Santa Barbara, also tripped off line.

Ormond beach is a two unit 1,500 MW oil \& gas-fired power plant located approximately $55 \mathrm{~km}$ west of the epicenter on the Pacific Ocean. Mandalay, located $14 \mathrm{~km}$ up the coast from Ormond Beach, includes two $215 \mathrm{MW}$ steam plants and a $147 \mathrm{MW}$ gas turbine. Ormond Beach Unit 1 and Mandalay Unit 1 were operating at 400 and $100 \mathrm{MW}$, respectively. The plants were providing power to the Ventura plain as well as supplying bulk power to the transmission grid via the Pardee Substation. The second unit at both stations was out of service for maintenance when the earthquake occurred.

Damage at the Pardee substation prevented transmission outside of the Ventura plain, resulting in an excess of generation. The plants tripped off-line due to over-frequency.

Ormond Beach experience about $0.15 \mathrm{~g}$ horizontal peak ground acceleration. A small crack was found in the Unit 1 deaereator following the event, preventing restart. The crack may have resulted from the earthquake, however, similar conditions have been observed during normal plant operation. No other damage was reported.

Mandalay experienced about $0.1 \mathrm{~g}$ horizontal peak ground acceleration and was not damaged. Operators attempted to restart Unit 1 in order to re-energize the Ventura plain. The large increase in customer demand to power lights, televisions and radios was more than the plant could supply on a reliable basis. Normal operation was established about twelve hours after the event when emergency fixes were implemented at the Pardee substation.

\subsubsection{Southern Los Angeles Plants}

LADWP operates three generating stations located south of Los Angeles. Scattergood, Harbor and Haynes generating stations are located about 30,50 and $55 \mathrm{~km}$ from the epicenter, respectively. The plants were not damaged by the earthquake but operating units shut down when the City of Los Angeles went black.

The Scattergood plant includes two $179 \mathrm{MW}$ oil \& gas-fired units and a $358 \mathrm{MW}$ gas-fired plant. Units 1 and 3 were in operation when the earthquake occurred generating 40 and $61 \mathrm{MW}$, 
respectively. Both units tripped off-line when the LADWP system went black. Station service power was provided by a generator at the Hyperion water treatment facility to assist operators in preparing the plant for restart. Units 1 and 2 were successfully synchronized to the system in the early afternoon on January 17 with Unit 3 following early the next morning.

Harbor includes five steam plants with a total generating capacity of $373 \mathrm{MW}$ and four gas turbines with a combined capacity of $76 \mathrm{MW}$. None of the units were on-line when the earthquake struck. The four gas turbines, used as peaker units, were all synchronized to the grid by 1:00 p.m.

Haynes is the largest LADWP plant located in the Los Angeles area with four $220 \mathrm{MW}$ and two $341 \mathrm{MW}$ steam plants, a total generating capacity of 1,570 MW. No damage was observed and Unit 1 synchronized to the system within 3 hours of the earthquake, the first LADWP station online.

\subsection{ELECTRIC POWER TRANSMISSION}

Several substations and converter stations saw very high ground accelerations. Earthquake damage (see Figures 3.3-1 and 3.3-2) to transmission towers, DC converter stations, and substations resulted in widespread local and isolated remote power outages lasting from minutes to several days.

Both $\mathrm{AC}$ and DC bulk power transmission lines provide power from remote generating facilities and terminate at a converter station and substations located within a few kilometers of the epicenter. High voltage electrical transmission facilities affected by the earthquake include the Sylmar, Rinaldi, RS-J, RS-U and RS-E, Pardee and Vincent substations. The locations of these substations are shown in Figure 3.3-3. Damage sustained by $230 \mathrm{kV}$ and $500 \mathrm{kV}$ transmission apparatus ranged from substantial to minor depending on the severity of grourid motion and seismic design features.

Two DC transmission lines provide bulk power to the Los Angeles area from remote power sources. A DC transmission line from the hydroelectric power producing Pacific Northwest terminates near the epicenter at a converter station in Sylmar. The DC converter station sustained significant damage that will disrupt the flow of power for an extended period of time. The second DC line originates at a large coal fired plant in Utah and terminates at a facility in the high desert, unaffected by the earthquake. Transmission system disruptions, however, resulted in an automatic shutdown of the Utah station which provides virtually all of its power to the Los Angeles area. 


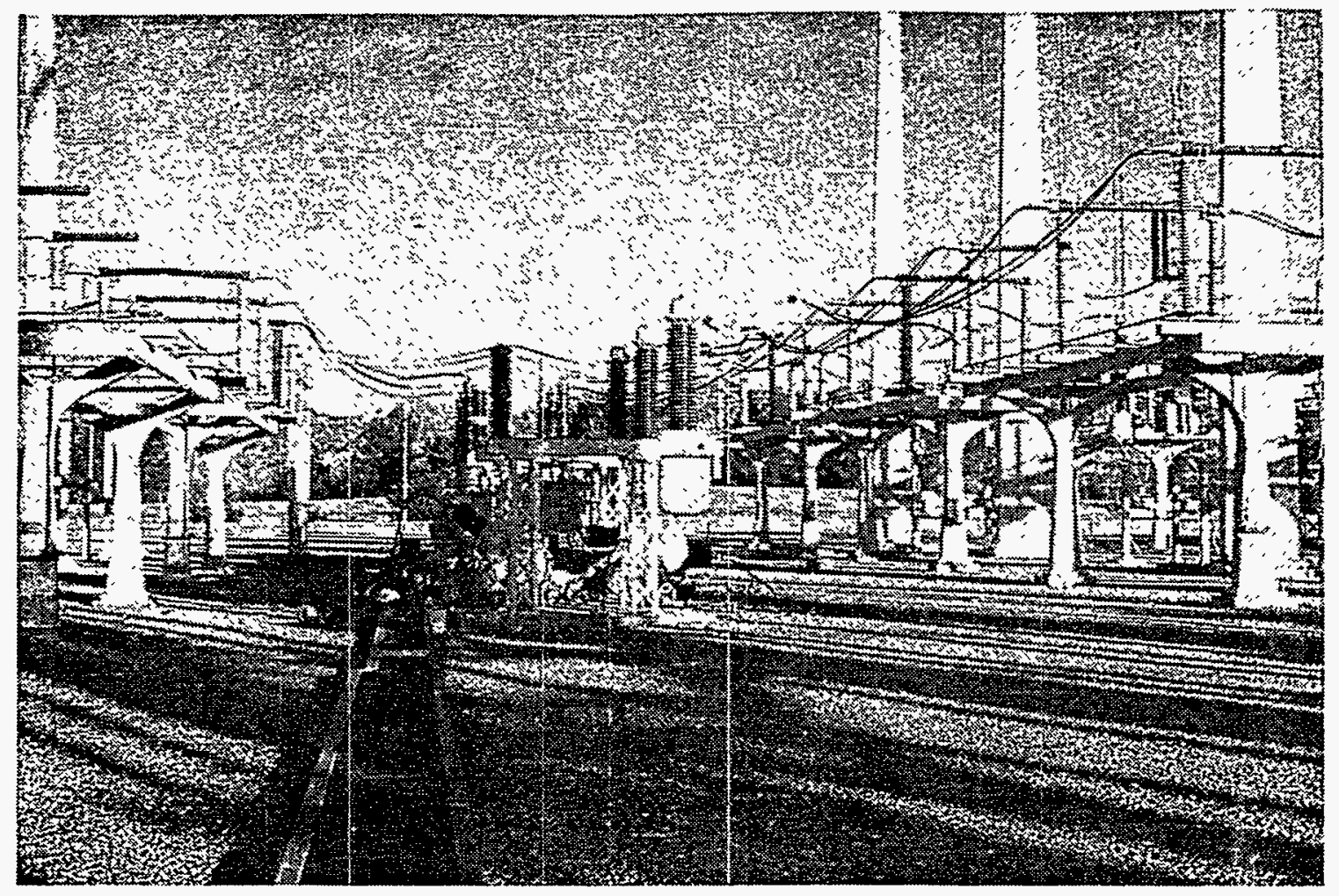

Figure 3.3-1: High voltage substation apparatus supported by brittle porcelain insulators were damaged at several substations [ref 3.3-1].

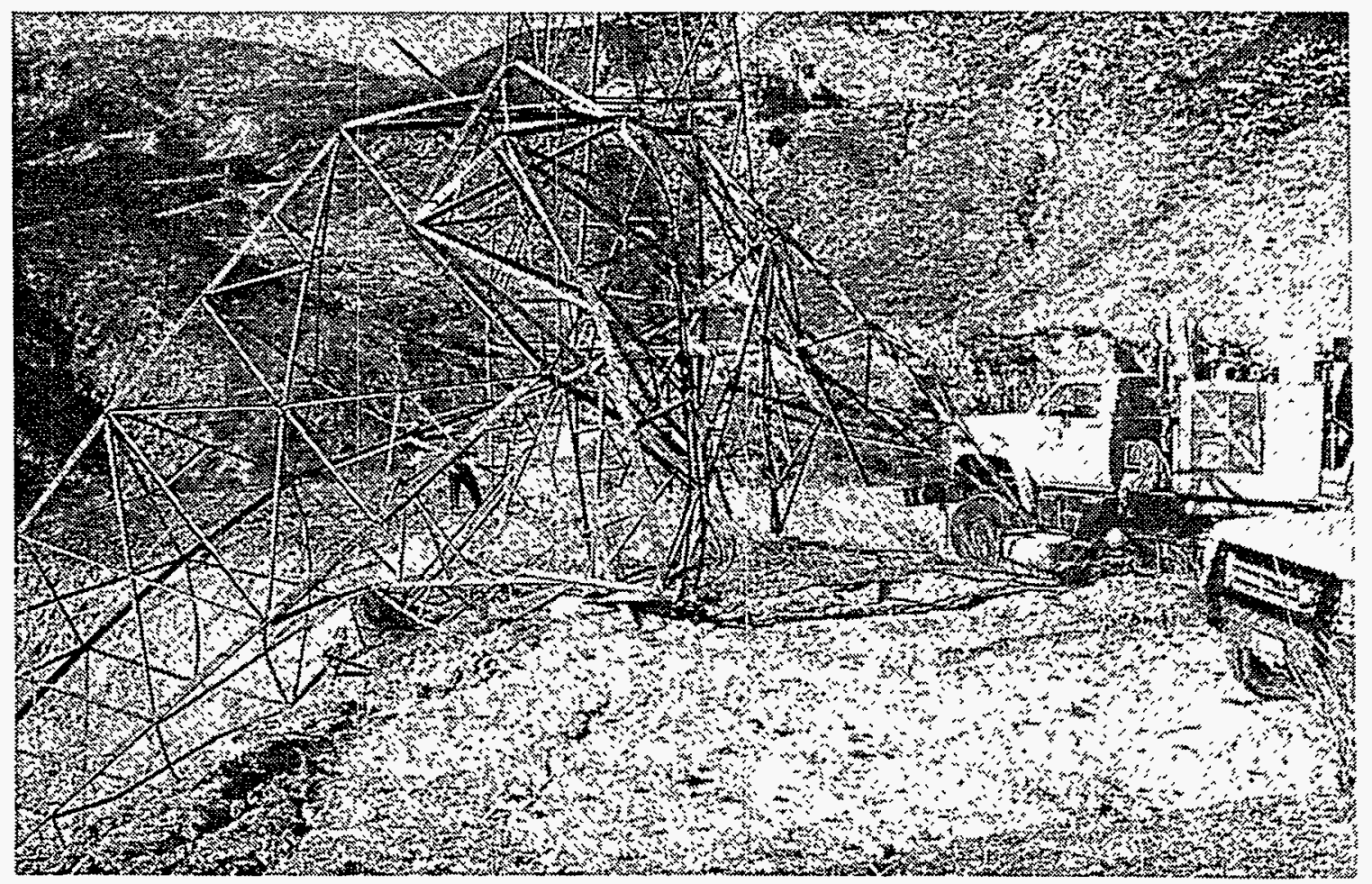

Figure 3.3-2: Several electrical transmission towers failed during the earthquake. Foundation distress was observed at most of the failed towers [ref 3.3-1]. 


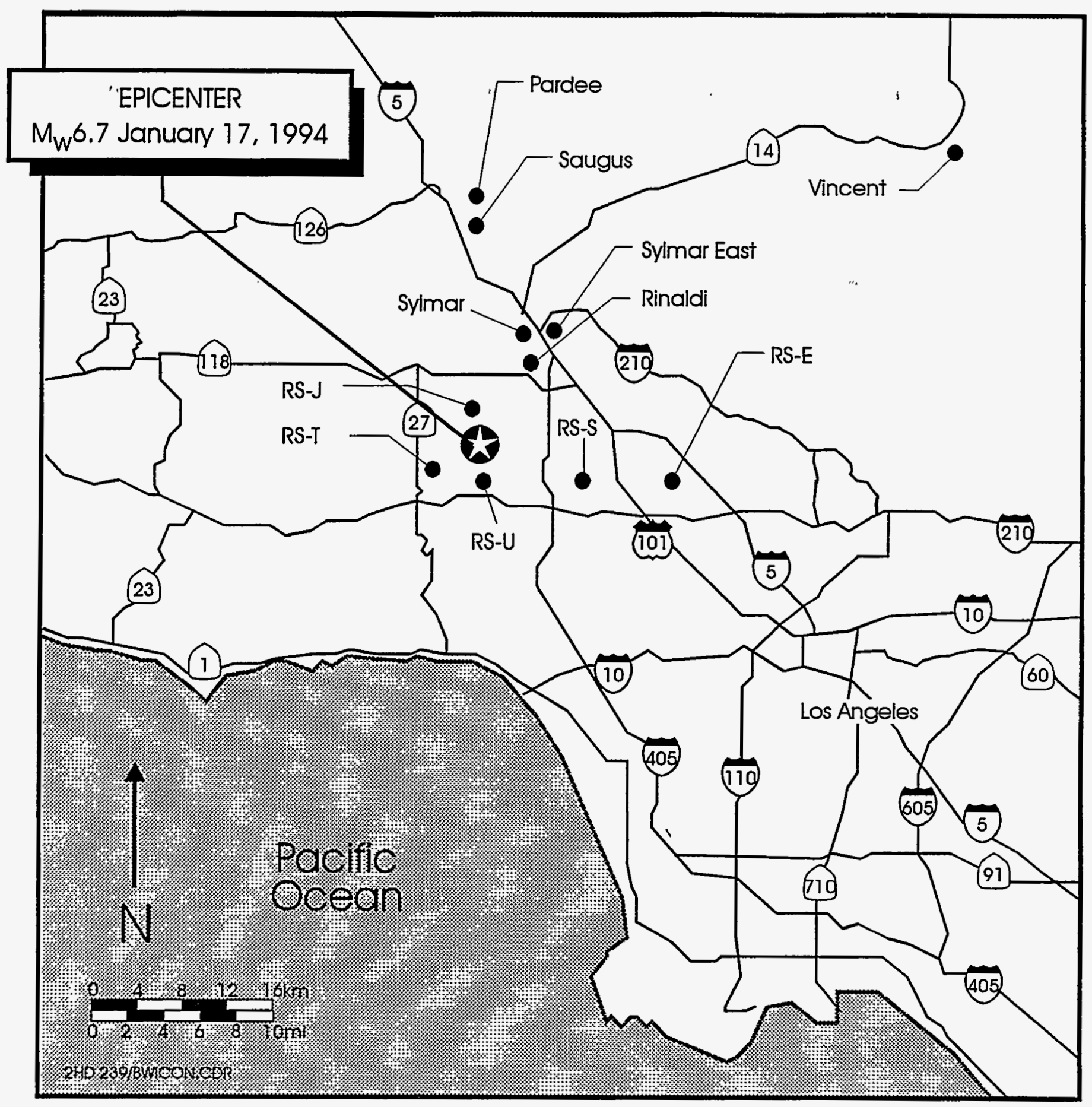

- Substations

Figure 3.3-3: Bulk Power Transmission facilities affected by the Northridge Earthquake. 
The plant tripped off line due to loss of the Los Angeles area load, contributing to the widespread blackouts.

High voltage transmission stations experienced ground accelerations approaching $1 \mathrm{~g}$ in both the horizontal and vertical directions, some of the highest free-field ground motions on record. Nearfield stations experienced damage to porcelain-supported power apparatus such as circuit breakers, disconnect switches, lightning arresters, rigid bus, capacitor banks and transformer bushings. Stations located farther from the epicenter which experienced lower ground accelerations, however, sustained damage to historically vulnerable apparatus such as live tank circuit breakers and disconnect switches supported by tall slender porcelain insulators. Damage sufficient to knock several $500 \mathrm{kV}$ circuits out of operation occurred at ground accelerations as low as $0.15 \mathrm{~g}$.

Transmission stations affected by the Northridge Earthquake experienced higher ground motion than during the 1971 San Fernando Earthquake, although, due to improvements in design, sustained considerably less damage. Live tank circuit breakers, historically vulnerable and costly to replace, have been replaced by dead tank and bulk oil circuit breakers at most of the substations affected by the earthquake. All of the dead tank and oil filled breakers performed without incident. Seismic instrumentation in-place during the 1971 event was much less extensive than the current array, and failure of several components that survived the 1971 event without damage confirms a more severe seismic environment in the recent event.

Improvements in the seismic design of high voltage substation apparatus since the 1971 San Fernando Earthquake resulted in substantially less damage. Improvements such as dead tank circuit breakers and innovative seismic designs such as vibration isolated suspension support systems proved to be effective. 


\subsection{REFERENCES}

3.1-1 Pacific Gas \& Electric Company, "Power Grid: Ties That Bind Western U.S.," Article by Carol Young, April, 1994.

3.1-2 Hall, John F., "Northridge Earthquake January 17, 1994, Preliminary Reconnaissance Report," Earthquake Engineering Research Institute, March, 1994.

3.1-3 Goltz, J.D. "The Northridge, California Earthquake of January 17, 1994, General Reconnaissance Report," National Center for Earthquake Engineering Research, March 11, 1994.

3.1-4 Verbal communication with Bill Cormish, Western Systems Coordinating Council, April, 1994.

3.1-5 The Orange County Register, Has Falling Only Begun, Business, January 26, 1994.

3.2-1. CSMIP, CSMIP Strong-Motion Records from the Northridge, California Earthquake of January 17, 1994, California Department of Conservation, Division of Mines and Geology, Office of Strong-Motion Studies, Report OSMS 94-07, February 18, 1994.

3.2-2 California Department of Conservation, Division of Mines and Geology, Office of StrongMotion Studies, CSMIP Strong-Motion Records from the Landers, California Earthquake of June 28, 1992, Report OSMS 92-09.

3.2-3 LADWP, Data Report, January 17, 1994 Northridge Earthquake Receiving Station East, RSE, Ground Floor, SMA-1 \#1105, February 11, 1994.

3.2-4 Jennings, C.W. and Strand, R.G., Geologic Map of California, Los Angeles Sheet, 1969.

3.2-5 EQE International, Recommended Piping Seismic-Adequacy Criteria Based on Performance During and After Earthquakes, EPRI NP-5617, 1988.

3.2-6 United States Department of the Interior, Geological Survey, Accelerograms Recorded at USGS National Strong-Motion Network Stations During the Ms=6.6 Northridge, California Earthquake of January 17, 1994, Open File Report 94-141, February 1994. 
3.2-7 California Department of Conservation, Division of Mines and Geology, Office of StrongMotion Studies, CSMIP Strong-Motion Records from the Whittier, California Earthquake of 1 October 1987, Report OSMS 87-05.

3.2-8 California Department of Conservation, Division of Mines and Geology, Office of StrongMotion Studies, CSMIP Strong-Motion Records from the Sierra Madre, California Earthquake of 28 June 1991, Report OSMS 91-03.

3.2-9 California Division of Mines and Geology, San Fernando, California, Earthquake of 9 February 1971, Bulletin 196.

\section{(3)}

3.2-10 United States Department of the Interior, Geological Survey, Strong-Motion Data from the 1

' October 1, 1987 Whittier Narrows Earthquake, Open-File Report 87-616.

3.3-1 Photograph provided by D. Ostrom, Southern California Edison. 


\section{INDUSTRIAL FACILITIES}

The Northridge earthquake rocked industrial facilities throughout the San Fernando Valley, Santa Monica, Burbank, Glendale, the Santa Clarita Valley and Los Angeles with some of the highest ground motions ever recorded in urban areas.

One third of California's manufacturing base rests within a far-field 40 mile radius of Northridge. Closer to the epicenter, over 12,000 manufacturing firms employ some 200,000 workers within a mid-range 20 mile radius of Northridge [ref 4.0-1]. Manufacturing, however, is overshadowed by the 97,000 business, professional and financial service companies that employ over 850,000 within the same area. Table 4.0-1 outlines industry located within a twenty mile radius of the earthquake's epicenter.

\section{Table 4.0-1: Industry within a Twenty Mile Radius of the Epicenter}

\begin{tabular}{|l|r|r|}
\hline \multicolumn{1}{|c|}{ Industry } & \multicolumn{1}{|c|}{ Firms } & \multicolumn{1}{c|}{ Employees } \\
\hline Agriculture & 1,516 & 9,840 \\
Mining & 205 & 1,749 \\
Construction & 9,818 & 57,986 \\
Manufacturing & 12,423 & 208,540 \\
Transportation/Communications & 4,200 & 59,036 \\
Public Utilities & 12,570 & \\
Wholesale & 38,539 & 88,924 \\
Retail & 16,393 & 252,131 \\
Finance/Insurance/Real estate & 42,025 & 164,683 \\
Business services & 38,606 & 295,043 \\
Professional Services & 322 & 403,936 \\
Public Administration & $\mathbf{1 7 6 , 6 1 7}$ & $\mathbf{1 , 5 5 8 , 6 3 5}$ \\
\hline Total & & \\
\hline
\end{tabular}

Source: Dunn \& Bradstreet Information Services

The near-field region is generally void of heavy "smokestack" industries. Additionally, many large manufacturing firms have vacated the region with service, commercial and light manufacturing companies remaining. Figure 4.0-1 shows a 2,000,000 square feet industrial facility located 11 kilometers from the earthquake epicenter. The former automobile assembly plant was shut down during the year preceding the earthquake and is currently vacant. "Available" signs are common along traditional industrial corridors such as railroad tracks.

Several large aerospace firms have facilities within the epicentral region, but these are currently involved with only limited production, reflecting the defense industry scale down. Thousands of smaller aerospace and defense industry suppliers and support firms have also been impacted by the 


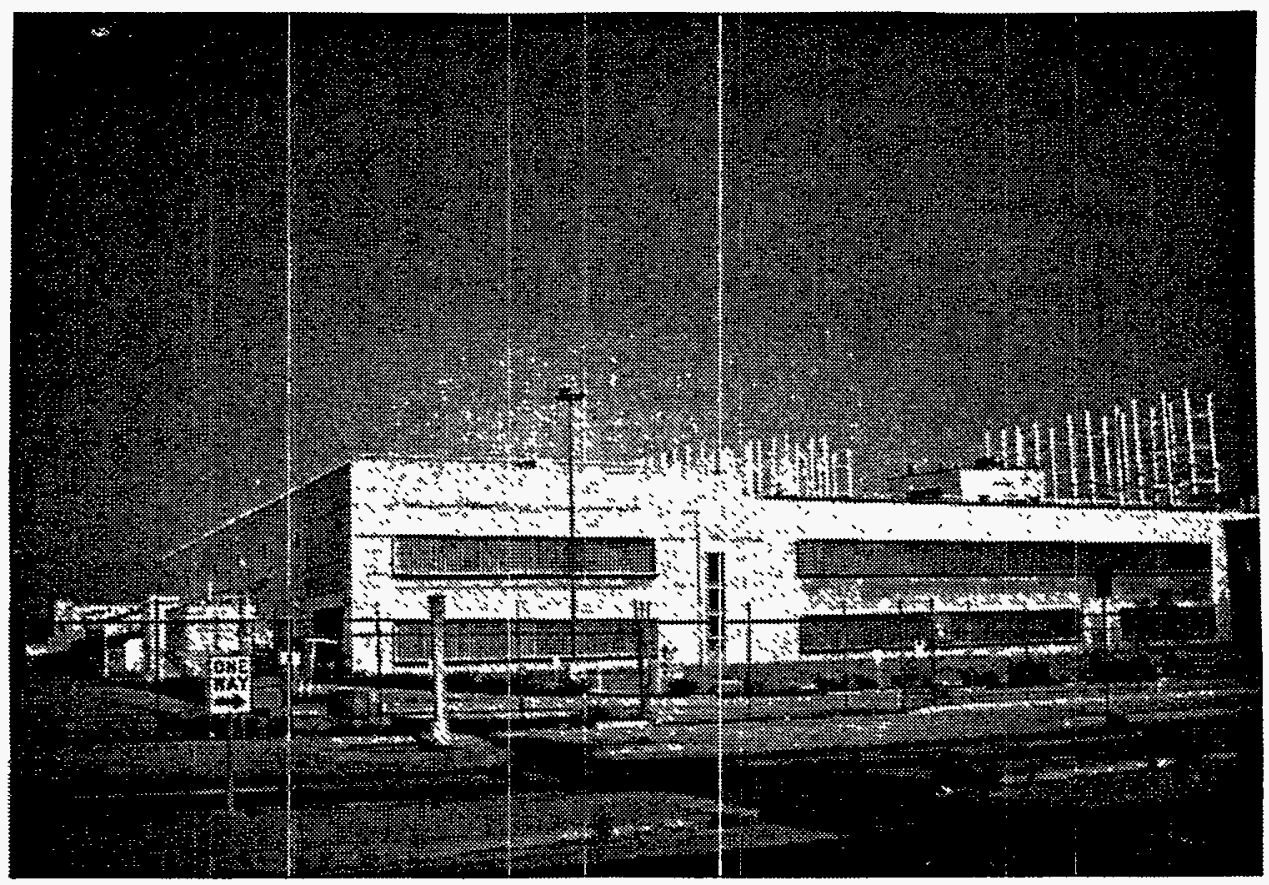

Figure 4.0-1: 2,000,000 square feet industrial facility located within the epicentral region. Like many large industrial facilities in the region, the plant is vacant.

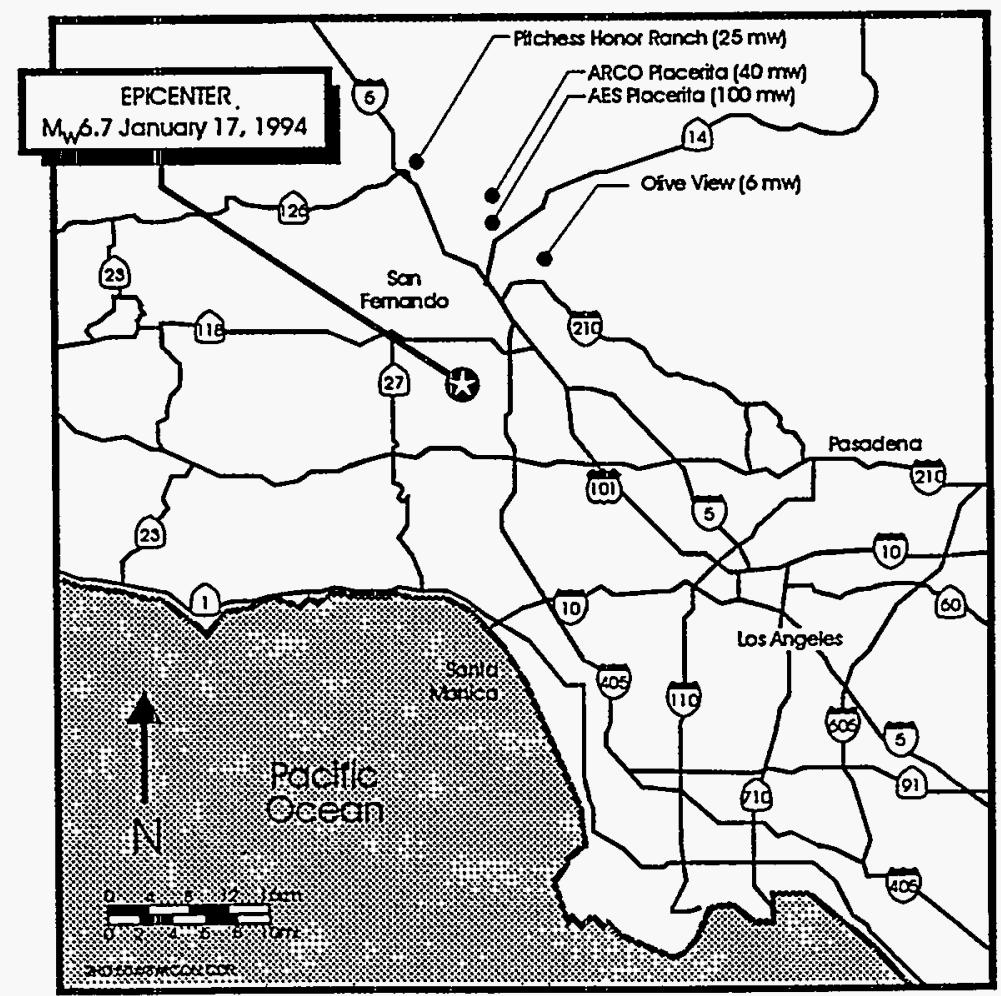

Figure 4.1-1: Independent Power Producers investigated following the Northridge Earthquake. 
scale down. Defense firms are generally not receptive to post-earthquake investigations due to security requirements.

Electrical power generation plants comprise some of the largest and heaviest industrial facilities within the earthquake effected region. The plants are also a key element of earthquake recovery operations. The performance of generating plants, consistent with past earthquakes, was positive with most facilities available for service soon after restoration of the power transmission and distributions systems. See Section 3.2 for additional information.

Several industrial facilities have expanded over the last decade into cogeneration. Industrial facilities have entered the electric generation market in response to economic, environmental and regulatory evolutions. Cogeneration facilities contain electrical, mechanical and instrumentation equipment and systems that are typical of installations used in most industrial applications. Facilities that include cogeneration plants were a key target for reconnaissance efforts since the equipment and systems are generally not unique or proprietary, thus, are accessible and of interest to a wide audience.

Facilities representing a diversity of industries and located within the heavily damaged areas were also investigated. These miscellaneous facilities represent the data processing, light manufacturing, warehousing, food processing, containers, medical products, assembly, metals finishing and defense industries. Most of the industrial facilities survived the earthquake with moderate damage to production equipment and the loss of inventory. Most standard equipment performed satisfactorily. Specialty manufacturing, production and assembly lines typically experienced minor damage and equipment misalignment that resulted in a significant loss of production.

The last area of focus was standby and emergency power systems. Emergency power is a critical element of emergency response and business continuity since typical electrical transmission and distribution systems may not be available nor reliable following significant earthquakes and ensuing aftershocks. Therefore, emergency power is a primary requirement for many earthquake recovery operations and for many businesses to maintain data and critical operations.

Reconnaissance findings for cogeneration facilities, hospital support systems, miscellaneous industrial facilities, seismic base isolated facilities and research facilities are summarized on the following pages. 


\subsection{COGENERATION FACILITIES}

Cogeneration, the simultaneous production of useful thermal energy and electric power from a fuel source, has gained in popularity among industrial energy consumers since the Public Utility Regulatory and Policies Act (PURPA) of 1978. The act gave license to anyone to build power plants and sell the electric power back to the utility at its avoided cost. Industrial energy consumers have capitalized on PURPA by combining electric power generation with steam and/or hot water production for existing loads. Post-earthquake reconnaissance teams focused on industrial facilities that include cogeneration plants since they are typically larger facilities and contain a diversity of electrical, instrumentation and mechanical systems.

Cogeneration facilities investigated following the Northridge earthquake range from very small plants that generate electricity for in-house use and emergency power, to large independent power producers whose primary purpose is to sell electricity to utilities for distribution via the power grid. Most of the plants withstood the earthquake with little or no damage, however, tripped off-line due to electrical grid disturbances. Cogeneration plants investigated are shown on Figure 4.1-1, along with peak ground acceleration records from nearby stations. A summary of each cogeneration facility investigated is provided below including a brief description, earthquake effects, and ground motion estimate.

\subsubsection{AES Placerita}

AES Placerita, an independent power producer, is the largest cogeneration facility affected by the Northridge earthquake. The facility includes two $40 \mathrm{MW}$ electric gas turbine generators, two heatrecovery steam generators and one $20 \mathrm{MW}$ steam turbine generator. Steam generated by the second heat-recovery steam generator is used for injection for oil recovery in the nearby oil fields. The two combustion turbines and one steam turbine drive $13.8 \mathrm{kV}$ generators which provide electricity to Southern California Edison at a stepped up voltage of $66 \mathrm{kV}$. The plant was commissioned in 1988 to provide $100 \mathrm{MW}$ of electricity to Southern California Edison.

The plant was off-line for scheduled maintenance when the earthquake occurred. Upon restart, there were no earthquake related problems associated with electrical or control equipment and systems. Significant damage was, however, observed for mechanical equipment such as tanks, demineralizers and associated piping. Other minor damage included computer terminals falling, shelves and book cases losing contents, a light fixture fell to the ground, as well as displacement and falling of miscellaneous unanchored items. 
The most significant earthquake effects were damage and, in some cases, failure of several flatbottomed liquid storage tanks. The facility includes a diversity of anchored flat bottom storage tanks ranging in vintage from older bolted tanks associated with the oil production fields that predate the cogeneration plant, to new welded steel tanks with engineered foundations and anchorage. The Northridge earthquake challenged all but the most robust tanks.

An engineered fire-water tank located on the hill above the facility sustained damage to the foundation, stretched anchor bolts, deformed chairs and lateral displacement of the tank (Figures 4.1.1-1 and 4.1.1-2). Ten of fourteen 2 inch diameter anchor bolts were bent and should not be reused [ref 4.1-1]. Many chairs buckled and the ring foundation was severely damaged. Attached lines had adequate flexibility to accommodate the displacements and the tank retained its contents. Adjacent to the fire-water tank, an older bolted steel tank experienced both elephant foot buckling at the base and shell deformation near penetrations, resulting in loss of contents through seam leaks. An oil field reclaimed water bolted steel tank 165,000 gal capacity that pre-dates the cogeneration plant was anchored with numerous $3 / 4$ inch anchor bolts. The tank shell experienced elephant-foot buckling at the base, several anchor bolts pulled out and bent, the foundation was damaged and small leaks developed at seams (Figures 4.1.1-3 and 4.1.1-4).

Skid mounted demineralizer tanks anchored with marginal details, including expansion anchors with only about 1 inch of embedment, failed their anchorage and moved about 6 inches. A crane was used to reposition the demineralizer skids to their original locations (Figure 4.1.1-5). Displacement of the 8 foot diameter by 15 foot high demineralizers resulted in failures at several cast iron and PVC water pipe fittings due to excessive anchor point displacement (Figure 4.1.1-6).

In general, welded steel piping performed well, however, at several locations, piping systems fell off of elevated rack supports. Differential displacement of the piping dislodged friction pipe clamps at several locations along a rack of supported piping run that crosses a dry wash between the water treatment plant and the cogeneration plant. The pressure boundary of welded steel piping was not compromised.

The Newhall area has one strong-motion instrument maintained by CSMIP located within 4 kilometers of the plant. Maximum free-field ground accelerations recorded at the Newhall LA County Fire Station were $0.63 \mathrm{~g}$ horizontal and $0.62 \mathrm{~g}$ vertical [ref 4.1-2]. The next closest instrument, at the Sylmar County Hospital located within 7 kilometers from the site, recorded maximum free-field ground accelerations of $0.91 \mathrm{~g}$ horizontal and $0.6 \mathrm{~g}$ vertical [ref 4.1-2]. 


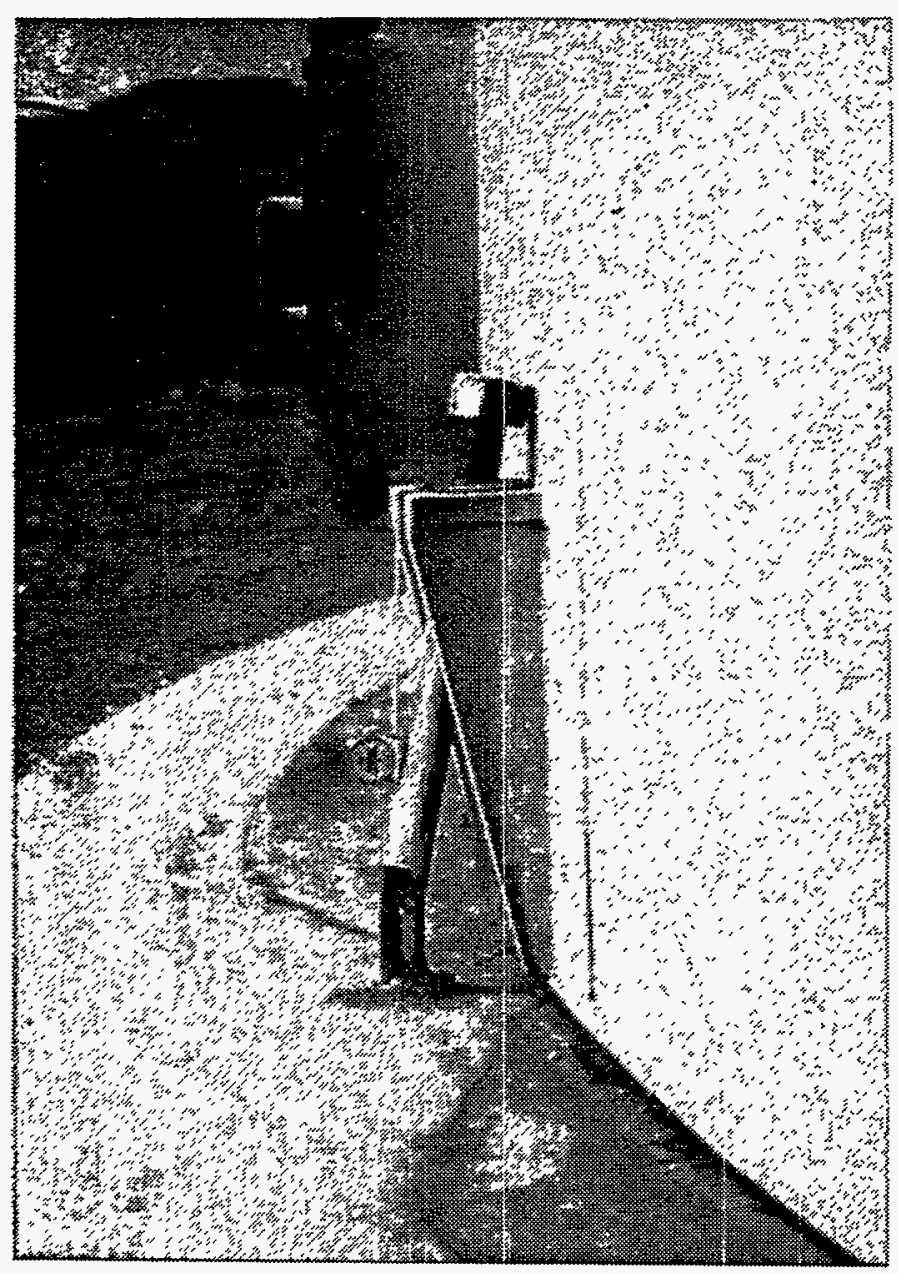

Figure 4.1.1-1: A welded steel AES Placerita fire-water tank sustained stretched anchor bolts and damage to the foundation. The new concrete was installed to repair and enlarge the foundation.

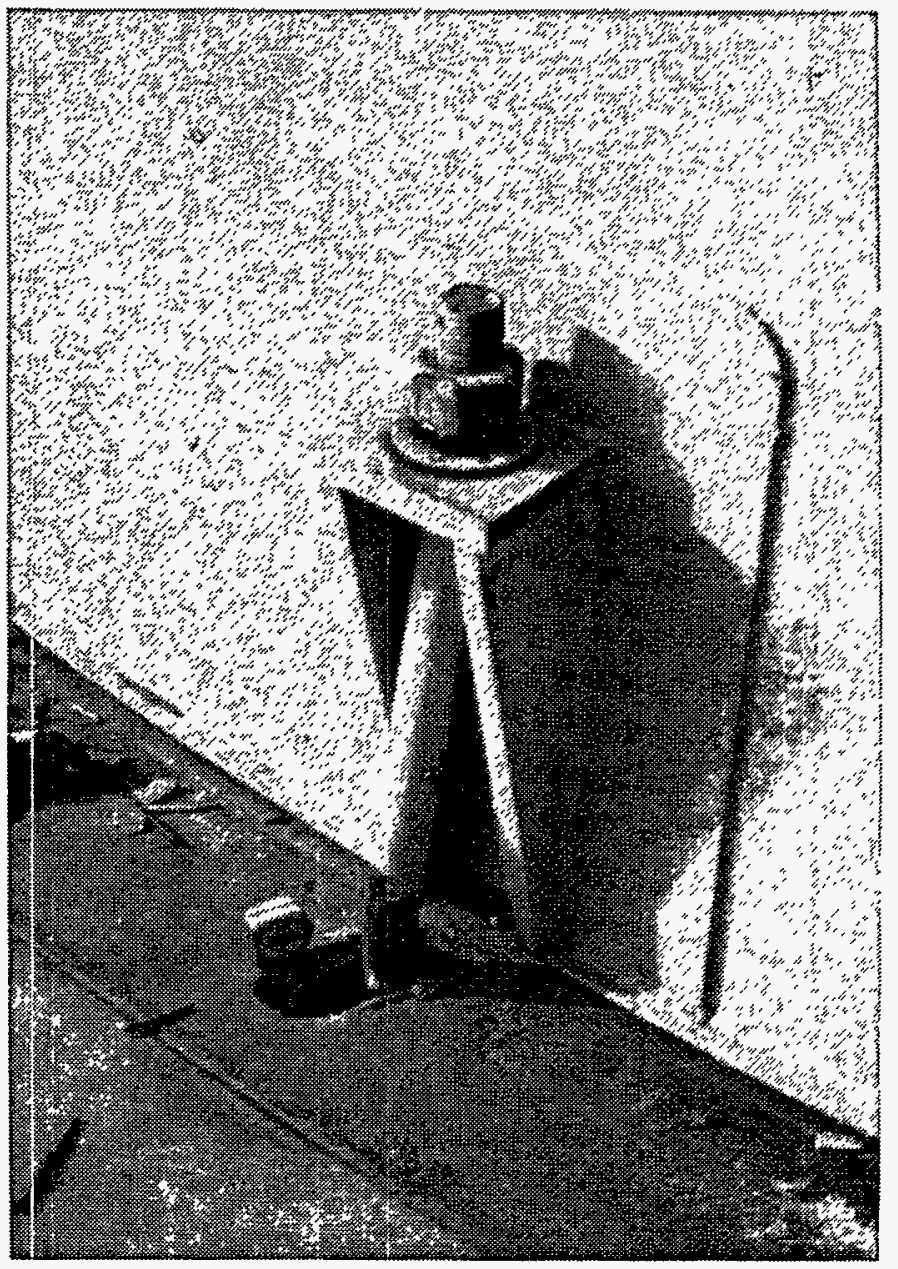




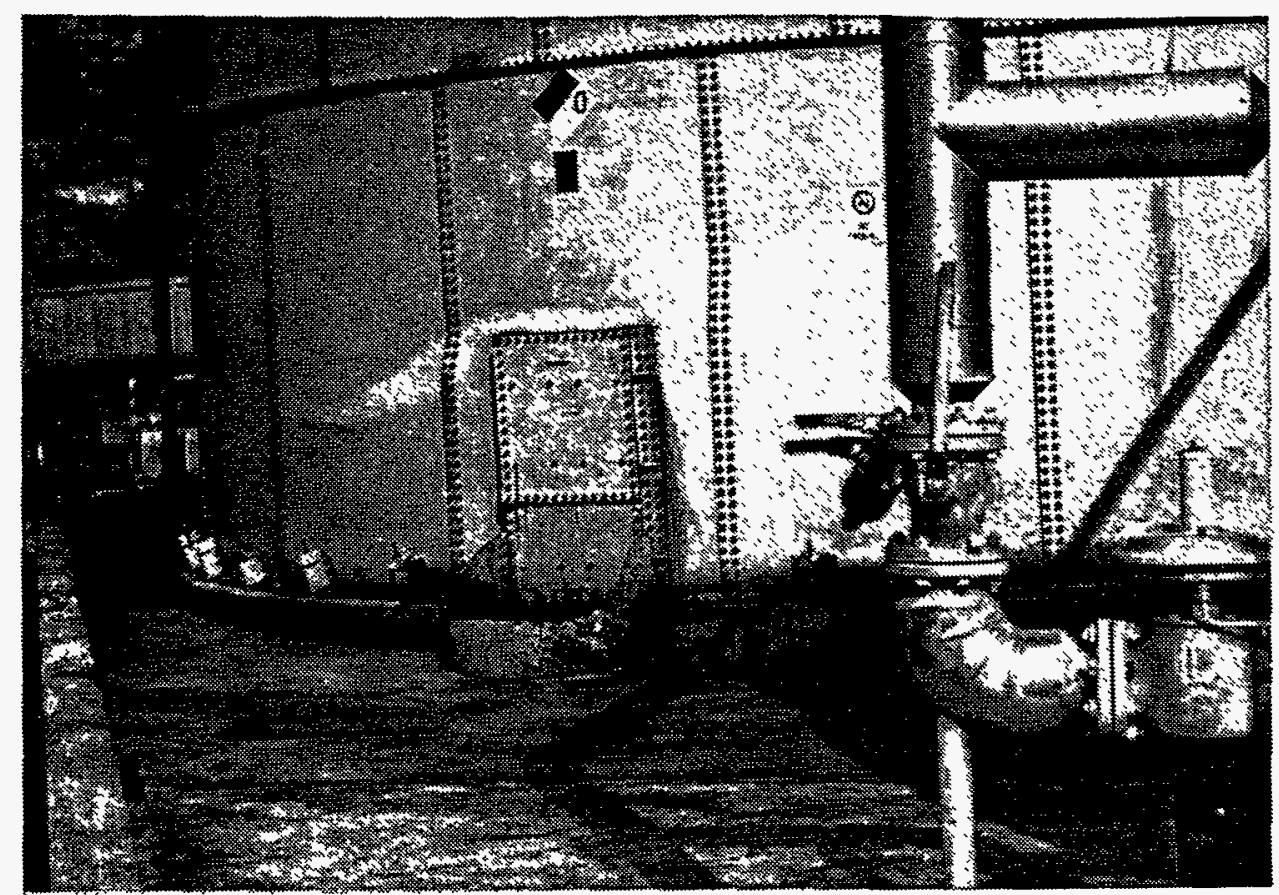

Figure 4.1.1-3: This oil field reclaimed water tank existed at the facility prior to developing the cogeneration plant. The 165,000 gal capacity bolted steel tank was anchored with numerous $3 / 4$ inch anchor bolts. The anchor bolts pulled out and bent, the shell experienced elephant-foot buckling at the base, the foundation was damaged and small leaks developed at seams.

Figure 4.1.1-4: Close-up view of damaged anchor bolts.

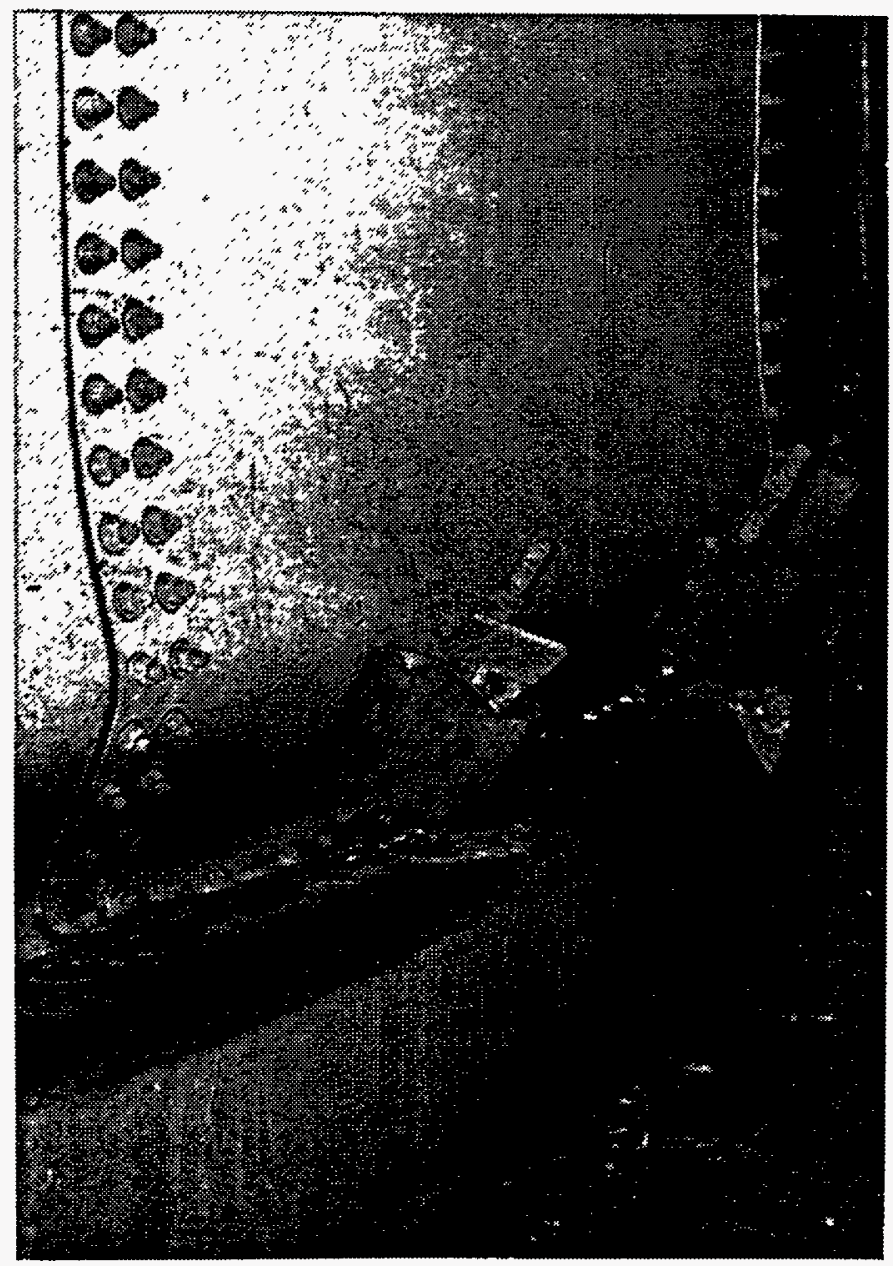




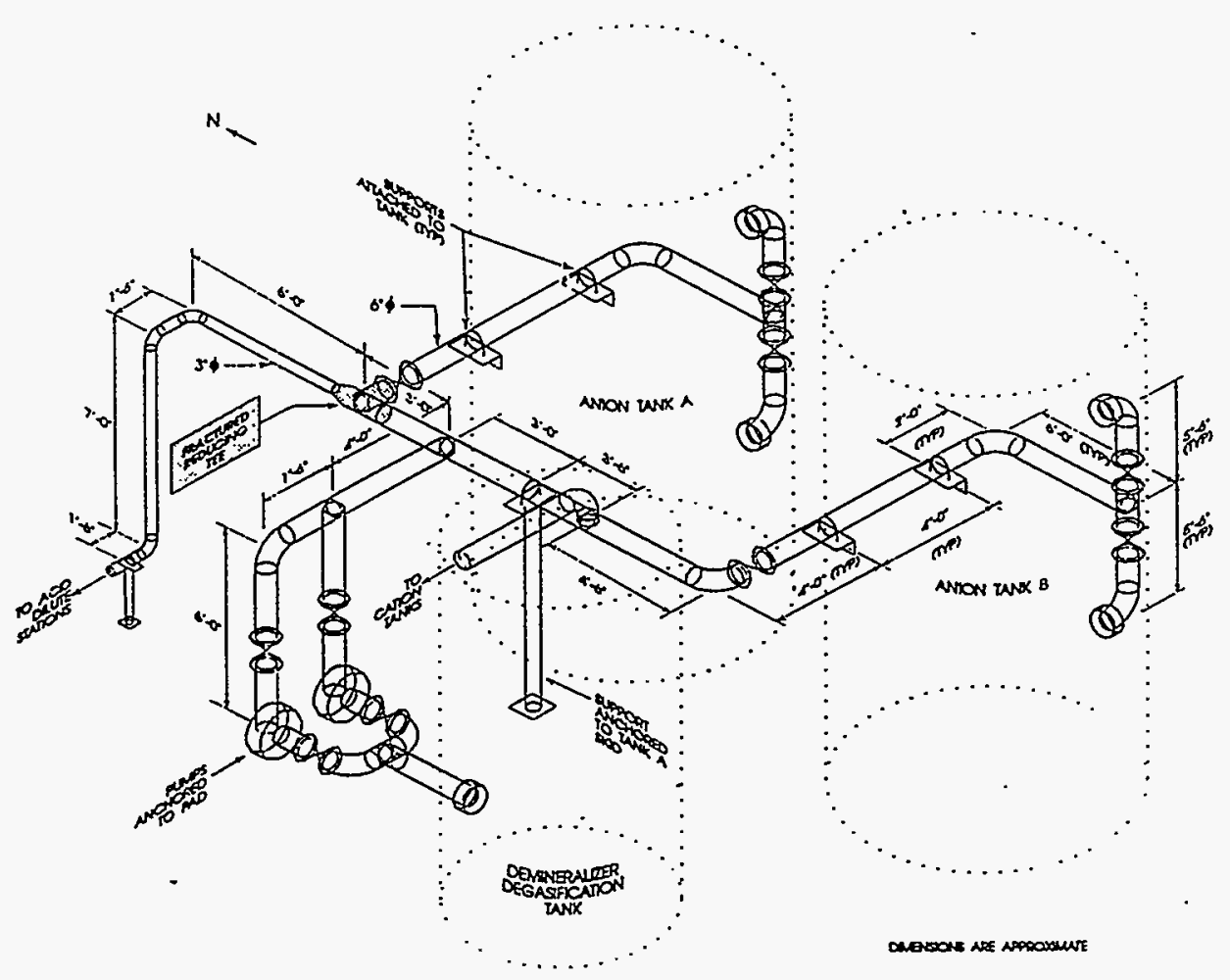

Figure 4.1.1-5: Sketch of the AES Placerita Canyon demineralizer piping and vessel arrangement. The shaded area shows the location of a fractured 6 inch diameter cast-iron fitting.

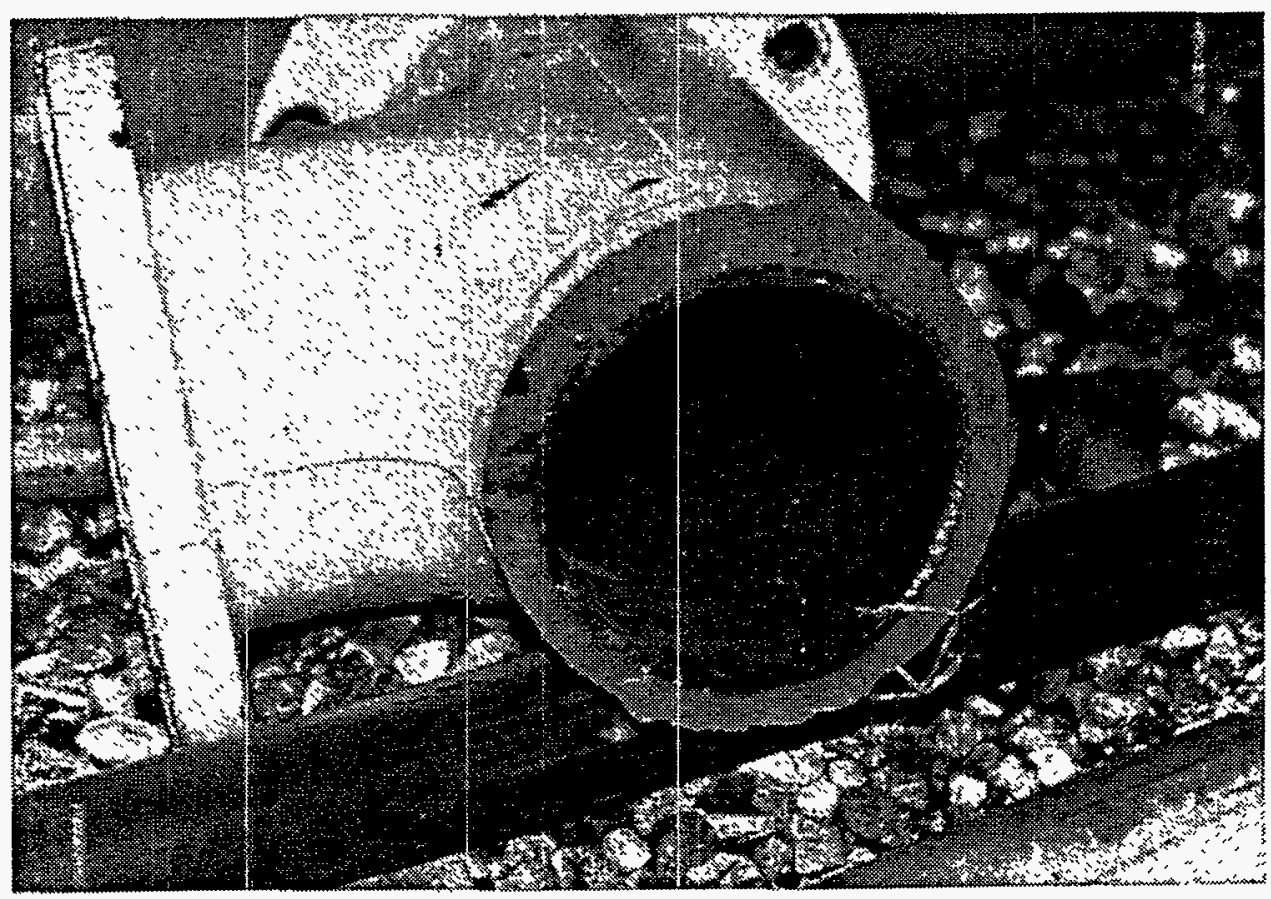

Figure 4.1.1-6: Anchorage failure and displacement of demineralizer skids resulted in failure of several cast iron water pipe fittings. 
Soil conditions at the plant and at the fire station are Alluvium [ref 4.1-3], with both facilities sited along a dry river beds that feed the Santa Clara River. The Newhall LA County Fire Station is a reasonable estimate of ground motion based on distance from the epicenter, proximity, similar soil conditions and observed damage at the plant. Figure 4.1.1-7 presents the accelerograms and response spectra plotted at 5\% damping for the Newhall CSMIP record [ref 4.1-4].

\subsubsection{ARCO Placerita}

ARCO Placerita, also an independent power producer, includes a $42 \mathrm{MW}$ electric cogeneration plant and several facilities that support oil field production.

The cogeneration plant includes two $21 \mathrm{MW}$ gas turbines and two heat recovery steam generators that produce steam for oil recovery operations. Electricity is generated at $12 \mathrm{kV}$ and stepped up to $66 \mathrm{kV}$ for interface with the SCE power grid. The plant consists of interconnected modular package units that were fabricated off-site and shipped to the site.

Oil production facilities located near the power plant include numerous tanks, vessels, piping and mechanical equipment. Steam from the power plant heat recovery system is distributed to local wells for injection via a vast above ground piping distribution network. The piping is supported for both gravity and axial loads (generated by expansion and contraction due to large temperature fluctuation), with sufficient piping flexibility to sustain equipment anchor point displacements experienced during the event. A $12 \mathrm{kV} / 480 \mathrm{~V}$ power distribution system provides power to pumps, wells, compressors and other electrical loads within the oil field.

The two gas turbines were providing power to the SCE electrical grid when the earthquake occurred. The gas turbines tripped due to vibration sensor activation, as designed. Restart of the facility to provide on-site steam and electricity was not feasible since the facility does not have black-start capability and power was not available from the power grid. The plant was successfully restarted upon restoration of the power grid 48 hours after the event. There were no earthquake related equipment or systems failures within the power plant. The production facilities, which are generally much older than the power plant, experienced tank damage and failure, minor isolated piping damage (but no failures) and vessel anchorage failures.

The oil production facilities include about 15 flat and cone bottom storage tanks ranging from older unanchored bolted steel tanks to recent vintage bolted steel tanks anchored to engineered foundations. The unanchored tanks sustained elephants-foot buckling at the wall to base joints. Figure 4.1.2-1 shows a typical unanchored tank following replacement of the entire first course 


\section{NORTHRIDGE EARTHQUAKE}

Newhall LA County Fire Station

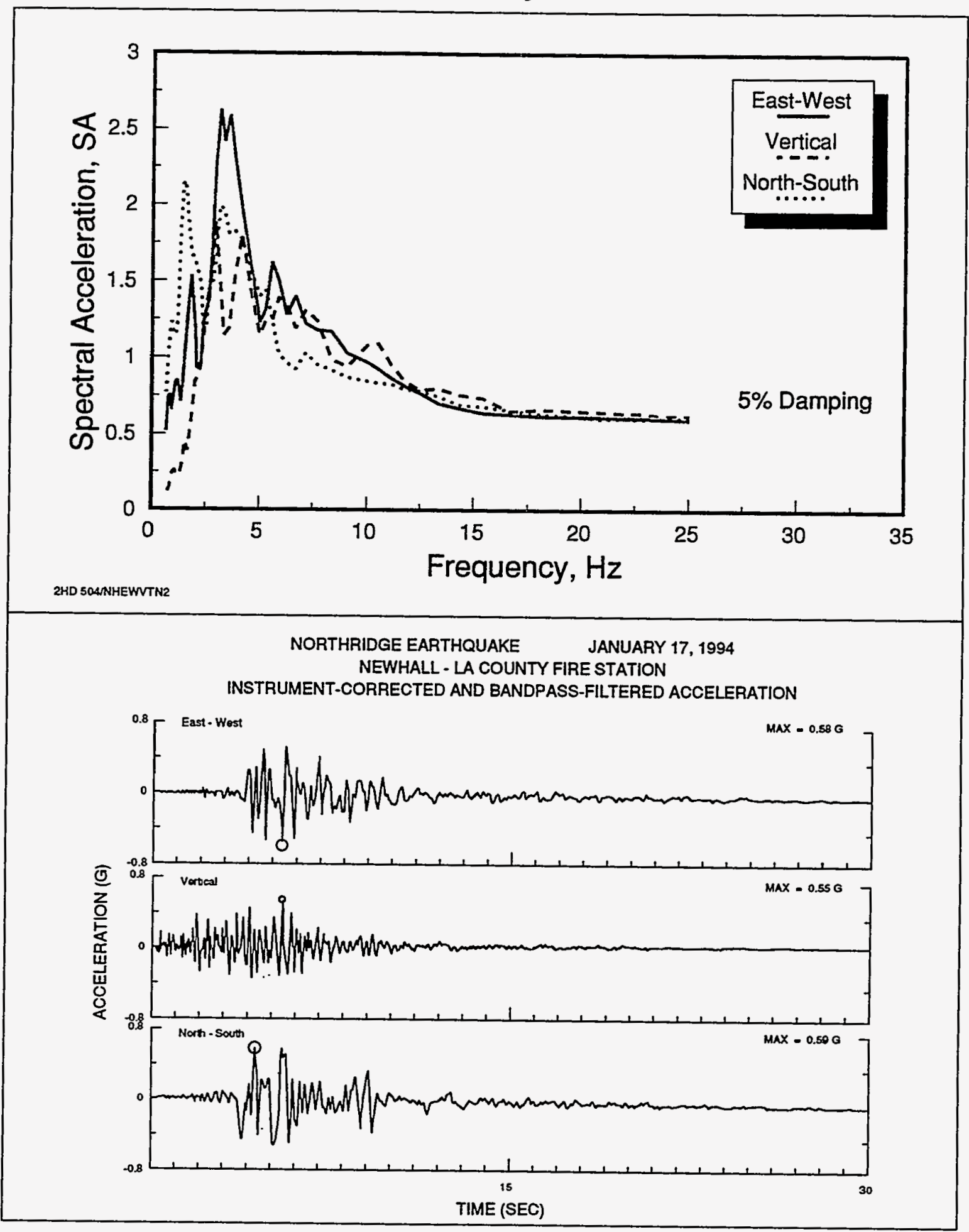

Figure 4.1.1-7: Response spectra and acceleration time-histories for the Newhall LA County Fire Station CSMIP station. 


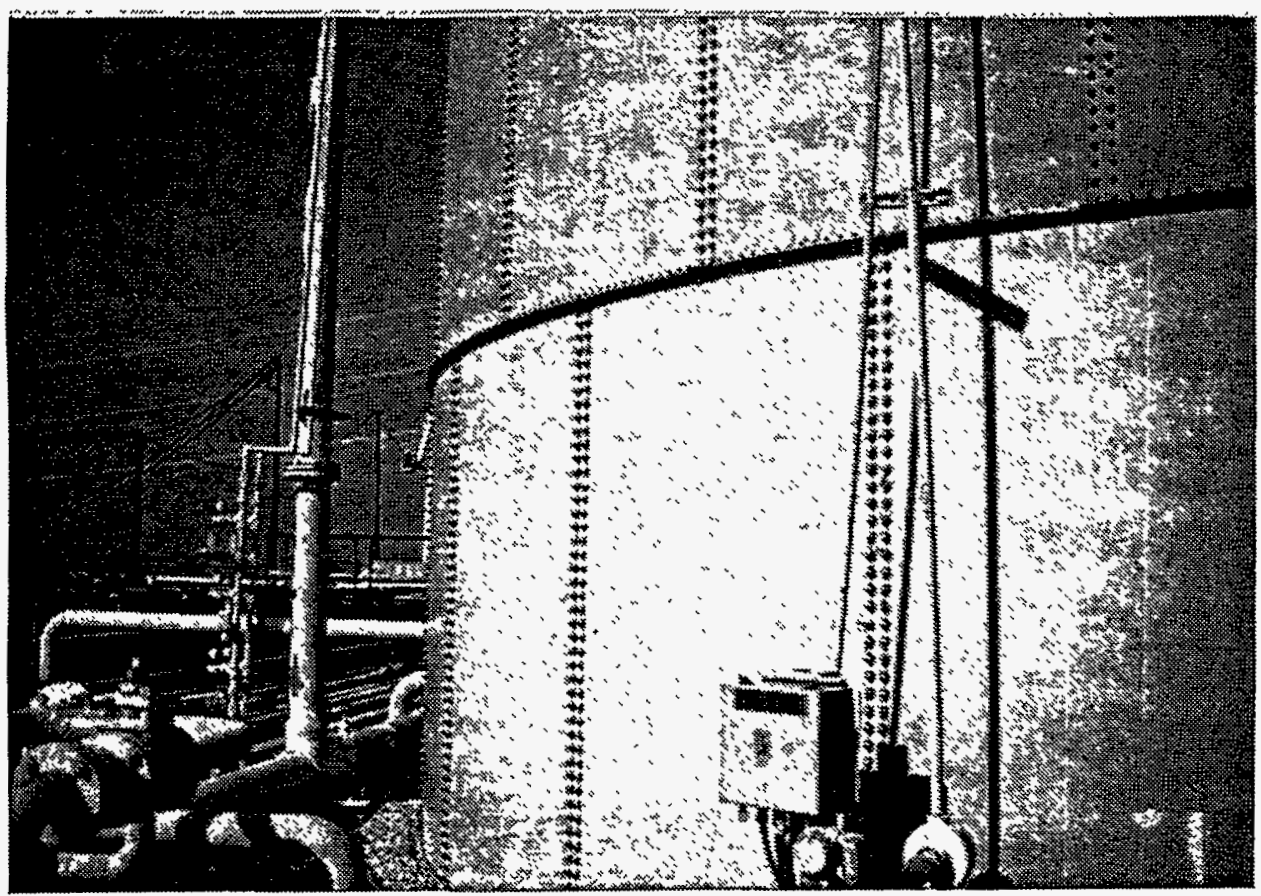

Figure 4.1.2-1: Unanchored bolted steel storage tank following replacement of the bottom course. 
due to buckling at the base. Figure 4.1.2-2 shows a partial inventory of bottom course panels that were removed from unanchored bolted storage tanks.

Newer tanks anchored to engineered foundations survived the earthquake without failure. Anchor bolts were, however, challenged as shown in Figure 4.1.2-3.

Most of the piping is supported only for vertical loads with adequate flexibility to accommodate tank displacements at nozzles. A few tank penetrations with rigid piping had nozzle failure (leaks). In one case, a line penetrated a secondary containment wall downstream of the tank with the containment wall acting as an anchor point, resulting in tank nozzle failure.

Only one instance of pipe support failure was discovered. A 12 inch diameter line was supported by a series of support structures for deadweight. One of the tallest supports was also a longitudinal anchor point due to lugs welded to the pipe. This support failed at a weld near the base. Corrosion and/or a poor quality weld may have contributed to the failure. The pipe support failure did not compromise the integrity of the line. No pipe failures were observed at the facility.

There were two instances of anchorage failure and three instances of significant yielding of anchorage for process vessels. Two large 12 feet diameter by 63 feet long horizontal knockout vessels that weigh about 500,000 lbs failed their anchorage (Figures 4.1.2-4 and 4.1.2-5). The vessels moved up to 6 inches, however, did not sustain vessel or piping failure due to adequate flexibility in attached lines. Pipe supports adjacent to the vessels were not anchored to the foundation, accommodating the large displacements. A third and recent vintage knockout vessel with engineered concrete piers and support saddles withstood the event without damage. Three water softener skids also challenged the capacity of their anchorage details. Flexibility of the attached piping systems to accommodate displacements prevented system failures.

ARCO Placerita is located within a kilometer of AES Placerita in the hills above the dry wash. The Newhall record of $0.63 \mathrm{~g}$ horizontal and $0.62 \mathrm{~g}$ vertical is the nearest indicator of ground motion [ref 4.1-2]. The instrument, located in the valley on alluvium, is on slightly different soil than the ARCO facility located near the top of hills. However, considering available information, the Newhall record is considered a reasonable estimate of ground motion based on distance from the epicenter, proximity and observed damage at the plant.

\subsubsection{Pitchess Honor Ranch}

The Pitchess cogeneration plant, located near Castaic Dam, is a $28 \mathrm{MW}$ power generation facility which provides electricity for a prison facility as well as for the power grid as an independent 


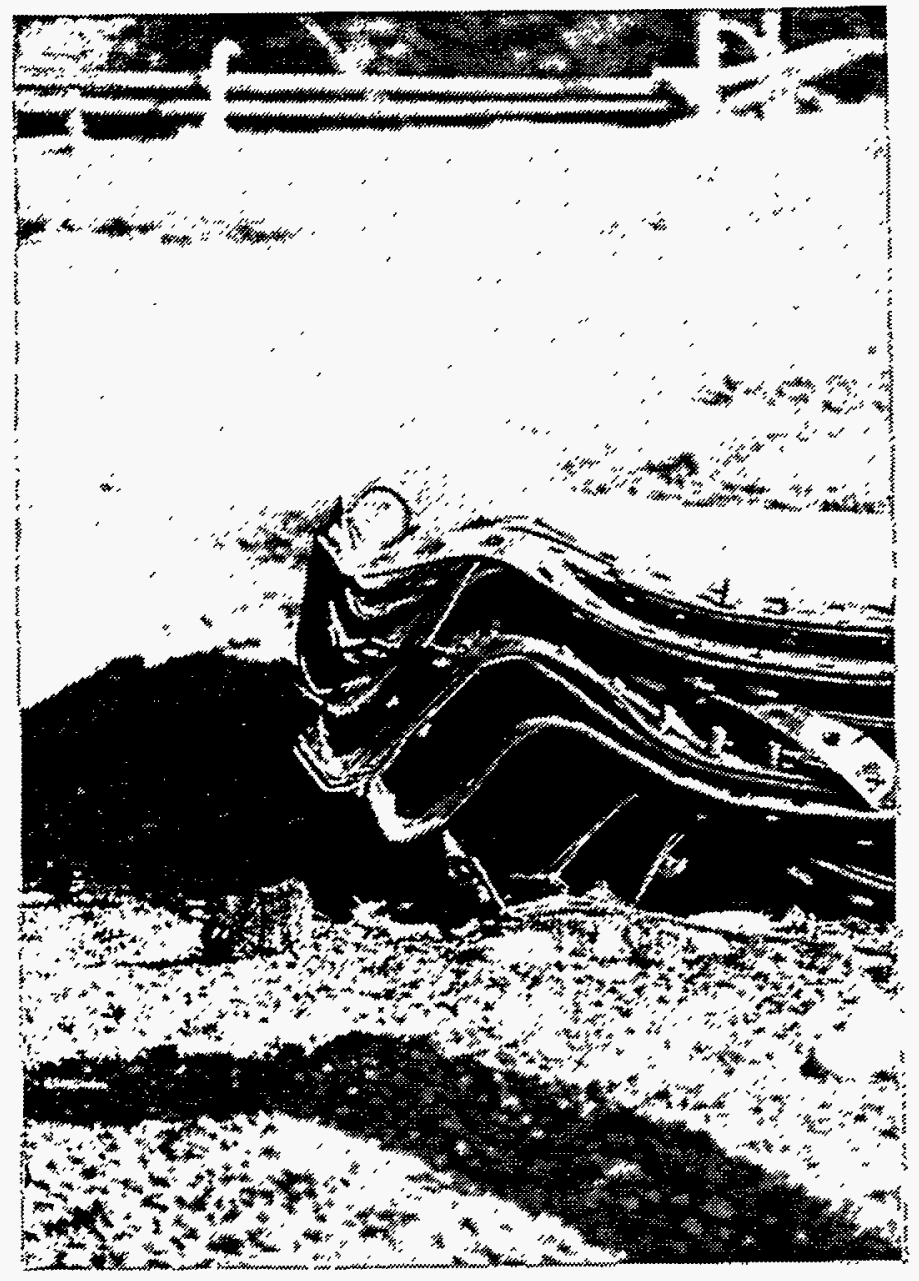

Figure 4.1.2-2: Partial inventory of buckled bottom course tank panels.

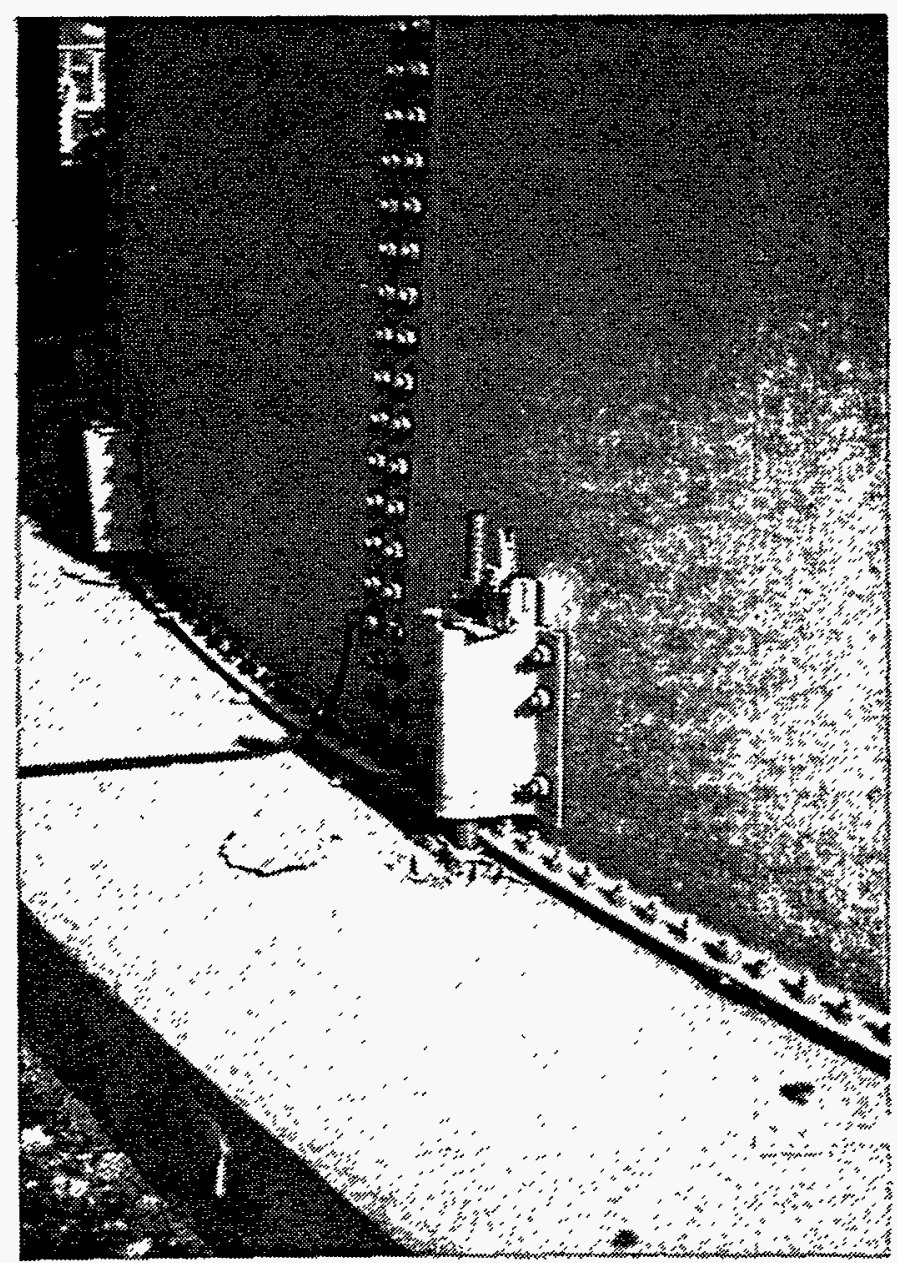




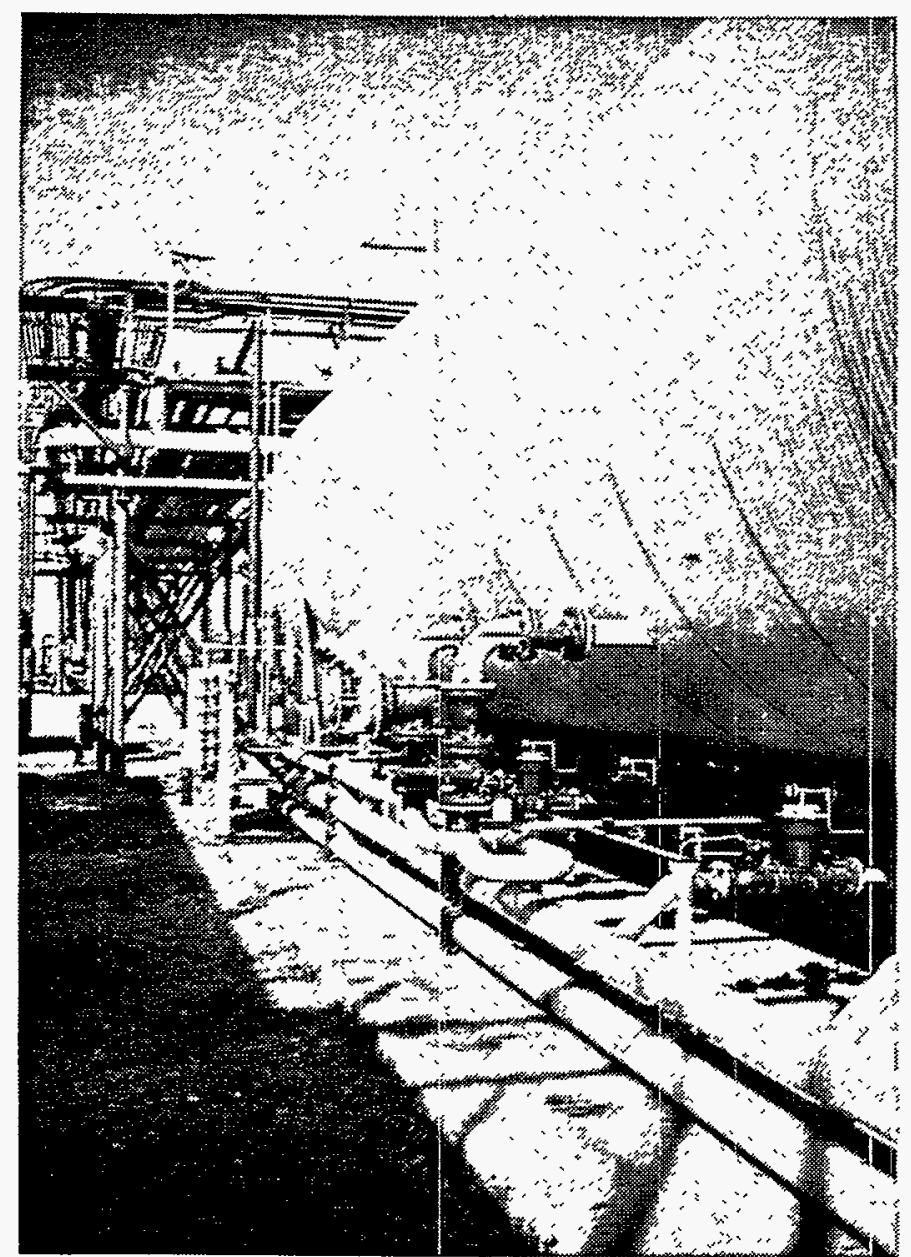

Figure 4.1.2-4: The 500,000 lbs vessel sheared anchor bolts and moved up to 6 inches. Flexibility of attached piping prevented system failure.

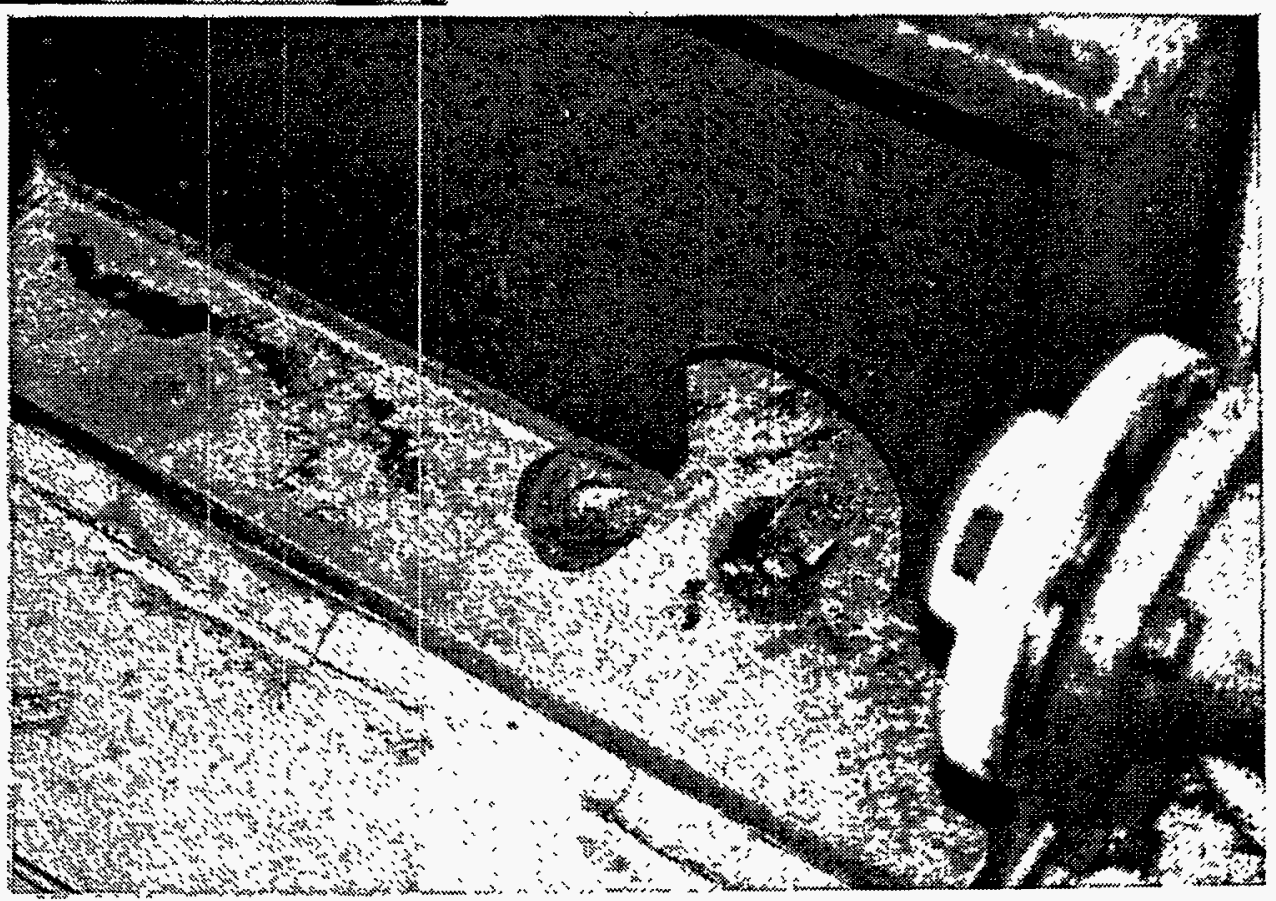

Figure 4.1.2-5: Close-up view of sheared bolt at vessel foundation. 
power producer. The combined cycle plant includes a $21 \mathrm{MW}$ electric gas turbine and a heat recovery steam generator. Recovered steam drives a $7 \mathrm{MW}$ electric steam turbine and supplies loads associated with prison facilities such as heating and absorption chillers. Electricity is produced at $12.5 \mathrm{kV}$ then stepped up to interface with the SCE power grid.

The Los Angeles County operated plant was commissioned in 1988. Seismic design criteria exceed UBC Zone 4 requirements.

The plant was operating when the earthquake occurred then tripped off-line due to either turbine vibration sensor activation and/or power grid voltage and frequency fluctuations. Emergency diesel generators provided back-up power for prison facilities. The cogeneration plant did not have black-start capability. Upon resumption of utility supplied power, operators were unable to reset the $12.5 \mathrm{kV}$ power breakers (Figure 4.1.3-1). The plant was otherwise undamaged and available for service pending resolution of the power breaker malfunction.

Operators were able to trace the breaker problem to misalignment of the breaker rail (Figure 4.1.32). This prevented the limit switch from permitting the breaker to fully rack-in. The problem was attributed to dislodged springs on the sliding alignment rail. Missing retaining clips allowed the springs to dislodge. The plant was restarted at approximately 6:00 a.m. the following morning, 25 $1 / 2$ hours after the earthquake.

The Pitchess cogeneration plant is located near two CSMIP strong-motion stations and an SCE facility that contains a strong-motion instrument. The Newhall strong-motion instrument maintained by CSMIP is located about 9 kilometers South-East of the Pitchess cogeneration plant and the Castaic instrument 7 kilometers North of the plant. Maximum free-field ground accelerations recorded by the Newhall LA County Fire Station are $0.63 \mathrm{~g}$ horizontal and $0.62 \mathrm{~g}$ vertical [ref 4.1-2]. The Castaic instrument recorded $0.59 \mathrm{~g}$ horizontal and $0.25 \mathrm{~g}$ vertical [ref $4.1-$ 2]. The SCE instrument, located about 2 kilometers from the plant, recorded $0.5 \mathrm{~g}$ horizontal and 0.35 vertical [ref $4.1-5$ ]. Soil conditions at the Pitchess plant and the CSMIP Castaic strongmotion instrument station are sedimentary rock [ref 4.1-3]. Conditions at the SCE facility and the Newhall LA County Fire Station are alluvium [ref 4.1-3].

All three sites recorded about $0.6 \mathrm{~g}$ horizontal peak ground accelerations. Therefore, due to similar soil conditions, the Castaic CSMIP record is judged to be a reasonable estimate of ground motion for the Pitchess cogeneration plant. 


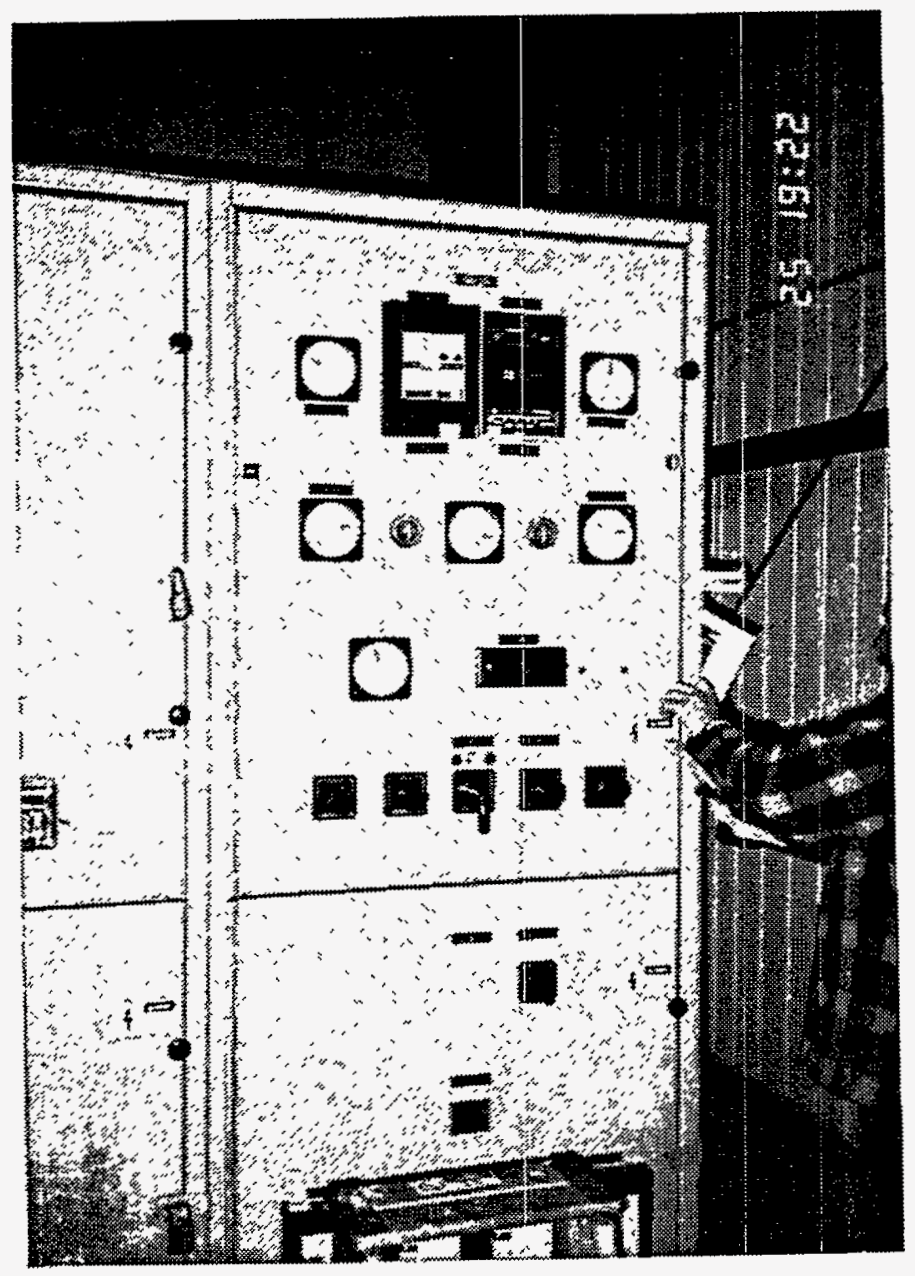

Figure 4.1.3-1: $12.5 \mathrm{kV}$ circuit breaker that would not reset, preventing restart following the earthquake.

Figure 4.1.3-2: The breaker could not be racked due to misalignment of the rails. Springs dislodged from the sliding rails due to missing retaining clips.

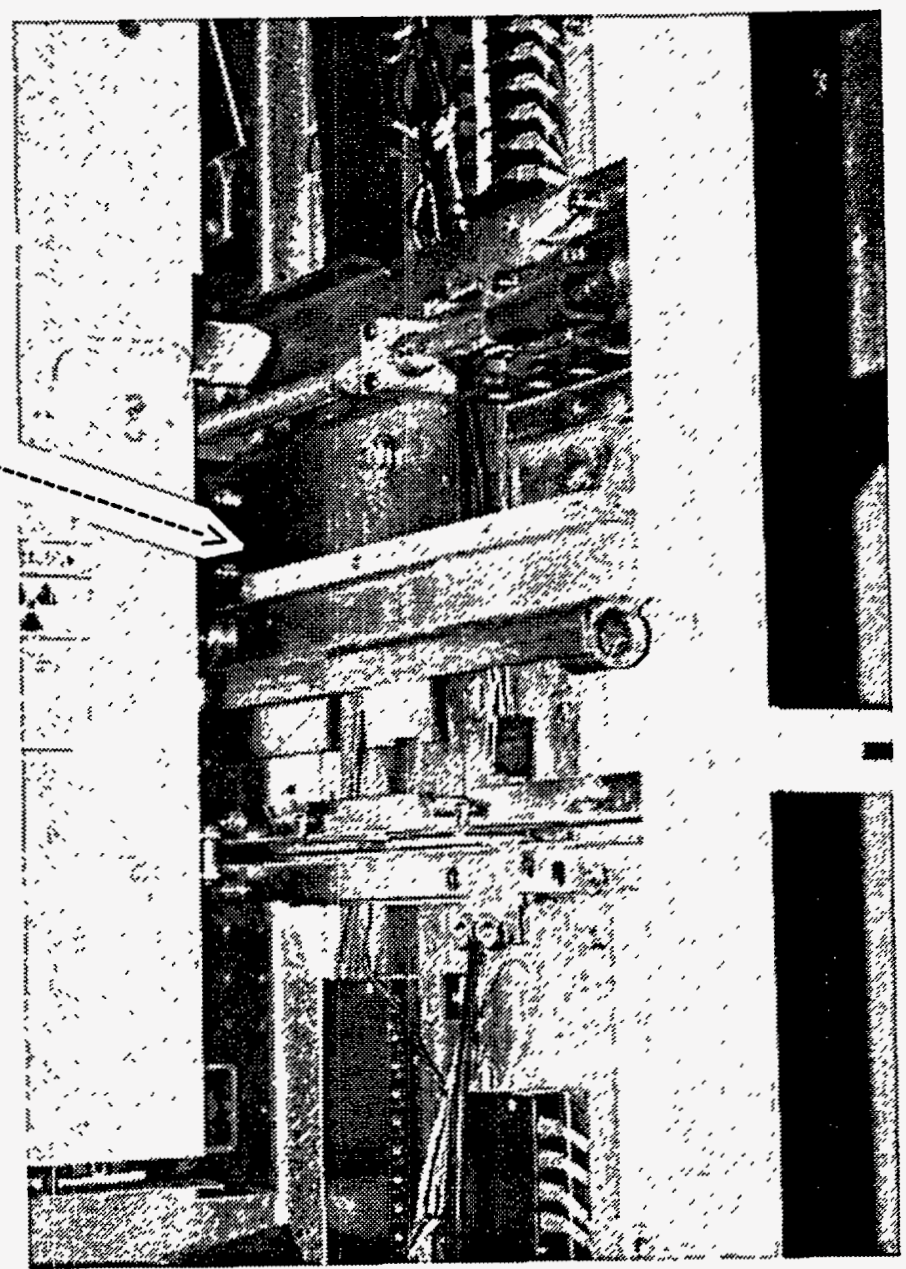




\subsubsection{Olive View Cogeneration Plant}

The Olive view cogeneration plant located adjacent to the six-story Olive View Los Angeles County Medical Center in Sylmar is a $6 \mathrm{MW}$ power generation facility which provides power to the adjacent hospital facility. Although an independent power producer, it does not currently tie to the power grid due to emission restrictions. Future upgrades of the emission controls will allow full function as an independent power producer. Recovered heat from the two 3 MW combustion turbines is used to supply steam and absorption cooling loads of the hospital.

While the plant is operated by Los Angeles County as a facility independent from the hospital, the plant was designed and constructed to meet all California Title 24 hospital seismic requirements when the new six-story medical center replaced (early 1980's) the hospital facilities that collapsed in the 1971 San Fernando Earthquake. The plant was operating and supplying all hospital loads when the earthquake occurred. The plant tripped off-line and the hospital emergency generators (2 each $2000 \mathrm{kw}$, Figure 4.1.4-1) immediately started and assumed the hospital electrical load. The cogeneration plant was inspected for damage, and finding none, the decision for plant restart was made. Black-start capability is provided by the hospital emergency generators. However, before cogeneration plant restart was initiated, the emergency generators stopped when the day tank ran out of fuel. The problem was traced to incorrect control wiring in the fuel transfer pump control logic. The wiring was corrected, fuel manually transferred, and the generators restarted. The plant was then restarted and assumed the hospital loads.

A CSMIP instrument, located less than $100 \mathrm{ft}$ from the plant, recorded peak free-field ground acceleration of $0.91 \mathrm{~g}$ horizontal and $0.6 \mathrm{~g}$ vertical [ref 4.1-2]. Figure 4.1.4-2 presents the accelerograms and response spectra plotted at 5\% damping for the Sylmar County Hospital record [ref 4.1-4]. The six-story hospital building is also instrumented under the CSMIP program. The roof instruments recorded over $2 \mathrm{~g}$ peak horizontal acceleration. As discussed in Section 4.2.3 of this report, there was failure of anchorage, vibration isolation mounts (with seismic restraints), and two 3 inch diameter cast iron control valves resulting in cooling water discharge. 


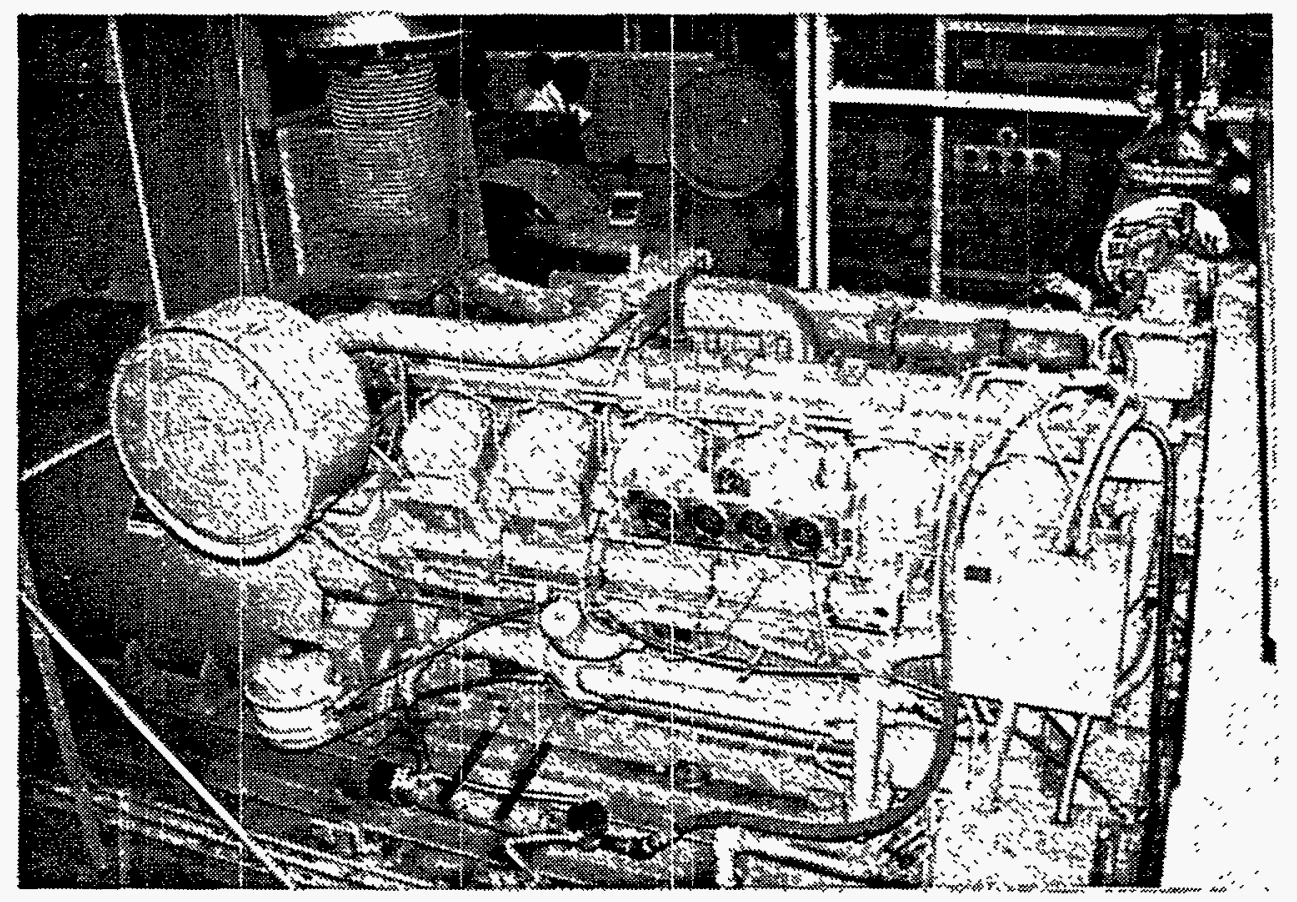

Figure 4.1.4-1: Olive View Medical Center and Power Plant Emergency Generators - the generators started and supplied power to the hospital until the day tank ran out of fuel. 


\section{NORTHRIDGE EARTHQUAKE \\ Sylmar County Hospital}

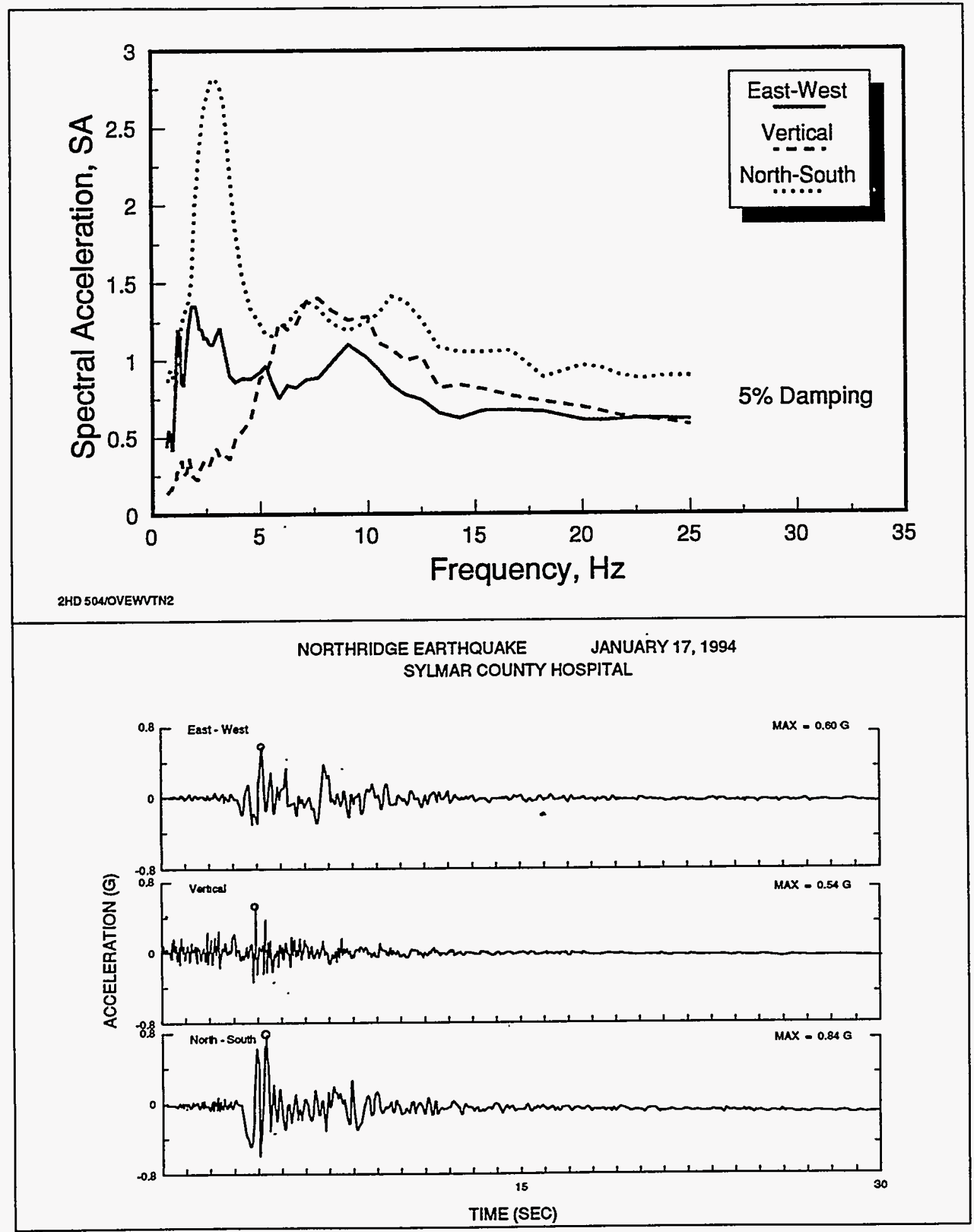

Figure 4.1.4-2: Accelerograms and response spectra plotted at 5\% damping for the Sylmar County Hospital. 


\subsection{HOSPITAL SUPPORT SYSTEMS}

At several hospitals in the earthquake-affected area, the main structures performed fairly well. However, the chilled water lines and fire protection lines suffered breaks or leaks in many of the connections or at building separations. In some cases, the water lines were attached to unreinforced masonry (URM) walls. The water leaks caused the following types of problems as examples: (1) loss of availability or of distribution of emergency power due to shorts in electrical cabinets; (2) loss of cooling to major critical components and electronics equipment; (3) lack of water and/or water pressure in fire protection systems; and (4) evacuation of occupants due to life safety or lack of support systems availability.

In one hospital complex, the main electrical transfer switch (from normal offsite power to onsite emergency power) failed to function properly immediately after the quake; even though the emergency diesel was running and was available to handle the electrical load. One example of an electrical relay problem was on an emergency power subsystem. The relay had intermittent problems prior to the Northridge Earthquake and malfunctioned again during the earthquake. In a penthouse on the roof of a hospital, the acceleration levels were so high that the inertial forces caused failure of the valve body on a 4-inch diameter chilled water line.

Vibration isolators worked well in those cases where there were also adequate seismic bumpers to limit the displacements. The air handler unit shown in Figures 4.2-1a and 4.2-1b lacked seismic bumpers and was damaged. Emergency diesel generators, chillers, air handling units, and compressors experienced problems with attached lines when vibration isolators were not seismically designed properly. On the roof of one hospital, an air handler unit's (AHU) anchorage configuration was good except for the inadequate length of the connecting bolts between the AHU and its vibration isolators. Due to failure of these connections, the AHU came off its supports and broke the attached lines.

Some of the hospitals affected by the Northridge quake include St. John's Hospital and Medical Complex in Santa Monica [ref 4.2-1], Northridge Hospital and Medical Center in Northridge [ref 4.2-2], Olive View Hospital in Sylmar [ref 4.2-3], Veterans' Administration Hospital in Sepulveda [ref 4.2-4], Holy Cross Hospital [ref 4.2-5], Indian Hills Hospital [ref 4.2-6], and Granada Hills Community Hospital in Granada Hills [ref 4.2-5]. Information on the performance of a base isolated hospital, the USC University Hospital, is provided in Section 4.4 .2 of this report. 


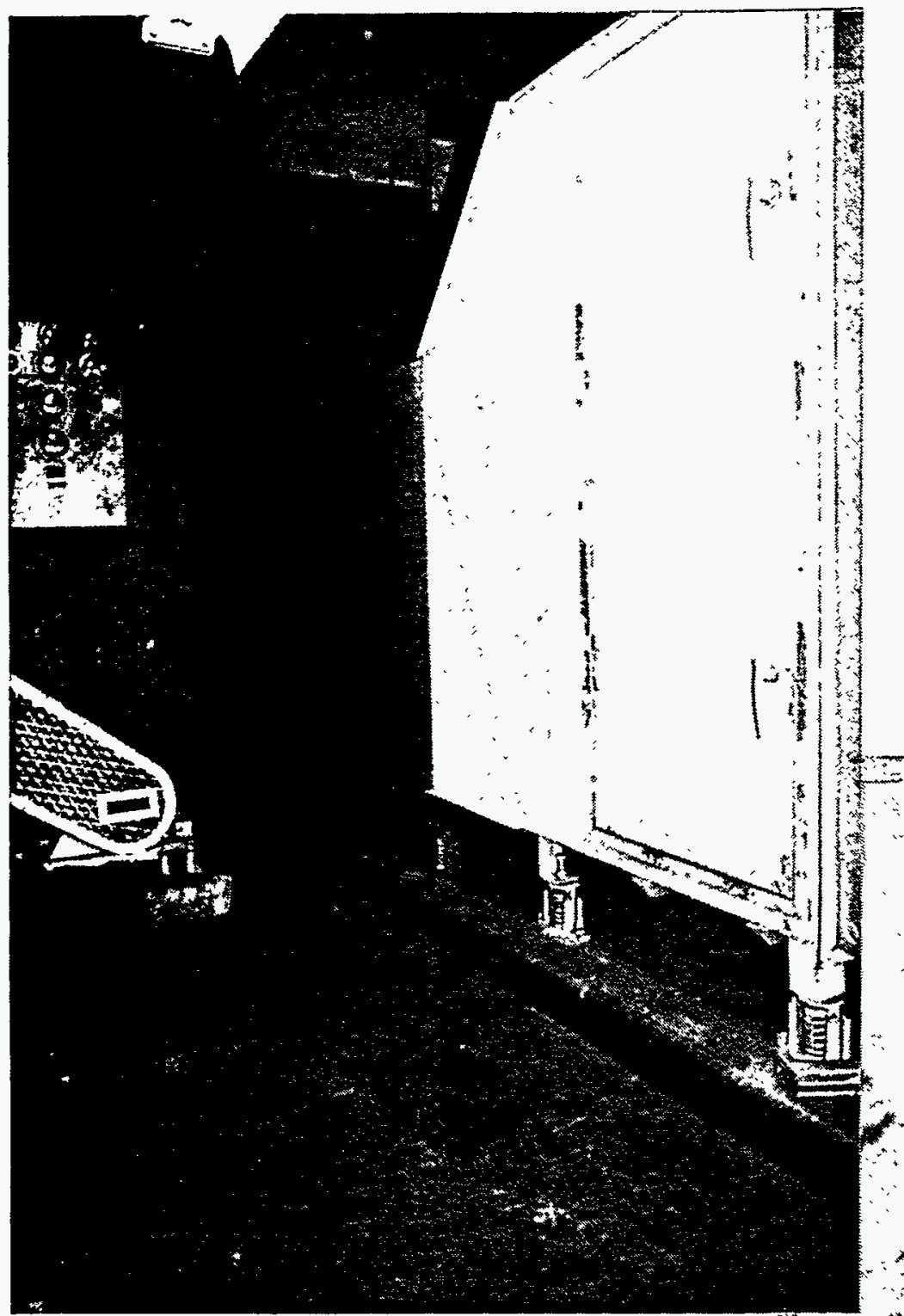

Figure 4.2-1a: Air handler unit with vibration isolators that lack seismic bumpers.

Figure 4.2-1b: Close-up of air handler unit with failed vibration isolator detail that lack seismic bumpers.

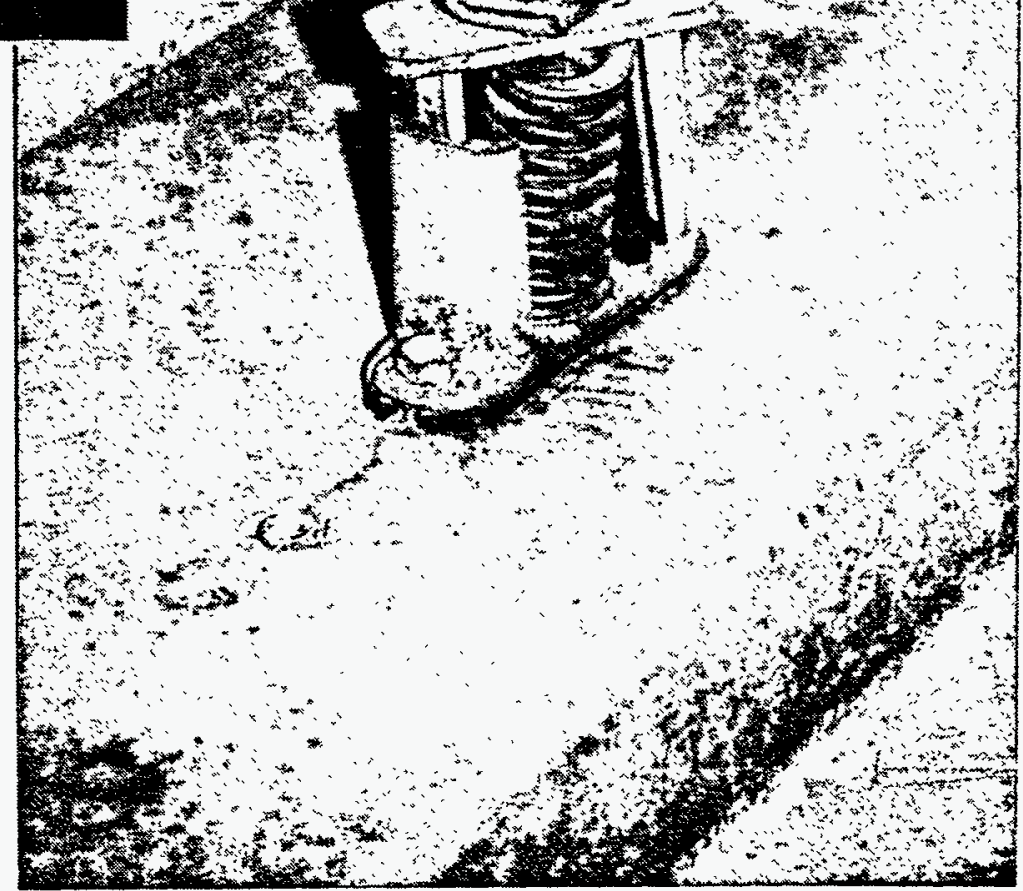


Further details on damage to water lines and failure of emergency generators at hospitals can also be obtained from a report by the State of California Office of State-wide Health Planning and Development (OSHPD) that is due to be available at the end of 1994 [see Reference 4.2-7].

\subsubsection{St. John's Hospital, Santa Monica}

At St. John's Hospital Complex, several problems occurred that caused the buildings to be evacuated or otherwise caused interruption of facility operations. The local ground motion was about $0.93 \mathrm{~g} \mathrm{E}-\mathrm{W}, 0.5 \mathrm{~g} \mathrm{~N}-\mathrm{S}$, and $0.25 \mathrm{~g}$ vertical. There are usually about 2000 employees at St. John's Hospital. Due to the earthquake damage, approximately 1500 people were laid off until the hospital could be returned to full operation.

The emergency generator ran for about 20 minutes until the transfer switch was flooded. Even though the generator had no structural damage, it was inoperational because the electrical transfer switch had water damage and burned out. Figures 4.2-2a and 4.2-2b show the engine / generator set which had vibration isolators with seismic bumpers. These bumpers prevented excessive lateral motion of the engine / generator set.

The 1.1 MWe cogeneration plant operated until the cooling tower lost its water contents. The ozone injection pipes (PVC) broke when the ozone tanks fell off their pedestals (see Figure 4.23a). It appears that the ozone tanks were unanchored. When the PVC pipes broke on the ozone injection lines, most of the water drained from the cooling tower on the roof down to the lower floors. The cooling tower was under repair for about 5 months.

Electrical distribution throughout the wings of the building was interrupted due to water leaks causing electrical shorts in the cabinets. At building separations, pipes broke due to differential movement. One example of pipe breaks at the building separations included a 6-inch diameter fire protection line. An expansion joint failed on one water line due to improper installation, and the water poured down several floors and leaked onto the emergency switchgear. Due to rail misalignment, 3 out of 14 elevators were not operational for about 3 months after the earthquake. On the roof of the central portion of the building, a plenum pulled loose from its fan enclosure during the main earthquake (see Figure 4.2-3b).

Much of St. John's Hospital is about fifty years old and has non-ductile reinforced concrete construction. The North wing at St. John's was already being demolished about 4 months after the Northridge Earthquake because of extensive diagonal cracking in the short piers between the windows on the second floor (see Figures 4.2-4a and 4.2-4b). The South wing at St. John's 


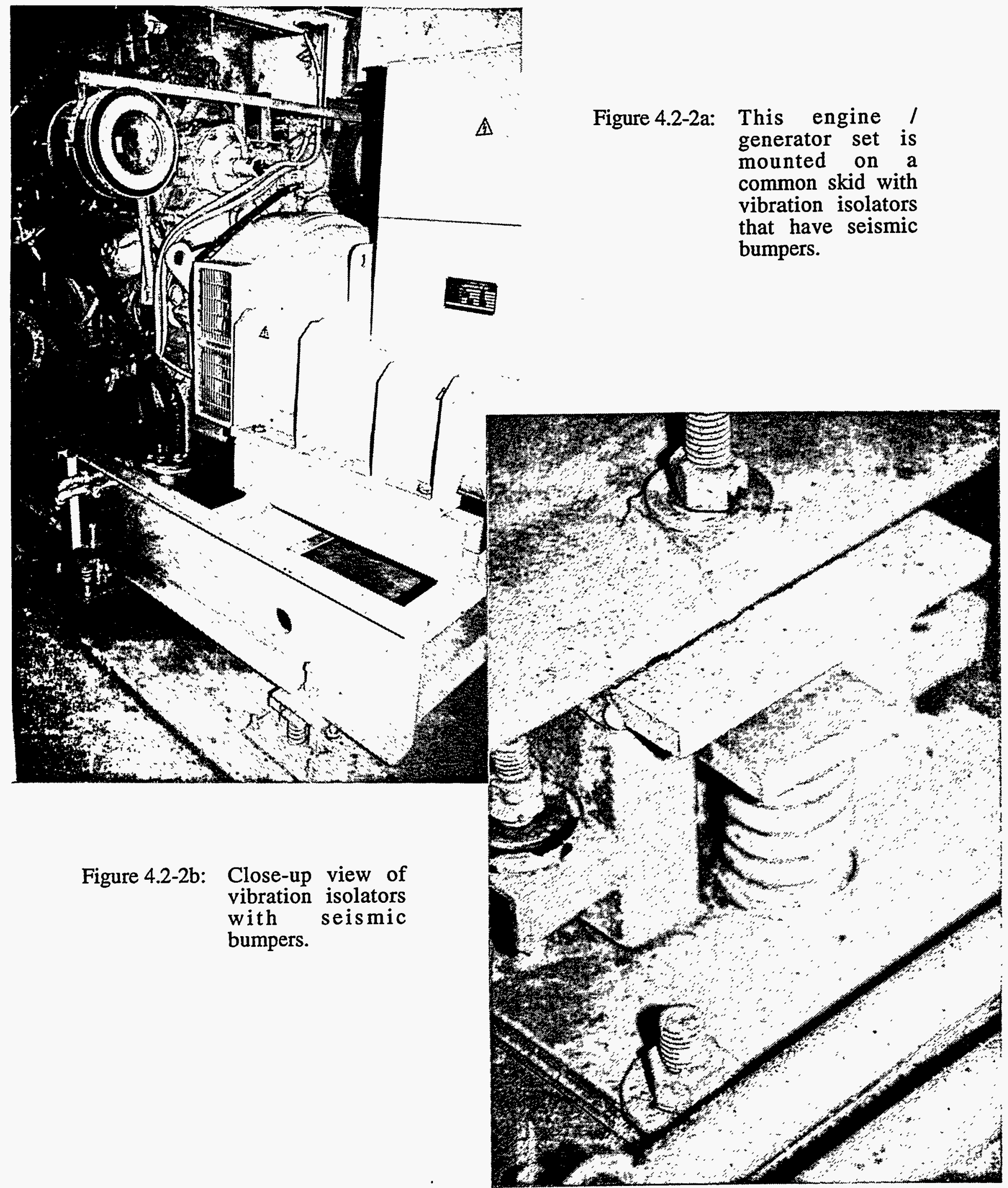




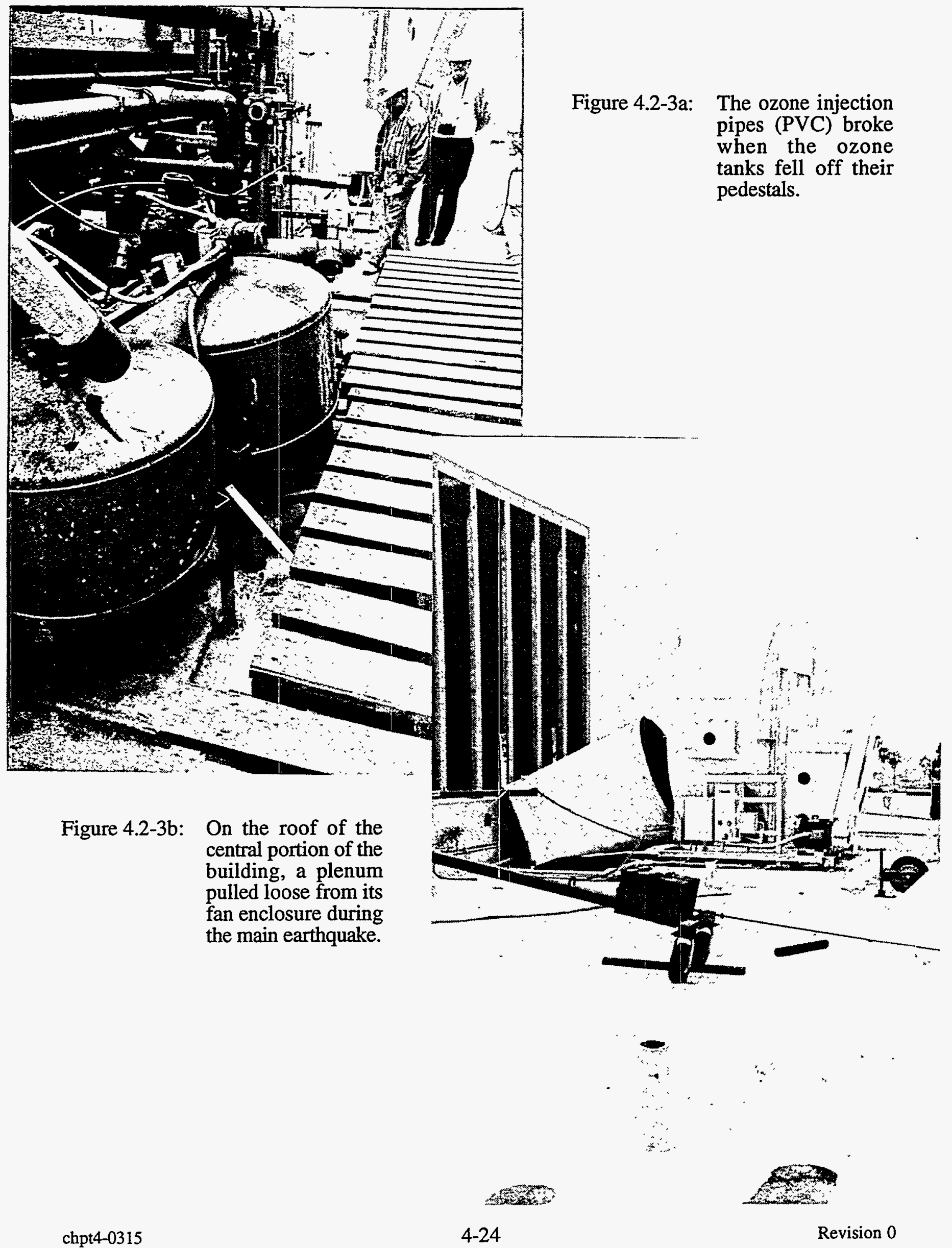




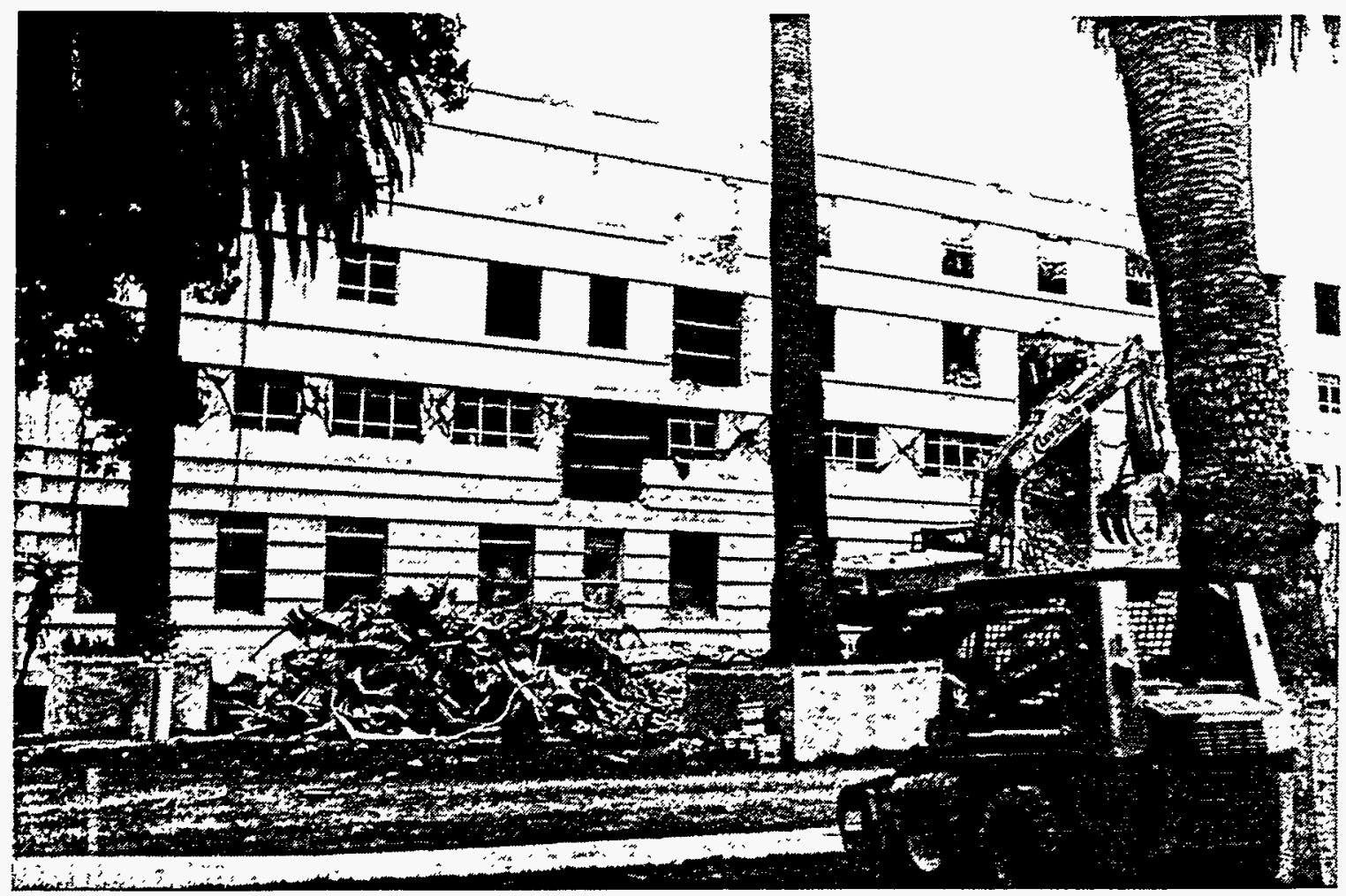

Figure 4.2-4a: The North wing at St. John's Hospital was already being demolished about 4 months after the Northridge quake because of extensive diagonal cracking in the short piers between the windows just above the second floor.

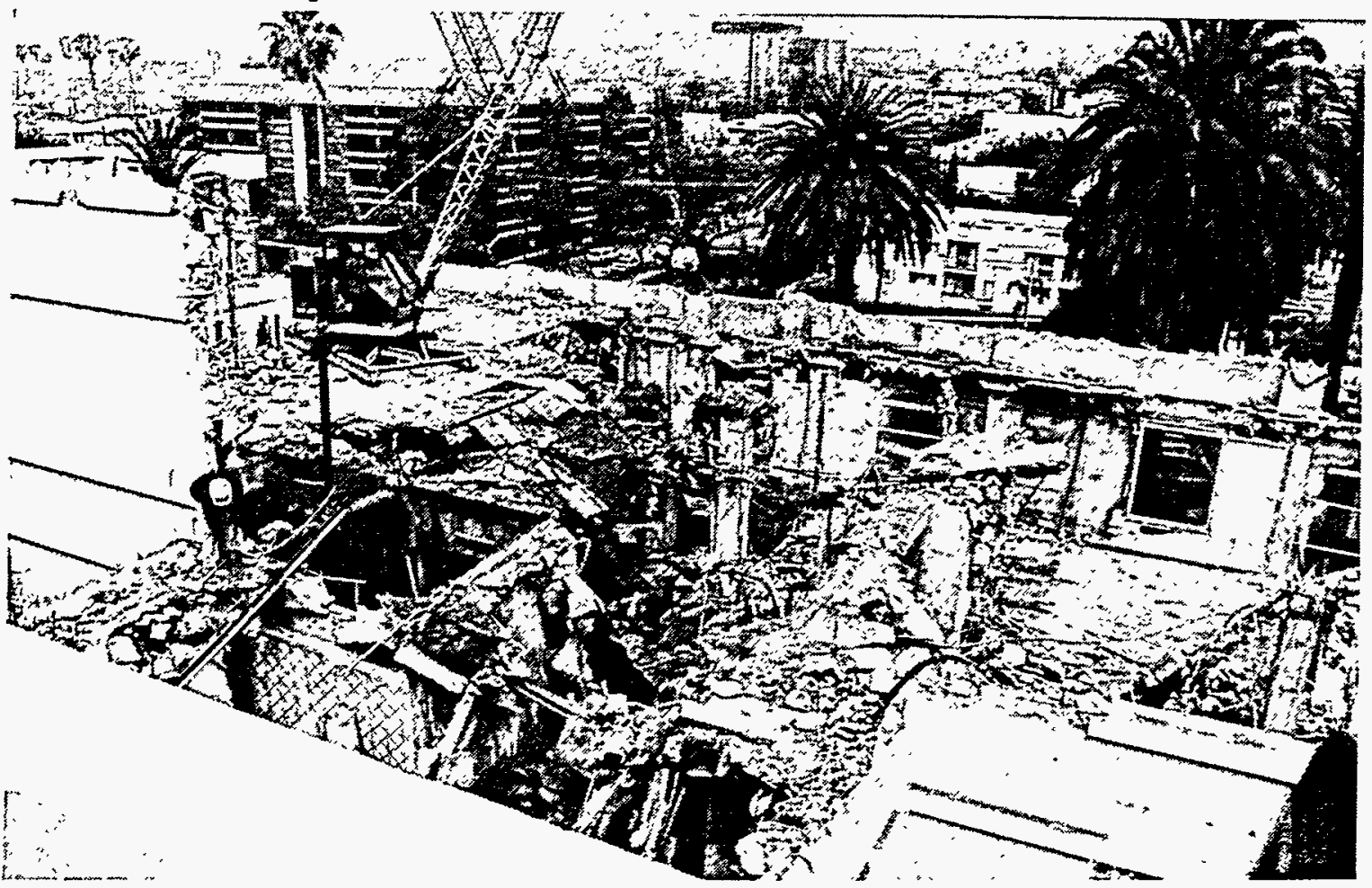

Figure 4.2-4b: View of the roof of the North wing at St. John's Hospital as it is being torn down. 
Hospital required major repair including bolting massive steel frames to the exterior of each floor (see Figures 4.2-5 and 4.2-6). Temporary shoring of floors was erected on the interior of the building with 12 -inch by 12 -inch wood timbers and with heavy, built-up steel wide-flange columns during the major repair. The Ross Center at the St. John's Hospital Complex was closed for about a month due to damage to poorly reinforced brick at the end stairwells.

\subsubsection{Northridge Hospital and Medical Center, Northridge}

Northridge Hospital and Medical Center is the only Trauma Center operating in the local Northridge area and is located about one mile from the epicenter. This facility experienced about $0.3 \mathrm{~g}$ to $0.4 \mathrm{~g}$ horizontal ground acceleration. The Holy Cross Hospital is the next nearest Trauma Center and is about 6 miles from the epicentral area. Due to earthquake damage, a temporary triage area had to be set up outside on the south side of Farr Tower (adjacent to the Emergency Room).

Within 10 seconds of the main seismic shock, the $500 \mathrm{kWe}$ emergency generator was up and available by battery start. One drawback was that the hospital air conditioning was not on the emergency power circuit. Another drawback was that a relay failed on an emergency power electrical panel. The faulty relay had a history of intermittent problems prior to the Northridge Earthquake and malfunctioned again during the main seismic event. The relay was replaced with a relay model with better reliability. The 1/2-inch diameter line, chilled water system was down for about four days following the earthquake. In the F Tower, a light fell and took out power to the Neonatal ICU on the 5th floor. The pathology lab experienced spills of solvents, toxics, plastic, and glass. This required clean-up by a Hazmat team the day after the main seismic event. The GTower at Northridge Hospital had brick veneer that spalled off and required restricted access to the vicinity of the building exterior (see Figure 4.2-7).

About 10 fire sprinkler heads experienced differential displacement which caused water leaks. There were also breaks in branch lines and mains on the fire protection systems. In the older buildings, the expansion joints on piping had some water leaks. There were water leaks in one of the operating rooms, and Pediatrics ICU had water in the corridor. A fire truck was able to pump water from the fire hydrant a block away and tie into the domestic water line at the Northridge Hospital. One of the labs was founded on mat footings and sank 4 inches. Adjacent to the lab was a wing of the building on pile foundations which did not settle. Storm drains and sewer lines broke due to the 4-inch differential movement of the structures. The Emergency Room (addition to Farr Tower) also had a spread footing and was built to 1992 code. The ER addition also settled 4 inches and severed the fire protection piping main that ran underneath the building. 


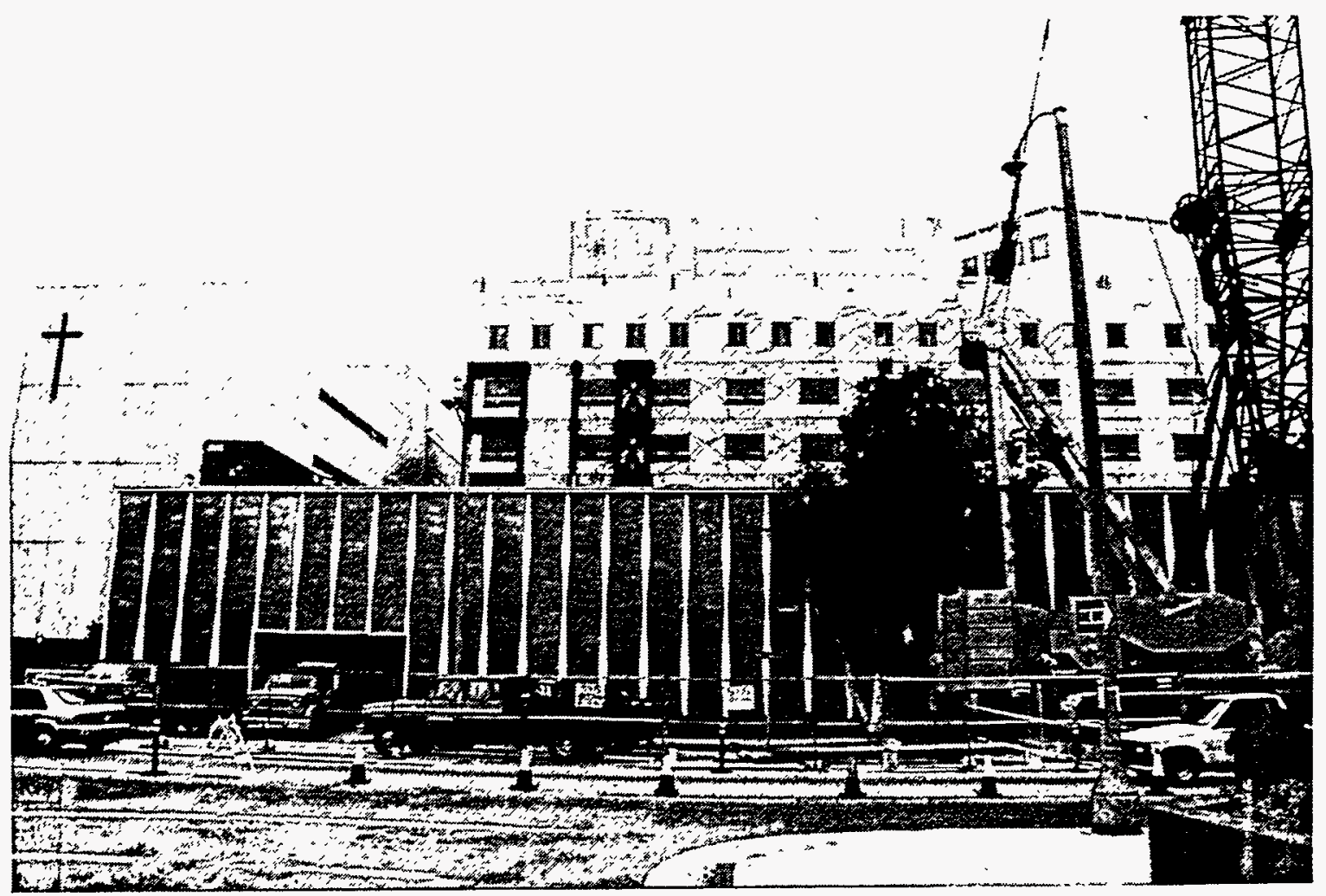

Figure 4.2-5: The South wing at St. John's Hospital required major repair including bolting massive steel frames to the exterior of each floor.

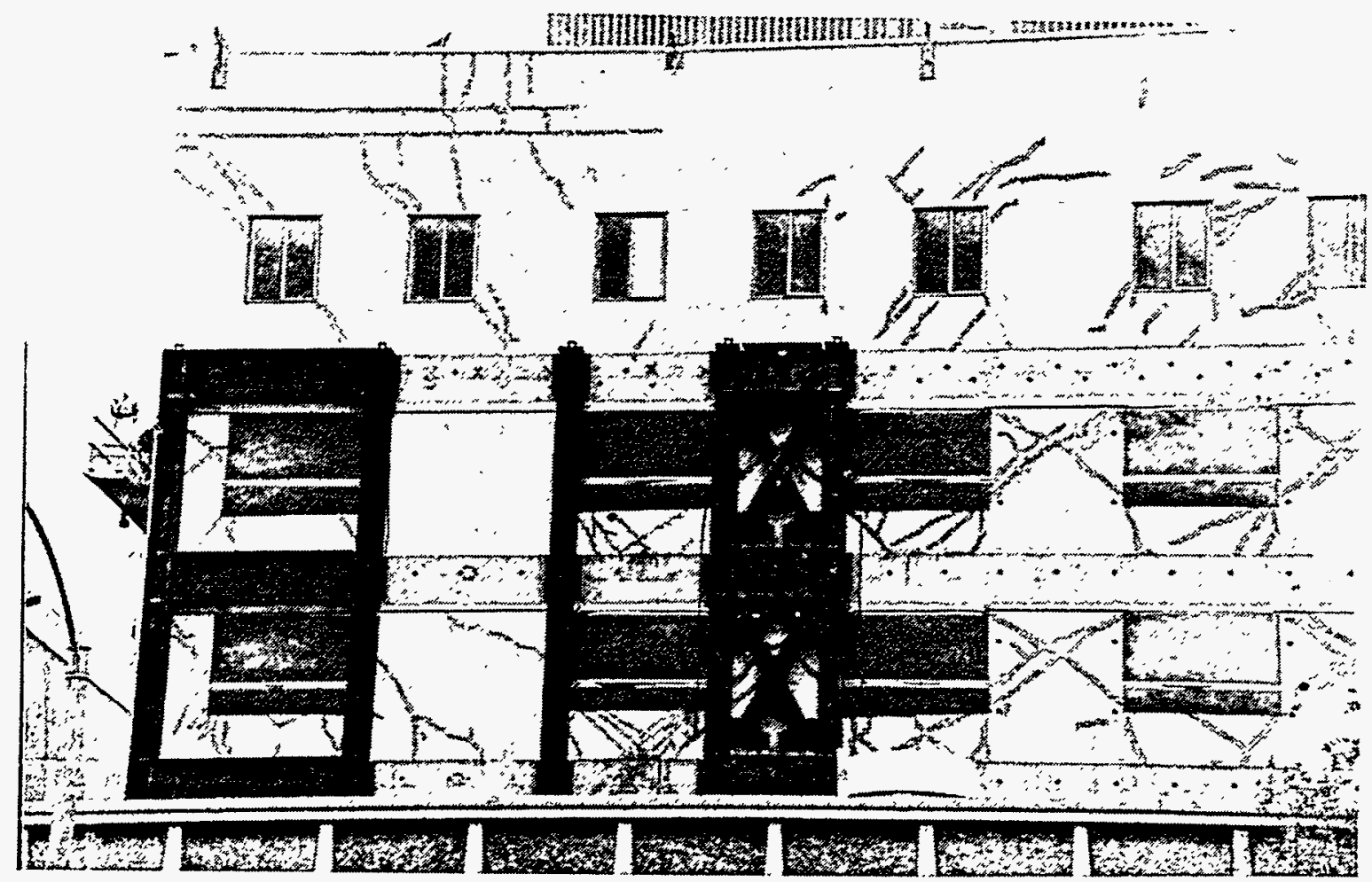

Figure 4.2-6: Close-up of the exterior steel frames and the epoxy injection of cracks in concrete walls during retrofit repairs on the south wing of St. John's Hospital. 


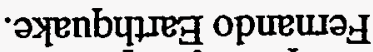

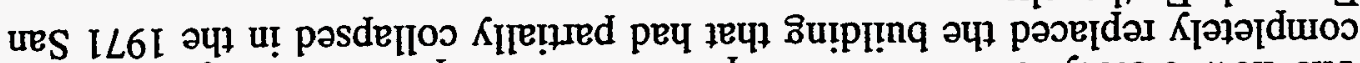

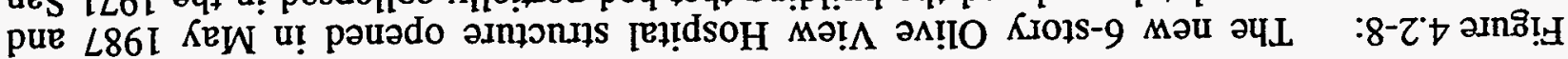

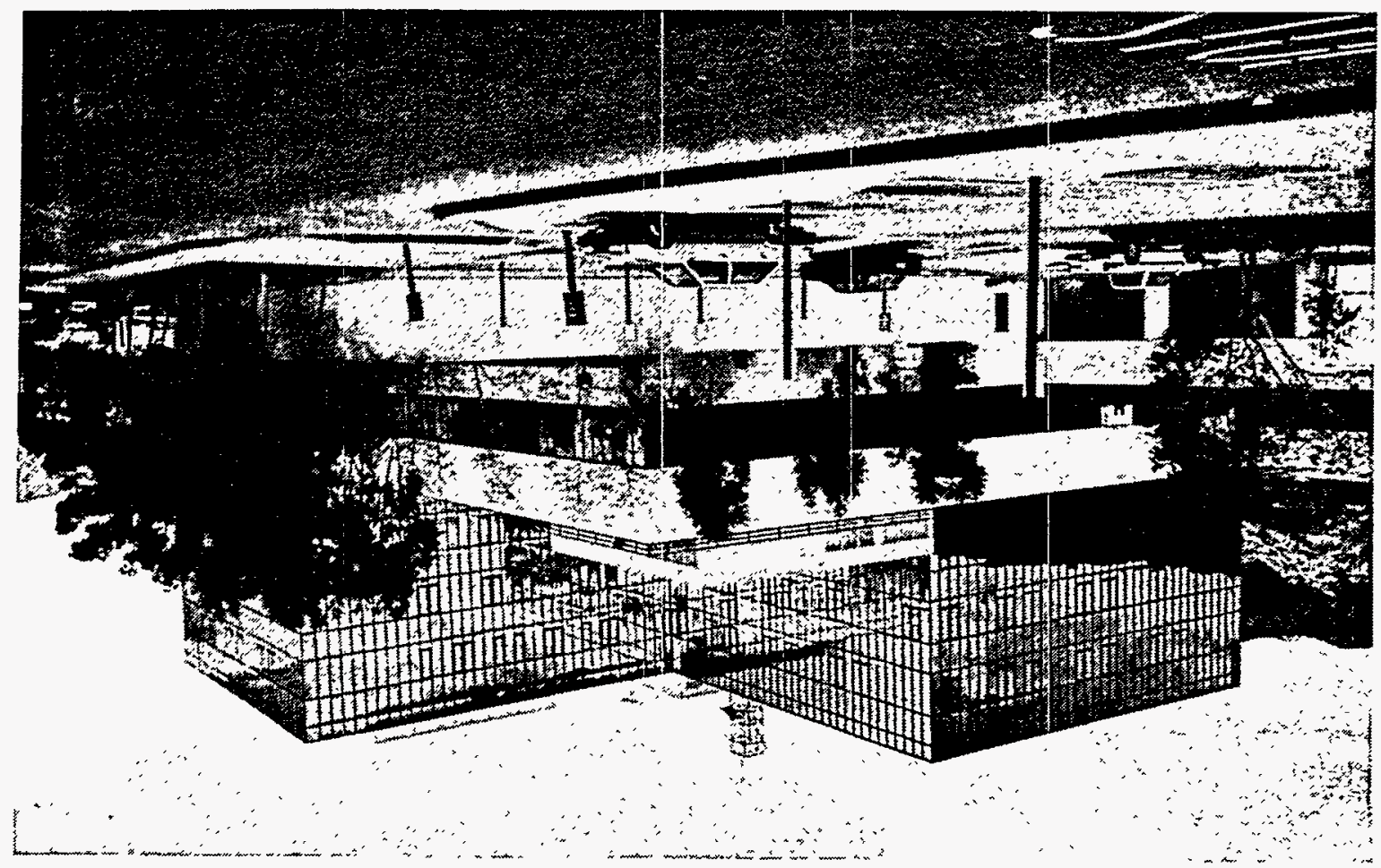

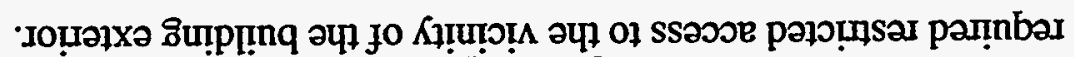

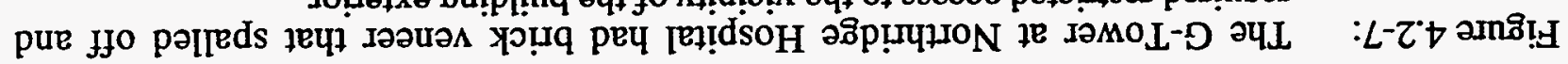

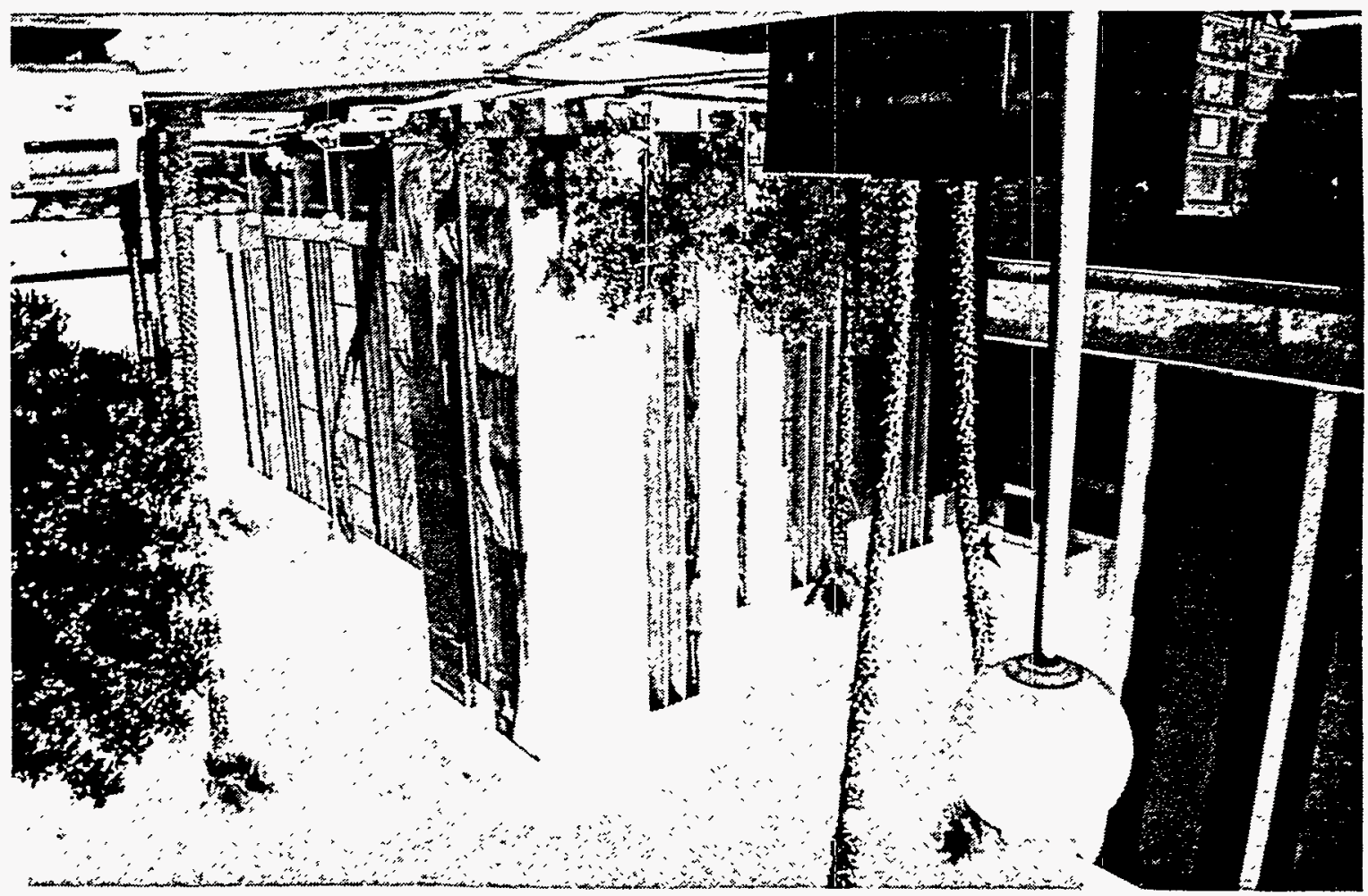




\subsubsection{Olive View Hospital, Sylmar}

The new 6-story Olive View Hospital structure opened in May 1987 (see Figure 4.2-8) and completely replaced the building that had partially collapsed in the 1971 San Fernando earthquake. The new Olive View building experienced about $0.84 \mathrm{~g} \mathrm{~N}-\mathrm{S}, 0.6 \mathrm{~g} \mathrm{E}-\mathrm{W}$, and $0.54 \mathrm{~g}$ vertical during the 1994 Northridge seismic event. The horizontal spectral acceleration at the roof was about $2.3 \mathrm{~g}$. Although the new structure performed well, some of the mechanical systems suffered damage which resulted in evacuation and reduced operation of the hospital for several days.

Fire sprinkler piping broke at threaded elbow joints, especially on the vertical branches that suspend the sprinkler heads (see Figure 4.2-9). In one of the penthouses, a valve body failed near its flange (see Figures 4.2-10 and 4.2-11) due to inertial forces on a 4-inch diameter chilled water line allowing water to leak down to the floors below. Since the highest priority was to safely evacuate the patients, the main water valves were not turned off for quite a while. Also on the roof, air handler units (AHUs) displaced horizontally about 8 to 12 inches due to failure of connections on the seismically-designed vibration isolators. The weak link on the vibration isolators was inadequate length of bolts fastening the AHU skid frame to the vibration isolators. As a result of the excessive differential movement, the attached lines broke. Elsewhere in the hospital, fire sprinkler piping and water lines connected to HVAC coils failed. The resulting water damage rendered the hospital inoperable and the facility was evacuated. Thus, while the hospital building was undamaged, the facility was not available for earthquake emergency response.

The emergency power generator came on right after the main quake but later stopped due to an empty day tank and failure of the controls to effect transfer of more fuel. Fortunately, the Olive View Cogeneration Plant had already restarted after being inspected. The performance of the cogeneration plant is discussed in Section 4.1.4 of this report. Outside of the main building and across the street from the cogeneration power plant, a vertical tank filled with oxygen partially collapsed against a metal fence apparently due to failure of leg welds on the tank.

\subsubsection{Veterans' Administration Hospital \& Medical Center, Sepulveda .}

Many of the buildings at the Veterans' Administration (VA) Medical Center in Sepulveda were constructed around 1952. These structures experienced horizontal acceleration of about $0.94 \mathrm{~g}$ (north-south) and $.74 \mathrm{~g}$ (east-west) and a vertical acceleration of about $.48 \mathrm{~g}$ during the 1994 Northridge Earthquake. The 5 to 6 story VA Hospital (see Figure 4.2-12) was evacuated due to structural damage, overturning of contents, lack of electrical power, and extensive water leaks from the fire protection system which had flooded many of the floors. The southeast and 


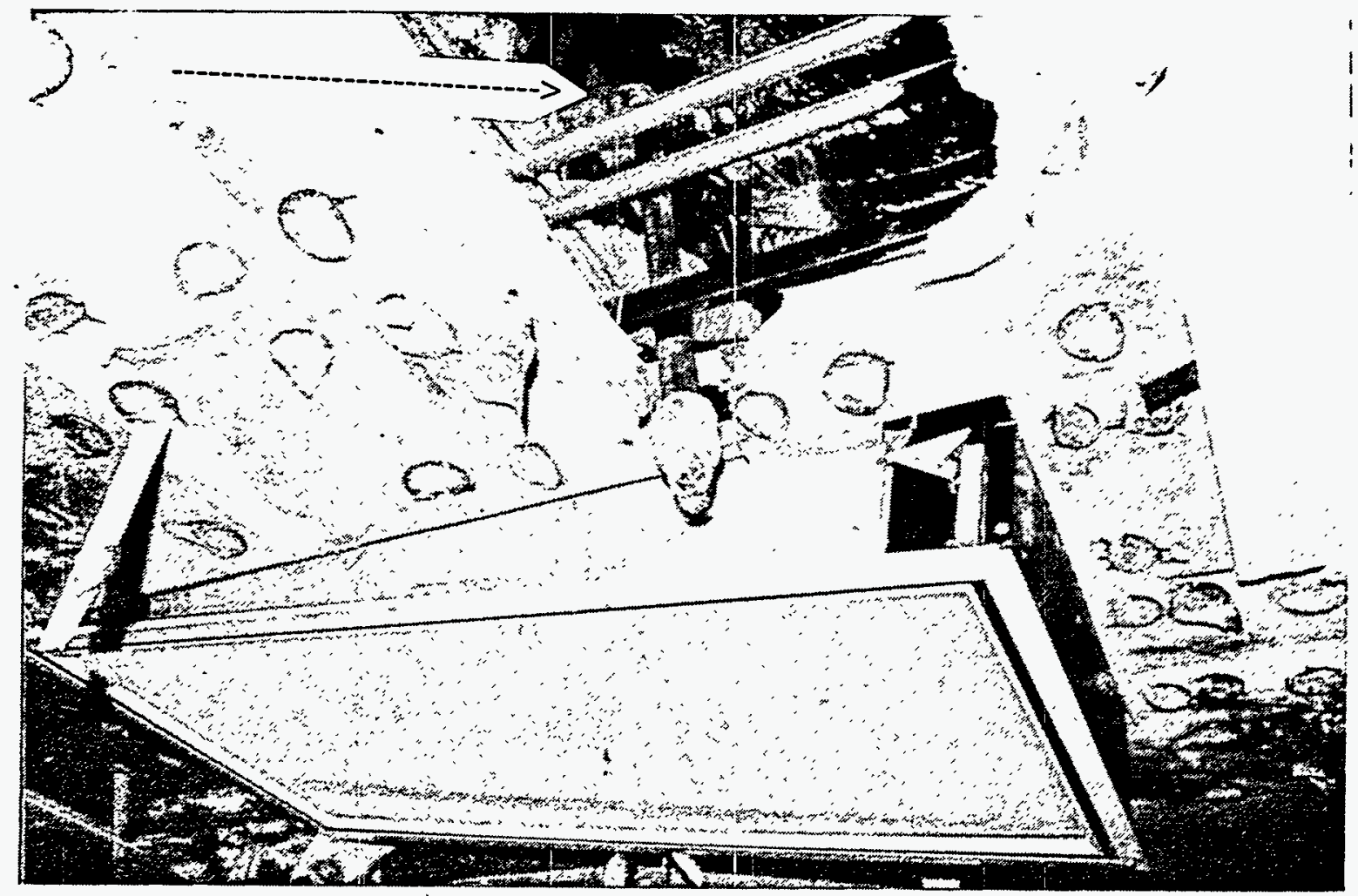

Figure 4.2-9: Fire sprinkler piping broke at threaded elbow joints, especially on the vertical branches that suspend the sprinkler heads [ref 4.2-5].

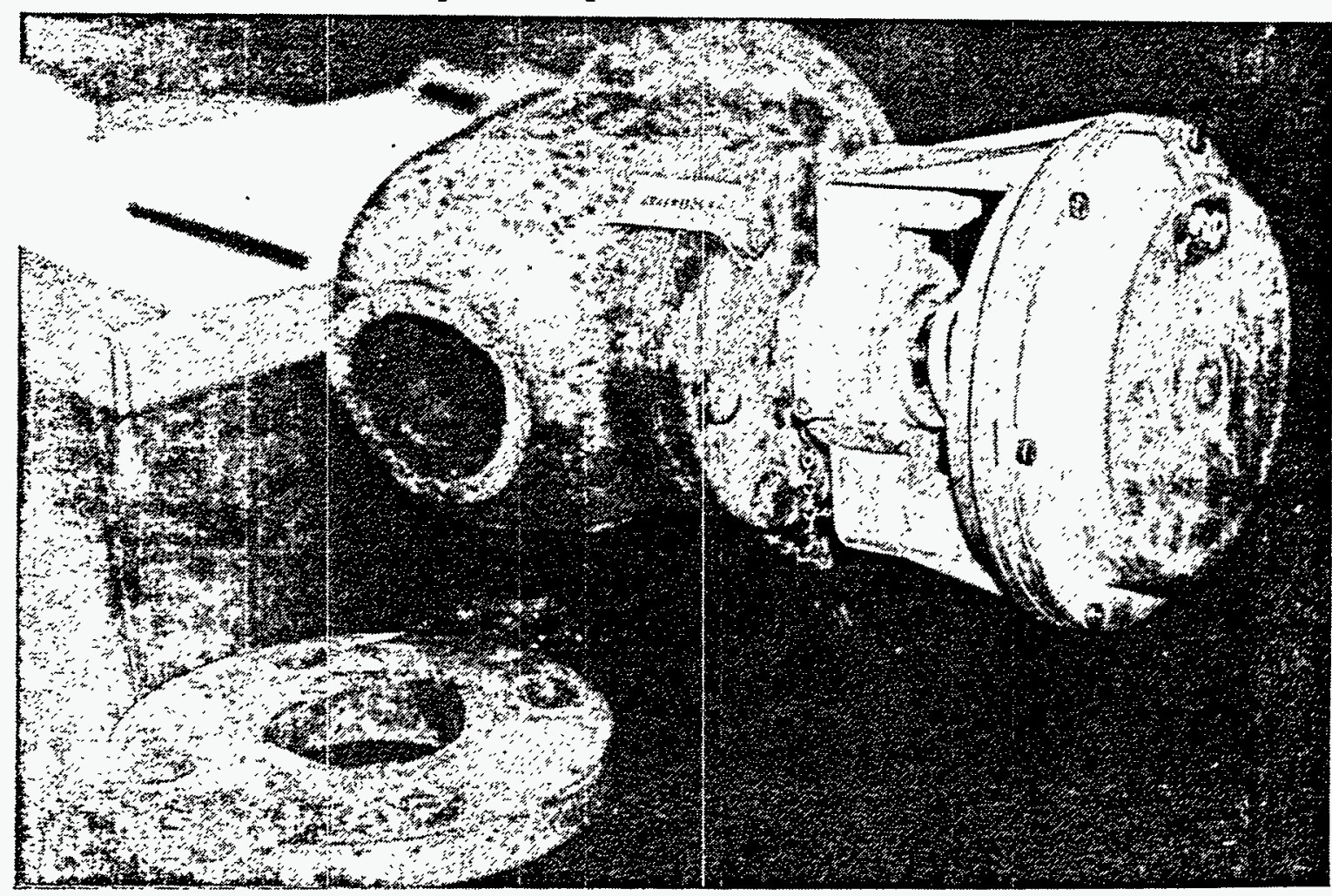

Figure 4.2-10: In one of the penthouses, a valve body failed near its flange due to inertial forces on a 4-inch diameter chilled water line allowing water to leak down to the floors below. 


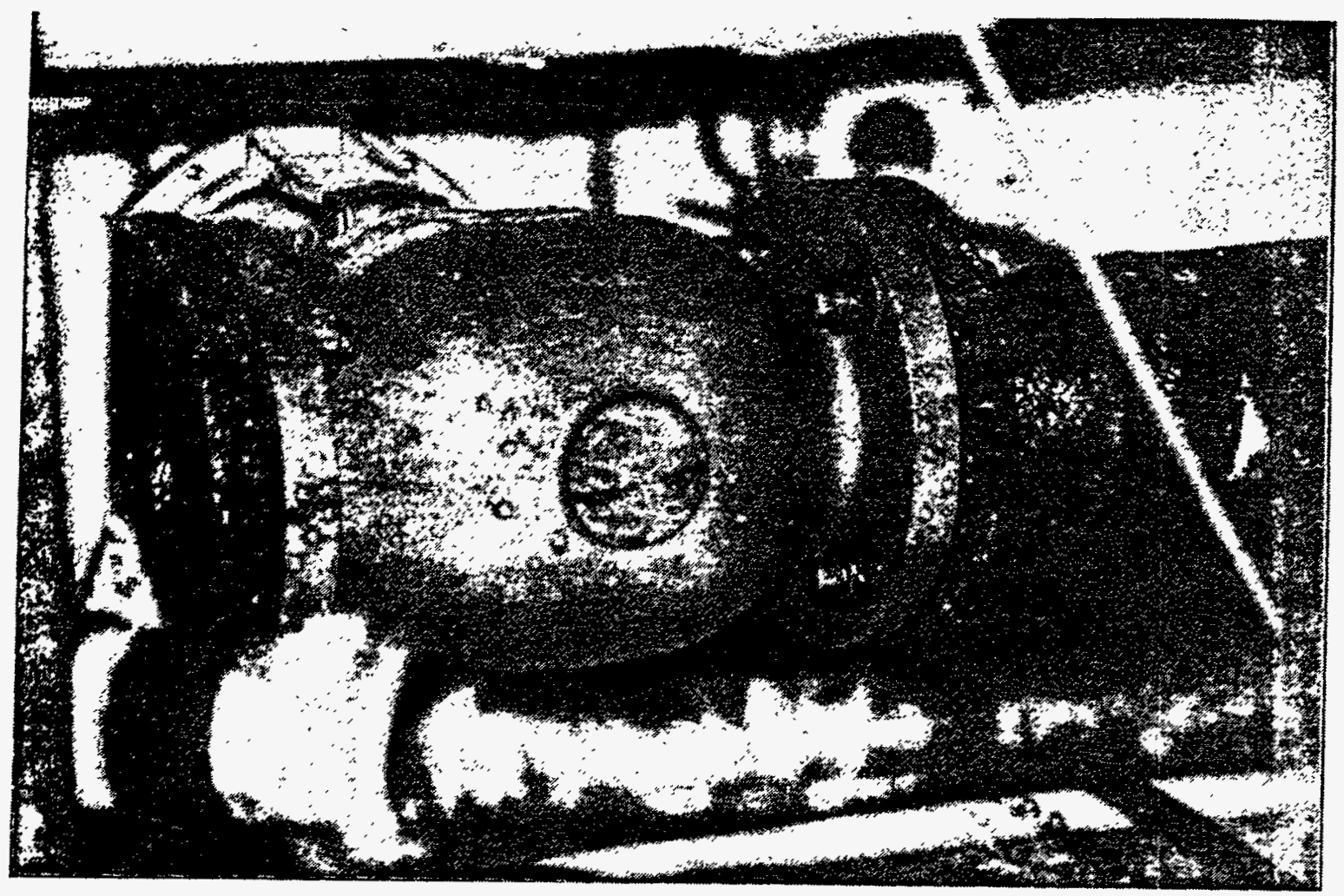

Figure 4.2-11: Close-up view of a replacement for the valve body that failed.

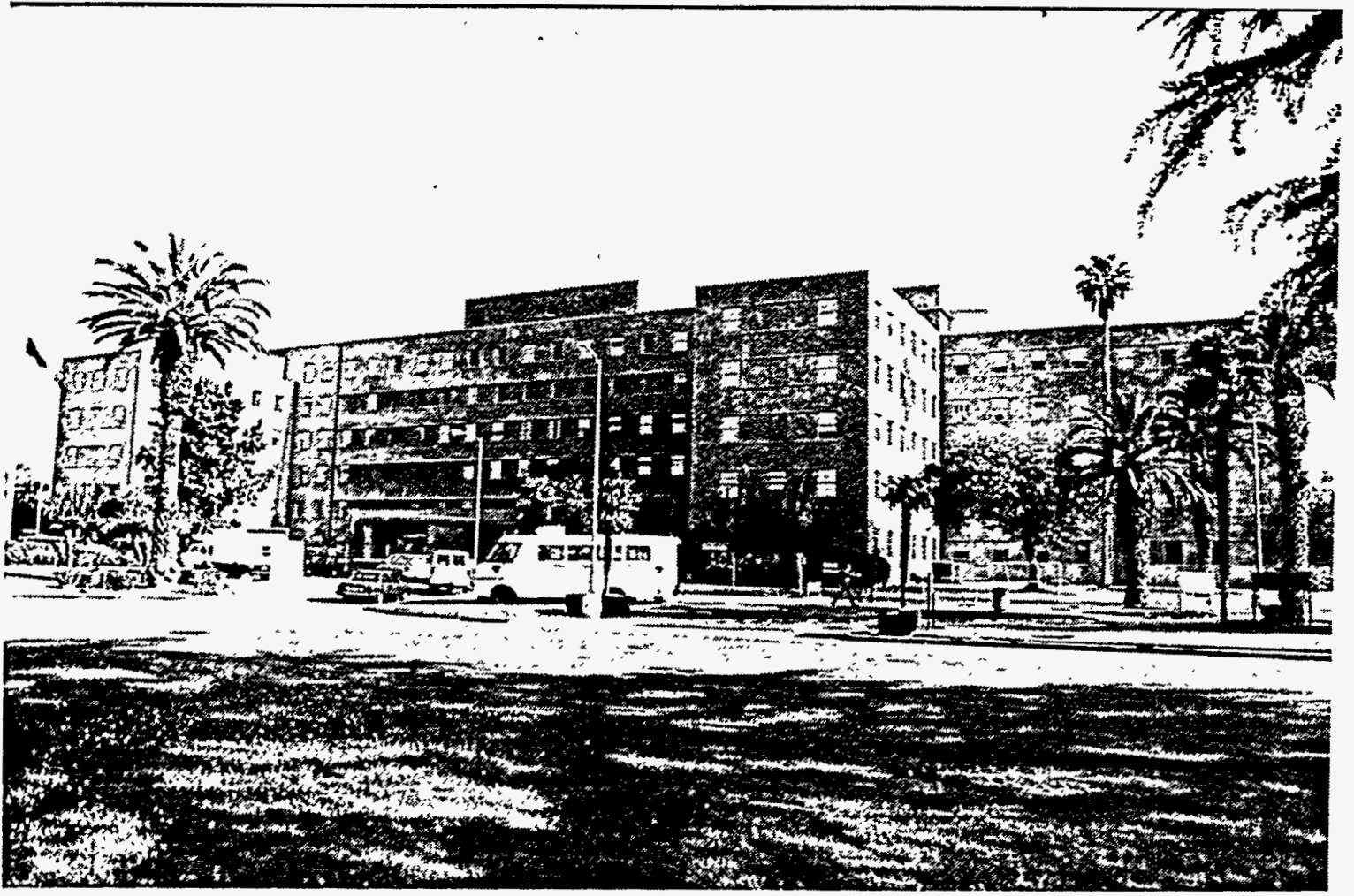

Figure 4.2-12: The 5 to 6 story VA Hospital (Building 3) was evacuated due to structural damage, overturning of contents, lack of electrical power, and extensive water leaks from the fire protection system and chilled water lines which had flooded many of the floors. 
southwest wings moved out of phase with the central core of the hospital (Building 3 ) and resulted in pounding at the roof and penthouse level (see Figure 4.2-13). As a result, a fan came off of its support inside the penthouse (see Figure 4.2-14) and the north wing experienced diagonal cracking on the short piers between the windows at the 4th and 5th floors (see Figure 4.2-15).

The emergency power generator for the critical circuits at the VA Medical Center started successfully and ran for about 45 minutes after the main seismic event. The main electrical transfer switch (from normal offsite power to onsite emergency power) failed to function properly immediately after the earthquake. Even though emergency power was being generated, there was no way to distribute it throughout the site.

At Building 40 which housed the main boilers and chillers, the main 14-inch diameter supply line to the main chillers sheared off about 3 inches below the flange where the vertical run of pipe went into the ground (see Figure 4.2-16). Also at Building 40, the natural gas line for the main boilers had an in-line seismic shut-off valve that continued to trip during the strong aftershocks. As a result, the operators bypassed the seismic shut-off valve to preclude frequent shutdown of the boilers (see Figure 4.2-17).

\subsubsection{Holy Cross Medical Center, Mission Hills}

Holy Cross Medical Center is about 6 miles northeast of the epicenter. This facility was closed primarily due to HVAC systems that became inoperable as a result of the earthquake. At the penthouse level, suspended fans swung and impacted the exterior louver panels (see Figures 4.218 and 4.2-19). There was also extensive water damage from leaks in fire sprinklers and other HVAC piping [ref 4.2-5]. This site experienced about $0.5 \mathrm{~g}$ horizontal ground acceleration.

\subsubsection{Indian Hills Hospital, Mission Hills}

The Indian Hills Hospital in Mission Hills suffered structural damage in the shear walls with concrete crushing and apparent lap splice failure at the construction joint at the fourth floor level [ref 4.2-6]. There also was water damage in the facility due to piping connections. This hospital is about 1 block east of Holy Cross Medical Center. Ceiling tiles and air diffusers fell from the ceilings. 


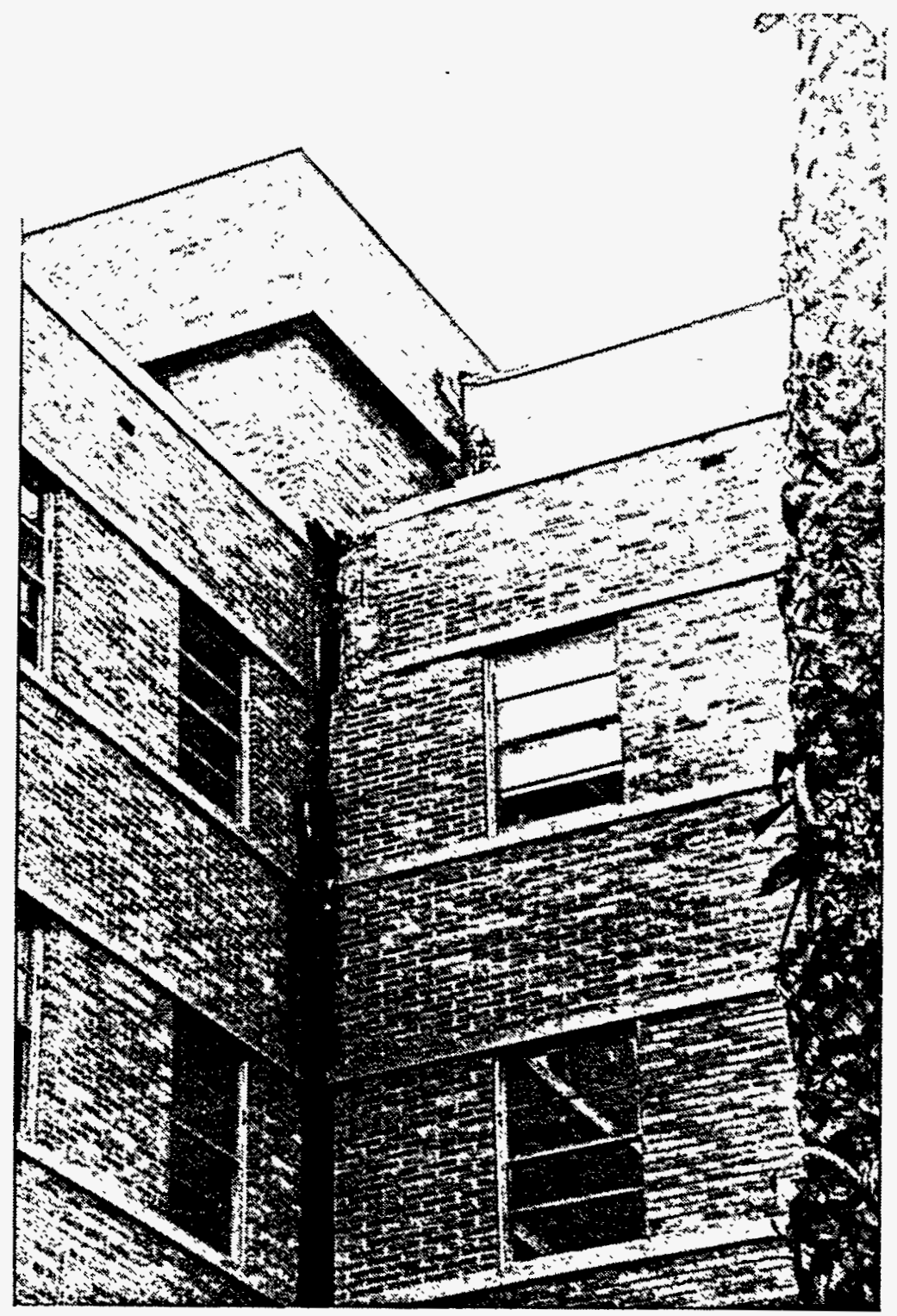

Figure 4.2-13: The southeast and southwest wings moved out of phase with the central core of the hospital (Building 3) and resulted in pounding at the roof and penthouse level. 


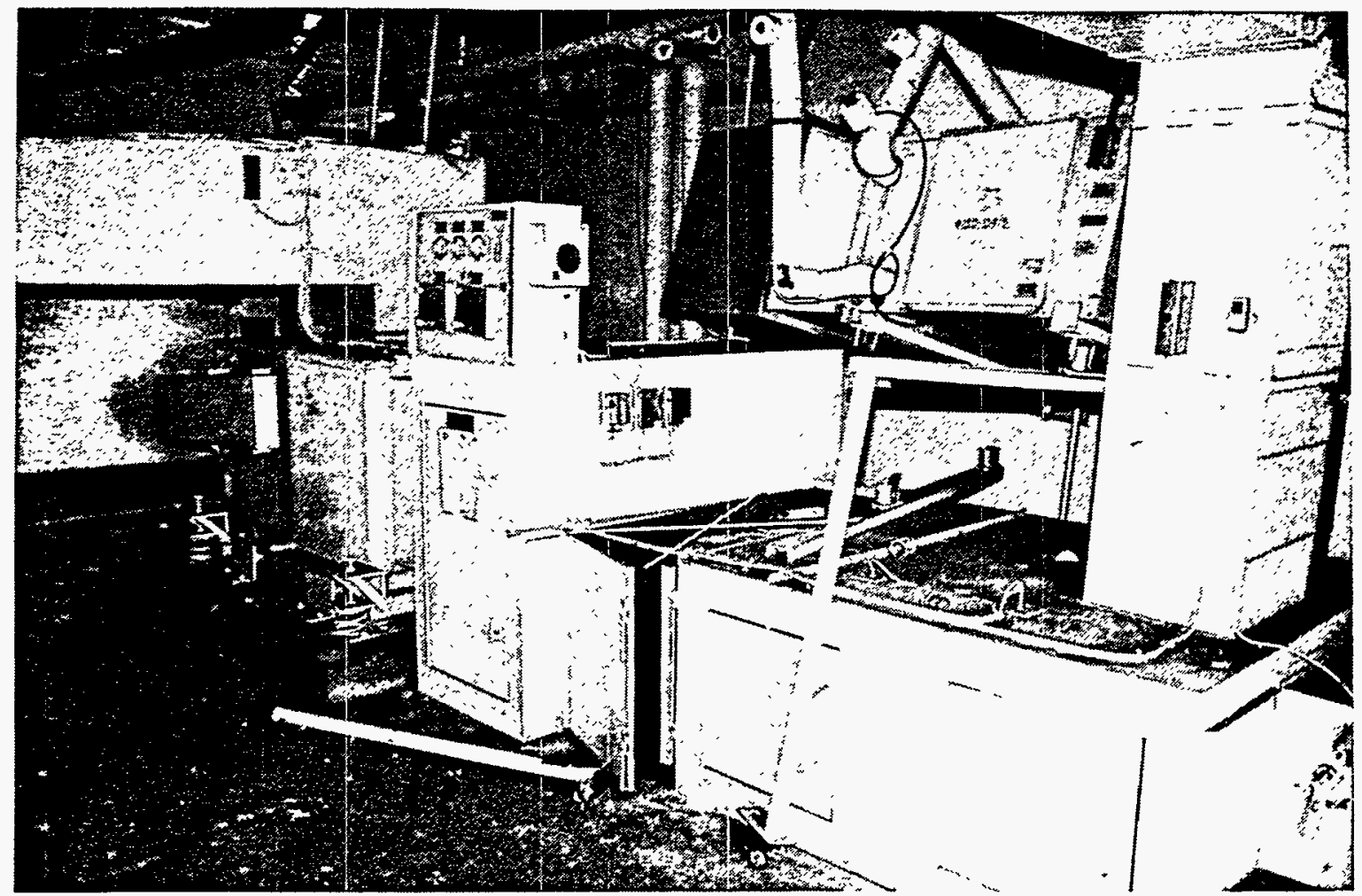

Figure 4.2-14: As a result of the pounding between the wings of the building, a fan came off of its support inside the penthouse.

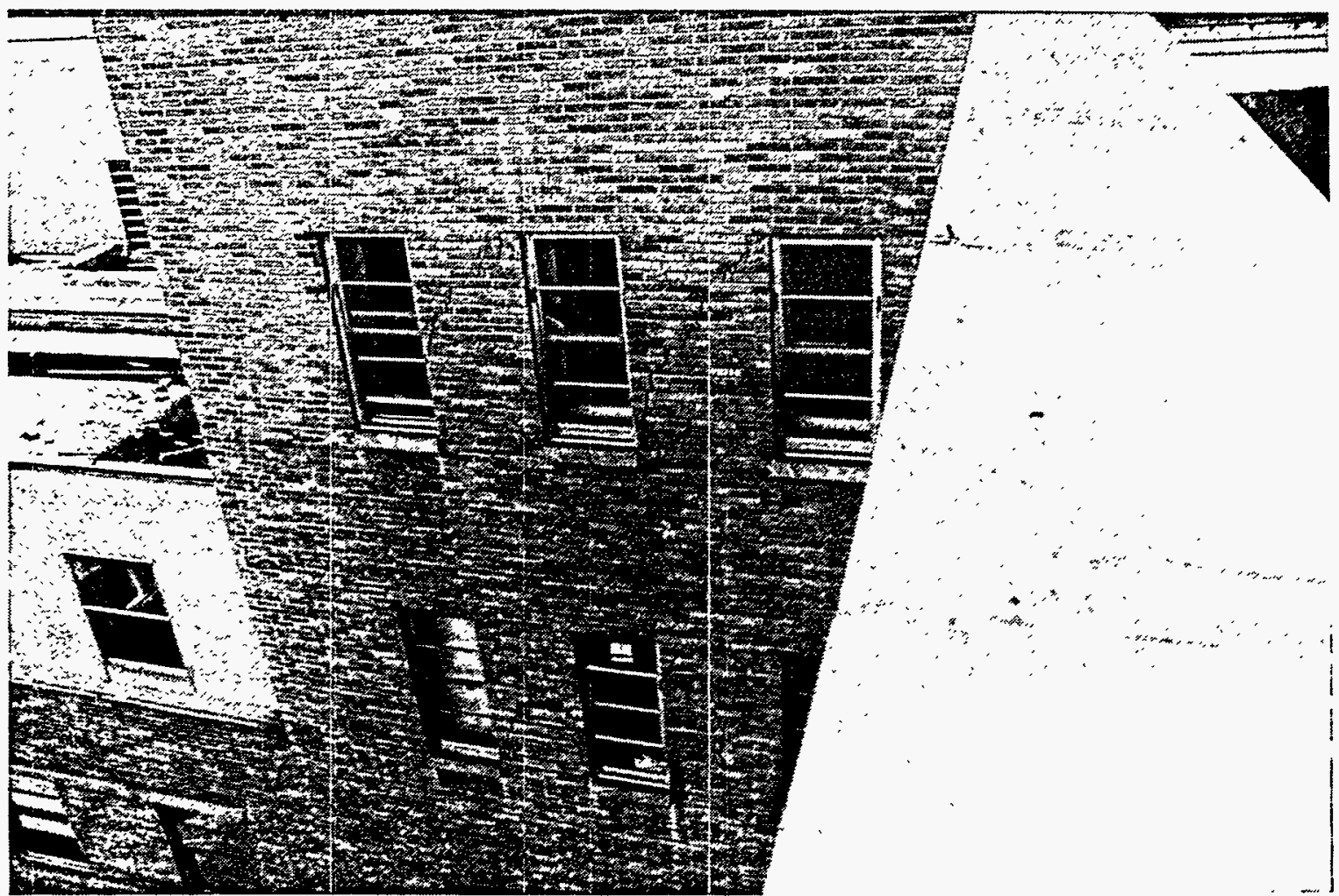

Figure 4.2-15: The north wing of Building 3 experienced diagonal cracking on the short piers between the windows at the 4 th and 5 th floors. 


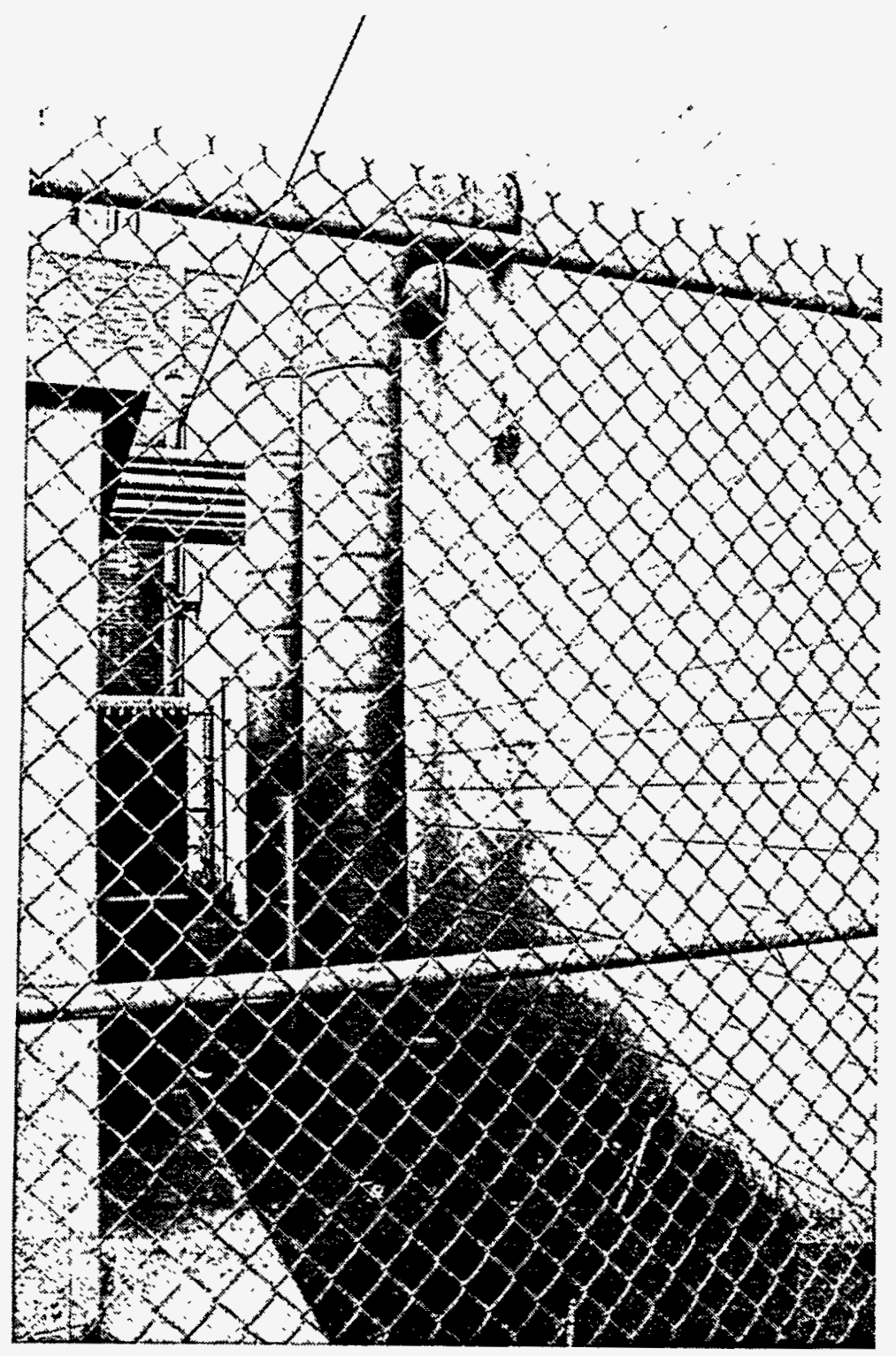

Figure 4.2-16: At Building 40 (of the VA Medical Center in Sepulveda) which housed the main boilers and chillers, the main 14-inch diameter supply line to the main chillers sheared off about 3 inches below the flange where the vertical run of pipe went into the ground. This photo was taken after repairs were made to the pipe. 


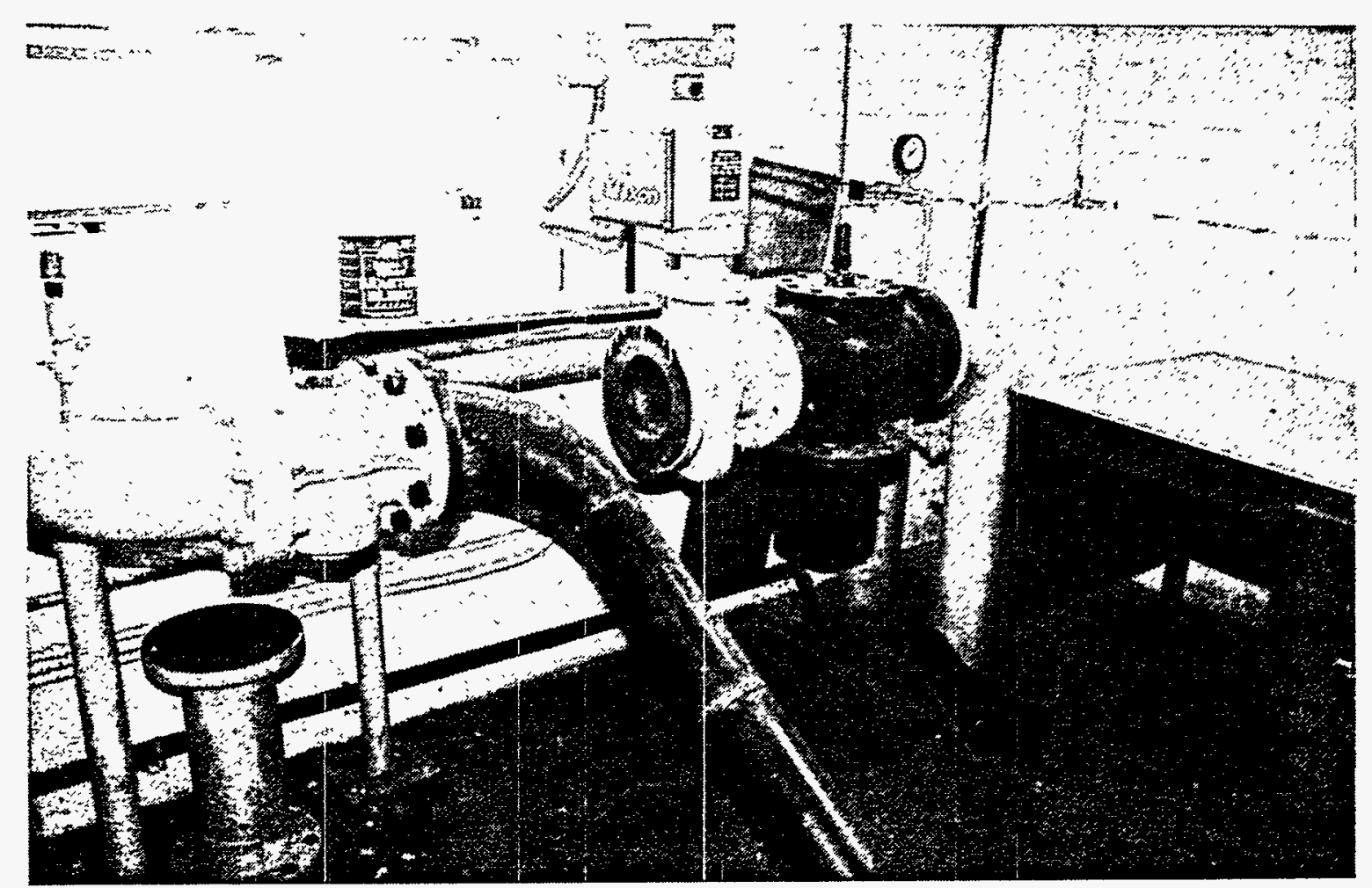

Figure 4.2-17: Also at Building 40 (of the VA Medical Center in Sepulveda), the natural gas line for the main boilers had an in-line seismic shut-off valve that continued to trip during the strong aftershocks. As a result, the operators bypassed the seismic shut-off valve to preclude frequent shutdown of the boilers. 


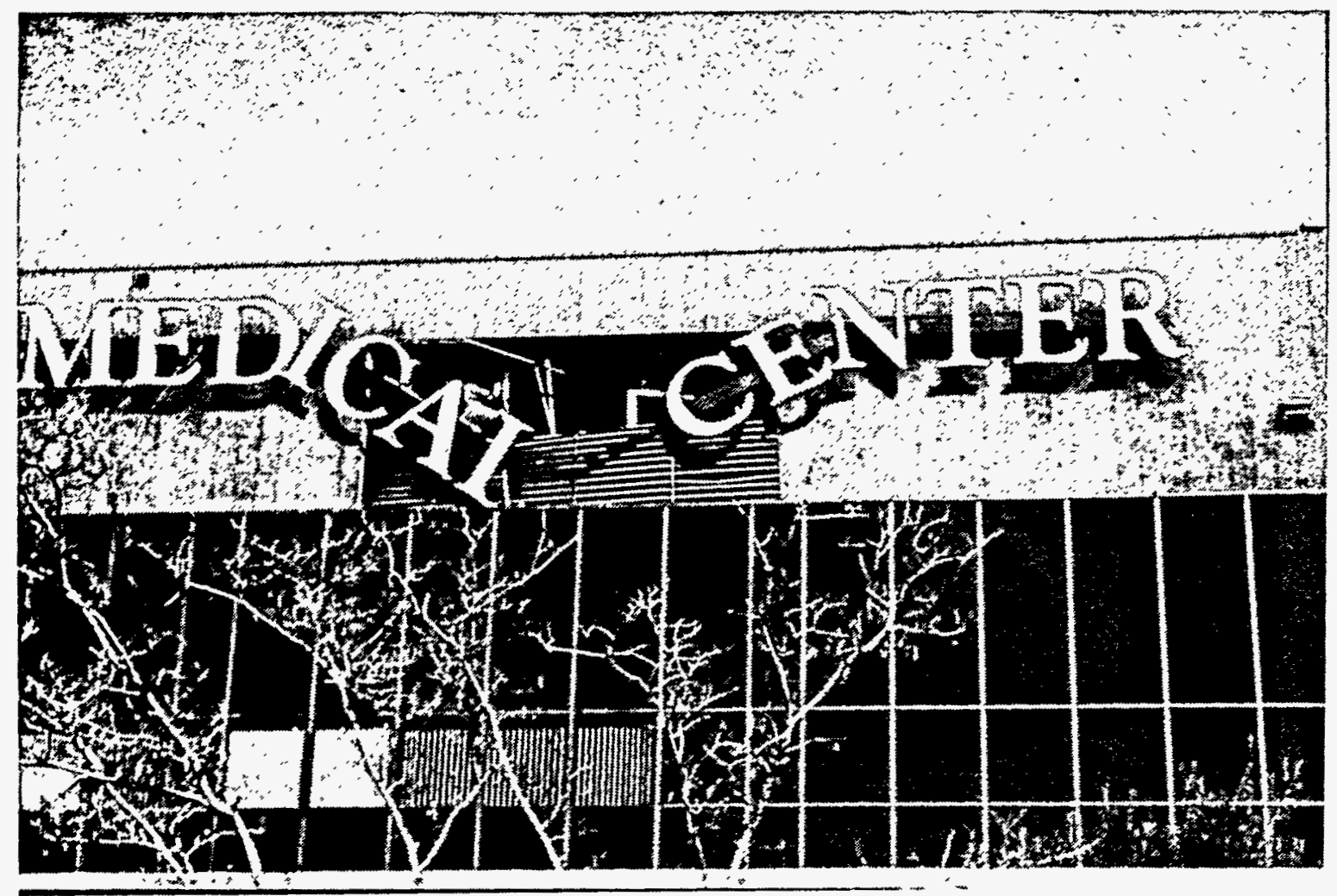

Figure 4.2-18: At the Holy Cross Medical Center in Mission Hills, suspended fans at the penthouse level swung and impacted the exterior louver panels [ref 4.2-5].

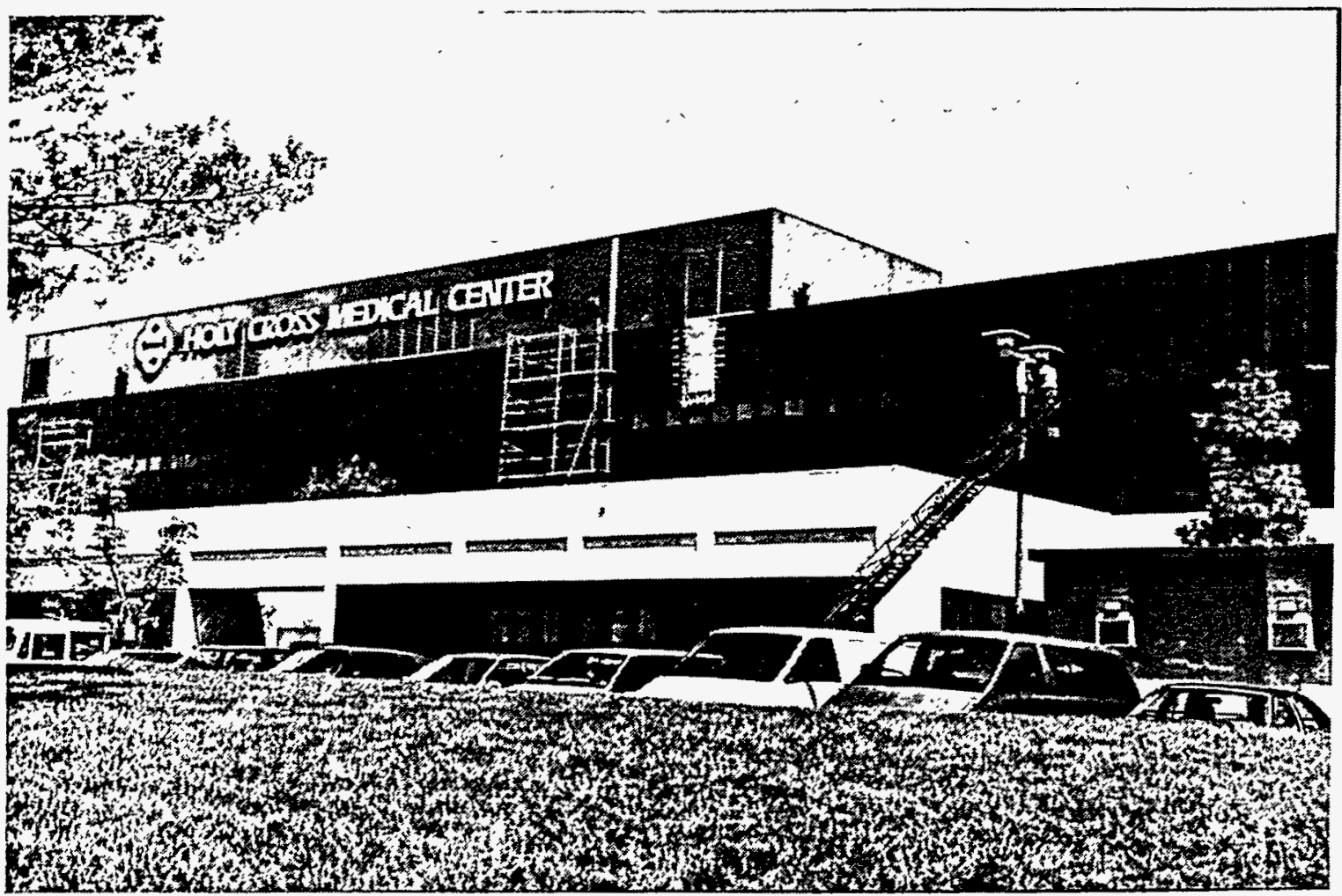

Figure 4.2-19: View of Holy Cross Medical Center in Mission Hills, showing the penthouse exterior louver panels during repair. 


\subsubsection{Granada Hills Community Hospital, Granada Hills}

This facility is located next to the collapsed Kaiser Permanente Medical Office Building and is about 3 miles from the epicenter. The estimated ground motion near the hospital was about $0.4 \mathrm{~g}$. The adjacent parking garage also suffered a partial collapse. Water damage occurred due to breakage of a pipe which had been attached to a domestic water supply tank that displaced on the roof. Many patients were treated in the parking lot since the water damage hampered important hospital functions [ref 4.2.5].

\subsection{MISCELLANEOUS INDUSTRIAL FACILITIES}

Earthquake impact on industrial facilities in the affected areas ranged from relatively good performances with business interrupted for less than one week to substantial interruption of more than ten weeks. Engineered electrical, mechanical and instrumentation equipment and systems generally withstood the earthquake without significant damage and were available for service following facility cleanup and building evaluation. However, substantial facility and inventory damage due to failure of fire protection systems and subsequent water damage was observed. Inventory damage due to warehouse rack failures was also observed. Facilities that require strict environmental control (such as clean rooms) could not resume operations until support systems such as heating, ventilating and air conditioning (HVAC) were restored. Additionally, several industrial facilities sustained misalignment of specialty equipment and lines, requiring considerable readjustment effort.

The failure of fire protection piping systems was a primary cause of damage to facilities, inventory and equipment as well as suspended business operations. Water damage and falling piping can close down a facility for days or weeks.

Warehouse storage racks were often challenged beyond capacity during the earthquake. Figure 4.3-1 show the storage section of a light manufacturing facility located in Santa Monica, water damage and rack failures destroyed the inventory.

Racks located in warehouse style retail centers sustained similar failures. Figure 4.3-2 shows bins filled with damaged racks observed adjacent to a warehouse style home improvement center located within $5 \mathrm{~km}$ of the epicenter. The photo was taken after the center was cleaned up, new racks installed, restocked and opened to provide supplies for earthquake repairs. Some of the aisles were filled with heavy merchandise that toppled from racks on the morning of the earthquake. Serious injuries may have occurred had the earthquake struck during shopping hours. 


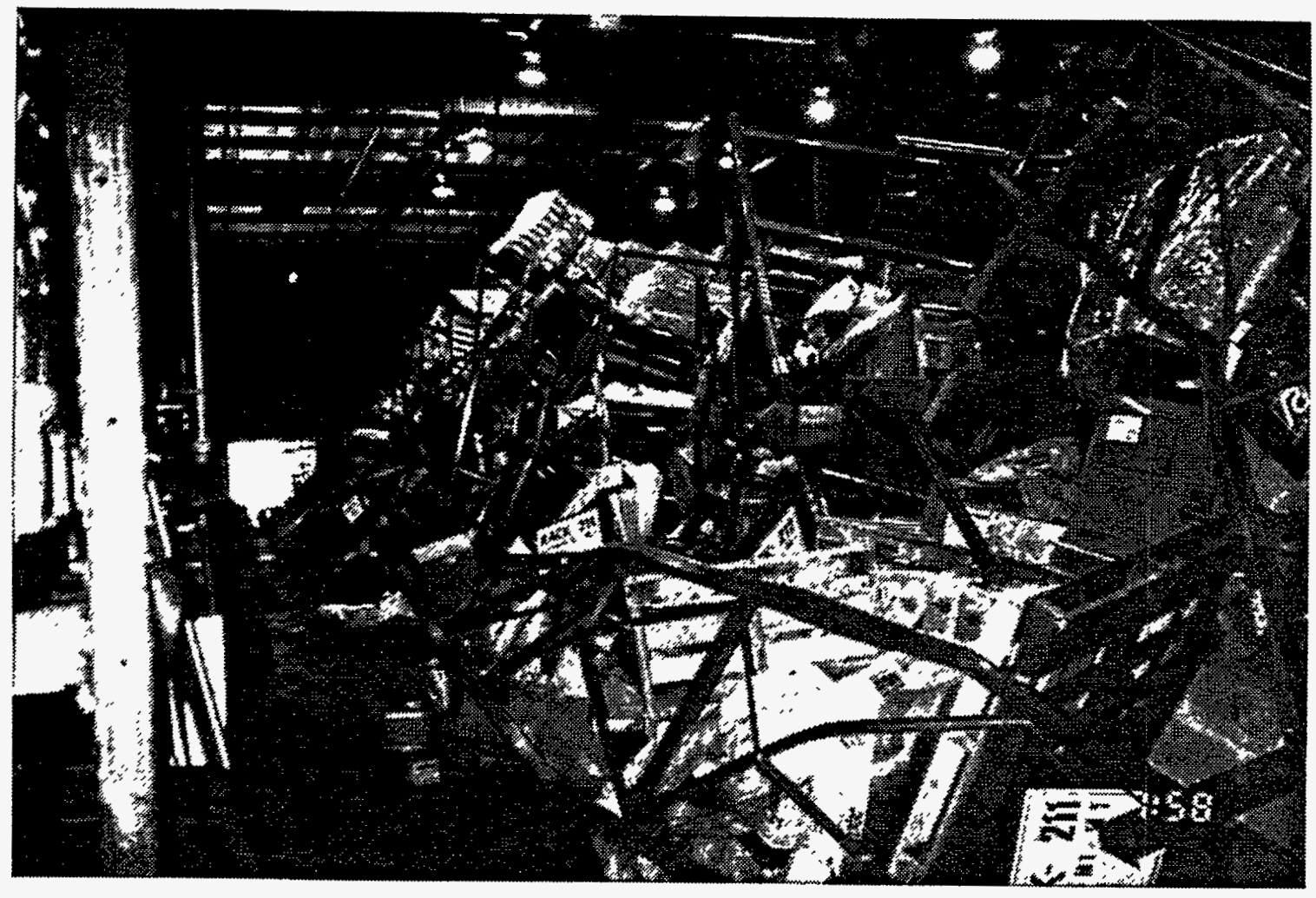

Figure 4.3-1: Heavy damage to storage racks in this warehouse nearly caused the entire building to collapse. These racks were loaded to $60 \%$ of their design load.

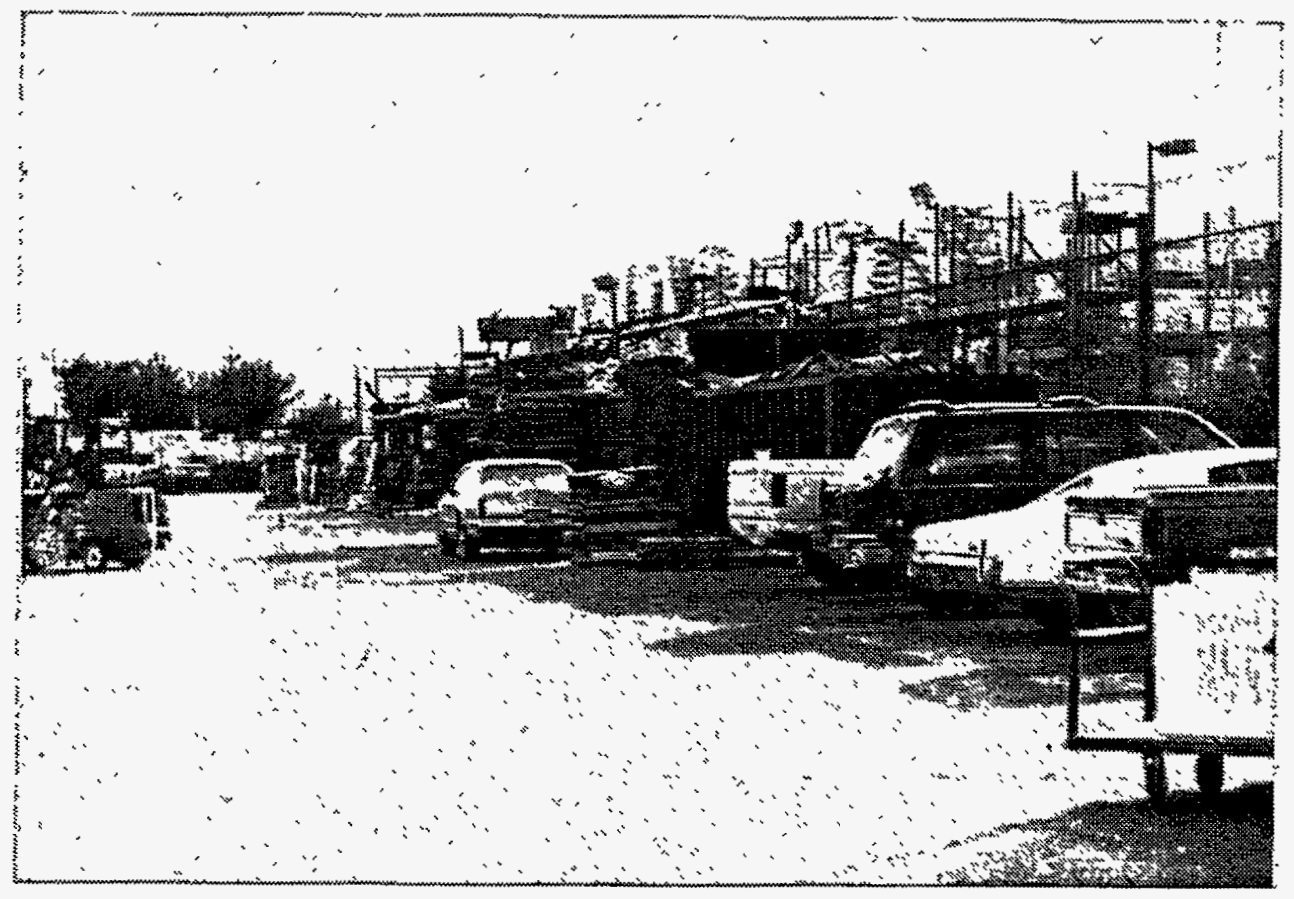

Figure 4.3-2: $\quad$ Storage bins filled with damaged racks from a warehouse style home improvement center located within $5 \mathrm{~km}$ of the epicenter. 
One of the most significant causes of damage during the earthquake was the widespread ejection of stored components from anchored or restrained storage shelving. In one manufacturing plant, specialized carbide tooling stored on wall anchored shelving was thrown onto the floor resulting in chips in the brittle tooling material and scratches in the polished tooling surfaces (machined with tolerance less than $0.001 \mathrm{in}$ ) rendering them useless. This damaged, alone, represented a monetary loss of $\$ 750,000$.

Misalignment of specialty manufacturing, production and assembly lines was reported at several facilities. The equipment is typically a series of modular units that are shipped separately then installed and aligned at the facility. Alignment tolerances are often very small and even slight distortions can cause the system to malfunction.

High technology facilities associated with computer, medical, and defense industries require stringent environmental control to operate their facilities. HVAC system failures prevented several high technology facilities from resuming operations. Equipment supported on vibration isolation systems and low capacity anchorage details was the primary cause of failures. Interaction with fire protection systems where piping impacted and damaged HVAC ducting and control instruments was also observed.

Several flat-bottom storage tanks sustained "elephant's foot" buckling. At one facility, a 250,000 gal unanchored firewater tank experienced an "elephant's foot" buckle around the entire base circumference. The tank discharge pipe was damaged, apparently by tank uplift, and the tank lost its contents. It should be noted that another slightly smaller unanchored fire tank at an adjacent (within $0.5 \mathrm{~km}$ ) facility also sustained a circumferential elephant's foot bulge. Numerous PVC piping breaks were observed in the chemical tanks at another facility. A 8,000 anchored steel tank emptied waste oil when its anchors pulled and severed a PVC discharge line pipe. Adjacent 8,000 gal tanks exhibited similar pulled anchors. Anchored fiberglass caustic soda tanks appeared intact but PVC piping broke at unanchored pumps.

\subsubsection{Data Processing Center}

A large financial data processing center housed on a campus of modern tilt-up buildings sustained damage to connection details in several tilt-up buildings (Figure 4.3.1-1) and extensive damage to nonstructural elements. Items that were not restrained such as files, personnel computers and work stations fell to the floor. 


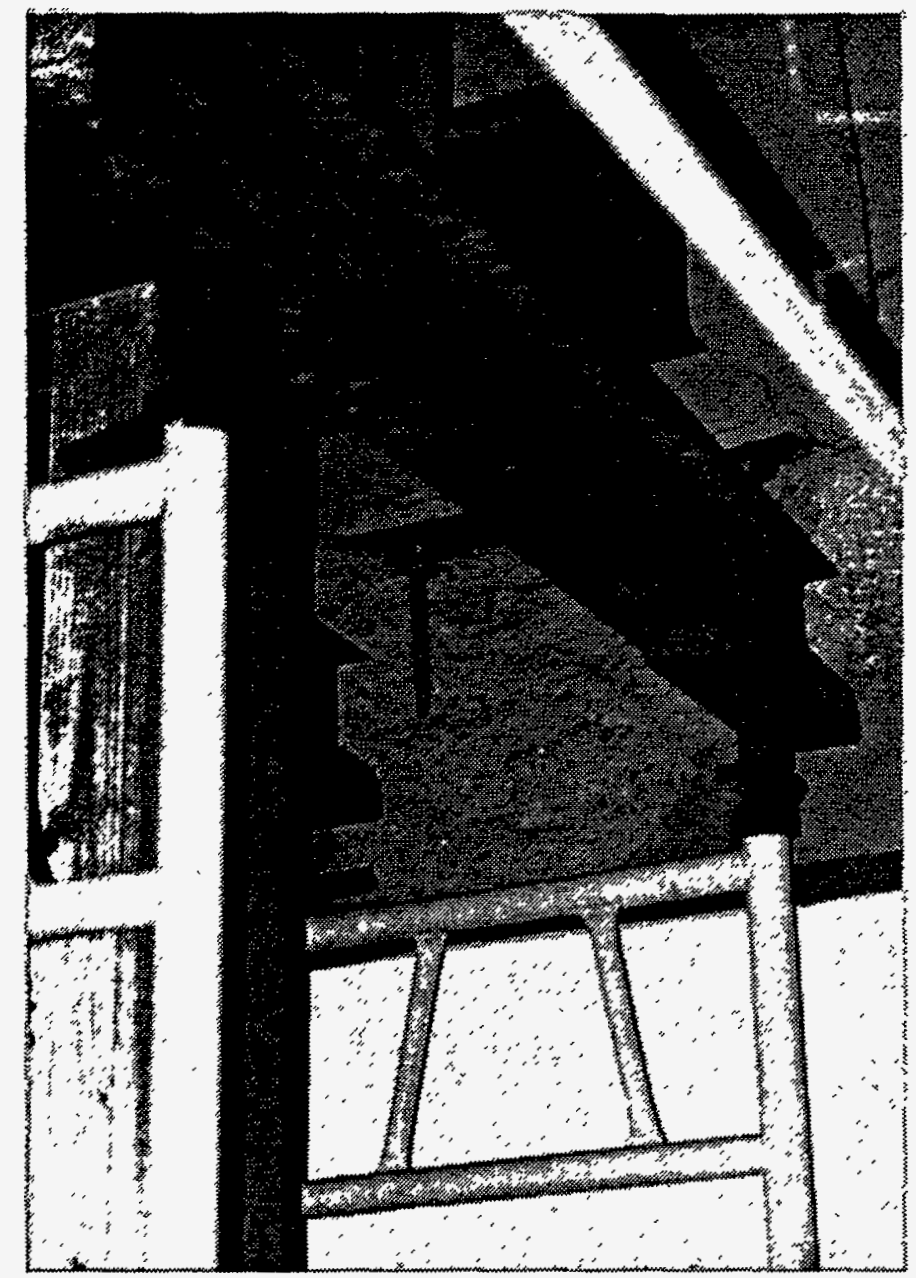

Figure 4.3.1-1: Connections in several tilt-up buildings sustained damage, exposing rein-forcing steel and anchor bolts. Temporary supports were installed and operations moved to an altemate location.

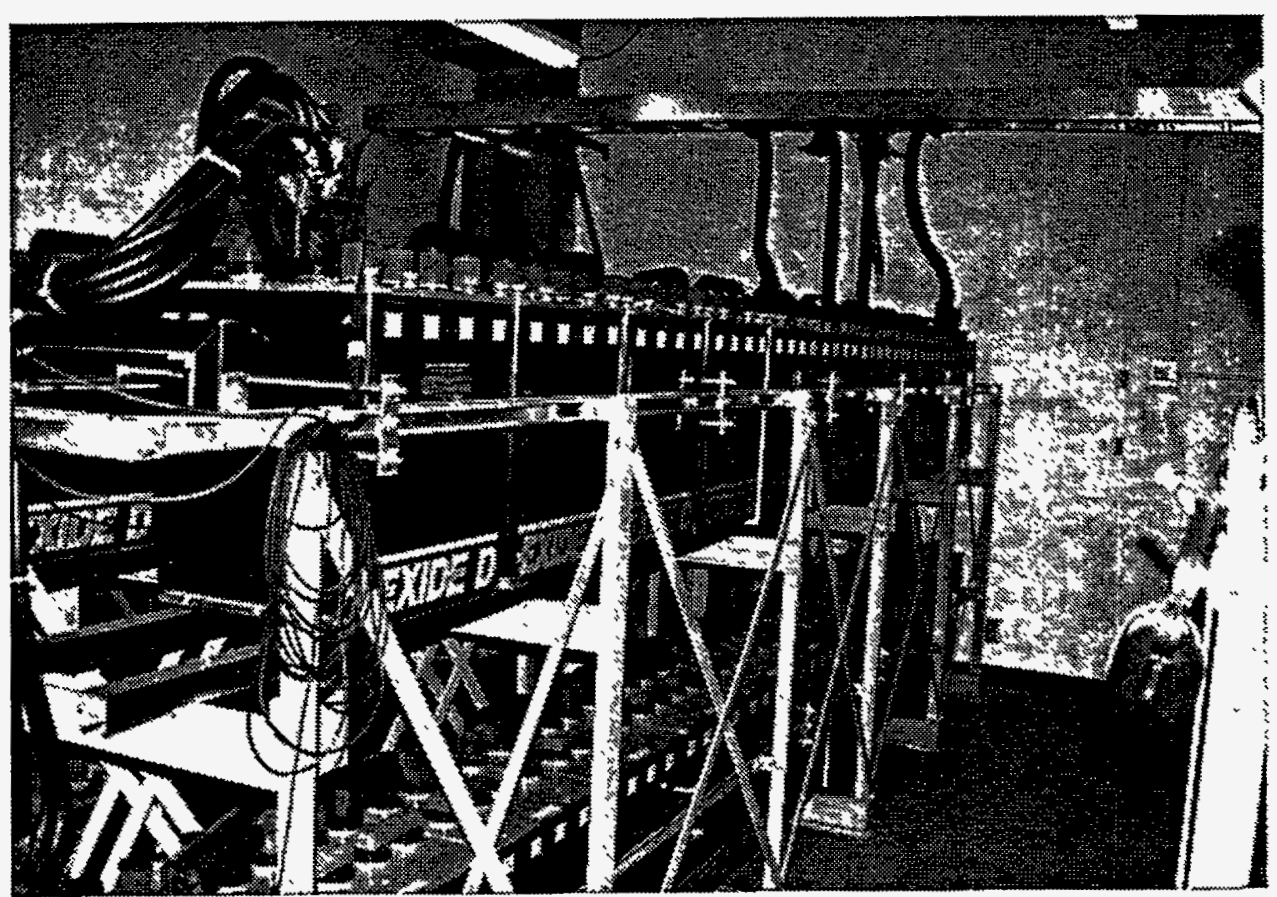

Figure 4.3.1-2: Engineered equipment such as these braced battery racks survived the earthquake. Minor pulling of battery rack anchor bolts was observed. 
The uninterruptible power supplies (UPS) and associated equipment such as batteries (Figure 4.3.1-2), diesel generators and electrical gear performed almost without incident. HVAC systems sustained damage to roof-mounted equipment that was supported on vibration isolation mounts and to duct mounted units that were more flexible that their attached water lines. Figure 4.3.1-3 shows an HVAC unit that fell from its vibration mounts. Figure 4.3.1-4 shows a duct mounted cooling coil that displaced, pulling apart a copper cooling line from the coil. This was an additional source of water damage in many facilities.

The positive performance of key data processing and support equipment, an emergency operations center with written emergency plan, and the extraordinary efforts of employees and contractors led to restoration of key services within about 2 hours.

\subsubsection{Anheuser-Busch Los Angeles, California Plant}

One of the larger industrial facilities in the San Fernando Valley is the Anheuser-Busch Los Angeles, California Plant, located within $5 \mathrm{~km}$ of the epicenter. The plant buildings, equipment and systems were extensively strengthened before the Northridge Earthquake. The facility, although surrounded on all sides by damaged structures, withstood the earthquake with relatively minor damage and was back in production within a few days. The site contains several large industrial buildings of vintages going back to the mid 1950s. The structures include large steelframe buildings and a variety of reinforced concrete buildings, most of which predate the 1971 earthquake.

Production facilities contain a diversity of mechanical, electrical, instrumentation and process equipment that withstood the event with only minor damage. Figure 4.3.2-1 shows the central facilities building. The building was retrofitted prior to the earthquake by adding a steel buttress to the exterior due to space limitations and to minimize the impact on plant operations. The most serious central facilities damage was a small pipe break on a tank drain line. The horizontal tank displaced a few inches, causing the rigid drain pipe to fail at the threaded penetration.

Several very large warehouse-type structures contain packaging materials and equipment as well as large inventories of finished product for shipping and distribution. Failure of over 2,000 linear feet of 8 inch diameter fire protection piping (Figure 4:3.2-2) affected a large portion of the warehouse. Supports failed and sections of pipe fell on pallets of finished product, resulting in the loss of inventory. Smaller diameter fire protection distribution lines also failed at several locations. Other significant earthquake effects observed in the warehouse structures were displacement of packaging equipment, a short circuit in a $13.8 \mathrm{kV}$ transformer and minor architectural damage. 


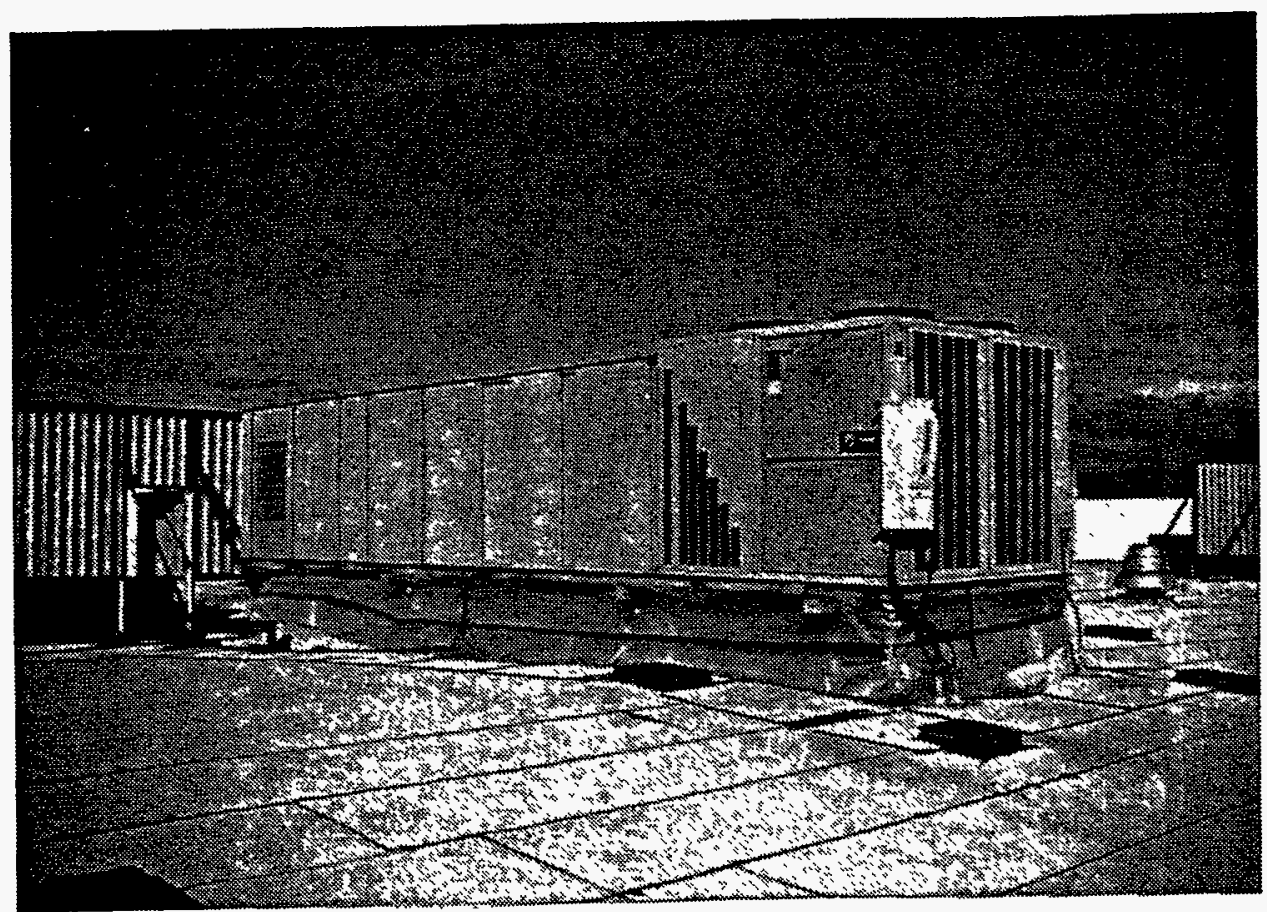

Figure 4.3.1-3: This HVAC unit fell off of its vibration isolation supports. The unit was operational after replacing the isolators with wood cribbing.

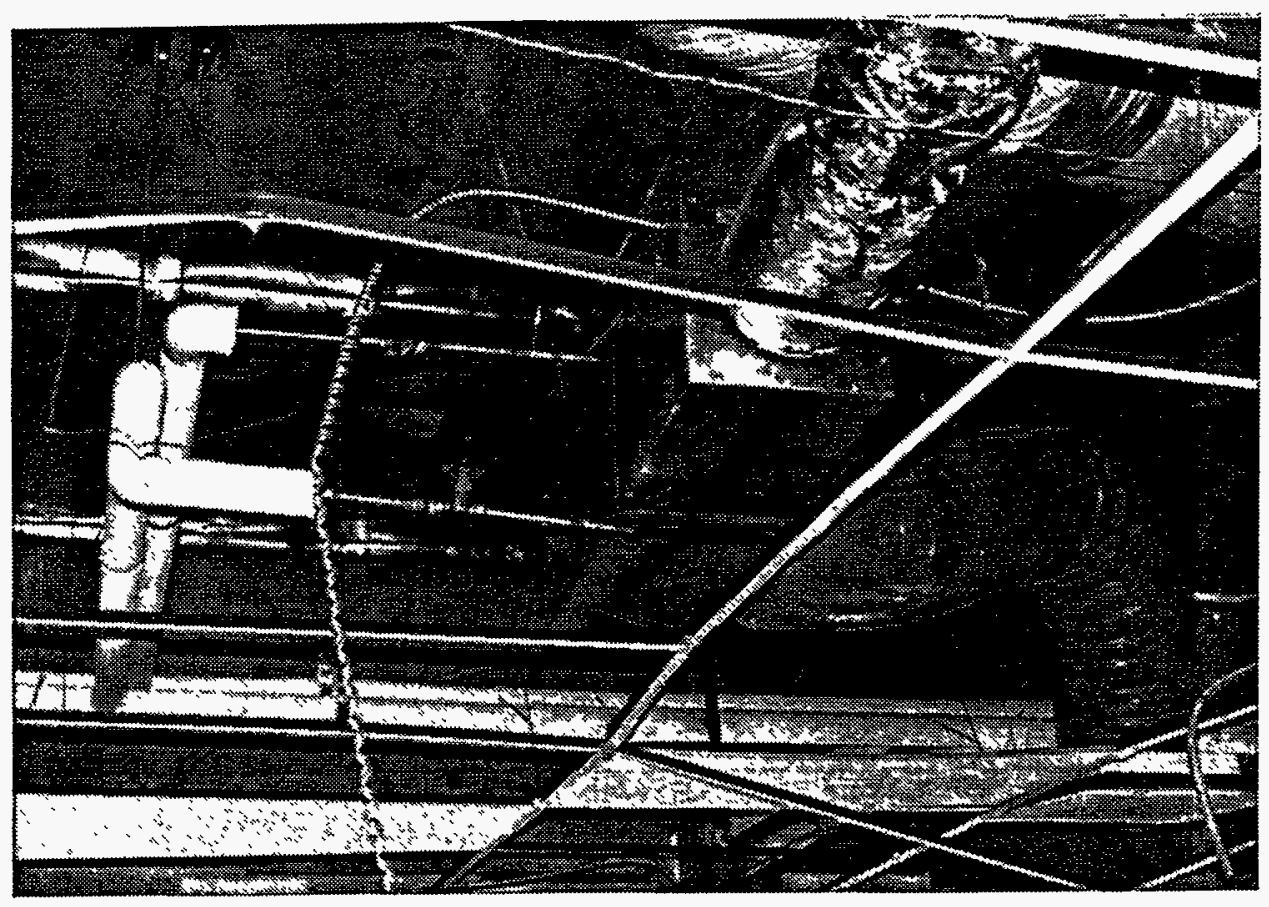

Figure 4.3.1-4: Several air handling units suspended above raised ceilings displaced and damaged copper cooling lines. 


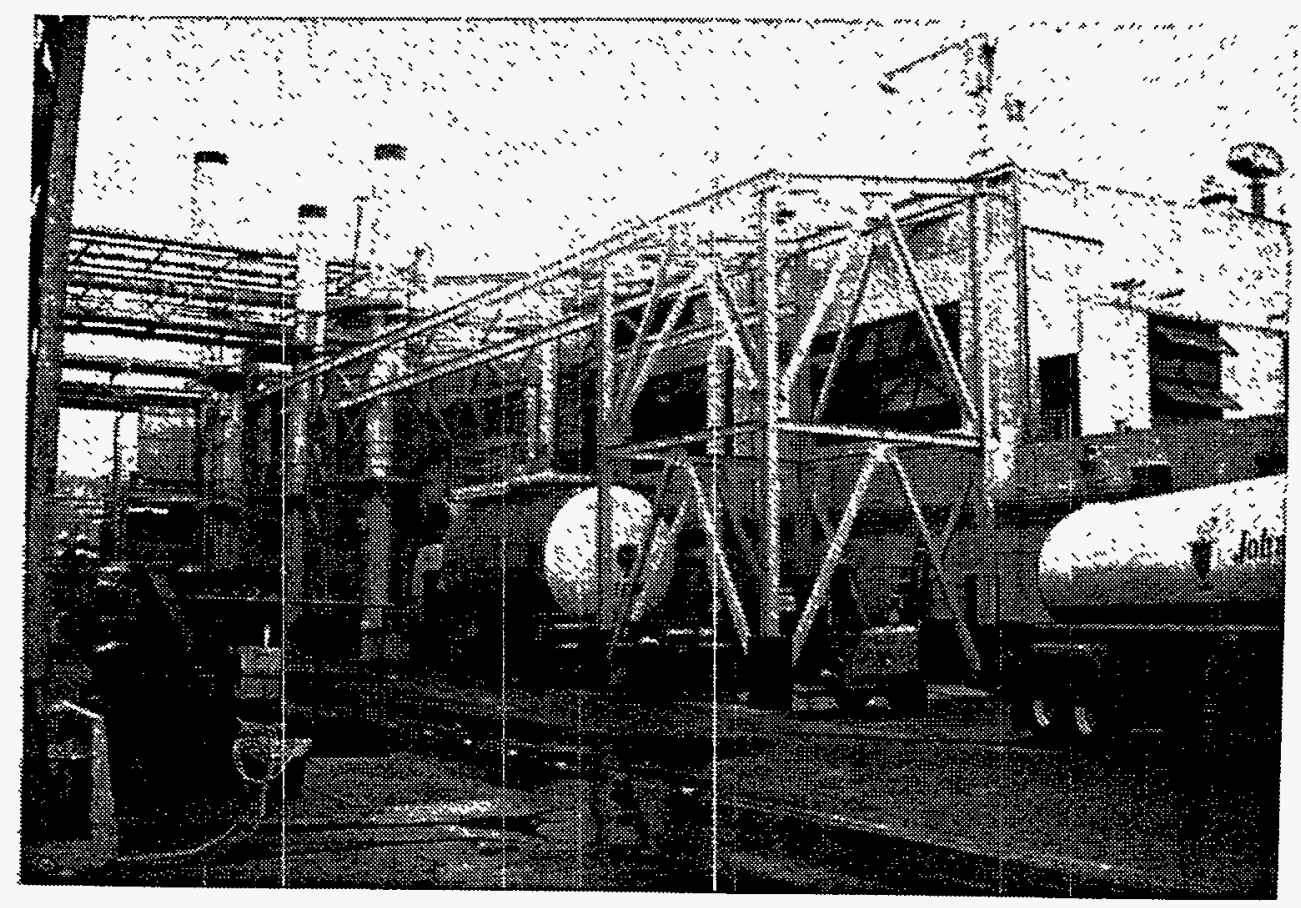

Figure 4.3.2-1: The central facilities building was retrofitted prior to the earthquake by adding a steel buttress to the exterior.

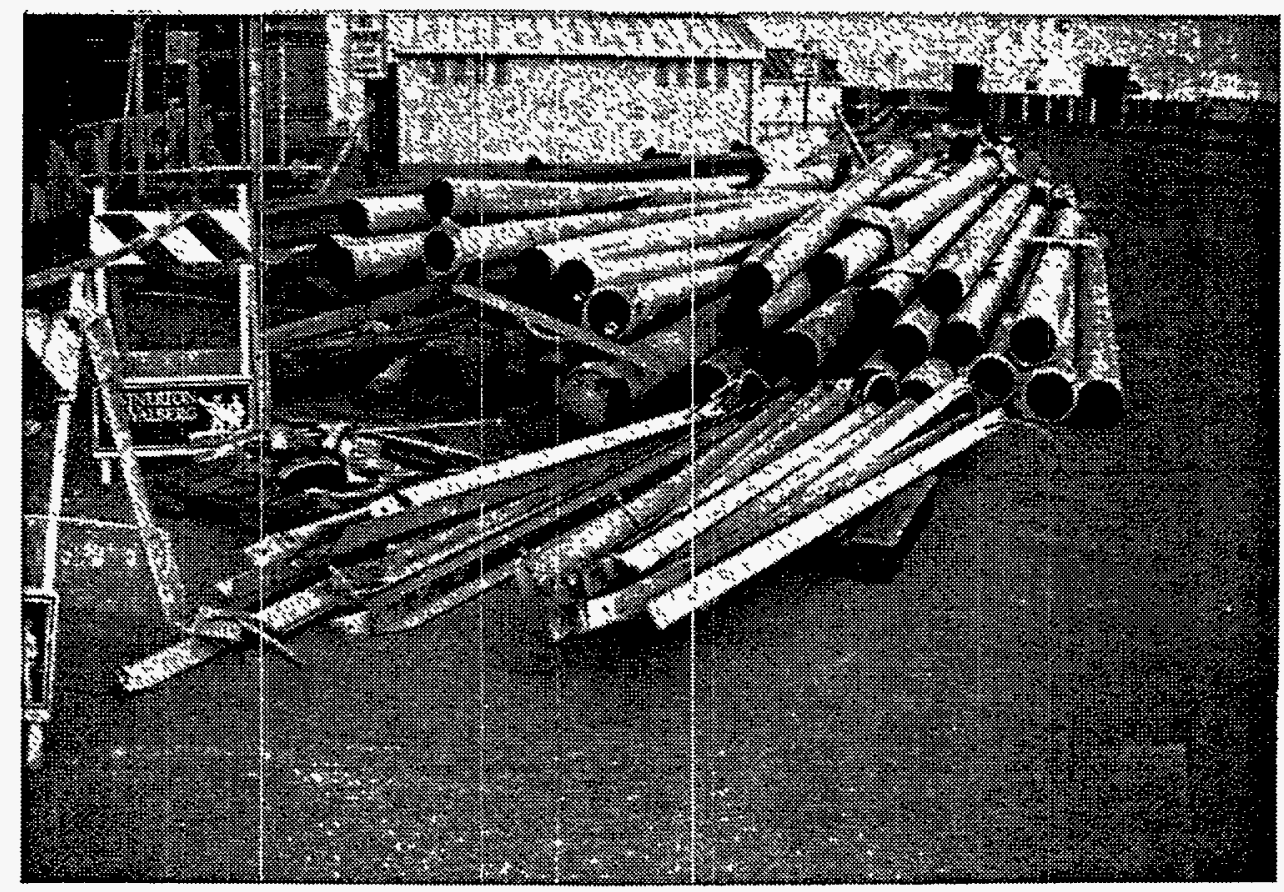

Figure 4.3.2-2: Over 2,000 feet of 8 inch diameter fire protection piping failed. The piping in the foreground was removed from the warehouse building. 


\subsubsection{Sand \& Gravel Plant}

A large sand \& gravel plant located in Sun Valley, approximately $20 \mathrm{~km}$ from the epicenter, survived the earthquake with only minor damage (Figure 4.3.3-1). The plant began operations in the early 1900's, with most of the existing facilities constructed from the 1940's into the 1970's. Plant heavy machinery includes excavation equipment, rock crushers and conveyers. Some production areas are over a mile from the central facilities, requiring long conveyers that pass through tunnels crossing several roads. Electrical gear operates at $4.16 \mathrm{kV}$ and $480 \mathrm{~V}$, feeding a diversity of mechanical equipment. Deep-well pumps with shafts over $300 \mathrm{ft}$ long serve the facility.

The plant survived the earthquake with relatively minor damage including several sheared bolts. Facility staff was able to survey the damage, make necessary repairs and resume production on Tuesday, the day following the earthquake. An increase in production was required to support post-earthquake construction activities.

\subsection{SEISMIC BASE ISOLATED FACILITIES}

Within 60 miles of the epicenter, there are nine seismic base isolated facilities or structures. Two of these structures experienced free-field accelerations greater than $0.3 \mathrm{~g}$ and both of them had no structural damage. The performance of these two structures, the Los Angeles County Fire Command and Control Facility and the USC University Hospital, will be discussed below. Several other isolated facilities, the Rockwell Seal Beach Building 80 and the Foothill Communities Law and Justice Center, had free-field accelerations less than $0.1 \mathrm{~g}$. The low accelerations at these buildings did not activate the softening affect of their isolation systems which are elastomeric bearings. At low levels of excitation, elastomeric bearings have high levels of lateral stiffness such that a building supported by the bearings will respond as if fixed-base. In the epicentral region, there are several other base isolated buildings including the Purdue Street residences and four structures which are under construction. Following the earthquake, there were no reports of structural damage at the four structures under construction. The Purdue Street residences suffered structural damage at the ground floor. These residences are three-story residential buildings which are supported on GERB steel helical springs and GERB viscous dampers and are located about 15 miles south of the epicenter. It is reported that there was evidence of considerable structural amplification in the horizontal and vertical directions as well as excessive motion within the buildings [ref 4.4-1]. The response of these residences demonstrates 


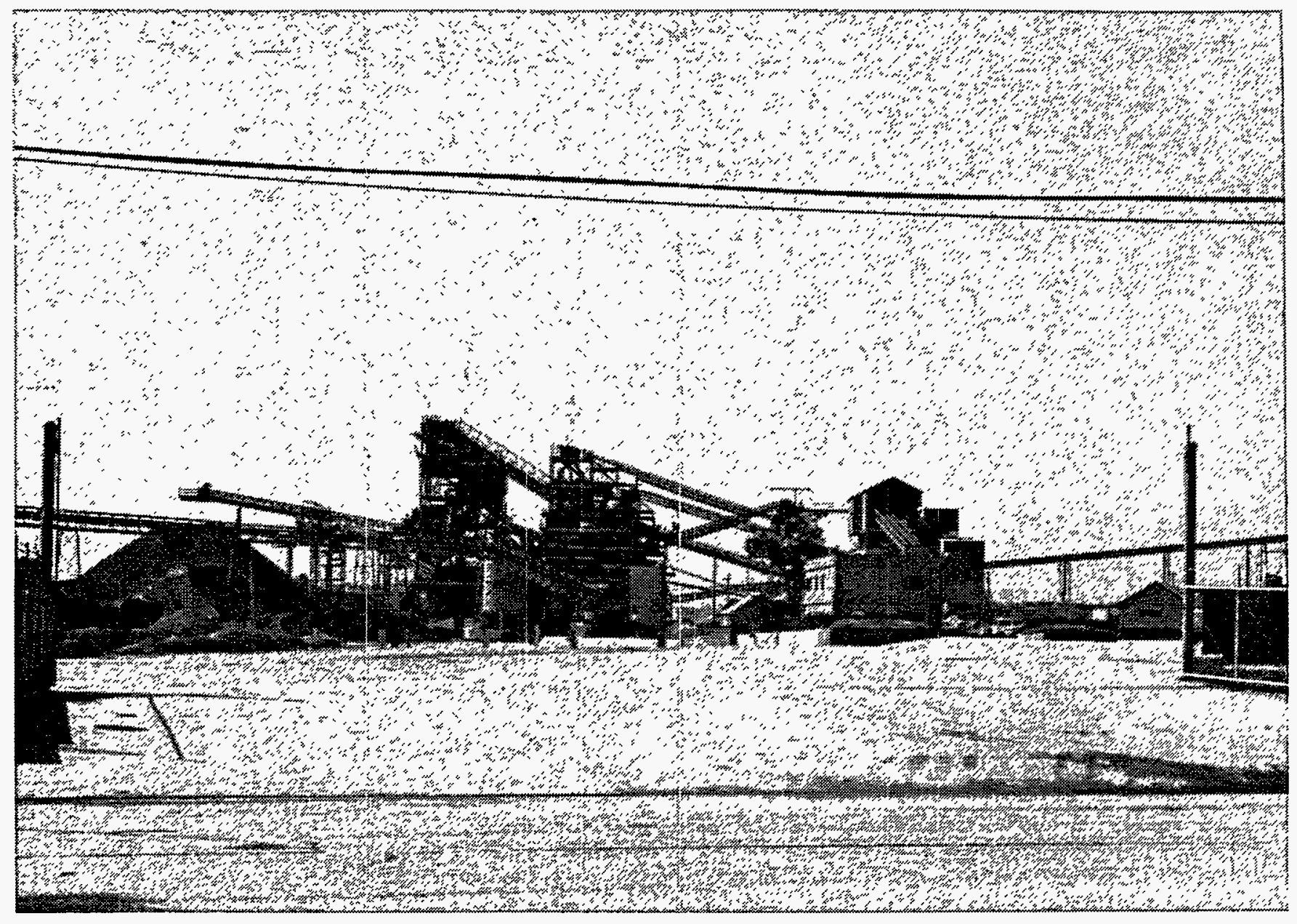

Figure 4.3.3-1: This large sand \& gravel plant includes several kilometers of conveyers. The plant was back in production the day after the earthquake. 
the necessity for properly engineering isolated structures to achieve desired performance. Further detailed information about the response of these residential buildings is not currently available.

While the base isolated structures performed as expected during the earthquake, there is concern about the response of these structures if they had been located nearer the epicenter. Research following the Northridge Earthquake and 1992 Landers Earthquake has revealed the presence of a displacement pulse or "fling" [ref 4.4-2]. This displacement pulse is a near-field phenomenon which acts perpendicular to the direction of fault propagation. The pulse is of concern for base isolated structures since long period buildings respond to long period, or large displacement, input. The effects of this pulse can be accommodated in isolated structures with a sufficiently large seismic gap around the base of the structure or with properly designed displacement restraints.

\subsubsection{Los Angeles County Fire Command and Control Facility}

The Los Angeles County Fire Command and Control Facility is the central hub for the emergency or "911" calls received by the County of Los Angeles. Located in East Los Angeles about 24 miles southeast of the epicenter, the facility, also known as the "911-Building" was completed in 1990. The "911-Building" is a two-story facility as shown in Figure 4.4-1 and the isolation system consists of 32 high damping rubber bearings underneath the first floor. Both during and following the earthquake, the 911-Building functioned as required and suffered no structural damage. Occupants of the building indicated that during the earthquake they felt a strong rolling motion and not a strong jolt [ref 4.4-3]. This observation is consistent with the expected behavior of an isolated building in which earthquake-induced short duration accelerations are transformed by the isolation system into long duration displacements. Based on records from the California Division of Mines and Geology (CDMG), the measured free-field accelerations at Station 24592 were 0.32 $\mathrm{g}$ and $0.26 \mathrm{~g}$ in the horizontal directions and $0.13 \mathrm{~g}$ in the vertical direction [ref 4.4-4]. The response of the building to these free-field accelerations is shown in Figure 4.4-2 with the corresponding instrument locations shown in Figure 4.4-3 [ref 4.4-4]. Based on the measured fundamental period and acceleration, the building moved about 1.0 inch in the north-south direction and 1.5 inches in the east-west direction during the earthquake. Near the entrance to the building, indentations in the dust indicated displacements of about 1.0 inch [ref 4.4-3].

Using the records in Figure 4.4-2, several observations about the building response can be made. First, the building primarily responded in the east-west direction which is consistent with the location of the epicenter relative to the building. Second, the horizontal fundamental period corresponding to the maximum response displacement is about 1.3 seconds [ref 4.4-3]. This period is less than the design period of 2.17 seconds in the longitudinal and transverse directions 


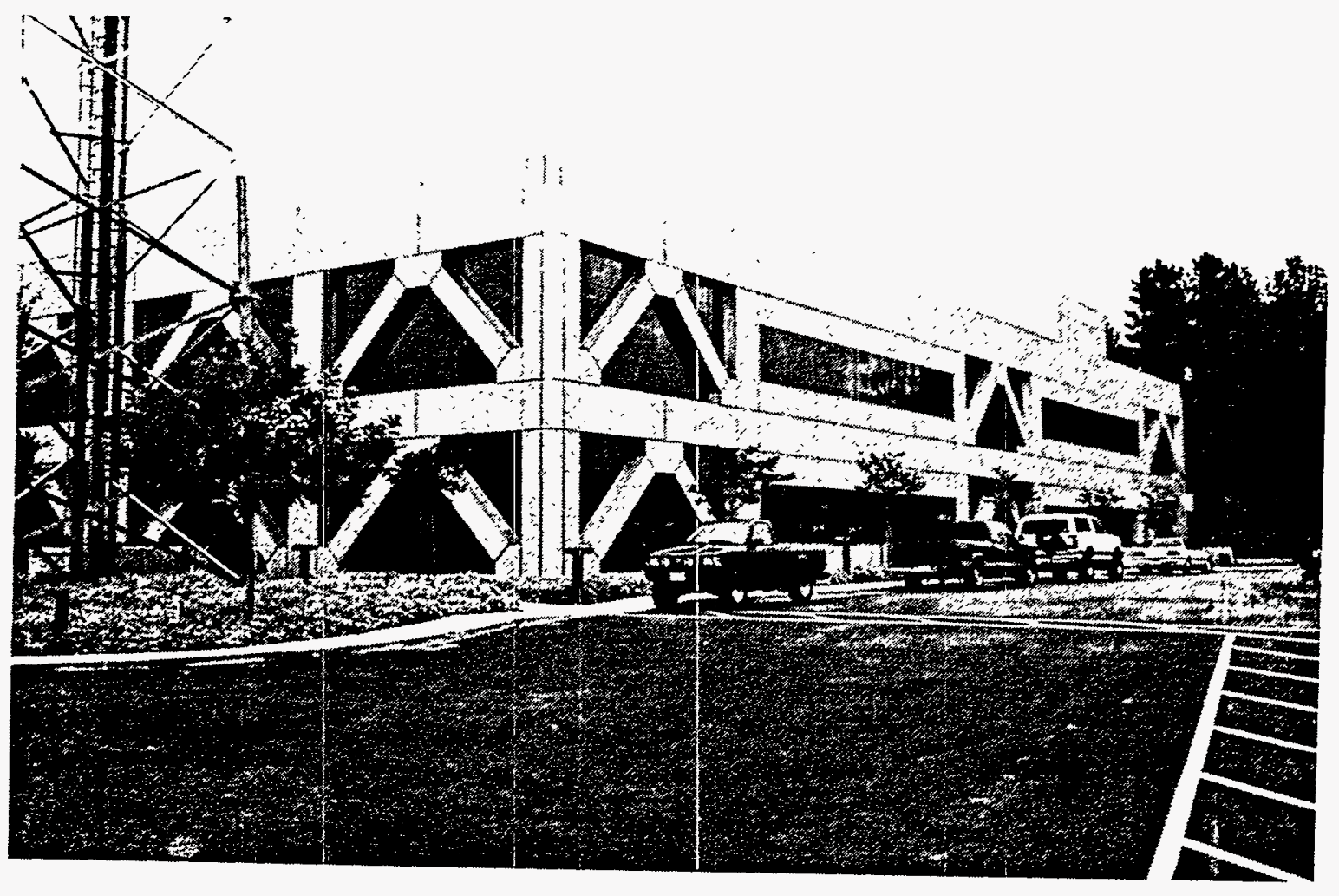

Figure 4.4-1: The Los Angeles County Fire Command and Control Facility is located about 24 miles southeast of the Northridge Earthquake epicenter. 
Los Angeles - 2-story Fire Command Control Bldg. (CSMIP Station 24580)

14 Roof: S. Wall - H

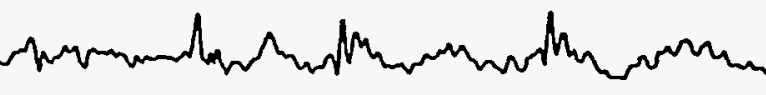

Max. Accel. = 0.249

15 Roof: Near Center - H

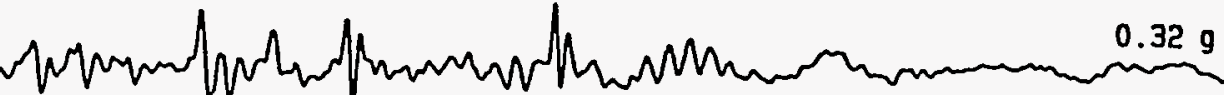

16 Roof: N. Wall - N $110.25 \mathrm{~g}$

12 2nd Floor: S. Wall - W

0.149

9 1st Floor: S. Hall - W

10 1st Floor: Near Center - $H$

11 1st Floor: N. Wall - W

6 Foundation: S. Hall - W

7 Foundation: N. Hall- $-\mathrm{H}$.

13 Roof: S. Wall - N

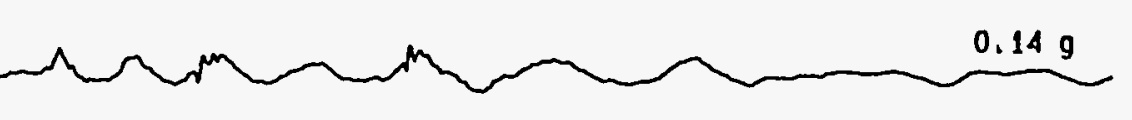

(23 9

作

8 15t Floor: S. Hall - N

5 Foundation: S. Hall - N

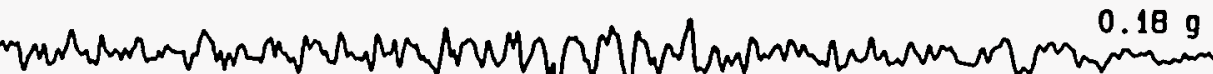

2 2nd Floor: Center of S. Side Slab - Up

Structure Reference Orientation: $\mathrm{N}=40^{\circ}$

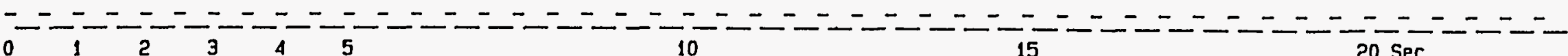

Figure 4.4-2: Strong motion records of the response of the Los Angeles County Fire Command and Control Facility during the Northridge Earthquake were obtained by the California Division of Mines and Geology [ref 4.4-4]. 
Los Angeles - 2-story Fire Command Control Bldg. (CSMIP Station No. 24580)

Perimeter braced steel frames isolated by laminated steel and rubber bearings.

Design date: 1988
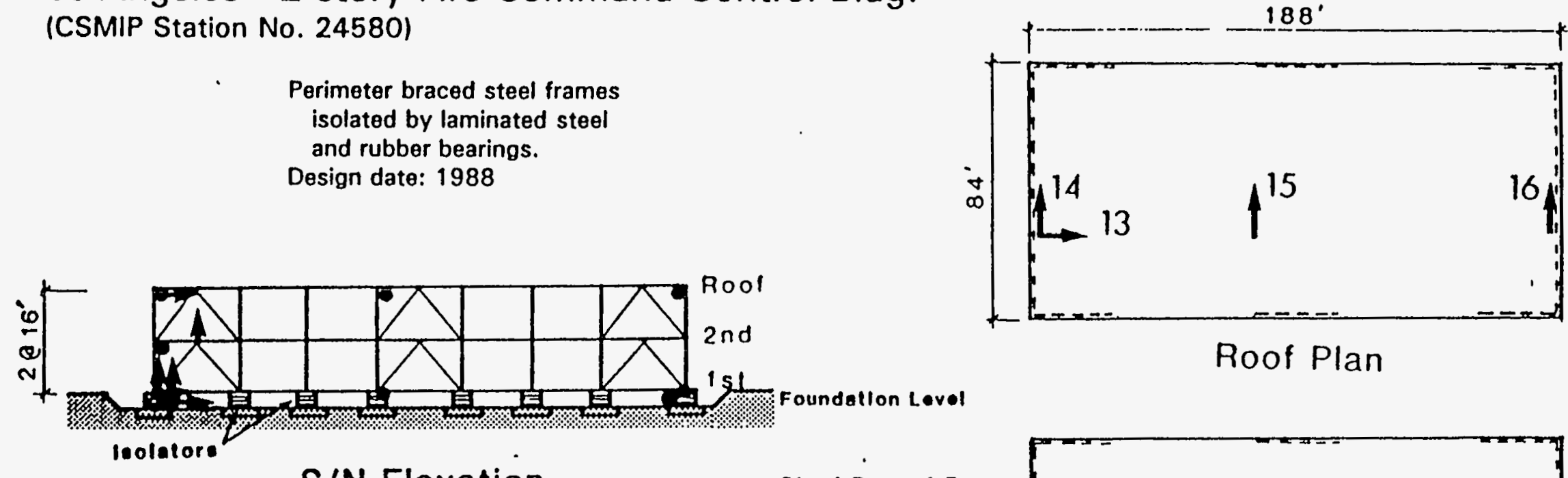

Roof Plan

总

SENSOR LOCATIONS

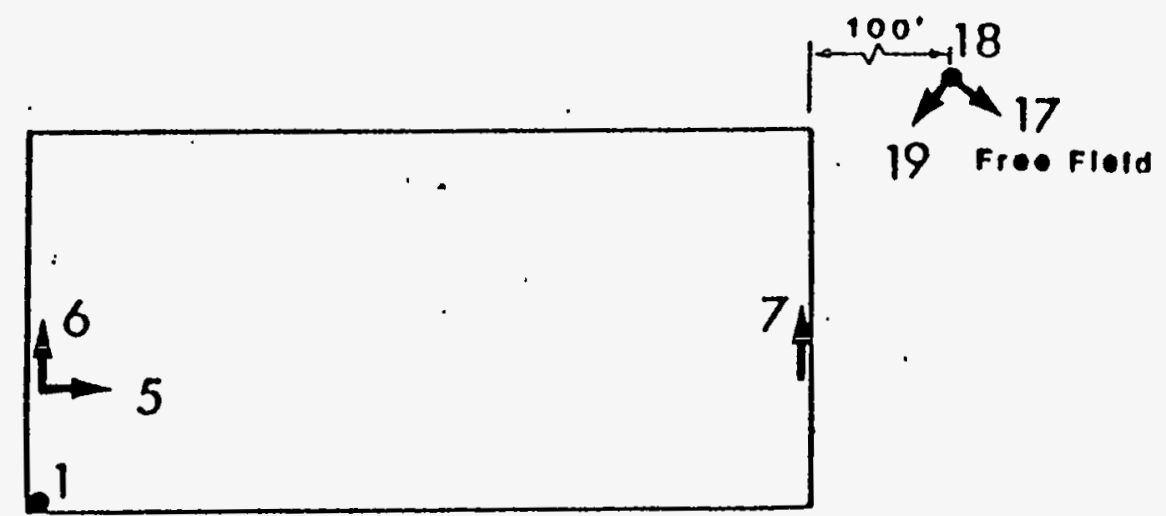

Foundation Level Plan

Siruclure Relerence

Orientation: $\mathrm{N}=40^{\circ}$

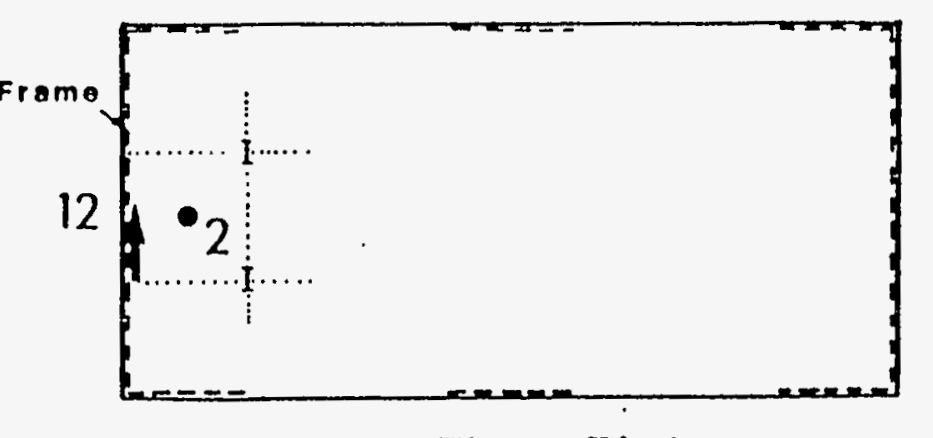

2nd Floor Plan

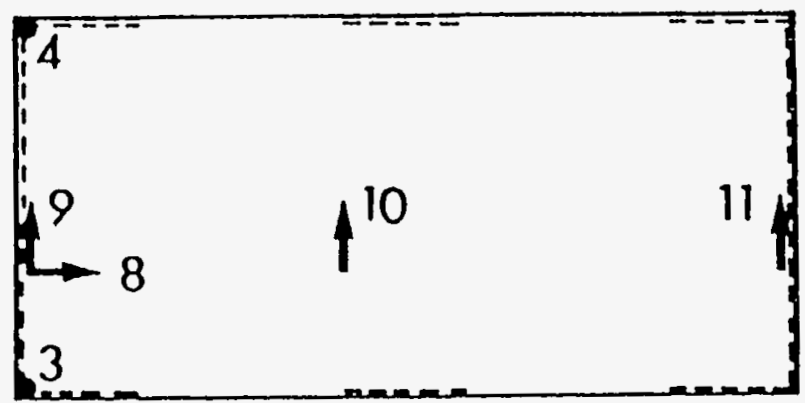

1st Floor Plan

Figure 4.4-3: Locations in the Los Angeles County Fire Command and Control Facility of accelerometers which are used in the California Strong Motion Instrumentation Program [ref 4.4-4]. 
[ref 4.4-5]. Since the design period is based on having the full softening effect of the isolation system for the largest design earthquake at the site, the period derived from the CDMG records indicate that the Northridge earthquake did not activate the isolation system to its design level. Finally, the building response had acceleration spikes especially at the north end of the building in the east-west direction. In the north-south direction, no spikes are evident in the CDMG records and the isolated building responded as expected.

During the earthquake, the building impacted a "hardened" entry-way at its northeast corner. These impacts caused a peak horizontal acceleration in the east-west direction of $0.35 \mathrm{~g}$ at the first floor and $0.25 \mathrm{~g}$ at the roof [ref 4.4-3]. While the spikes did not cause structural damage, they emphasized the importance of maintaining a seismic gap around an isolated building to prevent the impact of the building with its surrounding structures. Before the earthquake, the entry-way had been inadvertently "hardened" with a 2-1/2-inch thick, strong layer of reinforced concrete grout underneath the sacrificial tiles which covered the seismic gap or "rattlespace". As the building moved during the earthquake, the seismic joint at this location separated and closed resulting in impacts of the building with the "hardened" entry-way. This impacting continued for approximately 10 seconds until the grout layer broke up locally. Figure 4.4-4 shows the seismic gap and the damaged entry-way. After the grout layer broke up locally, the acceleration spikes disappeared and the isolated building responded as expected. A retrofit for the entry-way has been designed which permits the entry-way to move away freely from the building and not cause impacts of the building with the seismic joint. Further details about the design of the entry-way before and after the Northridge earthquake are available from Fluor Daniel, Inc.

One of the main reasons for deciding to isolate the 911-Building was that isolation provided the most cost-effective way to protect the operation of the equipment in the building during an earthquake. Some cost reduction was achieved by lessening the anchorage requirements of the internal equipment due to the decreased demand in the base isolated building. Examples of the unanchored computer equipment in the building that is required to remain operational during and following an earthquake are shown in Figure 4.4-5. During the Northridge earthquake, all the equipment performed as required and no contents were damaged or dislodged. On the second floor, some pendant light fixtures swayed during the earthquake and caused very minor nonstructural damage. A retrofit with wires is being used to restrain the motion of the fixtures. Since the facility did not lose offsite power, the backup generator and other emergency operations equipment were not used. 


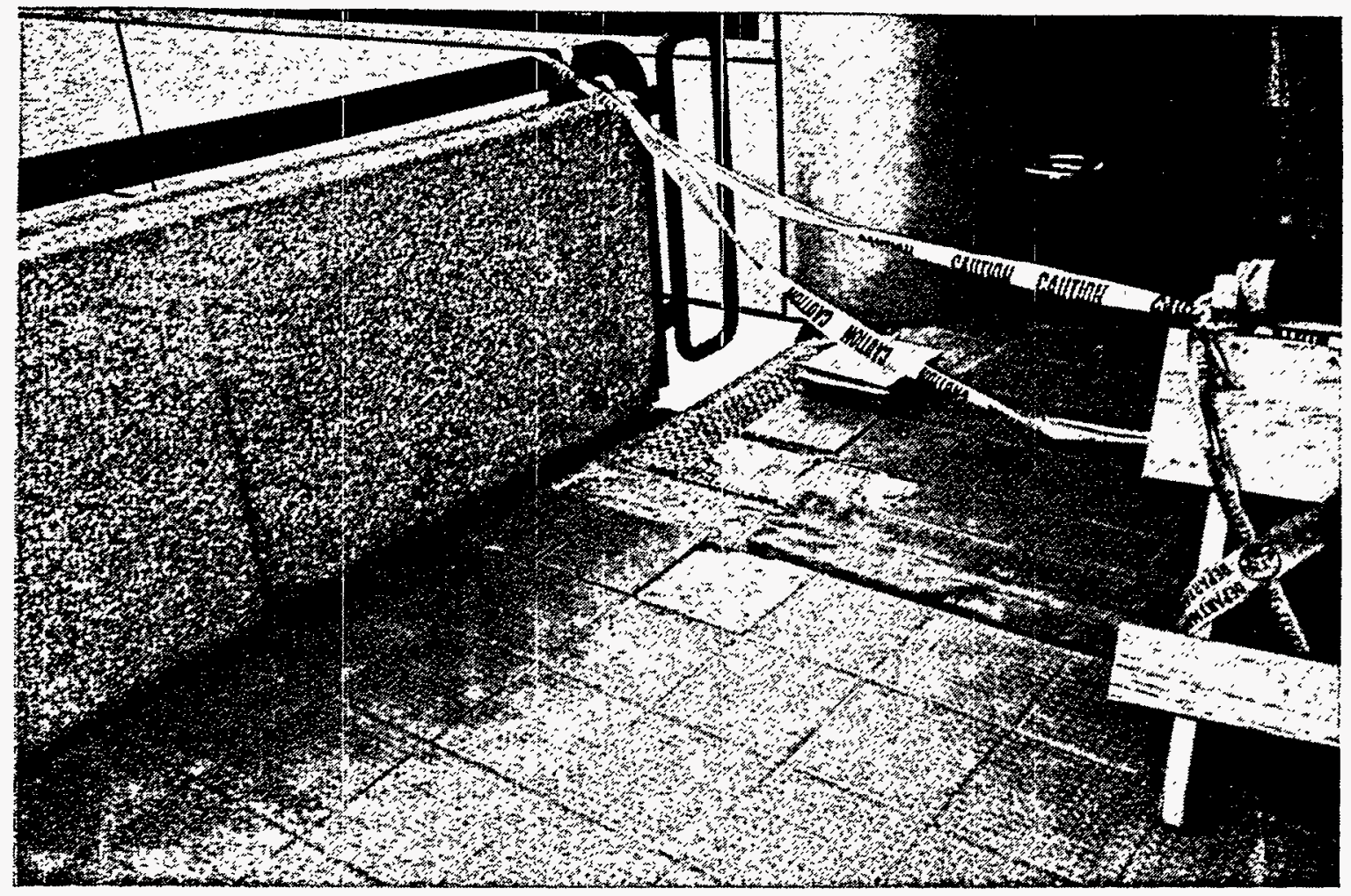

Figure 4.4-4: The tile-covered entry way over the seismic gap at the northeast corner of the Los Angeles County Fire Command and Control Facility was damaged.

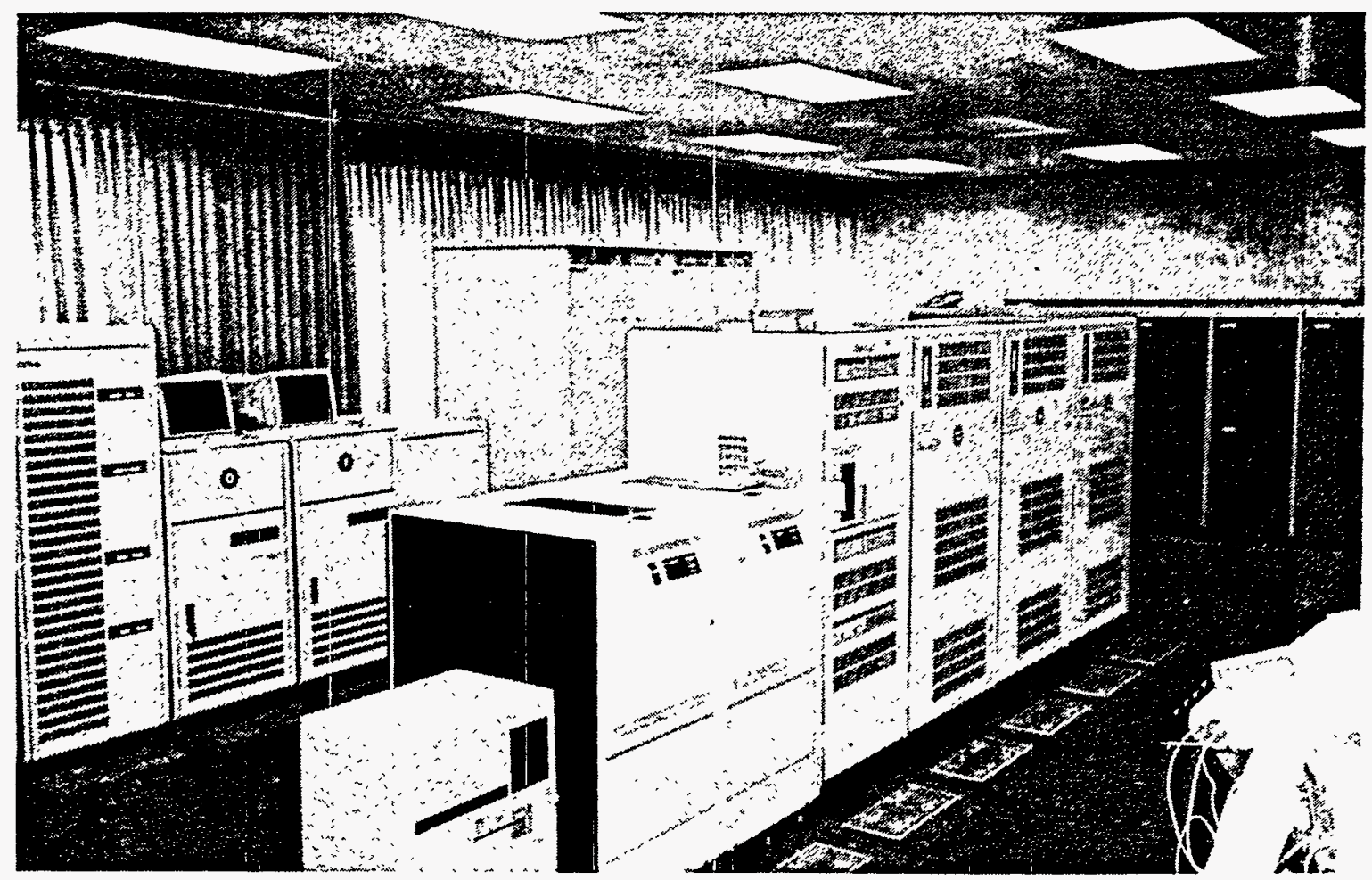

Figure 4.4-5: Unanchored computer equipment on the second floor of the Los Angeles County Fire Command and Control Facility remained fully operational. 


\subsubsection{USC University Hospital}

The USC University Hospital was completed in 1991 as the first base isolated hospital in the United States. The isolation system for the hospital is a combination of 81 high damping rubber bearings and 68 lead-core rubber bearings underneath the first floor. The hospital is located in Los Angeles about 22 miles southeast of the epicenter and, as shown in Figure 4.4-6, has seven stories. During and following the earthquake, the hospital had no structural damage and no contents, including those in the pharmacy, were damaged or dislodged. One stairwell suffered about $\$ 500$ in nonstructural damage due to relative displacements between the hospital and the stairwell. The measured CDMG acceleration records for the hospital with the corresponding

instrument locations are shown in Figures 4.4-7 and 4.4-8 [ref 4.4-6]. Based on those records, the peak free-field acceleration was $0.49 \mathrm{~g}$ which produced an acceleration underneath the isolation system of $0.37 \mathrm{~g}$. These accelerations are the largest levels that an isolated building in the U.S. has experienced to date. Research is being conducted to fully document the performance of the hospital during the earthquake, but the results are not yet available.

The records in Figure 4.4-7 indicate the benefits of isolation. The peak acceleration response was reduced from $0.37 \mathrm{~g}$ beneath the isolation system to $0.13 \mathrm{~g}$ above it. In addition, the earthquakeinduced, short duration accelerations were transformed by the isolation system into long duration motion. Structural amplification through the height of the hospital was relatively minor as the peak acceleration at the roof was $0.21 \mathrm{~g}$. It is reported that the structural amplification in a fixed-base structure of the same fundamental period as the hospital would have been a factor of about three based on elastic calculations [ref 4.4-1]. The motion in the hospital was sufficiently small to not activate the safety switches on the elevators.

Immediately following the earthquake, the hospital lost offsite power and had to rely on backup power for six hours. The $1500 \mathrm{KVA}$ emergency generators started less than 10 seconds after the loss of offsite power with no switching problems and they performed as required. Vibration isolators without seismic bumpers were used for the diesel generators as shown in Figure 4.4-9. Throughout the plant portion of the hospital, all the equipment was anchored. Utility lines which crossed the seismic gap around the hospital had sufficient flexibility to accommodate the motion of the hospital and did not sustain any leaks. Displacements of about 1.0 inch were observed on plates covering the seismic gap. Figure 4.4-10 shows the relative motion between plates covering the gap on the east side of the hospital. 


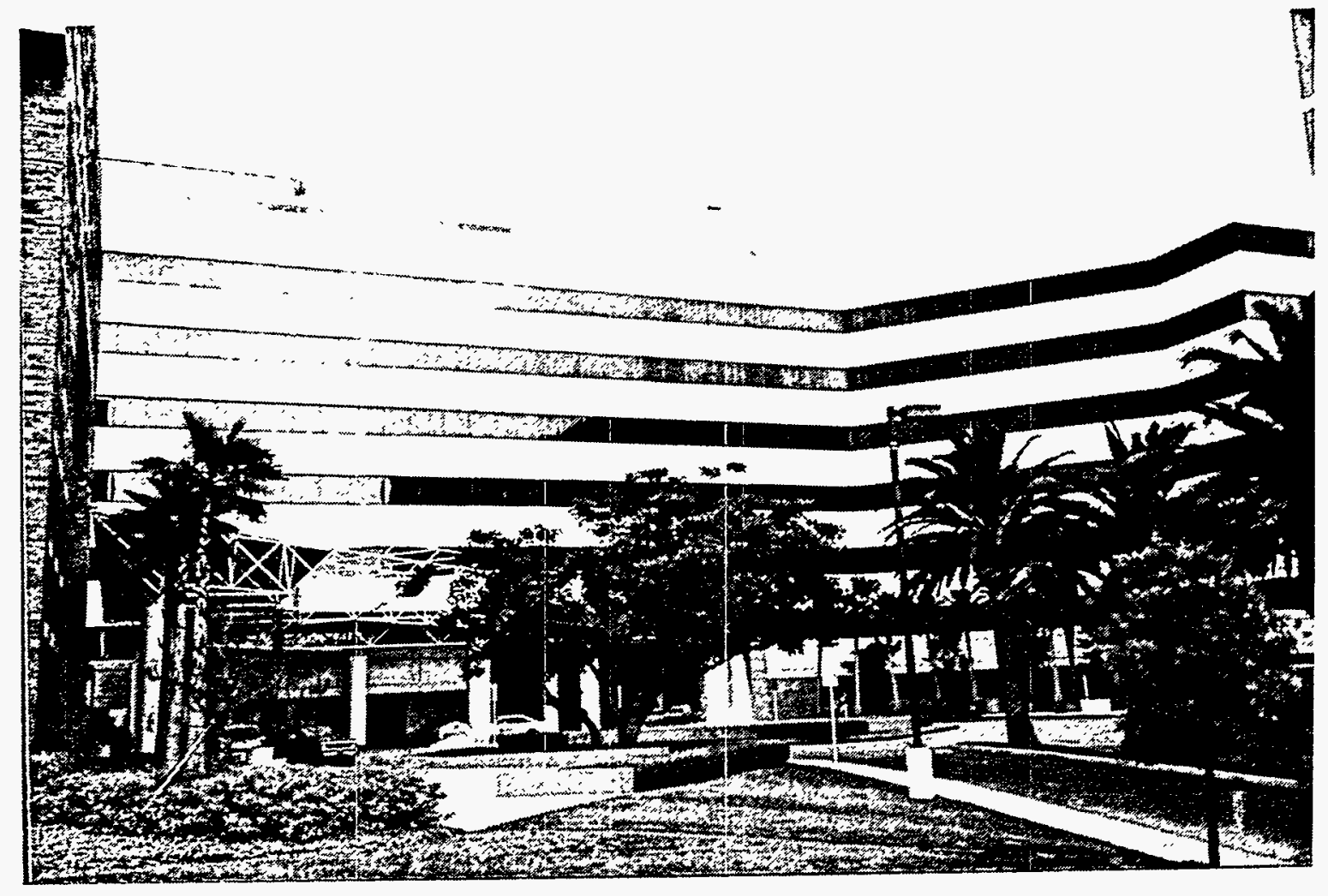

Figure 4.4-6: The USC University Hospital in Los Angeles, California is located about 22 miles southeast of the Northridge Earthquake epicenter. 
Los Angeles - 7-story University Hospital

(CSMIP Station 24605)

RECORD 24605-C0115-94017

21 Roof: Center - N

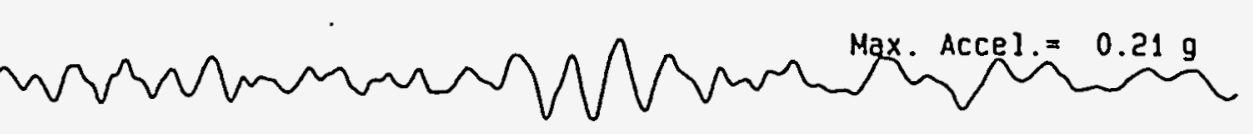

17 6th Floor: Center - N

$0.11 \mathrm{~g}$

13 4th Floor: Center - N

9 Lower Level: Center - N

5 Foundation Level: Center - N

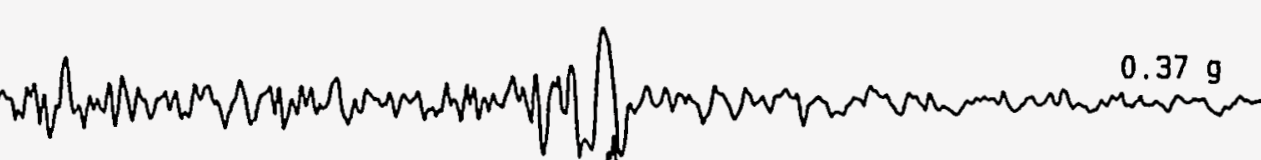
in

25 Free Field: - N

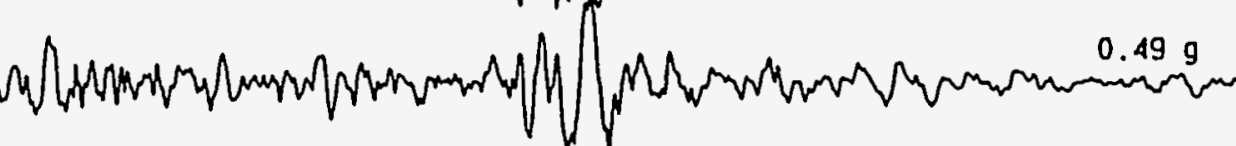

4 Lower Level: East Wall - Up

3 Foundation Level: East Wall - Up $0.09 \mathrm{~g}$

2 Lower Level: West Wall - Up $0.08 \mathrm{~g}$

1 Foundation Level: Hest Wall - Up $0.07 \mathrm{~g}$

26 Free Fleld: - Up 0.129 Structure Reference Orientation: $N=5^{\circ}$ $15-\cdots--7-7$

Figure 4.4-7: Strong motion records from the USC University Hospital during the Northridge Earthquake were obtained by the California Division of Mines and Geology [ref 4.4-6]. 
Los Angeles - 7-story University Hospital

SENSOR LOCATIONS

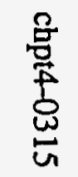

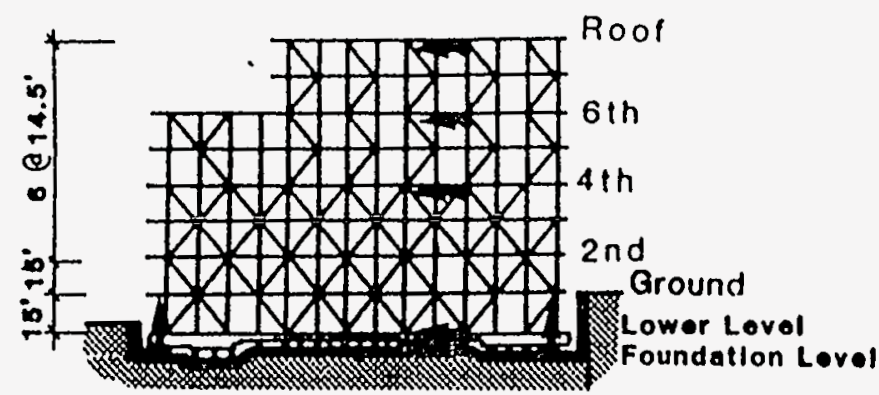

North Elovation
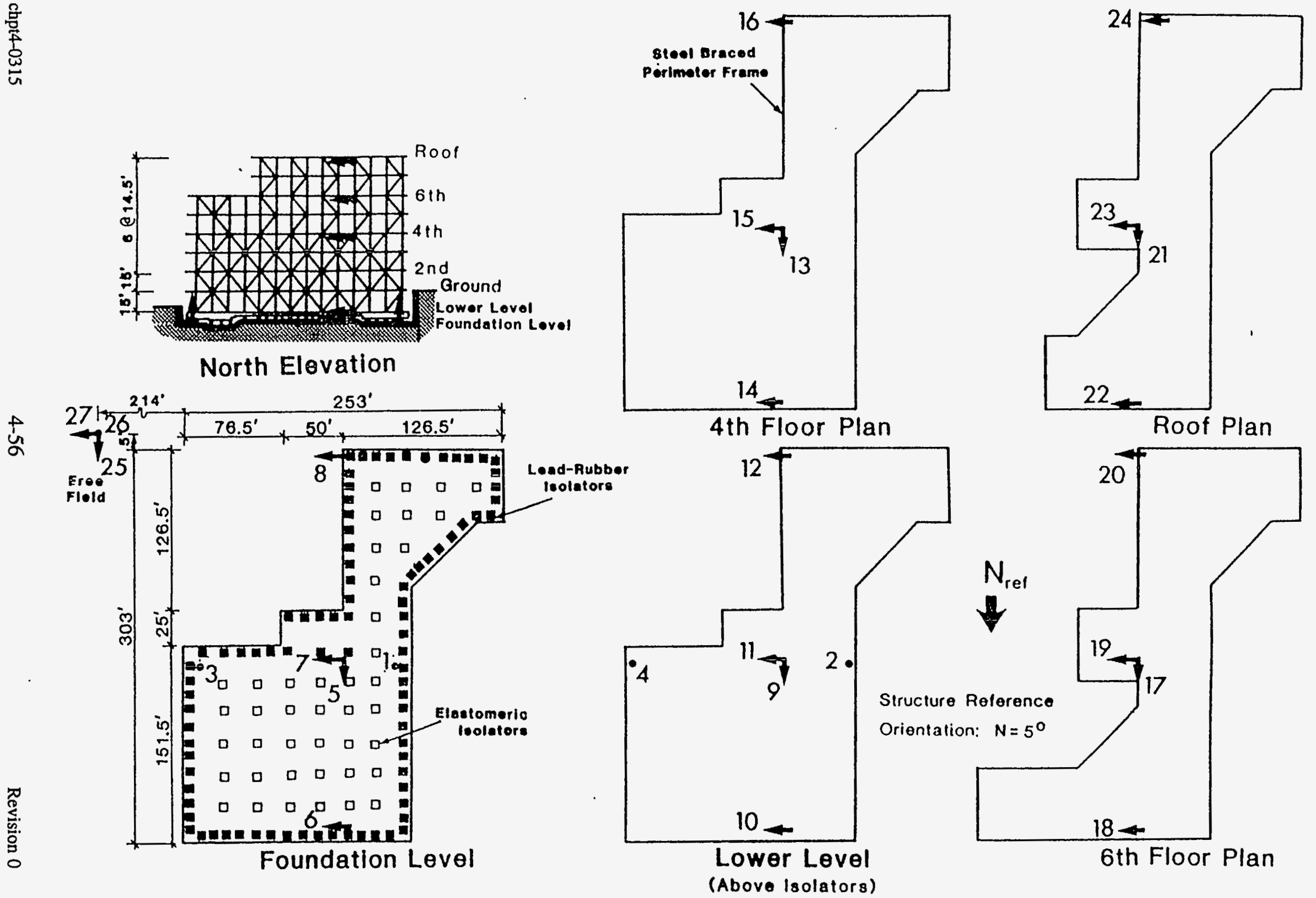

Figure 4.4-8: Locations in the USC University Hospital of accelerometers which are used in the California Strong Motion
Instrumentation Program [ref 4.4-6]. 


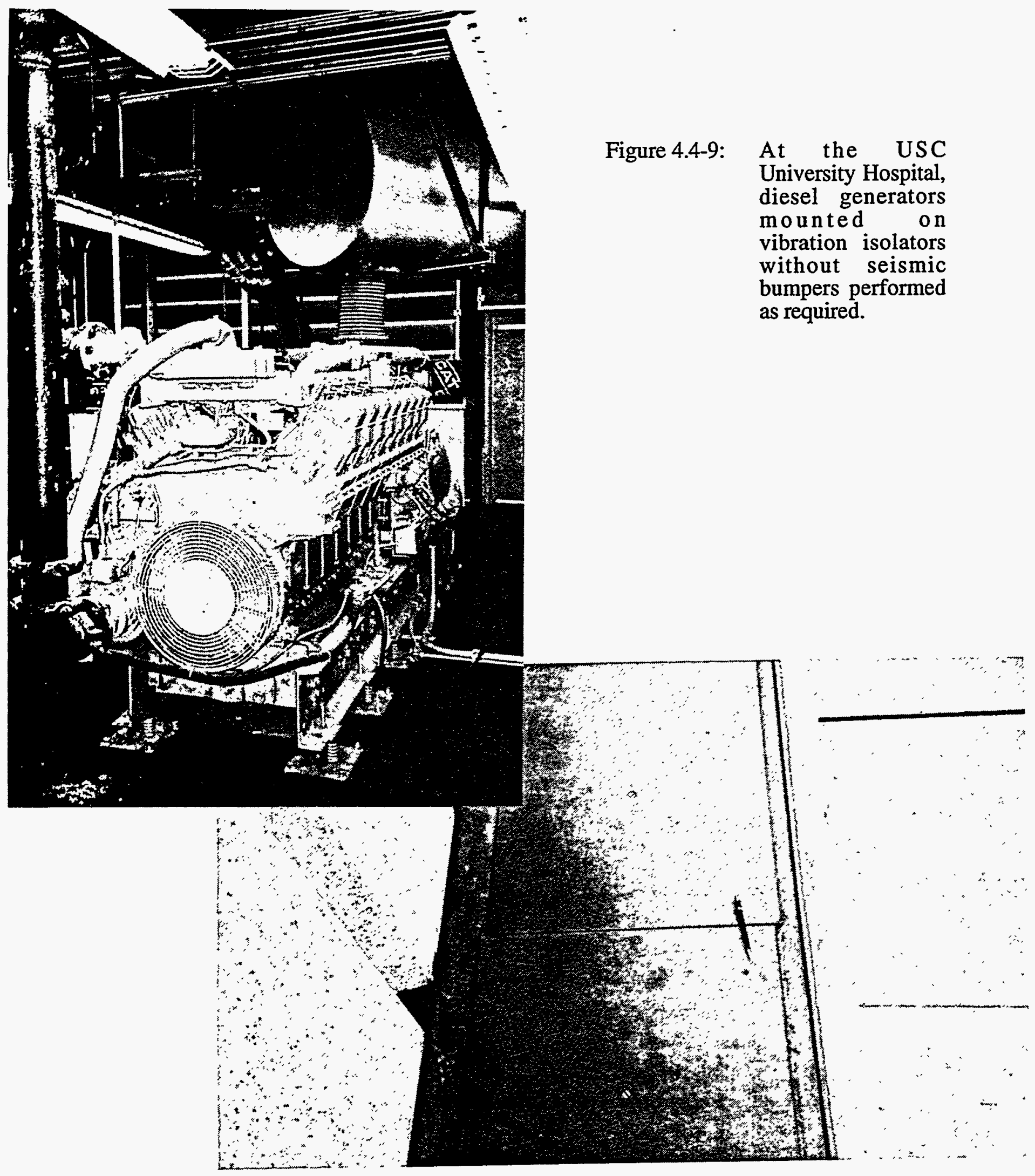

Figure 4.4-10: Relative motion of about one inch was observed on plates covering the seismic gap around the USC University Hospital. 
While the hospital suffered only minor nonstructural damage in a stairwell, the adjacent USC Healthcare Consultation Building had nonstructural damage and a nearby pediatric hospital suffered significant structural damage. In the consultation building, all the contents in the pharmacy were dislodged and damaged and there was minor damage to finish materials and suspended ceiling tiles. Initial reports from the pediatric hospital indicated sprinkler, emergency diesel, and structural damage similar to that evidenced at several other damaged hospitals near the epicenter.

\subsection{RESEARCH FACILITIES}

\subsubsection{Califomia State University at Northridge}

California State University at Northridge (CSUN) is a 350-acre campus located several miles north of the epicenter. Even though the campus serves nearly 25,000 students and 4000 faculty, there were few people on campus during the earthquake because classes were not in session. Due to its close proximity to the epicenter, there was damage to structures on the campus. Most notably, a relatively new parking garage collapsed, the library had significant structural damage, and a science building had a fire following the earthquake. Nonstructural damage to contents of buildings was also widespread. Three weeks after the earthquake, the campus was opened for classes even though many of the buildings were unavailable.

Parking Structure $C$ on the east side of the campus collapsed during the earthquake (see Figures 4.5-1 through 4.5-3). Constructed in 1991, the structure had a perimeter precast frame with interior precast beams, precast columns, and post-tensioned concrete slabs. A structural frame assembled from pre-cast concrete elements with no positive connections between the load-carrying members was a vulnerable configuration for many of the parking structures which, as a result, collapsed in the epicentral area. The exterior frame of the CSUN parking garage was designed to behave in a ductile fashion. However, the interior, short columns between ramps and adjacent floors attracted large loads but had low capacity for transferring lateral loads.

Oviatt Library at CSUN had damage to the architectural features near the roof line. Immediately after the earthquake, it appeared to be only cosmetic damage (see Figures 4.5-4 and 4.5-5). Upon further investigation by structural teams several weeks later, further significant damage was observed especially in the library additions. Close inspection of the steel braced frames in the additions revealed cracks which ran through the full thickness of the steel baseplate at the lower end of the X-bracing (see Figure 4.5-6) [ref 4.5-1]. This discovery focused attention on the brittle performance of connections in steel frame structures in the Northridge Earthquake. 


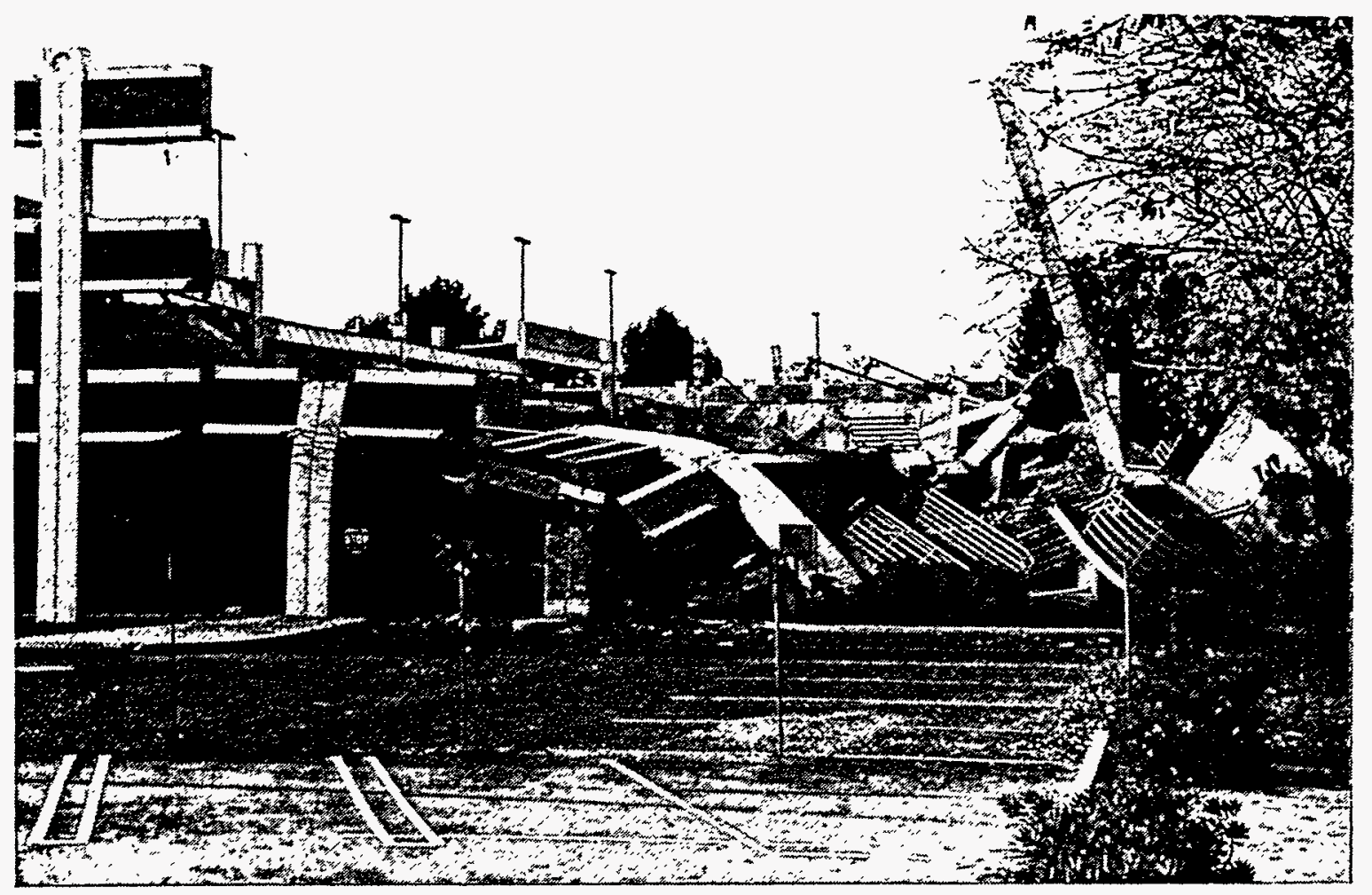

Figure 4.5-1: Collapse of Parking Lot $C$ at California State University at Northridge, looking NW from the SE corner.

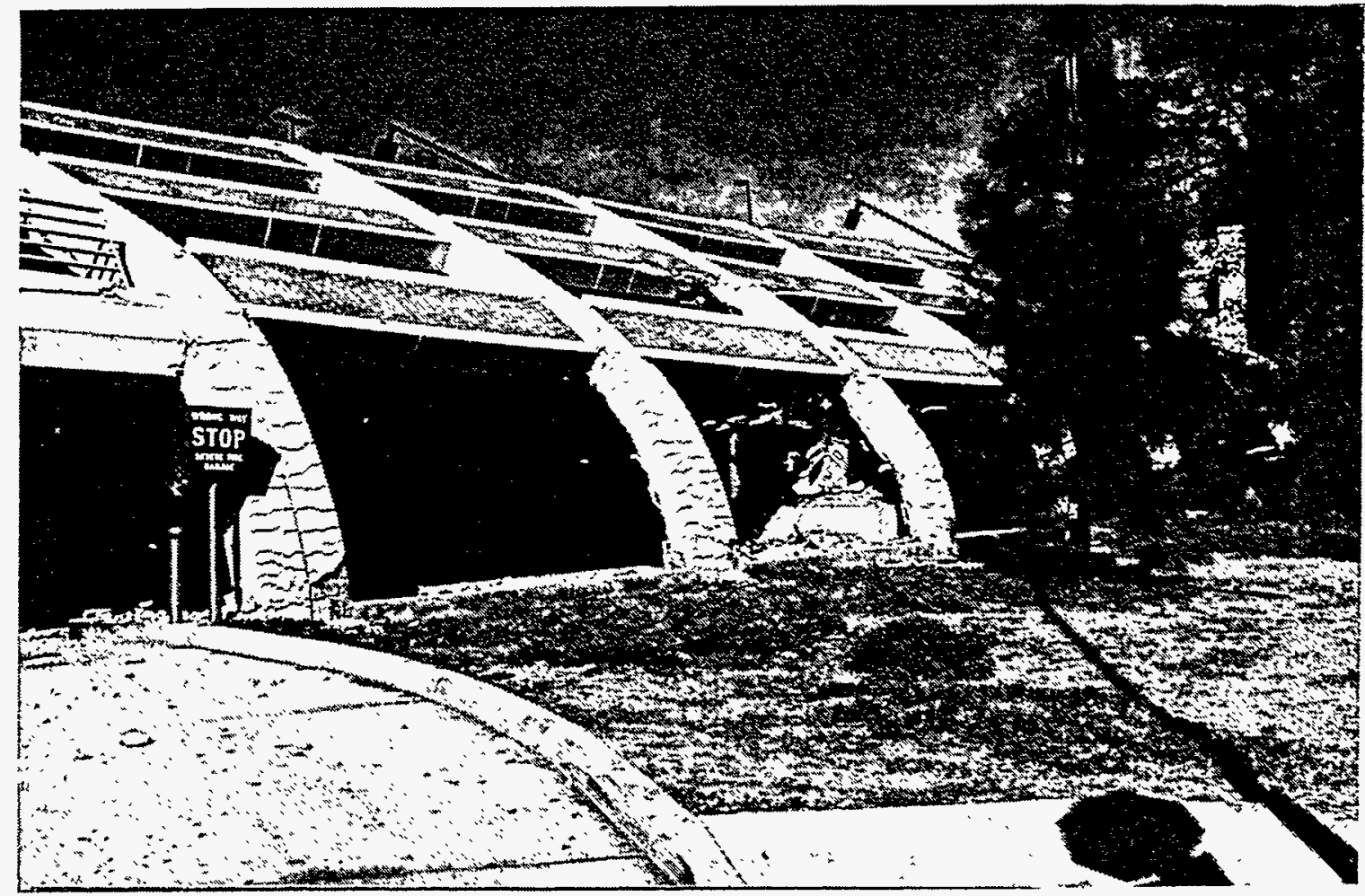

Figure 4.5-2: Ductile failure of exterior columns which contributed to the collapse of Parking Lot $C$ at California Sate University at Northridge. 


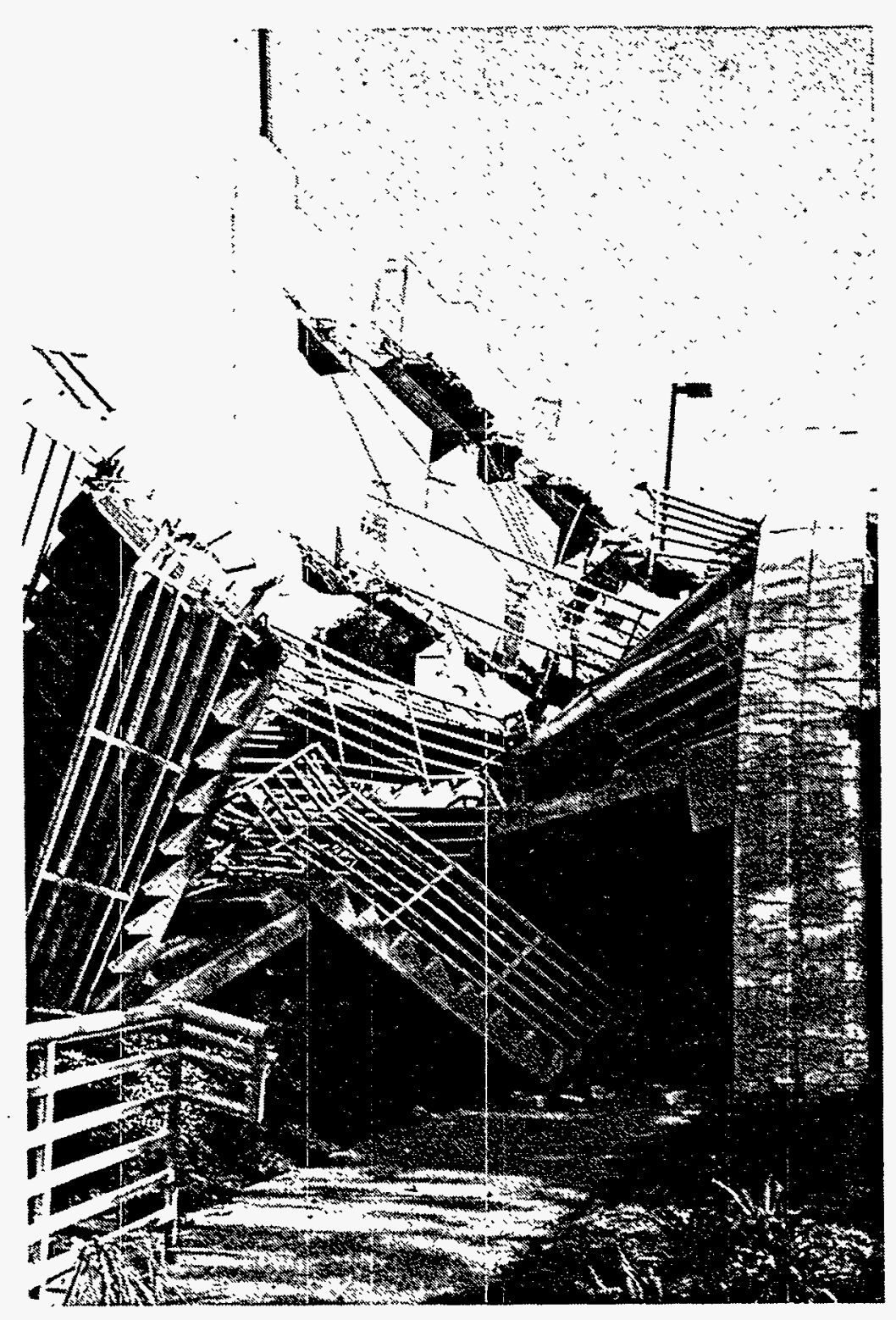

Figure 4.5-3: Collapse of the parking structure at California State University at Northridge, looking SW from the NE corner. Note the lack of positive connection between the beams and the corbels (beam seats on columns) and the short bearing seat at the ends of the beams. 


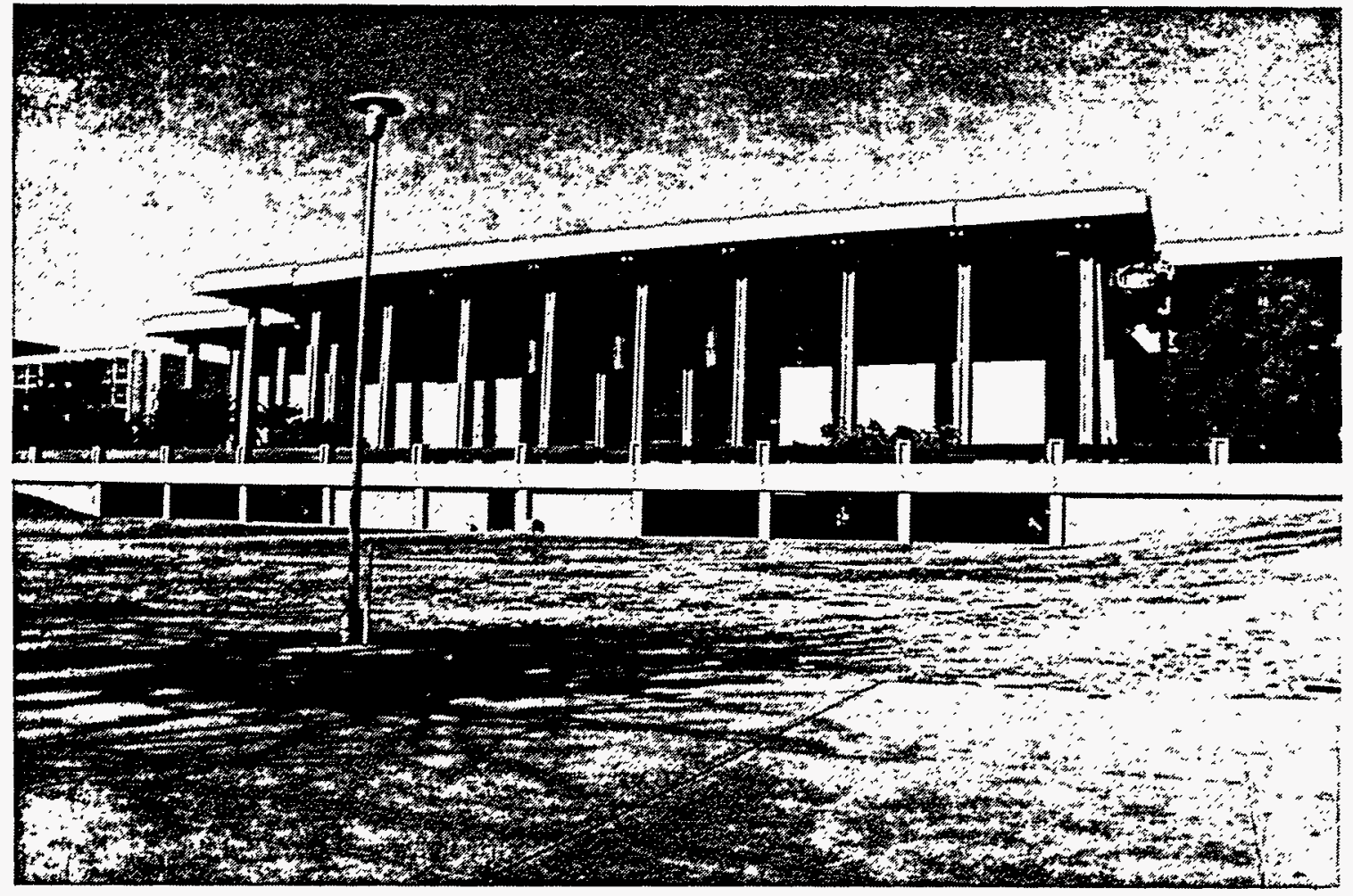

Figure 4.5-4: Oviatt Library at CSUN had damage to the architectural features near the roof line. Immediately after the earthquake, it appeared to be only cosmetic damage.

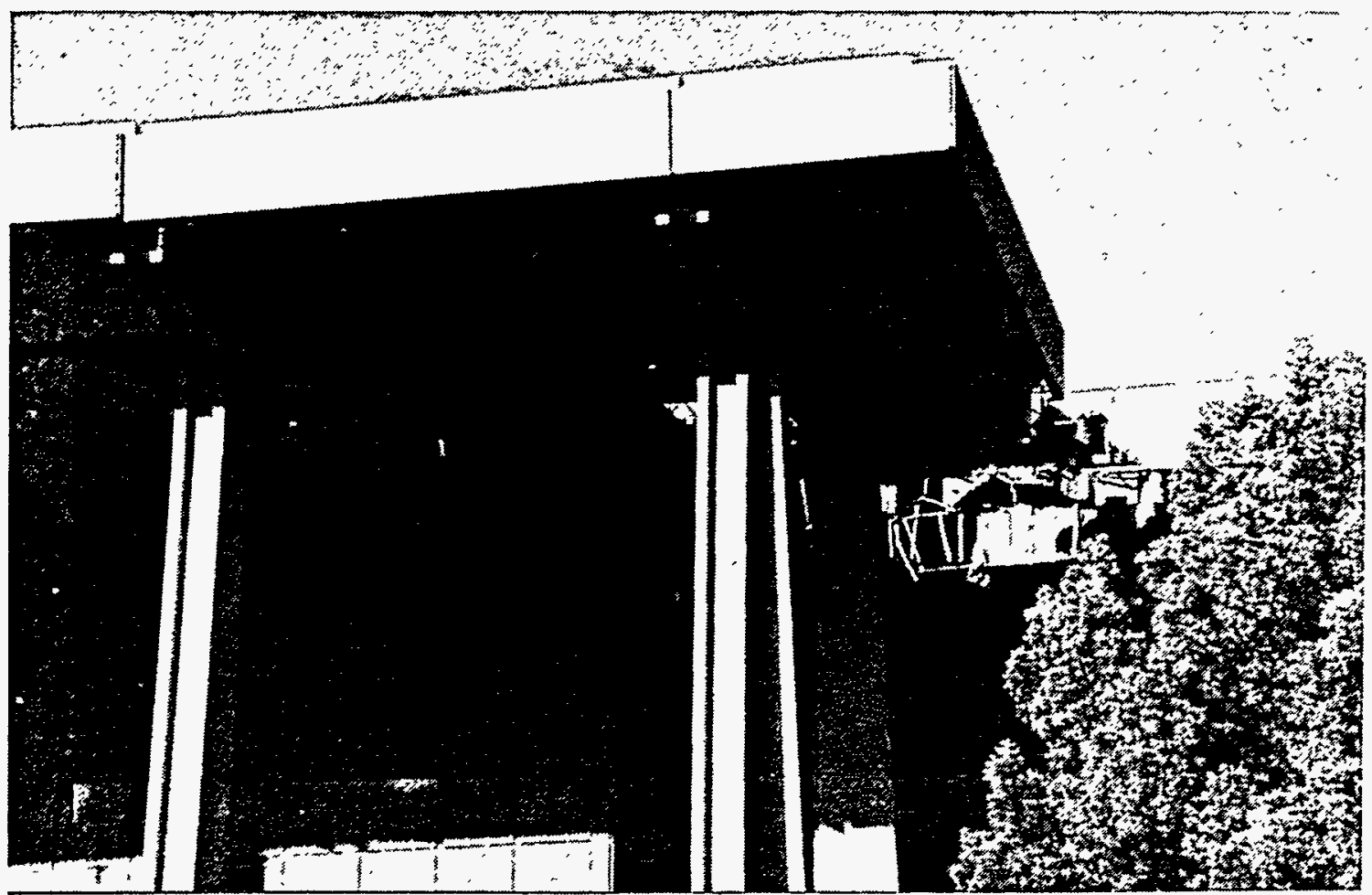

Figure 4.5-5: Close-up of damage to architectural features near roof of Oviatt Library at CSUN. 


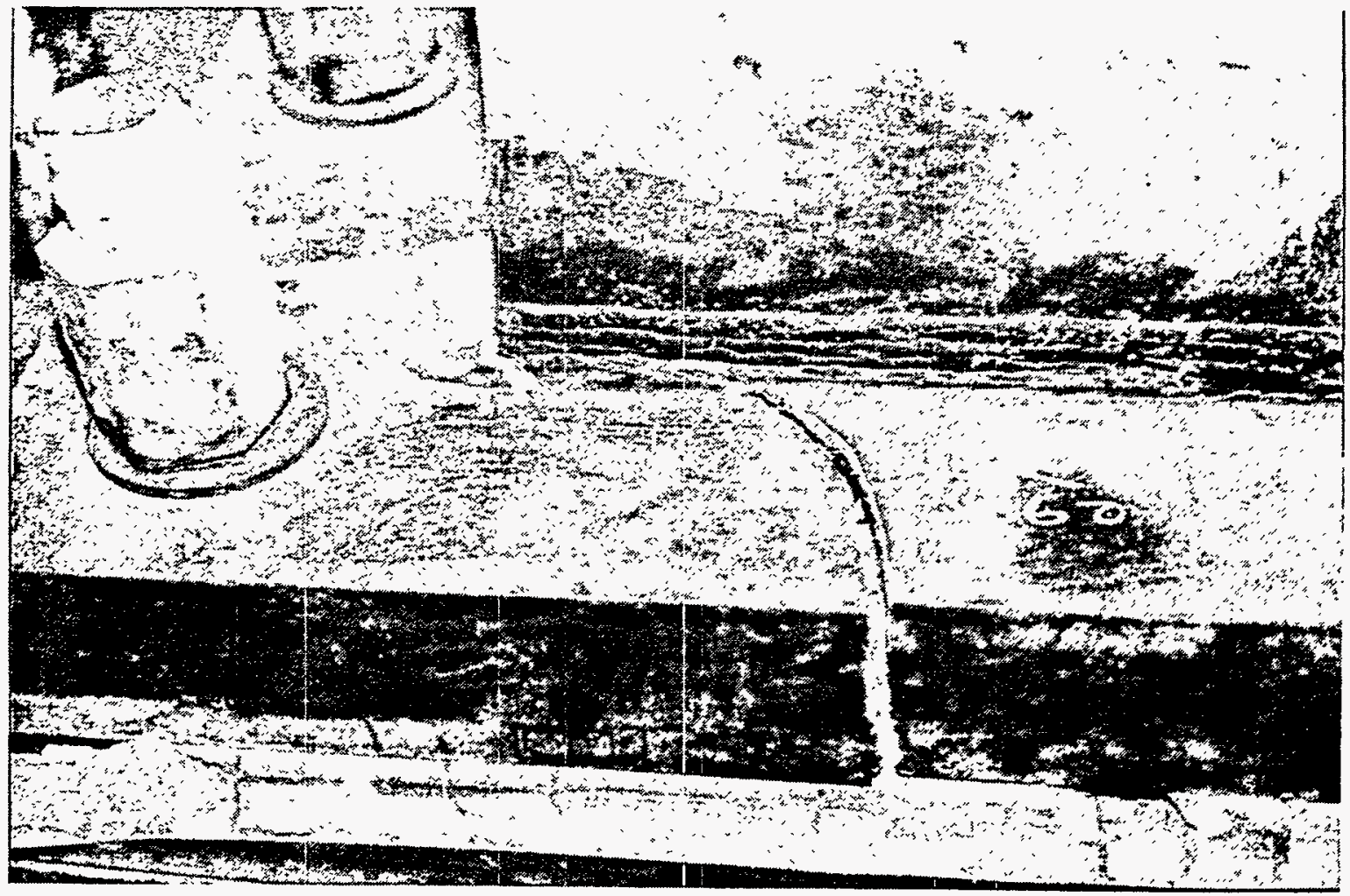

Figure 4.5-6: Upon further investigation by structural teams several weeks after the earthquake, cracks were discovered to run through the full thickness of the steel baseplate at the lower end of the X-bracing in Oviatt Library [ref 4.5-1].

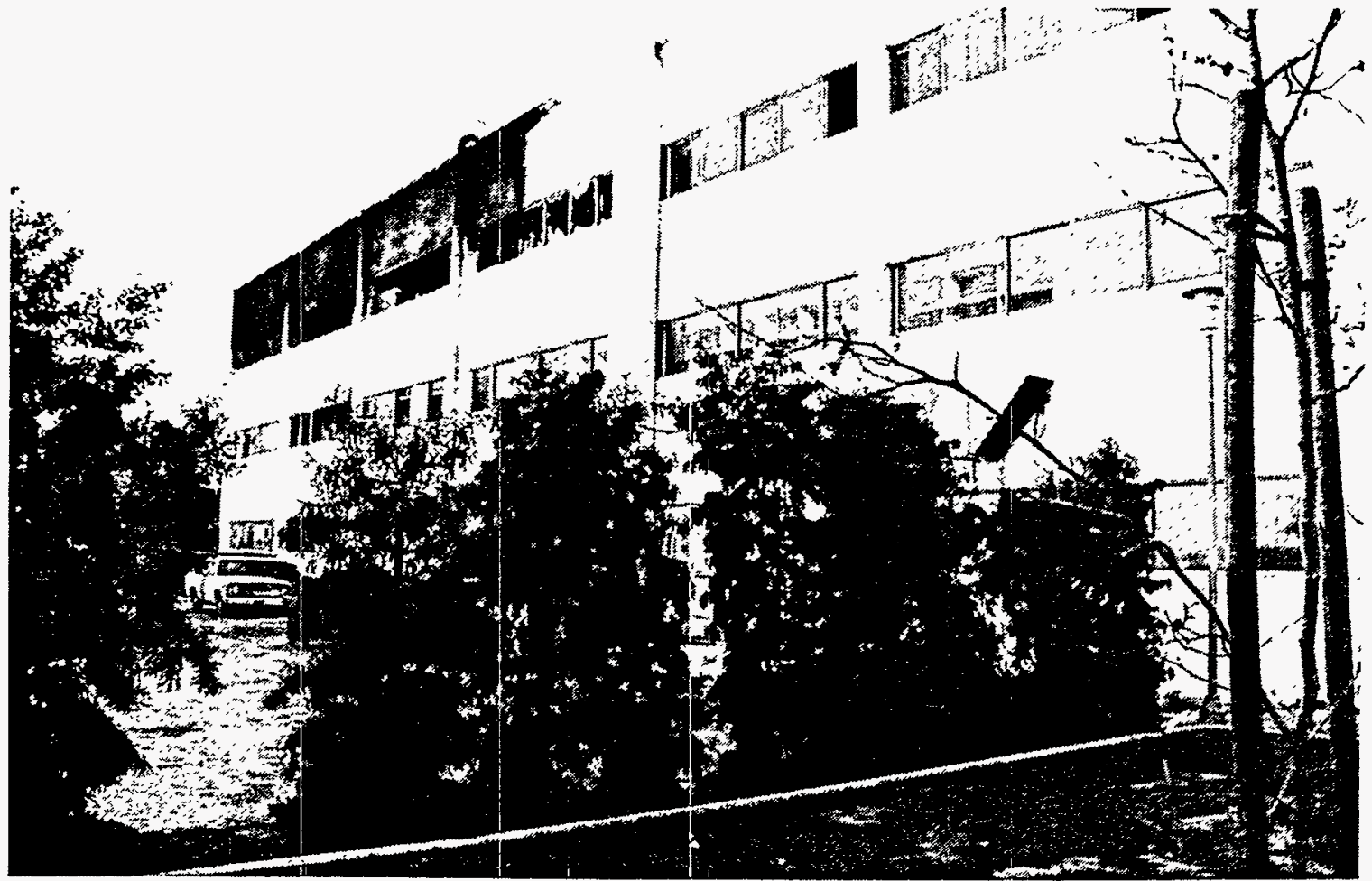

Figure 4.5-7: Fire in Science Building 3 at CSUN included toxic materials and required a Hazmat Team to perform clean-up operations. 
As a result of the Northridge Earthquake, a fire occurred in Science Building 3 at CSUN that included toxic materials and required a Hazmat Team to perform clean-up operations (see Figure 4.5-7). Near the science building, a trailer fell off of its pedestals so that the doorway was blocked by the stairway (see Figure 4.5-8).

\subsubsection{Energy Technology Engineering Center}

The Energy Technology Engineering Center (ETEC) is a DOE facility located about 10 miles west of the epicenter. It is a 90 -acre site with about 70 buildings on the western edge of the 2700 -acre Rocketdyne Field Laboratory which is operated by Rockwell International. Located near the top of hills between the San Fernando and Simi Valleys, the terrain surrounding ETEC is hilly and rocky and the geology is primarily bedrock with thin alluvium between bedrock outcrops [ref 4.5-2]. The earthquake caused several landslides north of the facility and one of those landslides closed a local access road as shown in Figure 4.5-9. Located at ETEC are major test facilities including the Sodium Pump Test Facility, numerous buildings housing test equipment, large storage tanks, a high pressure gas storage facility, and vacuum chambers.

ETEC had minimal damage following the Northridge Earthquake and was fully operational after lifeline services from offsite were repaired. The good performance of structures, systems, and components at ETEC was due, in part, to the moderate accelerations. Since ETEC is located on bedrock, there was little amplification of the incoming ground motion. Several locations at ETEC had USGS strong motion instruments and the accelerations measured at those locations are listed in Table 4.5-1 [ref 4.5-2].

Table 4.5-1: USGS Strong Motion Data from ETEC

\begin{tabular}{llc} 
Location & Direction & Magnitude \\
\cline { 2 - 3 } Freefield (Ground) & $90^{\circ} \mathrm{E}-\mathrm{W}$ & $0.29 \cdot \mathrm{g}$ \\
Freefield (Ground) & Vertical & $0.16 \mathrm{~g}$ \\
Freefield (Ground) & $360^{\circ} \mathrm{N}-\mathrm{S}$ & $0.23 \mathrm{~g}$ \\
Building 026 (Ground) & Horizontal & $0.32 \mathrm{~g}$ \\
Building 026 (Ground) & Vertical & $0.27 \mathrm{~g}$ \\
Building 462 (1st Floor) & $90^{\circ} \mathrm{E}-\mathrm{W}$ & $0.24 \mathrm{~g}$ \\
Building 462 (1st Floor) & $\mathrm{Vertical}^{\circ}$ & $0.23 \mathrm{~g}$ \\
Building 462 (1st Floor) & $360^{\circ} \mathrm{N}-\mathrm{S}$ & $0.34 \mathrm{~g}$ \\
Building 462 (6th Floor) & $90^{\circ} \mathrm{E}-\mathrm{W}$ & $0.41 \mathrm{~g}$ \\
Building 462 (6th Floor) & Vertical $^{\circ}$ & $0.40 \mathrm{~g}$ \\
Building 462 (6th Floor) & $360^{\circ} \mathrm{N}-\mathrm{S}$ & $0.40 \mathrm{~g}$ \\
Building 463 (Roof) & $90^{\circ}$ & $0.41 \mathrm{~g}$ \\
Building 463 (Roof) & Vertical $^{\circ}$ & $0.66 \mathrm{~g}$ \\
Building 463 (Roof) & $360^{\circ}$ & $0.76 \mathrm{~g}$
\end{tabular}




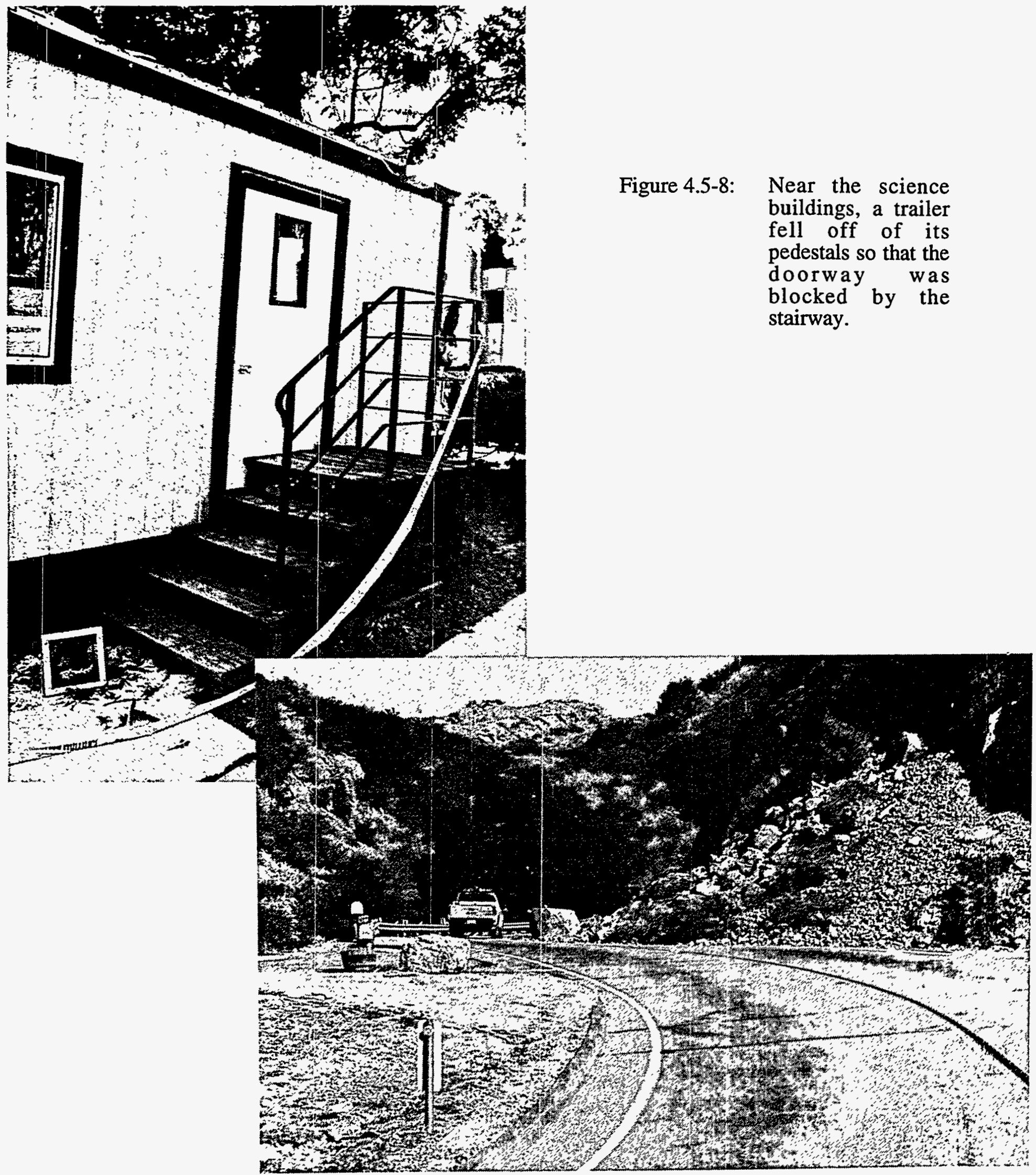

Figure 4.5-9: Landslides near the Energy Technology Engineering Center closed a local access road. 
The seismic mitigation efforts at ETEC also contributed to minor levels of damage. These efforts included site seismic risk assessments, anchorage requirements, and emergency response plans. While most structures, systems, and components (SSCs) survived the earthquake with no damage, there was some nonstructural damage and slight damage to internal lifeline systems. A horizontal nitrogen tank had damage due to spalling of its pedestal supports. The tank is 40-feet long and had both of its end restrained which did not permit motion of the tank during the earthquake. While the tank containment was not breached, the damage to its supports required that the tank was taken out-of-service. The beams for a bridge crane in a high bay had shear failure of their lateral supporting bolts. Within most buildings, the nonstructural damage consisted of repositioning equipment and repairing light fixtures which were not adequately supported.

In the Rocketdyne Field Laboratory, there was damage to the communication systems and repairs had to be made to telephone poles and lines and the public address system. The water system also had minor damage with a crack in a holding pond dam. Since there was minimal damage at ETEC, the response of SSCs at the facility and nearby Rocketdyne facilities may provide useful information for the DOE experience database for equipment evaluation. Information about the responses of SSCs which are unique to the DOE, such as glove boxes, would greatly enhance the existing database which primarily has data on SSCs found in nuclear power plants. In addition, there may be examples of successful techniques for seismic mitigation. Detailed evaluations are planned for collecting information about the response of SSCs at ETEC and nearby facilities including a $35 \mathrm{MW}$ cogeneration plant.

\subsection{EMERGENCY POWER SYSTEMS}

In many cases during the Northridge Earthquake, the emergency power systems at industrial facilities started up immediately and provided the necessary power to the critical systems and components throughout the buildings involved. However, as described in other sections of this report, individual components or seismic "weak links" inhibited or curtailed successful facility operations for days to weeks. These "weak links" included: failure of automatic transfer switches from normal offsite power to the emergency power circuit, failure of controls to properly switch from the empty fuel day tank to the auxiliary fuel tank, failure of piping on subsystems attached to the cooling tower which lost capacity to provide cooling water to the emergency power generators, and failure of relays in some of the emergency power distribution cabinets. Failure of piping connections, piping at building separations, and piping attached to poorly reinforced masonry partition walls in fire protection systems and on HVAC water lines resulted in extensive water leaks. These water leaks caused electrical shorts in the emergency power distribution cabinets. 


\subsection{REFERENCES}

4.0-1 The Orange County Register, Has Falling Only Begun, Business, January 26, 1994.

4.1-1 Jacobs/Wolder Engineering Company, AES - Placerita Earthquake Damage Assessment, January 25, 1994.

4.1-2 CSMIP, CSMIP Strong-Motion Records from the Northridge, California Earthquake of January 17, 1994, California Department of Conservation, Division of Mines and Geology, Office of Strong-Motion Studies, Report OSMS 94-07, February 18, 1994.

4.1-3 Jennings, C.W. and Strand, R.G., Geologic Map of California, Los Angeles Sheet, 1969.

4.1-4 Darragh, R., T. Cao, C. Cramer, M. Huang and A. Shakal, Processed CSMIP StrongMotion Records from the Northridge, California Earthquake of January 17, 1994: Release No. 1, California Department of Conservation, Division of Mines and Geology, Office of Strong-Motion Studies, Report no. OSMS 94-06B, February 7, 1994.

4.1-5 Ostrom, D., Verbal Communication, April 1994.

4.2-1 Interview with Satoshi Nitta, Assistant Director, Construction, St. John's Hospital, Santa Monica, CA, 5/04/94.

4.2-2 Interview with Bob Henson, Director of Facilities, Northridge Hospital \& Medical Center, Northridge, CA, 5/04/94.

4.2-3 Interview with Ron French, Assistant Director of Facilities, Olive View Hospital, Sylmar, CA, $2 / 08 / 94$.

4.2-4 Interview with Ron Foster, Facilities Engineering, Veterans' Administration Hospital, Sepulveda, CA, 5/06/94.

4.2-5 Earthquake Engineering Research Institute (EERI), "Northridge Earthquake January 17, 1994 Preliminary Reconnaissance Report".

4.2-6 Earthquake Engineering Research Center, "Preliminary Report on the Seismological and Engineering Aspects of the January 17, 1994 Northridge Earthquake", College of Engineering, University of California at Berkeley, CA, Report UCB/EERC-94-01, January 1994. 
4.2-7 Draft Report on "Performance of Health Care Facilities During the Northridge Earthquake: Damage to Water Lines and Failure of Emergency Generators" to be published at end of 1994 by California Office of State-wide Health Planning and Development (OSHPD).

4.4-1 Goltz, J.D., The Northridge, California Earthquake of January 17, 1994: General Reconnaissance Report, NCEER-94-0005, National Center for Earthquake Engineering Research, State University of New York at Buffalo; March 11, 1994.

4.4-2 Monastersky, R., "The Fatal Fling - A Maverick Earthquake Theory Spells Trouble for Tall Buildings", Science News, Vol. 145, No. 26, June 25, 1994.

4.4-3 Bachman, R., Structural Response of the Los Angeles Fire Command and Control Facility to the Northridge Earthquake, Fluor Daniel, Inc., January 25, 1994.

4.4-4 State of California Department of Conservation, Division of Mines and Geology, Third Quick Report on CSMIP Strong-Motion Data from the Northridge / San Fernando Valley Earthquake of January 17, 1994, Report OSMS 94-03, January 19, 1994.

4.4-5 Bachman, R.E., Gomez, M.J., and Chang, K.C., Verification Analysis of the Base Isolated Los Angeles County Fire Command and Control Facility, Fourth U.S. National Conference on Earthquake Engineering, Palm Springs, California, May 20 - 24, 1990.

4.4-6 State of California Department of Conservation, Division of Mines and Geology, First Quick Report on CSMIP Strong-Motion Data from the San Fernando Valley Earthquake of January 17, 1994, Report OSMS 94-01, January 17, 1994.

4.5-1 Earthquake Engineering Research Institute (EERI), Northridge Earthquake January 17, 1994 Preliminary Reconnaissance Report.

4.5-2 Onesto, A., Effects of the Northridge Earthquake on the Energy Technology Engineering Center, presented at the Natural Phenomena Symposium for California and Nevada DOE Sites, Oakland, California, November 17, 1994. 


\section{OTHER LIFELINES}

This chapter describes the seismic performance of other lifelines such as water systems, telecommunications, natural gas systems, and freeway structures. Pipeline distribution systems, carrying water, gas, and liquid fuels all suffered failures, much of which was attributed to permanent ground deformations. Transportation was disrupted by the failure of bridges along four major highways, Interstate (I-5), State Route (SR) 14, I-10, and SR-118. Seismic interaction between co-located lifelines is also an important issue arising from the Northridge Earthquake.

\subsection{WATER SYSTEMS}

\subsubsection{Los Angeles Department of Water and Power (LADWP)}

With approximately 660,000 service connections located within 60 miles of the epicenter, LADWP is the major distributor of water in the earthquake-affected region. LADWP supplies an average of 560 million gallons of water daily through an extensive lifeline system. Within the earthquakeaffected region, components of the LADWP system include: over 7,000 miles of water mains, about 85 booster pumping stations, five large storage reservoirs, nearly 100 storage tanks, the Los Angeles Owens River and Second Los Angeles Aqueducts, almost 90 pumping groundwater wells, two groundwater treatment facilities, several hydroelectric power plants, and the Los Angeles Aqueduct Filtration Plant [ref 5.1-1].

The earthquake did affect the performance of the LADWP system as shown in Figure 5.1-1. Earthquake-induced damage occurred in storage tanks, in the Los Angeles Aqueducts, and at the Los Angeles Aqueduct Filtration Plant. Additionally, many of the main trunk lines in the LADWP system either ruptured or sustained leaks. Numerous leaks in the smaller diameter pipes of the distribution system delayed the resumption of normal water service after the main components of the system such as the treatment plant were repaired. In the San Fernando Valley, over 1200 leaks were reported within the distribution network. There are several observations or lessons learned about the system performance during and following the earthquake. First, much of the damage in the LADWP system occurred in vulnerable pipelines. In addition, lack of flexible connections caused damage in storage tanks and their attached components. Next, there were interactions between the performance of the water system and other lifelines. Finally, redundancies in the system allowed service to be restored to most customers fairly quickly. 


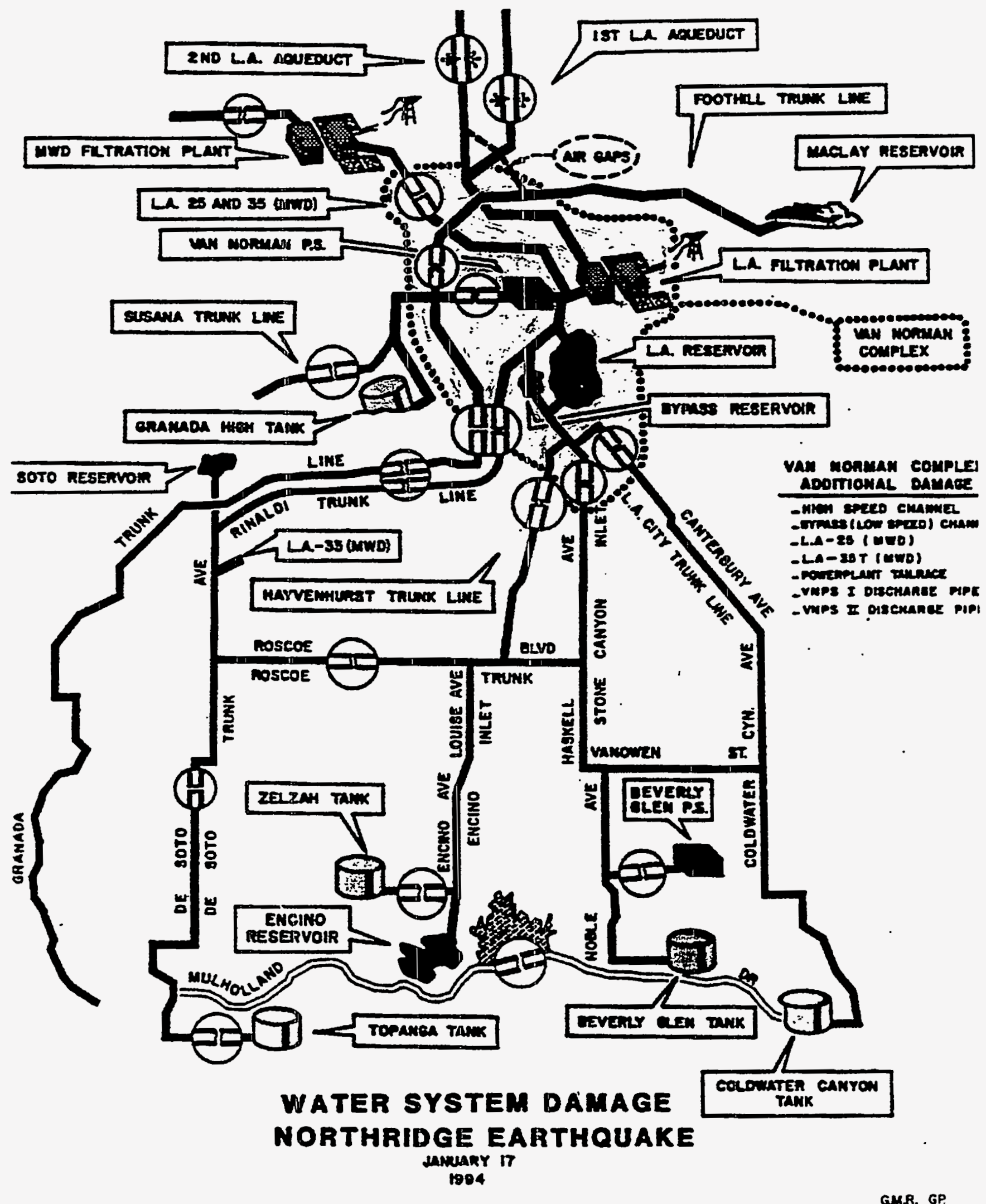

Figure 5.1-1: There was earthquake-induced damage to the water system operated by the Los Angeles Department of Water and Power [ref 5.1-9]. 
Much of the damage caused by the earthquake to the LADWP system occurred in water mains. The types of damage that occurred in water mains or pipelines included failures of floats in air valves, stretched dresser couplings, tensile tears in heat affected zones of welded slip joints, and buckling of welded slip joints. In some cases, especially within the small diameter distribution pipelines, corrosion reduced the strength of the pipelines. Leaks and breaks occurred as the tensile and compressive motion of the earthquake affected corrosion-weakened pipelines. Repairs to the water system including the distribution network were time consuming due to a draining, repairing, filling, and testing process which had to be repeated several times in some pipelines.

Before the earthquake, the Rinaldi Trunk Line had been identified as vulnerable in several locations where it was a relatively rigid concrete pipeline with no blow-off or shutoff valves. Without those valves, pressure changes induced by the ground motion of the earthquake had to be accommodated by the piping. Since the concrete pipeline was relatively rigid, several dresser couplings in the pipeline slipped causing leaks at those locations. Even though the dresser couplings were installed as expansion joints, they could not withstand the motion in the piping. A proposed retrofit is to use long-body dresser couplings which are more ductile since they allow for more elongation and less rotation. In addition, most modern pipelines are fabricated from welded steel pipe to allow for more ductile performance as compared to a concrete pipeline.

There were several locations where welded steel pipelines did not accommodate the earthquakeinduced ground motion. A location of failed welded steel pipelines was along Balboa Boulevard between Lorillard and Rinaldi Streets. Balboa Boulevard is a utility corridor with several lifeline systems including water, natural gas, electric power, telecommunications, oil, and sewer. At this location, which is about 4 miles northeast of the epicenter, Balboa Boulevard runs north-south and slopes downward from Lorillard Street to Rinaldi Street at about 1/8 to 1/4 inch per foot. Ground displacement at this location created a tensile zone near Lorillard Street and a compression zone near Rinaldi Street. Figure 5.1-2 shows a 2-foot overlap in a sidewalk parallel to Balboa Boulevard which was caused by compressional buckling of the ground surface during the earthquake. Passing through both zones are the 49-inch diameter Granada Trunk Line and the 68inch diameter Rinaldi Trunk Line which are both steel pipelines with welded slip joints. In the compression zone, the slip joints buckled and split near the top of the pipelines. Repairs to the slip joints are shown in Figure 5.1-3a. About 500 yards north of the compression zones, there were tensile failures near butt welded joints in the pipelines. Tensile cracks in the soil were evidenced near these failures as shown in Figure 5.1-3b. Extensive flooding occurred in the area due to the compressive and tensile failures in the water pipes. A combination of permanent ground motion and insufficient flexibility in the pipelines contributed to the failures at Balboa Boulevard. 


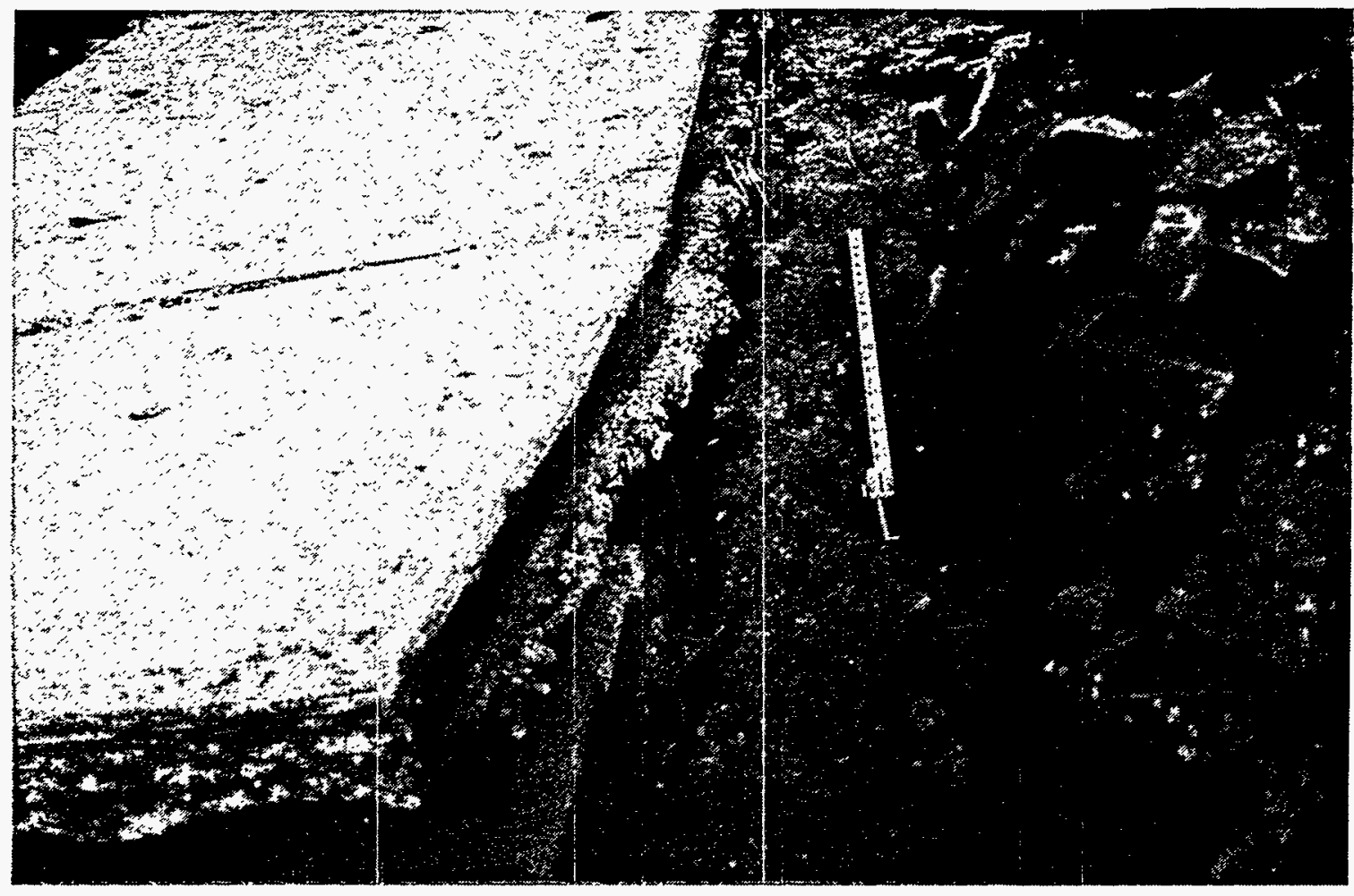

Figure 5.1-2: Due to compressional buckling of the ground surface along Balboa Boulevard, a two foot length of the north portion of the sidewalk moved over the south portion of the sidewalk.

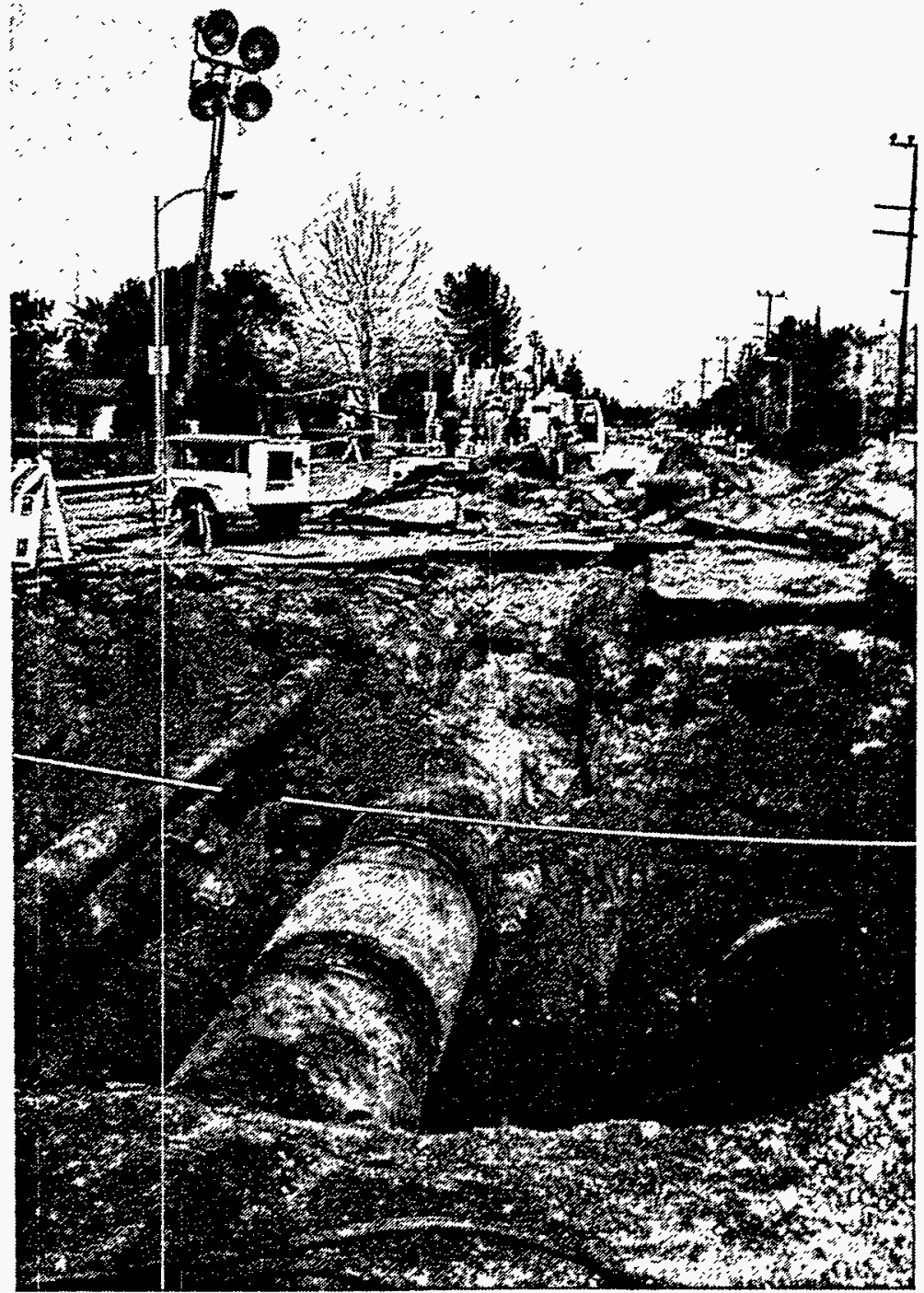




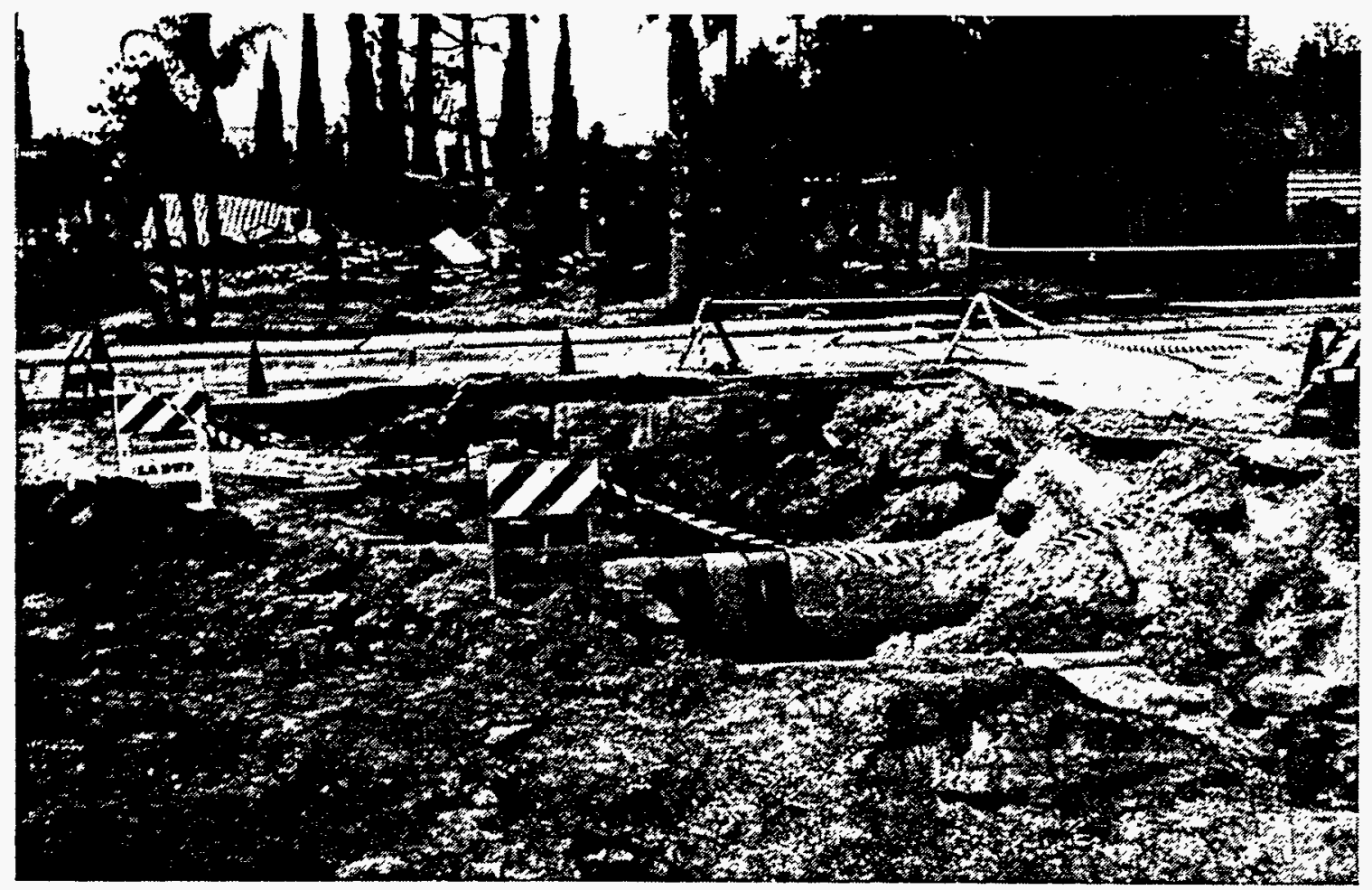

Figure 5.1-3b: Near tensile failures in water and natural gas pipelines, a tensile crack in the ground is evidenced as it crosses perpendicular to Balboa Boulevard.

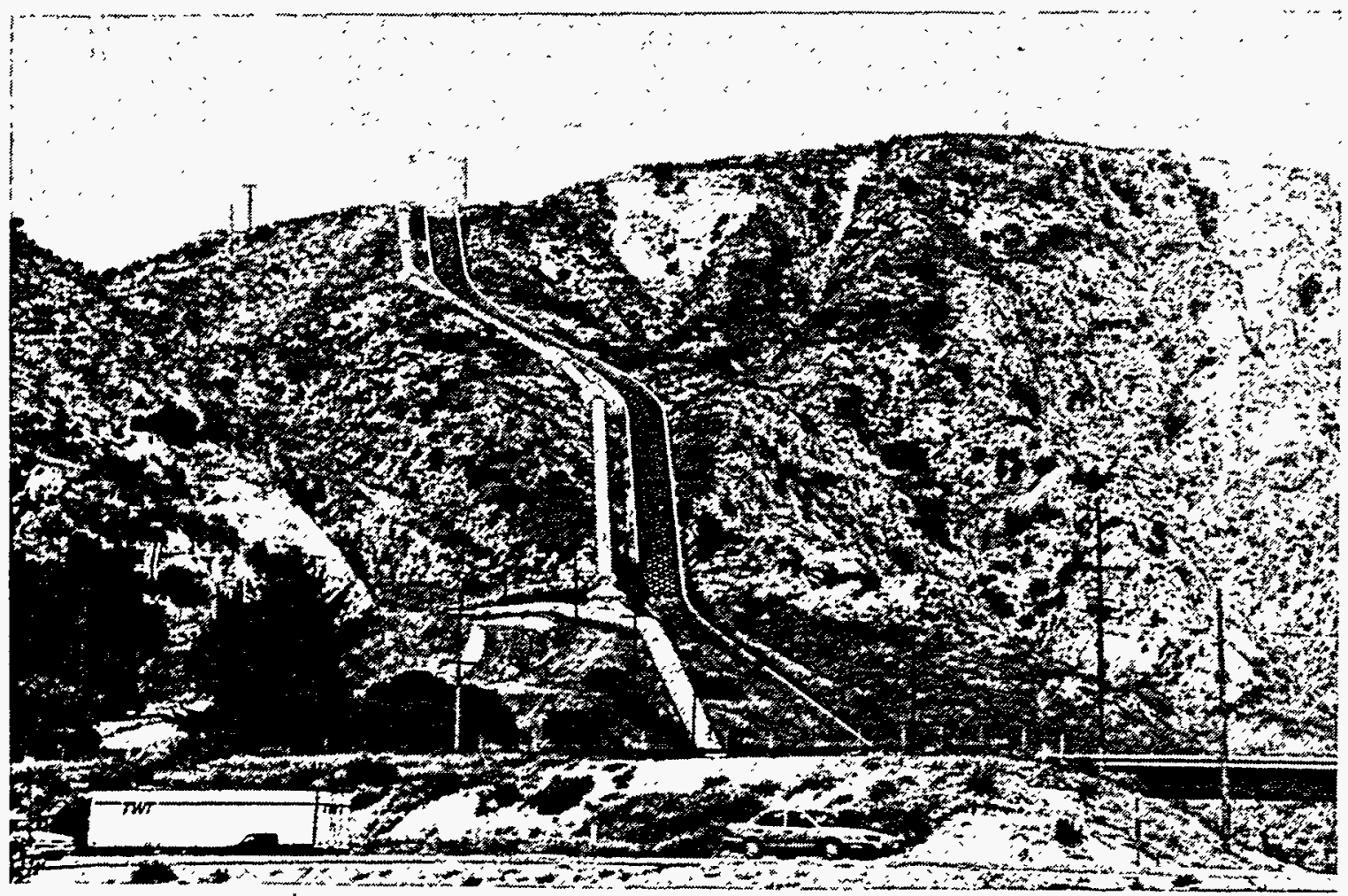

Figure 5.1-4: Two aqueducts operated by the Los Angeles Department of Water and Power pass through the top of Terminal Hill which is located about 10 miles northeast of the Northridge Earthquake epicenter. 
About $10 \%$ of the LADWP storage tanks failed at their base or roof. In older-vintage tanks, the roofs did not have the capacity to withstand the sloshing loads and they failed. The inlet and outlet lines in other older-vintage tanks also lacked sufficient flexibility to withstand the differential motion of the tank and the piping. The attached piping in the Granada High Tank, shown in Figure 5.1-1, ruptured due to the lack of flexible connections. Current LADWP design requires the roofs to support the sloshing loads and the inlet and outlet lines to have some flexibility. Typically, the storage tanks are unanchored flat bottom tanks and there was evidence of motion of these tanks throughout the LADWP system.

There were several cases of interactions between co-located lifelines during the earthquake. One example of lifeline interaction occurred along Balboa Boulevard between Lorillard and Rinaldi Streets. At the locations of tensile and compressive failures of the Granada and Rinaldi Trunk Lines, there were failures of a 22 -inch diameter steel natural gas pipeline. Failures of both the water and natural gas pipelines produced a dramatic image of flames rising from flowing water. Information about the failure in the natural gas pipeline and the ensuing fire is found in Section 5.3 of this report. Further south on Balboa Boulevard, there was lifeline interaction between the Balboa Boulevard Overcrossing, which spans the 118 Freeway, and the utilities carried by the overcrossing bridge. Electric power lines, water pipelines, natural gas pipelines, and telecommunication lines are carried through ducts and pipes supported by the bridge. Table 5.4-1 summarizes the utilities carried along the overcrossing. During the earthquake, the water pipelines ruptured and caused damage to the abutments of the bridge. The support system in the bin abutment was undermined and the seat abutment sustained damage at a front wall [ref 5.1-2]. As discussed in Section 5.4.5 of this report, the undermining caused by the water led to closure of the overcrossing.

Lifeline interactions also occurred between electric power and water systems. As discussed in Chapter 3 of this report, Los Angeles lost power immediately following the earthquake. Fortunately, most the main components of the water system had backup power supplies so there were no adverse affects from the loss of off-site power. There were adverse affects between the electric power and water systems in another utility corridor which exists near the interchanges of I5 and SR-14. In this area, there are examples of every type of lifeline system including water, natural gas, transportation, and electric power. During the earthquake, the aqueducts in this area sustained damage and the water from the damaged aqueducts interacted with the electric power lifeline at the Rinaldi Substation. Following the earthquake, repairs at the substation were hampered by the large volume of water which flooded the substation. The water slowed repairs in the switchyard and damaged computer equipment and files in the operations building. 
Following the earthquake, aqueducts and trunk lines providing the water supply for LADWP were damaged. Fortunately, redundancies in the water supply for the epicentral region and in the LADWP system permitted service to be returned to most areas within several days. While the aqueducts were being repaired, water was supplied from storage reservoirs and other regional sources. As storage reservoirs emptied, additional water was supplied by a local water wholesaler to accommodate the lack of LADWP water. In order to service the distribution system, damaged portions of the system were isolated while they were repaired. Using redundant paths, undamaged portions of the system were able to provide water to the epicentral region. In addition, pumpers from the Los Angeles Fire Department were used to pump water to high elevation service zones. Within a week, the aqueducts and the Granada Trunk Line, the most severely damaged trunk line, were placed in service and the pumpers were removed from the system. Twelve days after the earthquake, boil notices were lifted for Los Angeles.

\subsubsection{Los Angeles Aqueduct Filtration Plant - Van Norman Complex}

The Los Angeles Aqueduct Filtration Plant is a $600 \mathrm{Mg}$ / day treatment plant for water entering the LADWP system through the Los Angeles Owens River and Second Los Angeles Aqueducts. It is located within the Van Norman Complex about 6 miles northeast of the epicenter and it borders the Joseph Jensen Filtration Plant and the LADWP Sylmar Converter Station. The Van Norman Complex contains the Filtration Plant, three pumping stations, ten major pipelines, the Los Angeles Dam, the Upper San Fernando Dam, and the Lower San Fernando Dam. The Upper and Lower San Fernando Dams are old dams which are no longer used for water retention. About two miles northeast of the Van Norman Complex, the measured peak free-field accelerations from strong motion instruments at the Olive View County Hospital were $0.91 \mathrm{~g}$ in the horizontal direction and $0.60 \mathrm{~g}$ in the vertical direction [ref 5.1-3]. These levels of acceleration as well as the local soil conditions at the site contributed to some damage sustained at the complex during the earthquake. Fortunately, earthquake mitigation procedures and practices used since the 1971 San Fernando Earthquake minimized the damage at the facility.

The Filtration Plant is situated on a sedimentary basin that can be susceptible to ground settlement and liquefaction during earthquakes. It is reported that there was significant ground settlement between two and eight inches at various locations at the site [ref 5.1-4]. There were cracks in the ground up to several inches in width throughout the Van Norman Complex. The ground settlement at the Filtration Plant caused several chlorine lines, a PVC ozone vacuum line, and electrical conduits to be severed. In addition, a rigid PVC pipeline attached to an overflow tank was ruptured by differential motion between the tank and the attached piping. The PVC pipeline 
had insufficient bracing to limit its motion. There were also leaks in chlorine lines and other pipelines throughout the plant which caused flooding in pipe and utility galleries. After repairing the significant damage, the plant was returned to full operation in one week. Portions of the plant were shut down several weeks after the earthquake when the sealant used to repair the earthquakeinduced leaks failed.

The dams and associated pipelines at the Van Norman Complex experienced damage during the Northridge Earthquake mostly due to ground settlement. There were about 25 breaks or leaks in the major pipelines at the complex. While the pumping stations at the complex had very minor damage, they were useless until the pipelines were repaired. The Los Angeles Dam had minor cracking in its asphalt lining and it is reported that it settled 0.29 feet [ref 5.1-4]. A 73-inch diameter riveted steel pipe exiting an abutment of the Lower San Fernando Dam ruptured causing extensive flooding in the area. In addition, a 3-foot diameter pipe suffered severe pier damage near the Upper San Fernando Dam. At some locations, the pipeline dropped off its support columns.

Similar to the Filtration Plant, the Donald Tillman (80 Mgd) and Los Angeles - Glendale (20 Mgd) Water Reclamation Plants suffered minor damage during the earthquake. Both plants lost off-site power for about 8 hours and resumed full operation within a day. Some of the process equipment such as the aerators and clarifiers became misaligned or jammed and there was minor cracking in process piping. At the Tillman Plant, the railings in the clarifier tanks were displaced when 3/8inch diameter pins attaching their plastic brackets to the tank walls became dislodged. Since the scrapers were supported by the railings, the chain movement of the scrapers was jammed. It is reported that emergency power was not used at the Tillman Plant due to unexpected performance of the $1500 \mathrm{~kW}$ diesel generator. After the plant lost off-site power, the generator started but produced strange noises and sparks and was shut down by the operator. There was nonstructural damage to a maintenance building near the plant due to dislodged warehouse stock and fallen ceiling tiles and ducting. The dislodged material slowed repairs to the plant since it covered needed equipment and supplies. None of the earthquake-induced damage affected the treatment processes and there was no biological system loss at the Tillman Plant [ref 5.1-5].

The Filtration Plant and reclamation plants performed relatively well during the Northridge Earthquake due to the seismic mitigation procedures and practices used within LADWP. Much of these procedures and practices were based on lessons learned from the performance of the LADWP water system during the 1971 San Fernando Earthquake. Significant ground settlement and liquefaction occurred at the Van Norman Complex and there was widespread damage in the LADWP water system following the 1971 earthquake. Damage at the Upper and Lower San Fernando Dams was sufficient enough to require the construction of the Los Angeles Dam. 
Further information about the response of the LADWP water system including the Van Norman complex during the 1971 San Fernando Earthquake is available in Engineering Aspects of the 1971 San Fernando Earthquake [ref 5.1-6].

As mentioned earlier, two LADWP aqueducts enter the Filtration Plant at its north end. These aqueducts deliver an average of 430 million gallons per day which is about $75 \%$ of the water supply for LADWP [ref 5.1-1]. At the Filtration Plant, there were cracks in the concrete aqueduct channels due to settlement of the supporting soils. These and other cracks in the aqueducts were repaired with epoxy grout. More extensive damage occurred in the Second Los Angeles Aqueduct about 6 miles northwest of the plant. Before entering the San Fernando Valley, the aqueducts pass through the top of Terminal Hill as shown in Figure 5.1-4. While the concrete relief tank at the top of the hill suffered no damage during the earthquake, the Second Los Angeles Aqueduct was ruptured at a dresser coupling. On the north side of Terminal Hill, the aqueduct pipe is supported on concrete saddles which are anchored to a slope with long rods as shown in Figure 5.1-5.

During the earthquake, ground settlement caused the saddle points to slide about 4 inches downhill. Due to this motion, the pipe slid and became separated from the saddles. As the pipe slid, it created several buckled sections at the bottom of the slope and it caused a coupling to rupture at the top of the slope. The buckled sections formed hinges at the heat-affected zone for the welds on the bell-and-spigot joint and bulged up to 6 inches in height, but they did not rupture the pipe as shown in Figure 5.1-6. At the coupling, the aqueduct pipe was pulled apart by about 8 inches and the coupling lacked sufficient ductility to accommodate that displacement. The coupling consisted of eight $13 / 8$-inch diameter restrainer rods attached to brackets welded to two 77-inch diameter pipes [ref 5.1-5]. To increase the ductile performance of the pipe connection, the single coupling was replaced with a pair of couplings 15 inches apart. The aqueduct was returned to operation four days after the earthquake.

\subsubsection{Joseph Jensen Filtration Plant}

The Joseph Jensen Filtration Plant is operated by the Metropolitan Water District of Southern California (MWD) which is a wholesaler of water within Southern California. MWD consists of 14 cities, 12 municipal water districts, and one county water authority. In 1991-92, MWD sold about 14\% of its water to LADWP which accounted for 65\% of the needs of LADWP [ref 5.1-7]. The two sources of water for MWD are the State Water Project (SWP) from Northern California and the Colorado River. Within the earthquake-affected region, components of the MWD system include the SWP Aqueduct, the Joseph Jensen Filtration Plant, several water storage tanks, a hydroelectric power plant, and a network of pipelines. Most of the damage to the MWD system 


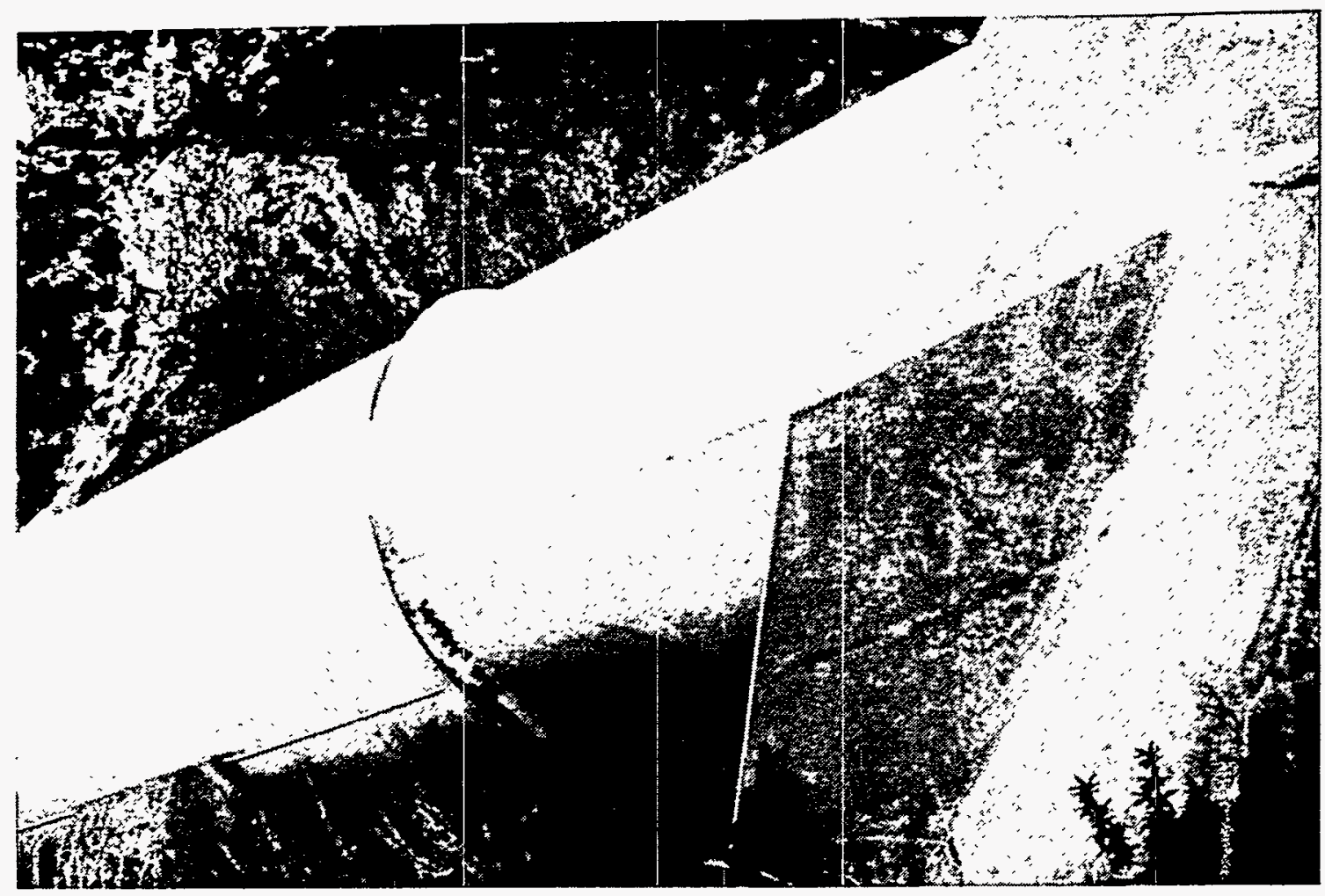

Figure 5.1-5: The Second Los Angeles Aqueduct is supported on concrete saddles which are anchored to the north slope of Terminal Hill [ref 5.1-9].

Figure 5.1-6: On the north slope of Terminal Hill, the Second Los Angeles Aqueduct sustained buckled sections with bulges up to six inches in height [ref 5.1-9]. 
occurred at the Joseph Jensen Filtration Plant. There are several observations or lessons learned about the performance of the Filtration Plant during and following the earthquake. First, local soil conditions significantly contributed to the damage at the plant. Second, earthquake mitigation procedures and practices used since the 1971 San Fernando Earthquake minimized the damage at the facility.

The Jensen Plant is a $550 \mathrm{Mgd}$ treatment plant for water entering the Los Angeles basin through an aqueduct from Castaic Lake, which is part of the SWP. It is located about 6 miles northeast of the epicenter and it borders the LADWP Van Norman Complex and Sylmar Converter Station. Due to expansion at the site, about $60 \%$ of the plant was under construction during the earthquake. The measured peak accelerations from strong motion instruments at the ground level in structures at the site were $0.98 \mathrm{~g}$ in the horizontal direction and $0.52 \mathrm{~g}$ in the vertical direction [ref 5.1-4]. These levels of acceleration as well as the local soil conditions at the site contributed to the damage sustained during the earthquake.

The plant is oriented north-south with the aqueduct from the SWP entering at the north end and water basins at the south end, as shown in Figure 5.1-7. While the west side of the site is in cut, the east side is an engineered fill slope with a maximum height of 40 feet [ref 5.1-4]. In addition, the local soil is alluvial fill similar to that found in sedimentary basins such as the San Fernando Valley. Following the earthquake, evidence of ground motion and settlement was observed especially within the engineered fill. Cracks up to three inches wide with several inches of vertical offset were evidenced in the eastern slope of the site [ref 5.1-4]. The ground settlement within the engineered fill caused a rupture in one of the two 84-inch diameter influent pipelines which connect with the aqueduct at the north end of the site. The buried, steel inlet pipes, which are 13/16-inches thick, moved between one and two inches towards the free side of the slope. One pipe cracked near the heat affected zone of a welded bell-and-spigot joint and this released about $25 \mathrm{ft}^{3} / \mathrm{sec}$. The crack initiated in the pipe and not in the weld and it caused the pipe to shear as shown in Figure 5.1-8. In addition to the area near the inlet pipes, the ground settled about six inches vertically around the Operations Building. This settlement caused PVC chlorine lines to leak and severed other lines and conduits between construction joints in the building. Within the Operations Building, there was interior damage such as fallen contents as well as minor structural damage. Near the Operations Building, damage also occurred to the wooden baffles within the mixing basins. Since the baffles are designed as expendable, they could not withstand the levels of sloshing in the basins. Finally, the Finished Water Reservoir, which is a covered reservoir, sustained minor cracking in its asphalt lining and within a few concrete columns. 


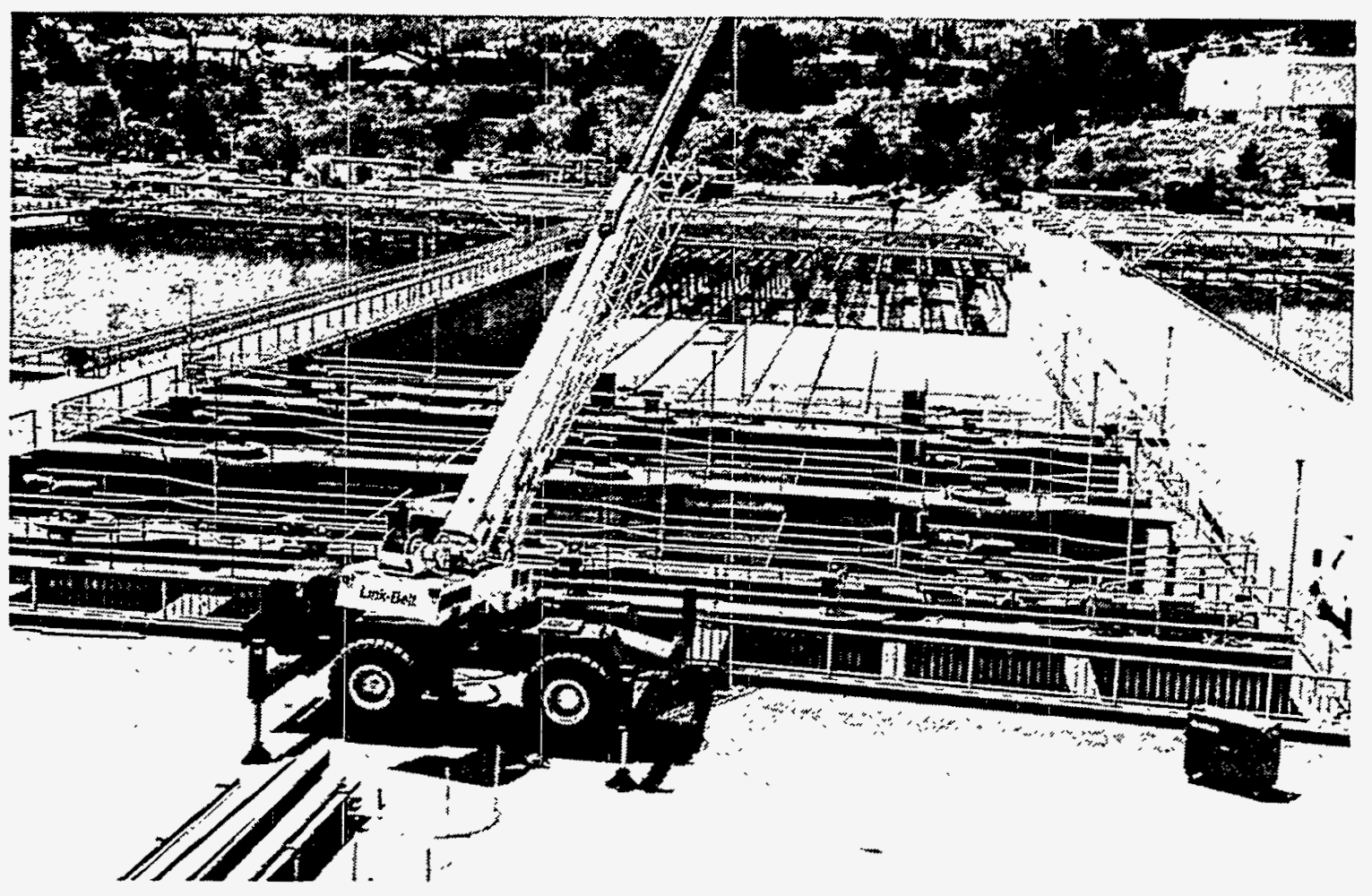

Figure 5.1-7: The Joseph Jensen Filtration Plant is operated by the Metropolitan Water District of Southern California.

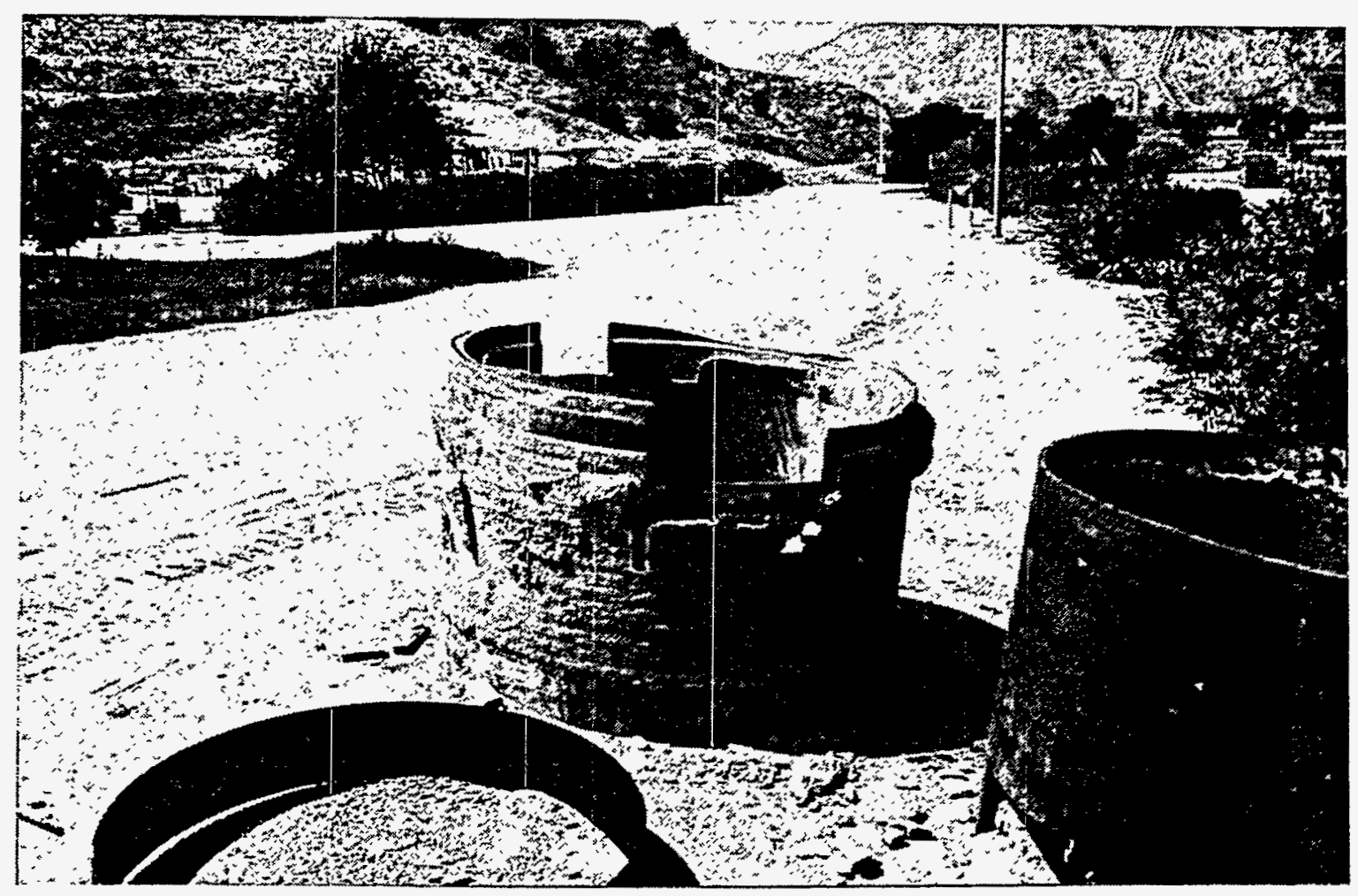

Figure 5.1-8: Section of the 84-inch diameter pipe which ruptured at the Jensen Plant. 
Damage at the Jensen Plant was minimized due to the earthquake mitigation procedures and practices used at the facility. Much of these procedures and practices were based on lessons learned from the performance of the facility during the 1971 San Fernando Earthquake. Due to damage caused by the 1971 event, startup of the facility was delayed by two years even though the original portion of the facility was $90 \%$ complete. The Control Building had extensive damage due to liquefaction and ground settlement and most of the concrete columns supporting the roof of the concrete reservoir were severely damaged. In addition, several water tanks were damaged due to inadequate anchorage. Further information about the response of this facility during the 1971 San Fernando Earthquake is available in Reference 5.1-6. Even though the magnitude and the distance of the Jensen Plant from the epicenter of the 1971 San Fernando and 1994 Northridge Earthquakes were similar, in 1994 the plant received less damage and had restored operations in a week.

Several mitigation procedures and practices that improved the performance of the Jensen Plant during the Northridge Earthquake included an emergency response plan, a soil densification program, and piping designs allowing for sufficient flexibility. Immediately following the earthquake, an emergency operations center was activated at the MWD Headquarters Building in Los Angeles. The center was useful in organizing the appropriate response staff and identifying the portions of the MWD system that needed attention. At the Jensen Plant, the ruptured inlet pipeline was isolated from the system and placed back into service within 72 hours. Similar to other facilities within the epicentral region, the Jensen Plant lost off-site power immediately following the earthquake. The emergency generator for the facility came on-line as required and operated for 34 hours. With power, the pumping and other pieces of mechanical equipment functioned as required and there were no reports of relay or motor control center problems. In addition to an emergency response plan, a soil densification program was used to increase the capacity of the soil in the plant. To counteract potential ground settlement and liquefaction at the site which consists of alluvium fill and a high water table, gravel was placed in wells which were drilled near the Operations Building. In 1994, it appeared that the gravel wells offered some resistance to ground settlement as compared to the soil response in 1971.

Throughout the Jensen Plant, efforts were made to provide sufficient flexibility in piping and attached lines. To accommodate relative motion at connections, sleeve dresser couplings were used for piping in the Operations Building. While most of these couplings leaked after the earthquake, they were returned to full operation by tightening the coupling and installing new gaskets as required. Flexible attached lines were used with two 1.75-million gallon, backwash tanks on the west side of the plant. One of the tanks was being used during the earthquake, while the other was under construction. Since the tanks were unanchored, they moved between 2 and 3 
inches during the earthquake. As shown in Figure 5.1-9, the motion of the tanks was accommodated by the attached lines and the tanks did not suffer damage. Near the northern end of the Jensen Plant, no lines were severed in the chlorine tank farm which is shown in Figure 5.1-10. Most of the tanks in the farm were not anchored and there was evidence of tank motion. Fortunately, there was sufficient slack in the attached lines to prevent leaks or tank damage.

\subsubsection{Response of Other Systems}

Water supply and distribution systems serving the Santa Clarita and Simi Valleys were affected by the earthquake. In the Santa Clarita Valley, about 15 miles north of the epicenter, there were over 300 leaks in the distribution network and the boil notice was not lifted until 18 days after the earthquake. Fortunately, damage to the water treatment facilities in the area was moderate. At the Castaic Lake Water Agency Water Treatment Plant, several bell-and-spigot joints separated or were cracked. South of the plant, a 54-inch diameter, reinforced concrete, transmission line experienced a failure rate of about one break per mile. Located also in the Santa Clarita Valley, two Los Angeles County water reclamation plants suffered minor damage during the earthquake. Both plants lost off-site power for 48 hours but their emergency generators started and performed as required. At the reclamation plants, there were cracking and leakage in several concrete basins and some flooding in underground galleries. Some of the process equipment such as the aerators and clarifiers became misaligned or jammed and there was minor cracking in process piping. It is reported that none of the damage affected the treatment processes and there was no biological system loss at the plants [ref 5.1-8].

Within the Santa Clarita Valley, there was damage to both welded and bolted water storage tanks. Several internal roof trusses collapsed inside welded steel tanks due to the sloshing motion of the water. In Valencia, an 800,000 gallon water tank was damaged due to rupture of its inlet and outlet piping which lacked sufficient flexibility to accommodate the motion of the tank. The rocking motion of the tank caused elephant's foot buckling at the base of the tank. As the piping failed, the evacuation of the water produced a suction inside the tank resulting in roof damage. Proper ventilation at the roof of this tank may have prevented its roof damage by relieving the vacuum effect caused by the escaping water. A thicker walled tank would have prevented the wall buckling at the base.

In addition to damage to water tanks in the Santa Clarita Valley, there were examples of good and poor performance of water tanks in the Calleguas Water District which serves the Simi Valley. Two welded-seam steel tanks located about 10 miles northwest of the epicenter lost their contents when inlet and outlet piping ruptured. A rigid tee connection in the piping between the two tanks 


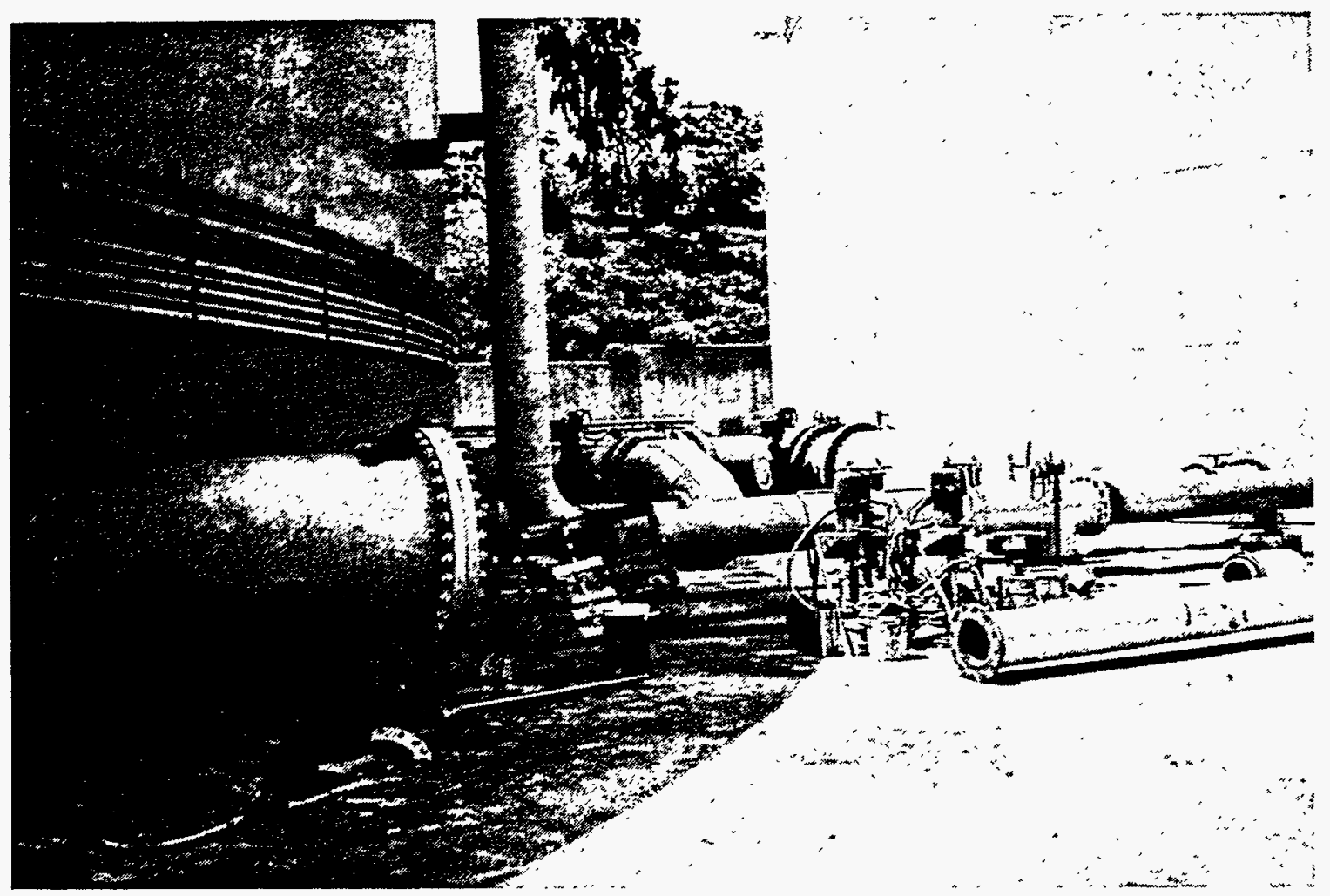

Figure 5.1-9: Attached lines between two unanchored tanks at the Jensen Plant accommodated the relative motion of the tanks.

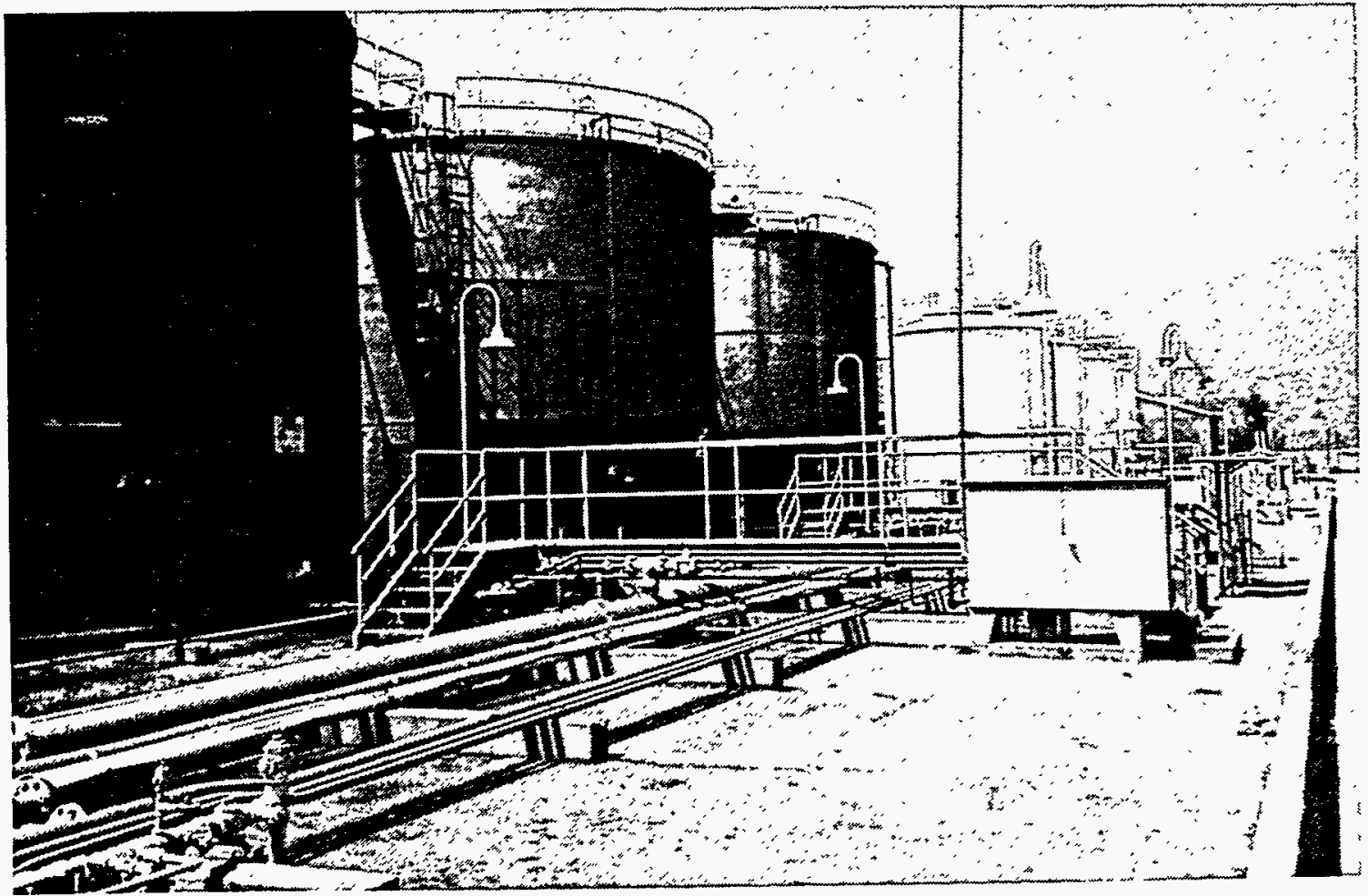

Figure 5.1-10: There was minor evidence of relative tank motion in the chlorine tank farm at the Jensen Plant. 
was severely cracked due to differential motion between the adjacent tanks during the earthquake. In addition, a 12-inch diameter, cast iron, valve body ruptured when there was differential movement at the rigid connection between the attached piping and the tank during the earthquake. Cast-iron components, such as the valve body shown in Figure 5.1-11, typically do not have sufficient ductility to accommodate large displacements. Fortunately, there was adequate ventilation at the top of the tanks which allowed the evacuated tanks to appear salvageable. As shown in Figure 5.1-12, the tanks did not suffer roof collapse or elephant's foot buckling. The tanks were each holding about one million gallons of water and this water flooded several homes in a nearby neighborhood as shown in Figure 5.1-13. In contrast to the performance of those two tanks, several other tanks closer to the epicenter appeared fully functional. Located about 5 miles

northwest of the epicenter, a 300,000-gallon and a one million-gallon welded-seam steel tank showed no evidence of structural damage. As shown in Figure 5.1-14, the tanks had flexible, elastomeric couplings between the tank valves and their inlet and outlet pipes entering the ground. The flexible couplings permitted relative motion between the tanks and the rigid piping.

Throughout the epicentral region, other components of the water system were damaged by the earthquake. Lift stations, such as the one shown in Figure 5.1-15, had ruptured piping due to ground settlement and relative motion of the equipment. Interestingly, this lift station contained a Mercoid Switch connected to pressure transmitters as shown in Figure 5.1-16. Due to sloshing of the mercury in the switch during the earthquake, inadvertent change of state may have occurred. In addition to lift stations, water collection systems experienced minor damage including cracked sewer lines and joint misalignments. Finally, many water pipes within 20 miles of the epicenter were broken by compression and tension due to ground motion and settlement. Many pipelines were weakened by corrosion and thus were susceptible to earthquake-induced damage.

\subsection{TELECOMMUNICATIONS}

As in any other natural disaster, the performance of communications systems during and after earthquakes crucially impacts emergency response and short-term and long-term recovery. Specifically, communications systems play an important role in many areas which includes locating, requesting help, and providing assistance to injured people or those who are in imminent danger; dispatching help to areas of fire following earthquakes; damage assessment and providing input to local, state, and Federal agencies; providing crucial information, such as the location of public shelters, water and food supplies, and road closures, to the general public; providing law enforcement and surveillance of the impact area providing national security; supporting financial transactions; planning and prioritization of recovery; and supporting data transfer activities. 


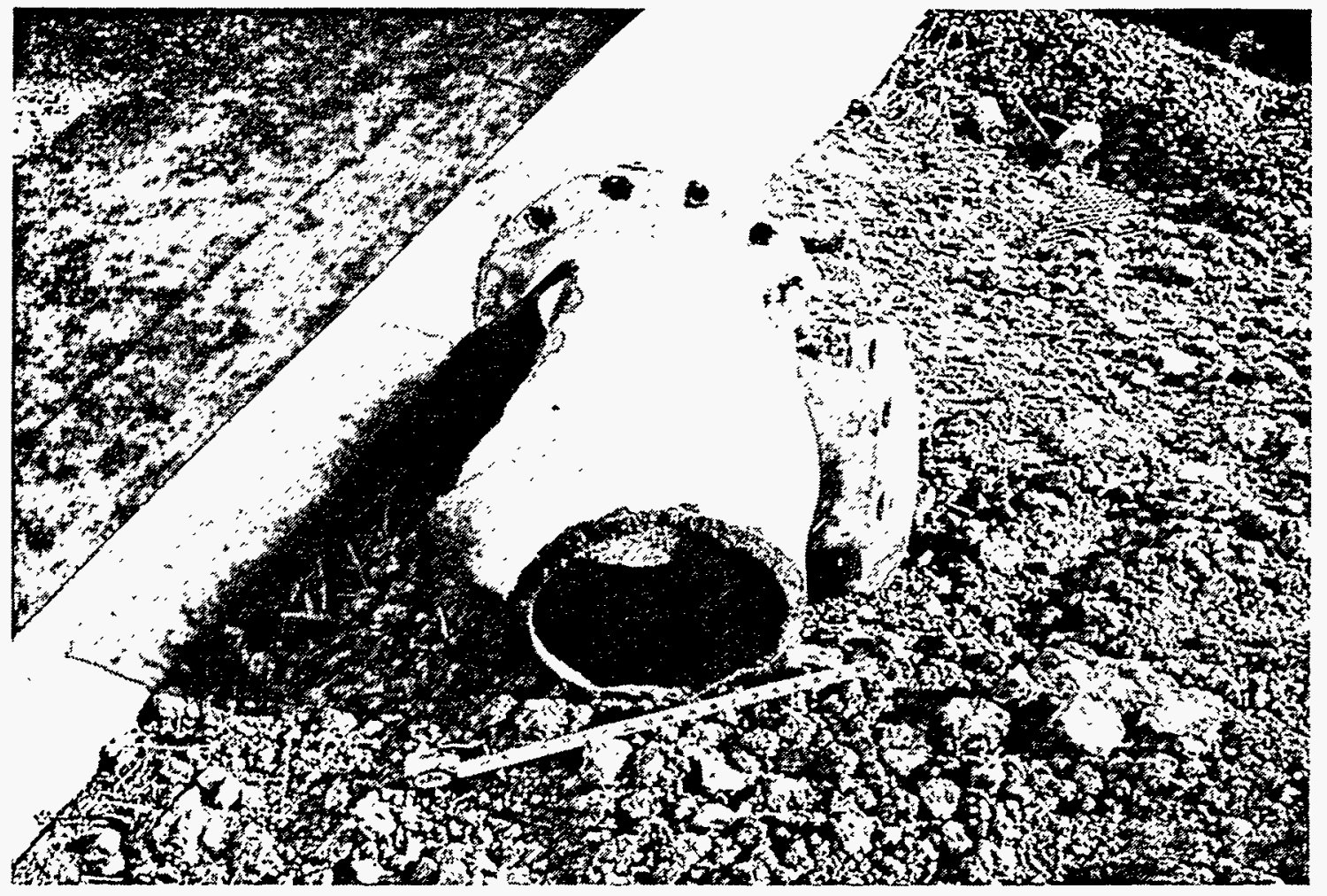

Figure 5.1-11: A cast-iron valve body ruptured on a 12-inch diameter line due to relative motion between the tank and the attached piping.

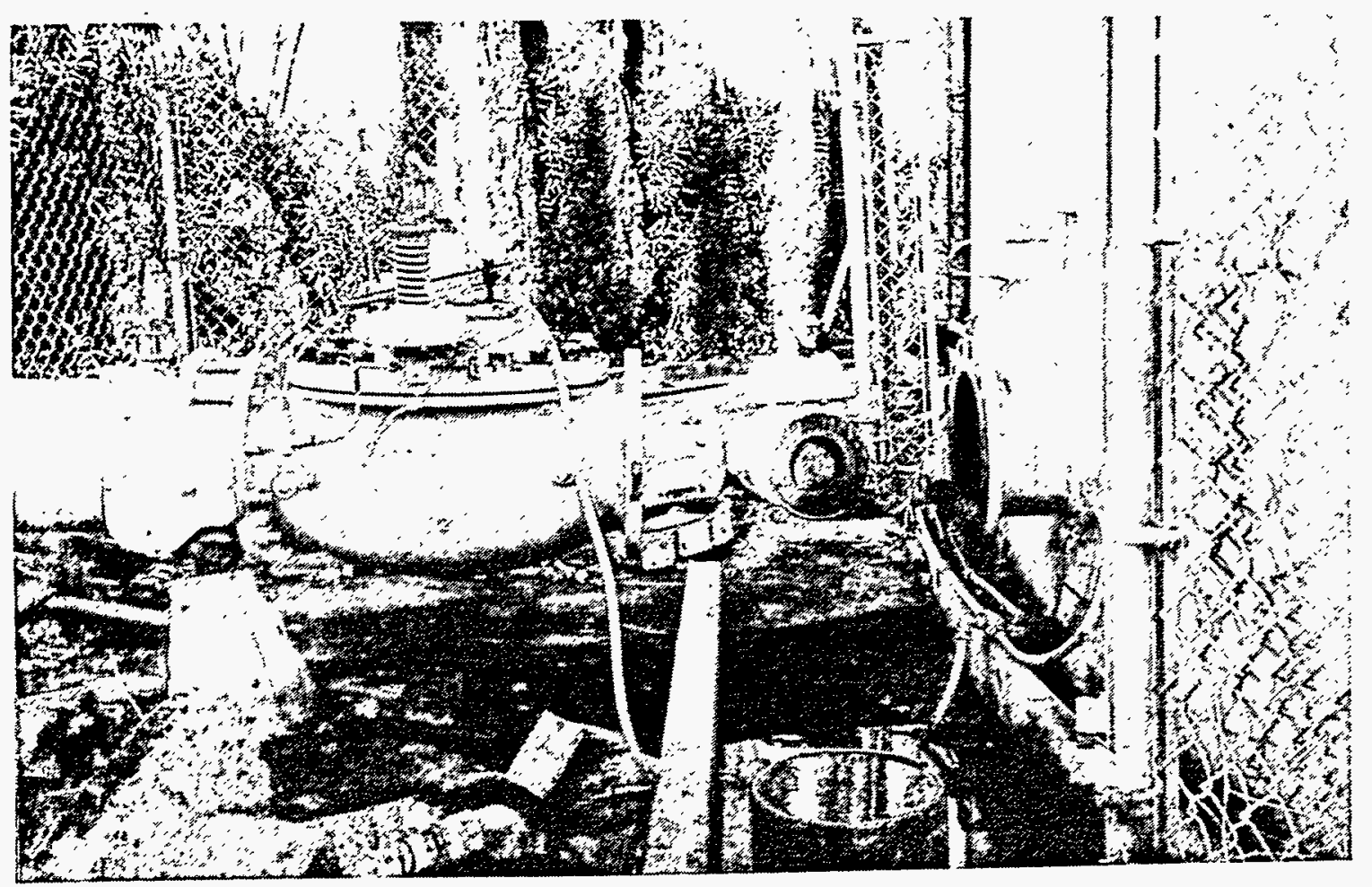

Figure 5.1-12: Adequate ventilation at the top of the tank prevented roof and wall damage when a valve body on an attached line ruptured. 


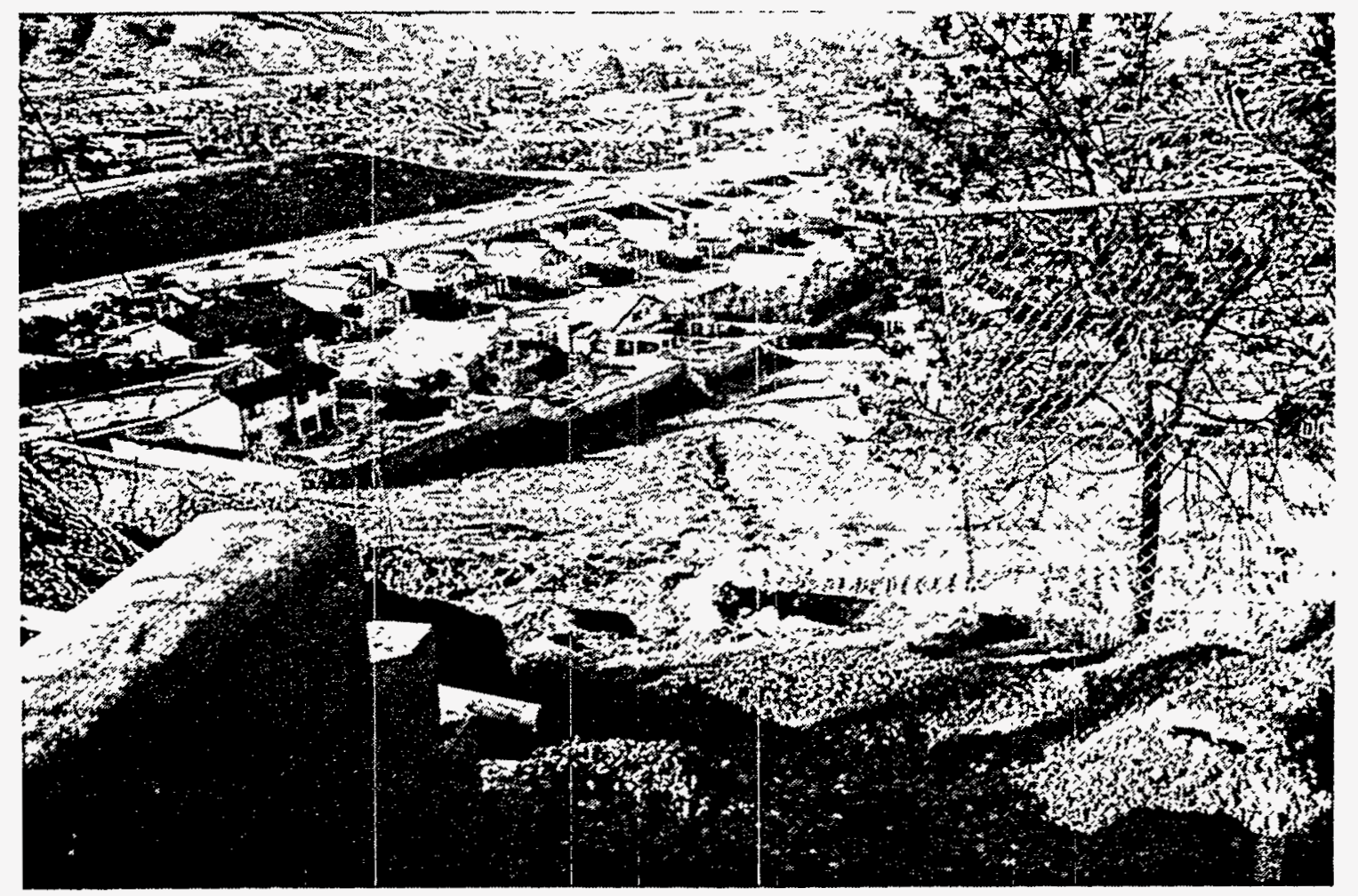

Figure 5.1-13: Several homes were flooded by water that rushed out of two tanks that had ruptured attached piping.

Figure 5.1-14: The flexible connection on the attached piping accommodated the relative motion of the tank and piping.

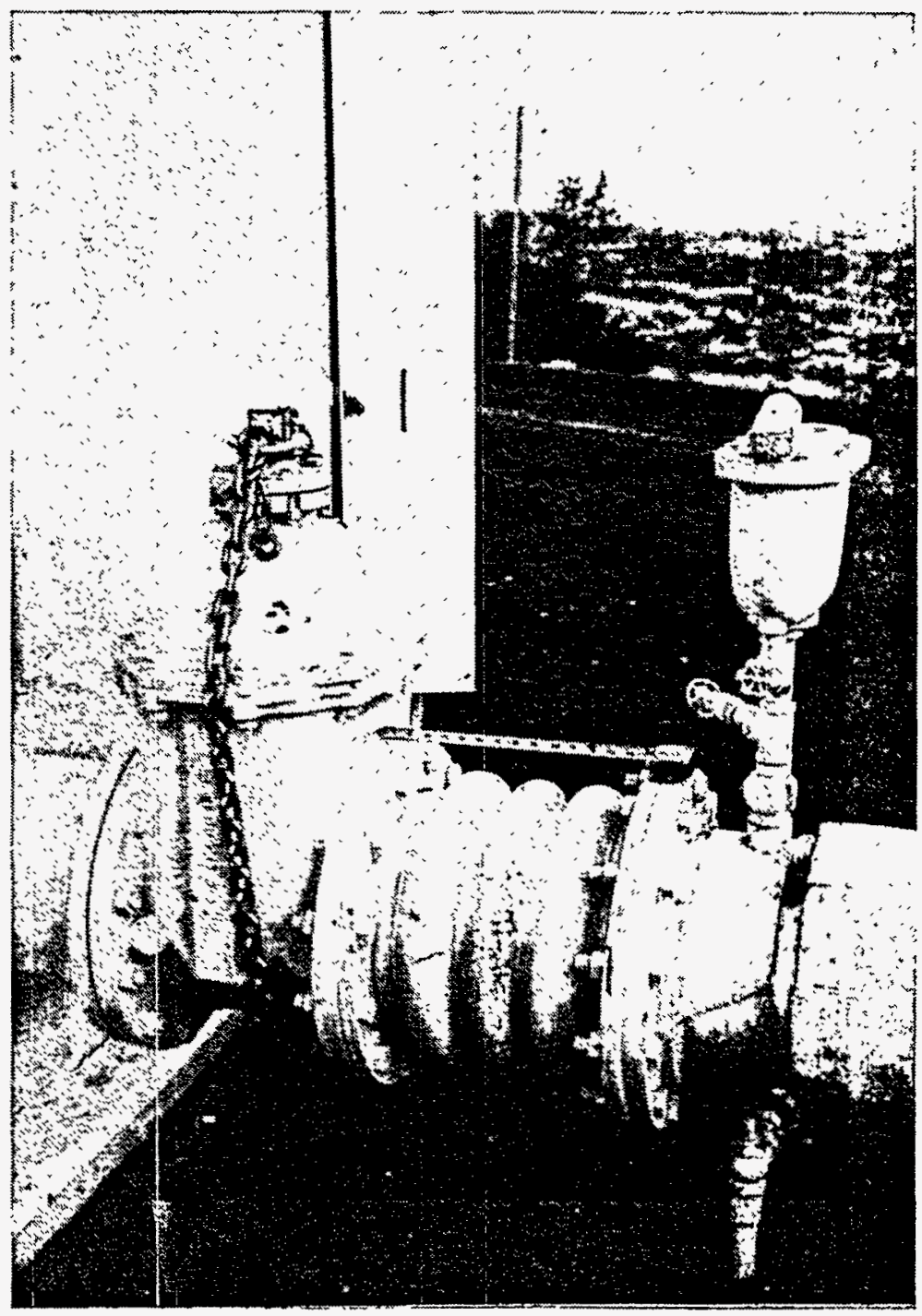




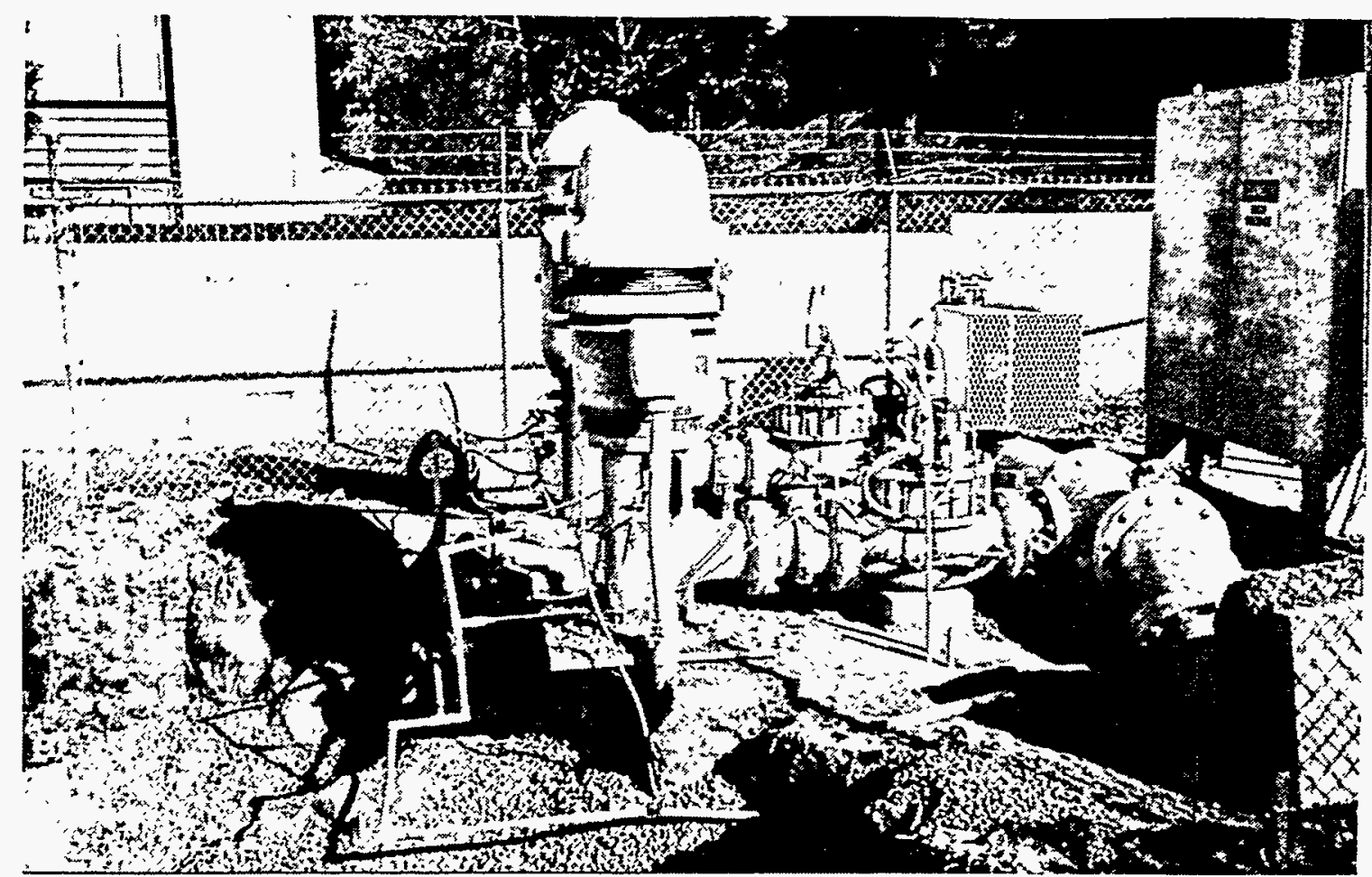

Figure 5.1-15: Ground settlement at the lift station caused underground attached piping to crack and leak.

Figure 5.1-16: A Mercoid Switch connected to the pressure transmitters at a lift station may have had an inadvertent change of state.

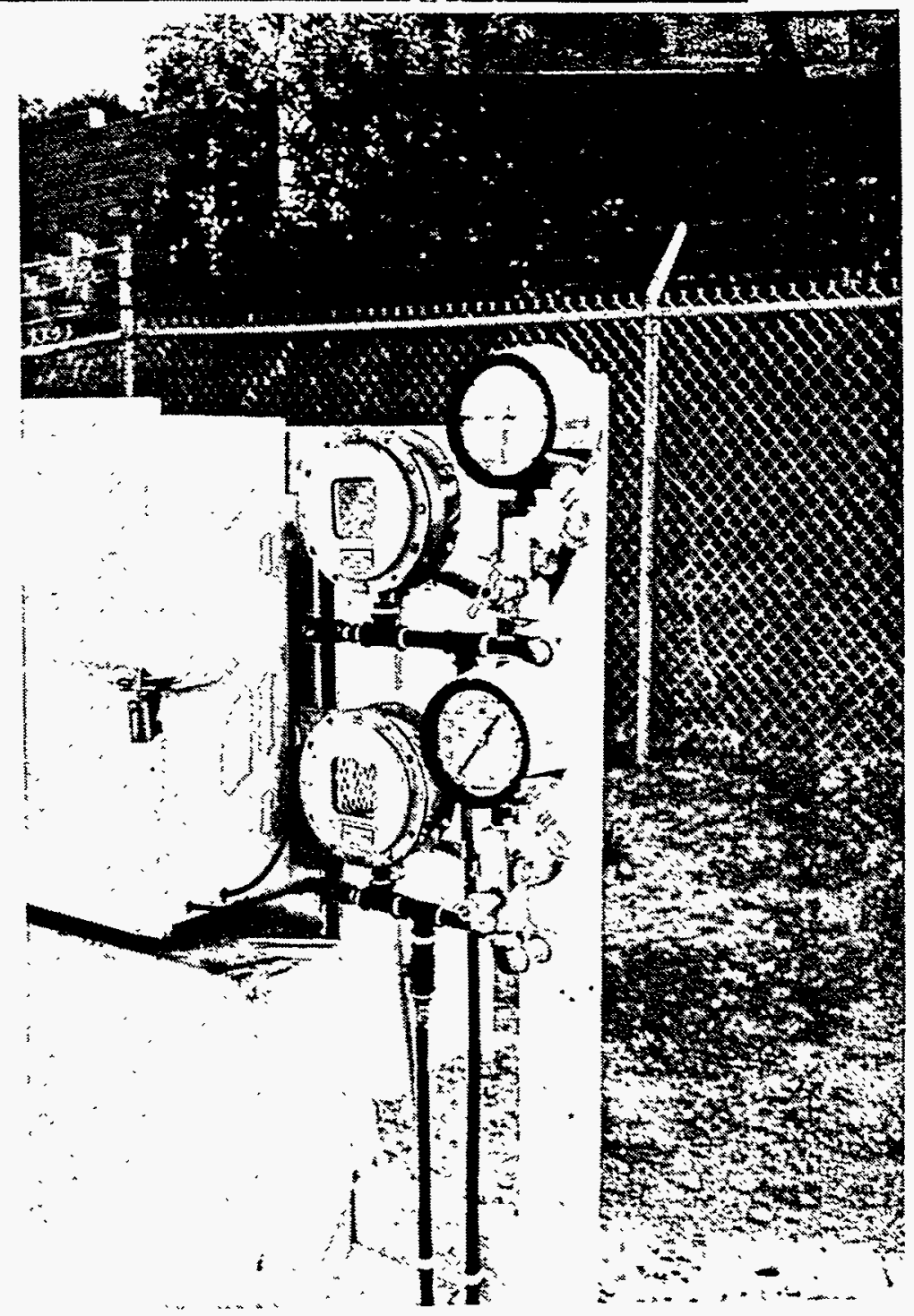


Communication systems include the telecommunications network (i.e., Public Switched Network), cellular mobile radio systems, radio and TV stations, dedicated telemetry systems, cable television, news media (printed), electronic mail networks, and ham radios. In general and by far, the telecommunications network is the most important of all communications systems, especially immediately after major disasters such as earthquakes. This section concentrates on the performance of the telecommunications network in the Northridge Earthquake.

Figure 5.2-1 shows the locations of local exchange carriers' major facilities in the earthquake area, which includes end offices, central offices with access tandem and remote switching units. Some of the inter-exchange carriers, (i.e., long distance carriers) have points of presence in one or more of these facilities. There are cable (copper and fiber optic) and radio links between these facilities, which are not shown in this figure. The majority of these facilities lost commercial electric power and had to rely on backup power. Interruption of city water service caused some disruption to the cooling functions of central offices.

Immediately after the earthquake, local exchange carriers (LECs), such as Pacific Bell and GTE, reported disruption and jams in the local telephone traffic throughout the earthquake-affected area, including Northridge, Canoga Park, Newhall, Simi Valley, West Los Angeles and Pacific Palisades. Inter-exchange carriers (IECs), such as AT\&T and MCI, implemented network management controls to curtail long-distance calls into the state to free lines for emergency calls, but most area residents could make calls out of state.

In the epicentral area, the loss of power disrupted an IEC unit, cutting off long-distance service to thousands of customers in all four of the southern California's area codes, including 213 for Los Angeles, 310 for West Los Angeles, 805 for Bakersfield and 818 for Pasadena. One of the IECs lost service on two of its main electronic switching systems in its office near the epicenter because it could not start a backup generator and had to rely on batteries, which were depleted after about 6 hours. Inter-exchange carriers generally relied on backup power supplies and, in some instances, needed to truck in water for cooling systems. In several central offices, circuit cards were shaken loose on the switches, which required manual reinsertion. Some limited interruption was reported in both local and long distance service caused by damaged telephone system buildings, malfunctions of equipment, and damaged phone lines.

Computer users turned to electronic mail when they were unable to make long-distance telephone calls into and out of earthquake area. However, there is a report that some computer networks had been knocked out. Cellular telephones proved to be very useful immediately after the earthquake but also became saturated very soon. Usage increased on carriers' cellular systems following the 


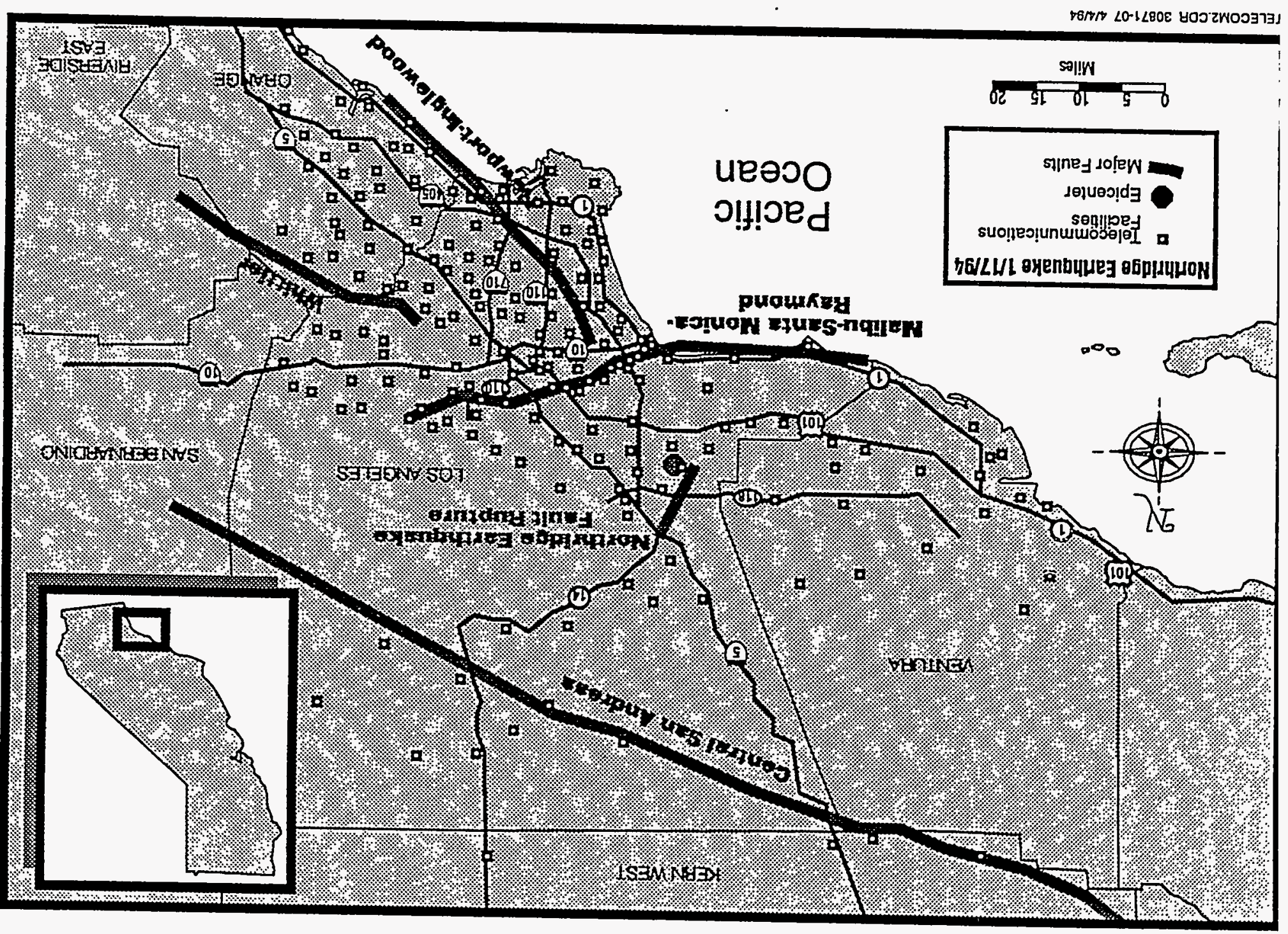


event on January 17th. PacTel Cellular experienced a $25 \%$ increase in calls going through its system. The cellular network was operating at $95 \%$ capacity because of downed land lines. The immediate impact of the earthquake was even felt in the San Francisco Bay area. PacTel Cellular in Walnut Creek was forced to switch to generators and battery power after it lost commercial electricity. McCaw Cellular Communications Inc. reported that a small number of cell sites were damaged and electrical power was cut off to 20 other cells in its Los Angeles area operations. Portable generators were flown in from around the country and cells were brought back to service within few days.

\subsection{NATURAL GAS SYSTEMS}

\subsubsection{Southern California Gas Company (SoCalGas)}

Within the Los Angeles metropolitan area, the natural gas system is owned and operated by SoCalGas which has the largest customer base in the U.S. In 1993, SoCalGas had about 4.6 million metered services with about 3,800 miles of steel transmission pipelines, 26,800 miles of steel distribution mains, and 14,900 miles of plastic distribution mains [ref 5.3-1]. The transmission pipelines usually are 8 to 36 inches in diameter operating at pressures exceeding 150 psi and while the distribution pipelines usually are 2 to 12 inches in diameter operating at pressures less than 60 psi. Plastic piping used in the distribution mains is fabricated from medium or high density polyethylene. SoCalGas has a third type of pipeline, distribution supply lines, which usually are 2 to 12 inches in diameter operating from 100 to $400 \mathrm{psi}$. Within the extensive lifeline system operated by SoCalGas, there were approximately 151,000 natural gas outages following the earthquake. About $80 \%$ of the outages were customer initiated. One week after the earthquake, about 84,000 customers had service restored and one month after the earthquake, almost 120,000 customers had service restored [ref 5.3-1]. The information in the rest of this section is from statistics and discussion in reference 5.3-1.

Some of the gas outages were due to damage to the distribution system. According to SoCalGas statistics, about 770 metallic distribution mains and services were damaged of which about 560 occurred where corrosion, material, or construction defects were observed. In addition, there were 27 locations of damage to polyethylene pipes at couplings and fittings. Overall, the plastic piping provided good seismic performance. In most cases, repairs to the distribution system were relatively quick. Most of the repair-intensive damage to the SoCalGas system occurred in the transmission system. 
As shown in Figure 5.3-1, there were several locations of breaks and leaking flanges in the transmission system. In some cases, there were lifeline interactions between the damaged gas pipelines and adjacent lifeline systems such as electric power and water mains. It is reported that there were 35 repairs to transmission pipelines at locations of non-corrosion related damage. About $75 \%$ of those repairs occurred at cracked or ruptured oxyacetylene girth welds. These type of welds were used in SoCalGas pipelines prior to World War II and they are currently characterized as poor quality due to a lack of appropriate procedures for their fabrication. Oxyacetylene welds often have defects such as lack of proper fusion, overlapping and undercutting at the weld toe, and inadequate root penetration. Due to the inferior weld quality of oxyacetylene girth welded lines, SoCalGas has identified those lines as the most vulnerable to earthquake effects. According to SoCalGas statistics, $83 \%$ of all earthquake-related repairs due to ground vibrations have occurred in oxyacetylene girth welded lines. During the Northridge Earthquake, Figure 5.3-1 shows that the highest amount of damage due to ground vibrations occurred on Line 1001 which had oxyacetylene girth welds. In addition, there was damage to Lines 85 and 122 which had oxyacetylene girth welds.

As indicated in Figure 5.3-1, Line 1001 conveys natural gas between Newhall and Fillmore through Pico and Potrero Canyons. The 12-inch diameter pipeline was constructed in 1925 and was operating at an internal pressure of 245 psi during the earthquake. The line had 24 breaks at oxyacetylene girth welds and one section of buckled pipe. One of the ruptured welds was under California State Highway 126 near the town of Fillmore. There was interaction between the gas and electric power systems at this location as gas escaping from the damaged welds was ignited by a downed power line.

Prior to World War II, the procedures for welding SoCalGas transmission pipelines involved either oxyacetylene or electric arc girth welds. According to SoCalGas statistics, only about $3 \%$ of earthquake-related repairs due to ground vibrations have occurred in electric arc welded lines. In some cases, electric arc girth welds used unshielded techniques in which the molten weld was exposed directly to the atmosphere. Gas inclusions and uneven heating were caused by these techniques which produced an inferior quality weld. A location of a damaged steel pipeline with electric arc girth welds was along Balboa Boulevard about 4 miles northeast of the epicenter. Line 120 was constructed beneath Balboa Blvd. in 1930 with unshielded electric-arc girth welds and was operating at a pressure of 175 psi during the Northridge Earthquake.

As discussed in Section 5.1 of this report, Balboa Boulevard is a utility corridor with several lifeline systems including water, natural gas, electric power, telecommunications, oil, and sewer. As indicated in Figure 5.3-2, there were six major pipelines underneath Balboa Boulevard between 


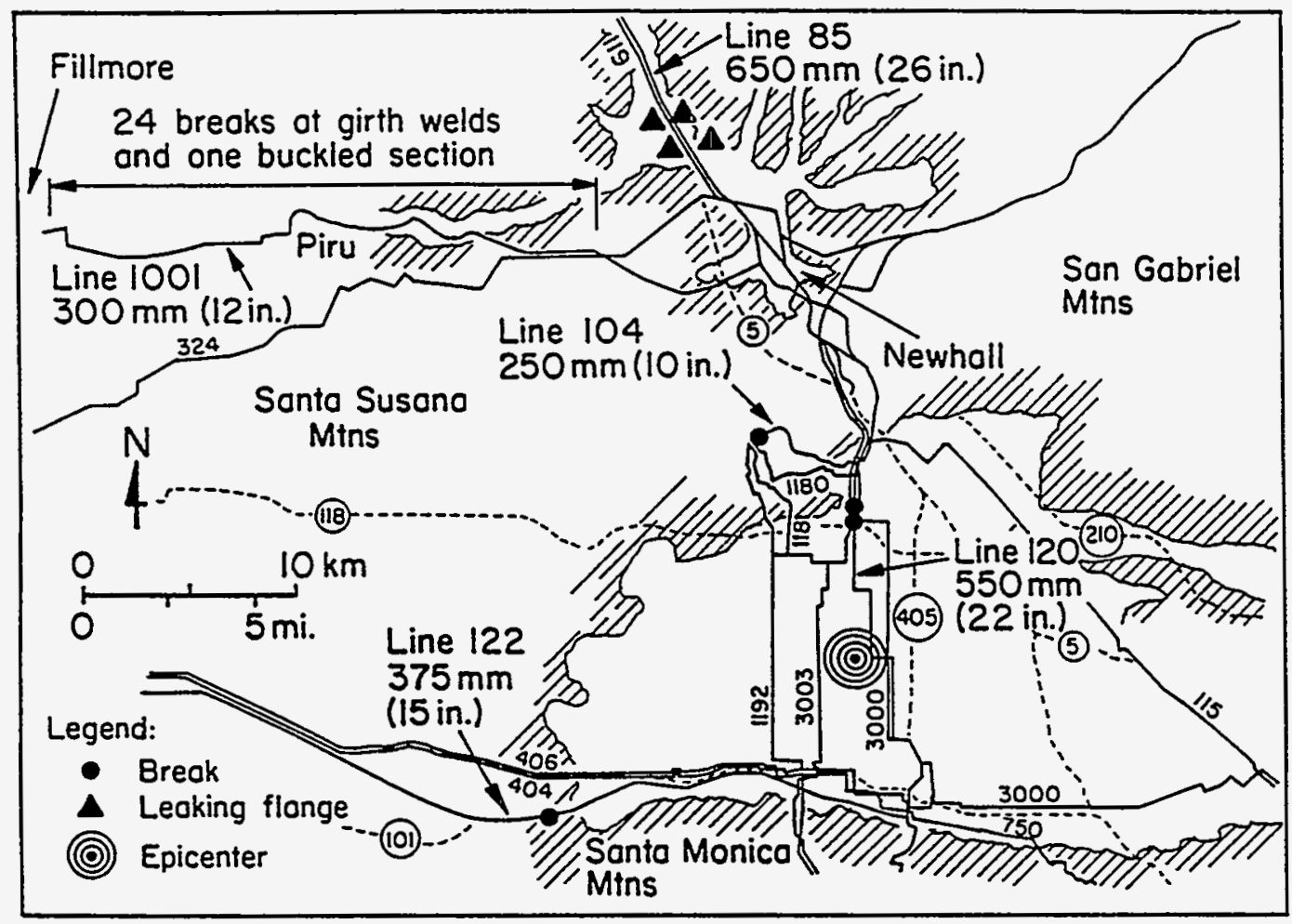

Figure 5.3-1: There are several natural gas transmission pipelines in the epicentral region which sustained damage during the earthquake [ref 5.3-1]. 


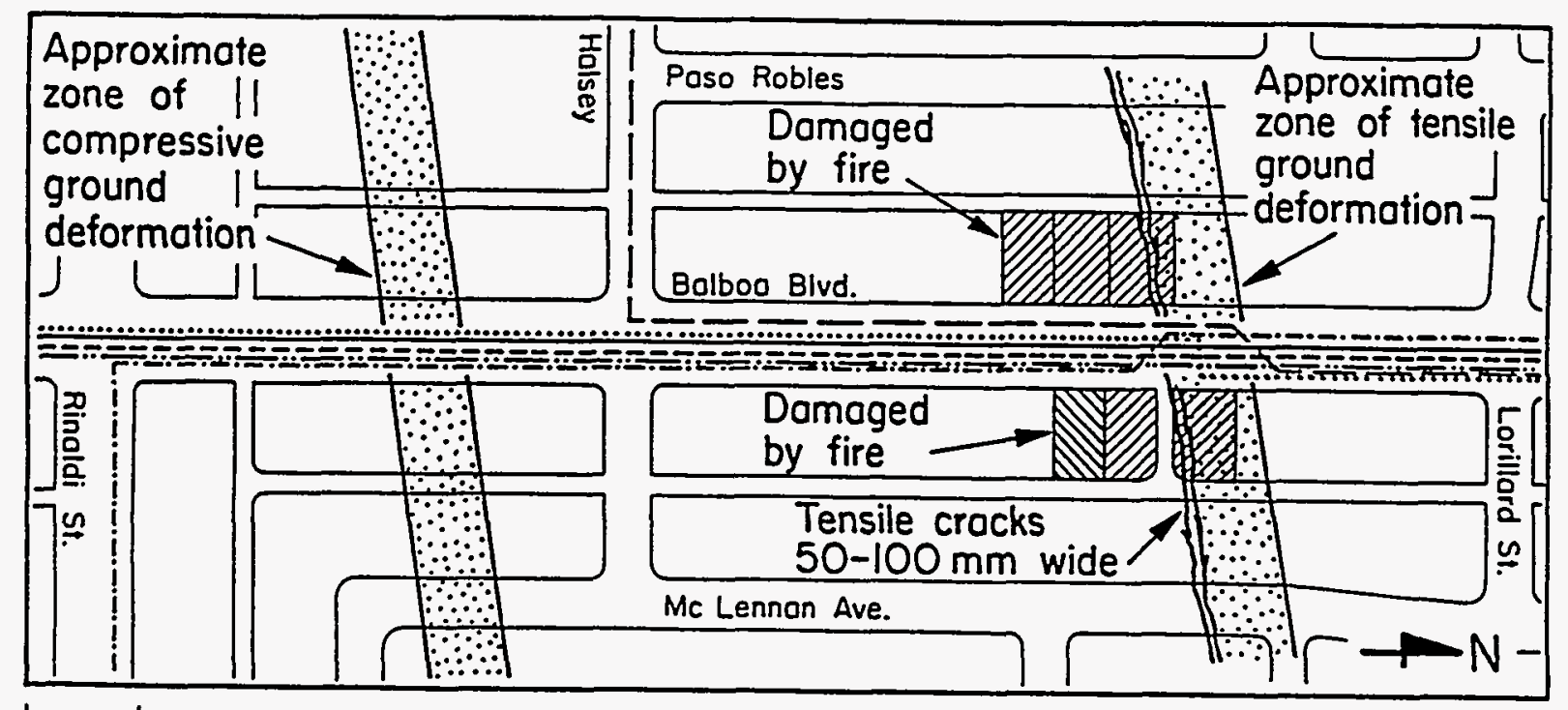

Legend:

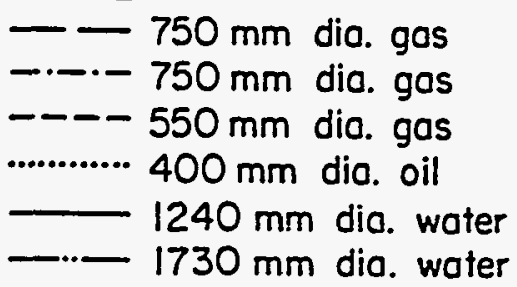
QUlla House totally
destroyed

House portially

destroyed

Figure 5.3-2: Tensile and compressive ground deformations contributed to the damage along Balboa Boulevard between Lorillard and Rinaldi Streets [ref 5.3-1].

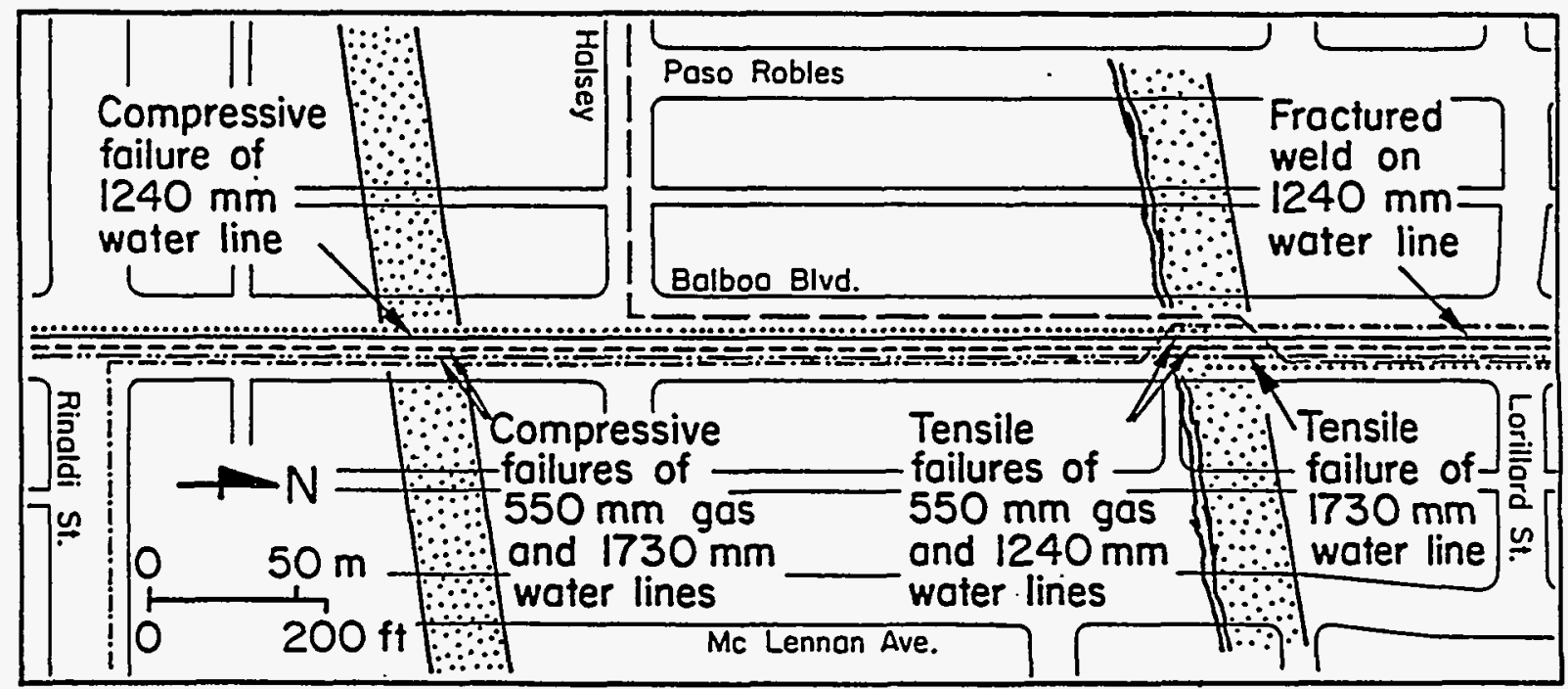

Figure 5.3-3: Underneath Balboa Boulevard and between Lorillard and Rinaldi Streets, both gas and water pipelines had failures [ref 5.3-1]. 
Lorillard and Rinaldi Streets. These pipelines included the 22-inch diameter Line 120 for natural gas, the 49-inch diameter Granada Trunk Line for water, the 68-inch diameter Rinaldi Trunk Line for water, and the 16-inch diameter Mobil Oil pipeline. Further information about the water mains can be found in Section 5.1 of this report and about the oil pipeline can be found in Section 5.4. In addition to the already mentioned oil, water, and gas pipelines, there were also two 30-inch diameter gas transmission pipelines and several smaller diameter sewer, water distribution, and gas distribution pipelines. The earthquake caused ground displacements which created a tensile zone near Lorillard Street and a compression zone near Rinaldi Street as shown in Figures 5.3-2 and 5.3-3. Figure 5.3-3 also shows that in both the compressive and tensile zones, Line 120, the Granada Trunk Line, and the Rinaldi Trunk Line had failures. The adjacent 30-inch gas pipelines, which were about 40 years old, were not damaged. Interestingly, Line 120 was scheduled for replacement at the time of the earthquake. Underneath McLennan Avenue, which is parallel to Balboa Boulevard, a new 24-inch diameter pipeline with electric arc girth welds had been constructed. It was not in service during the earthquake and since it suffered no damage, it has replaced Line 120.

In the compression zone, compressional buckling of the ground surface caused a 2-foot overlap in a sidewalk parallel to the east side of Balboa Boulevard as shown in Figures 5.1-2 and 5.3-4. Examinations of Line 120 and the Granada Trunk Line disclosed a compressive buckling of about 10 inches. Repairs of the buckled sections of Line 120 and the Granada Trunk Line are shown in Figure 5.3-5. About 500 yards north of the compression zone, there were tensile failures in Line 120 and the water trunk lines. Tensile cracks about 2 to 3 inches wide in the soil were evidenced near these failures as shown in Figures 5.1-3b and 5.3-6. The ground deformation indicates that lateral spreading occurred in the local alluvial fan sediments. The orientation of the pipelines relative to gravity also contributed to the ground deformation. At the location of pipeline damage, Balboa Boulevard runs north-south as it slopes downward from Lorillard Street to Rinaldi Street at about $1 / 8$ to $1 / 4$ inch per foot.

There was interaction of the damaged Line 120 with both adjacent water and electric power systems. Failures of the water mains caused extensive flooding in the area which affected repair efforts with Line 120. In addition, natural gas which leaked from the tensile failure in Line 120 was ignited by a vehicle which was stopped by the flooding. The ensuing fire destroyed five homes and partially destroyed another one as shown in Figures 5.3-2 and 5.3-6. Failures of both the water and natural gas pipelines produced an unusual image of flames rising from flooding water. 


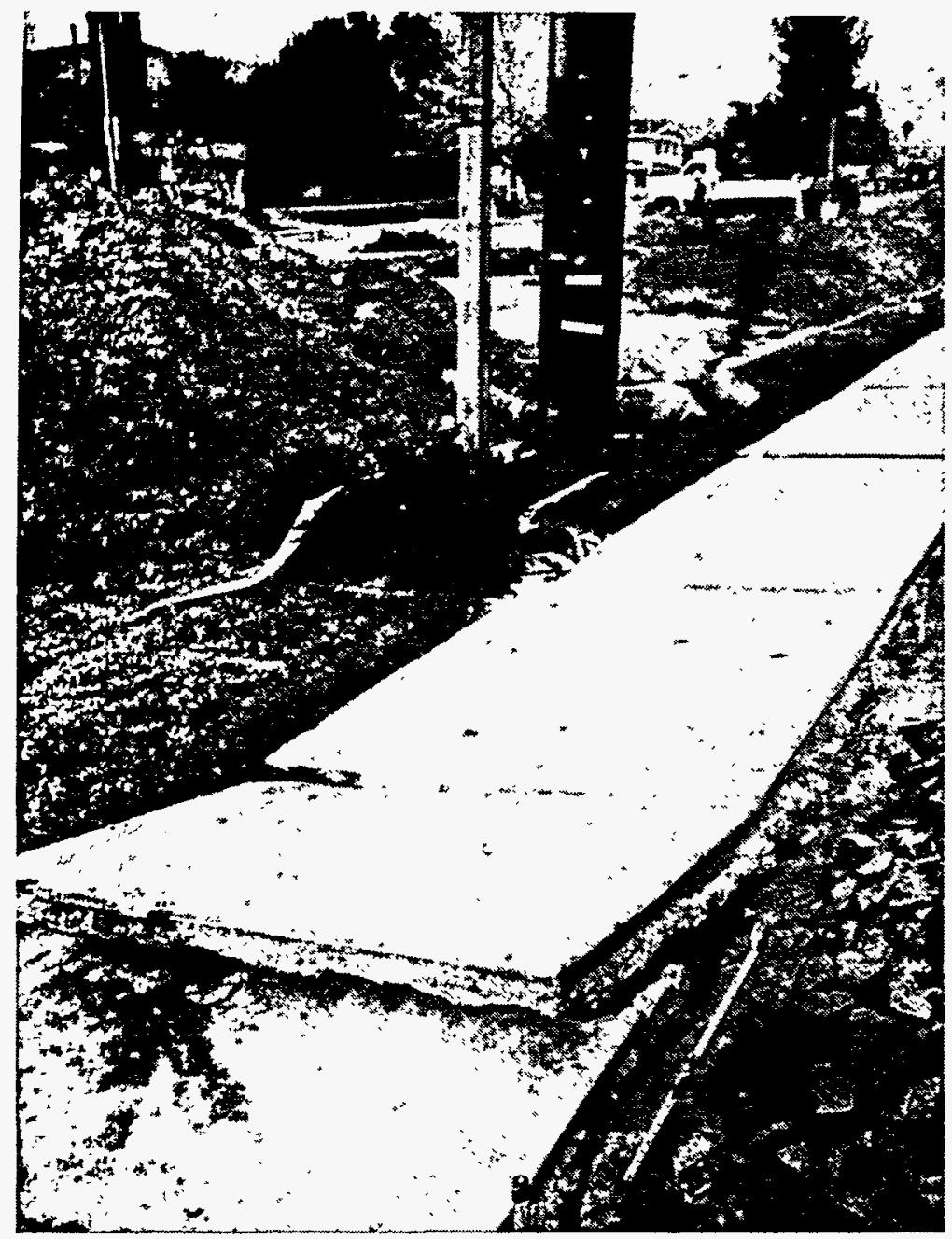

Figure 5.3-4: In the zone of compressive ground deformation, the north portion of the sidewalk parallel to Balboa Boulevard moved over the south portion with a relative displacement of about two feet.

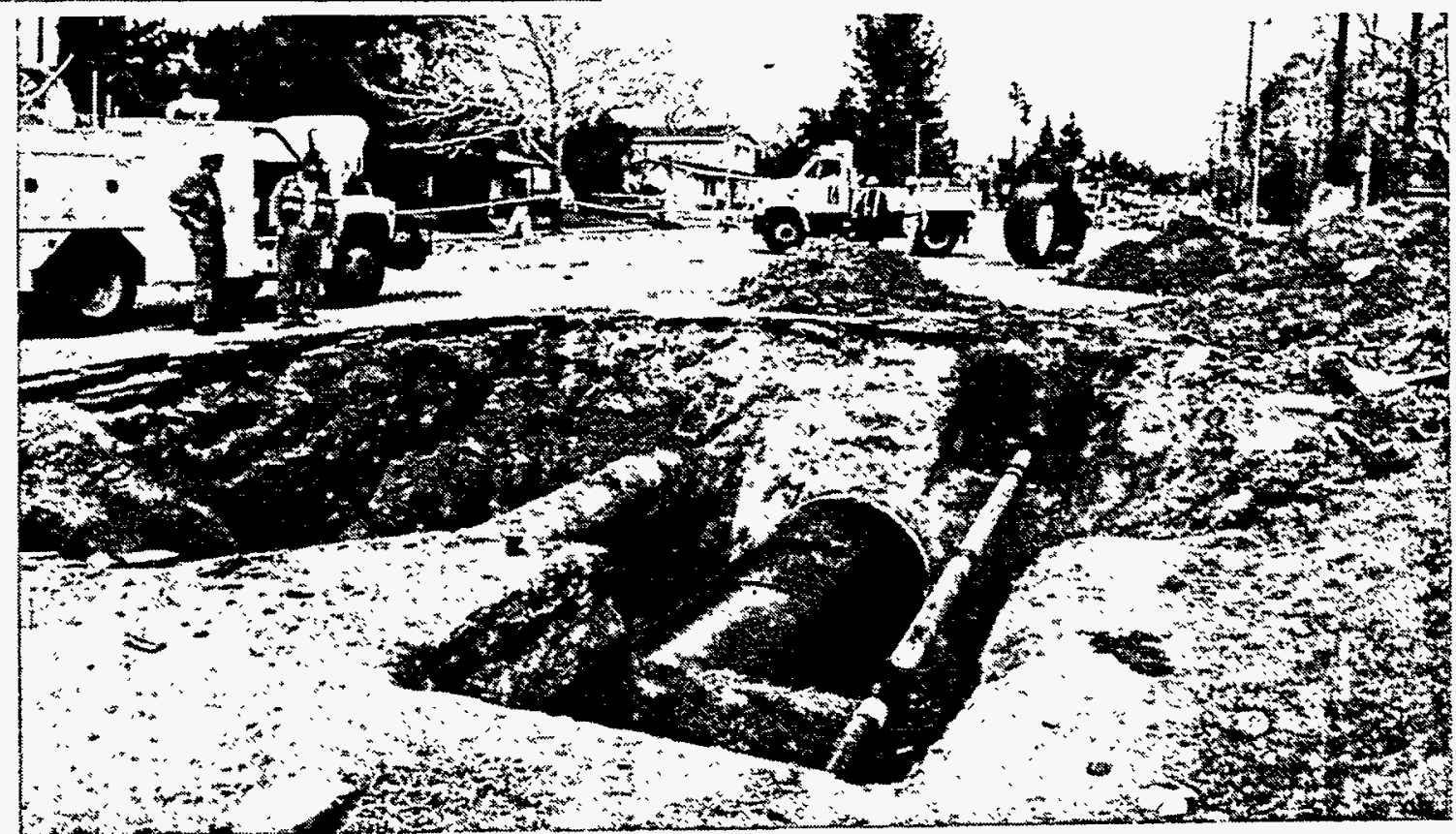

Figure 5.3-5: A natural gas distribution pipeline, Line 120, was buckled in the zone of compressive ground deformation. A larger diameter water pipeline next to the gas pipeline was also buckled. 


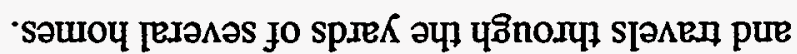

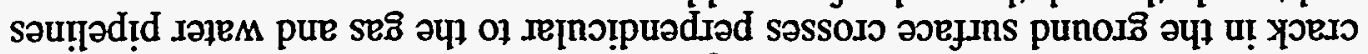

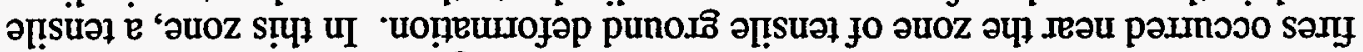

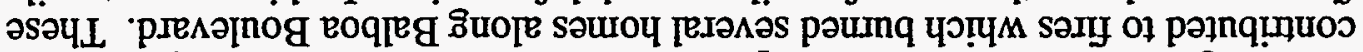

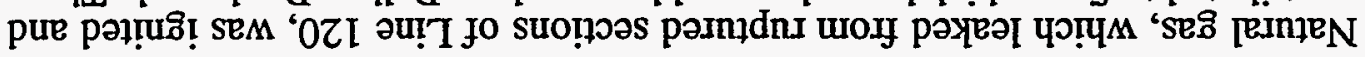

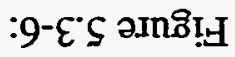

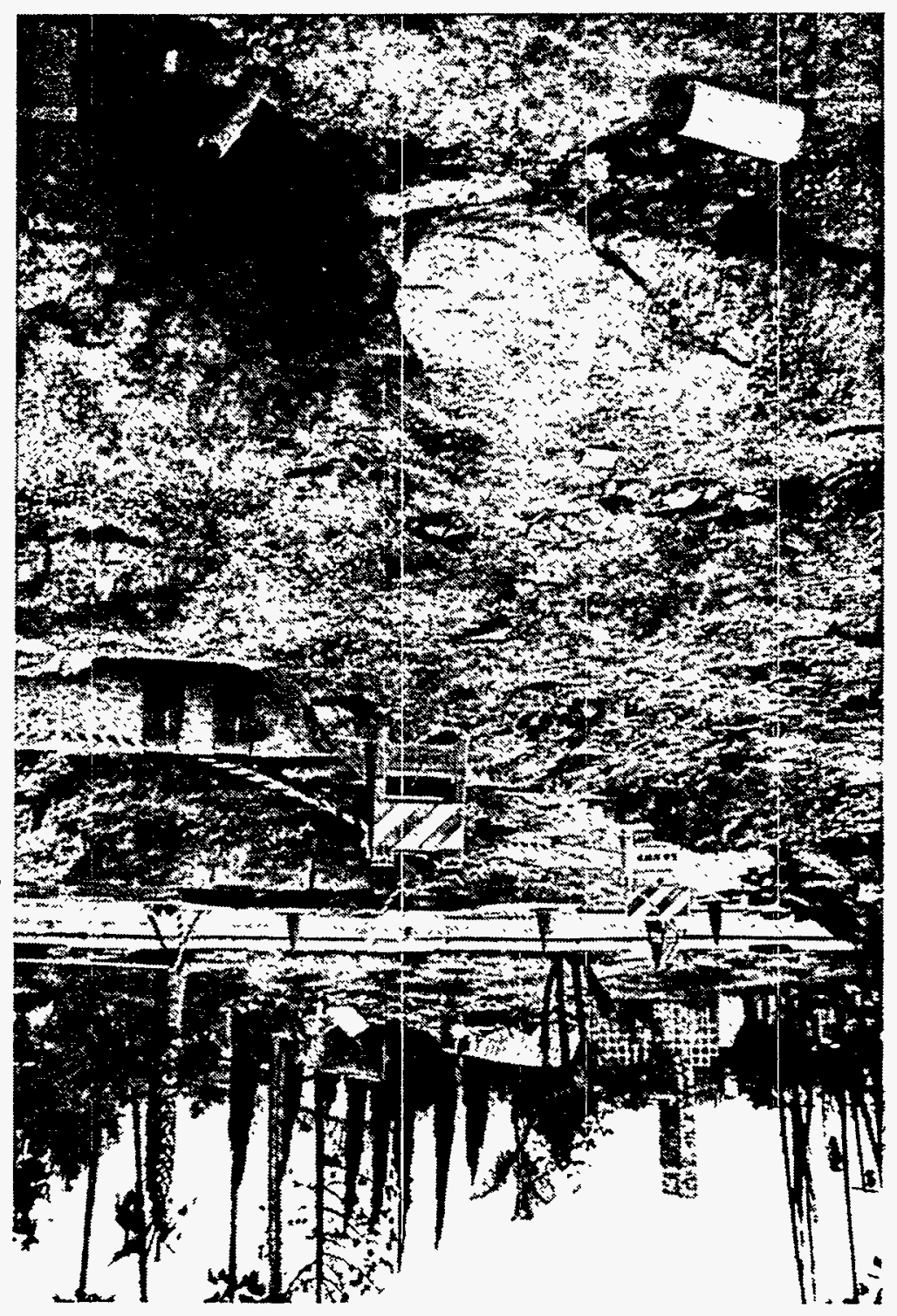


The overall performance of the SoCalGas transmission system was similar to that experienced in previous earthquakes. Damage to Lines 1001 and 120 occurred in previously identified vulnerable locations. It is reported that no breaks or service disruptions have occurred in post-World War II SoCalGas pipelines constructed with quality welds. In addition, there is also a very low incidence of damage to transmission pipelines due to corrosion. In addition to the pipelines, several SoCalGas facilities including the Aliso Canyon Gas Storage Facility and the Honor Rancho Storage Field had damage. Both of these facilities are used to store natural gas in underground reservoirs.

\subsubsection{Aliso Canyon Gas Storage Facility}

The Aliso Canyon Facility, which was once used for oil production, has gas injected during low demand periods in the summer and withdrawn during high demand periods in the winter. At this facility, the supply of gas was interrupted for five days due to earthquake damage. Located about 5.5 miles northwest of the epicenter, the facility covers about 3,600 acres with 35 miles of access roads. This facility is about 5 miles west of the Los Angeles County Fire Station in Newhall. Based on measurements by the California Division of Mines and Geology, the Fire Station experienced $0.63 \mathrm{~g}$ in the horizontal direction and $0.62 \mathrm{~g}$ in the vertical direction [ref 5.3-2]. Earthquake damage included a break in Line 104, one collapsed oil storage tank, several damaged storage tanks, deformation of pipe supports caused by ground settlement, displacements of injection and withdrawal pipelines due to landslides, and transformers displaced from their poles.

It is reported that damage to the 10 -inch diameter Line 104, which was operating at a pressure of $228 \mathrm{psi}$, was due to slope displacement perpendicular to the pipeline [ref 5.3-1]. An adjacent 4inch diameter steel fuel oil line was also damaged at the same location. Line 104 was constructed in 1941 with electric arc girth welds. Ground motion also undermined the supports for several injection and withdrawal lines in the facility. In addition, fallen debris from landslides and slope movement deformed pipelines. There were no ruptures or leaks of aboveground withdrawal and injection lines in the facility.

Several water and oil storage tanks in the facility had damage. Water supply was disrupted in the facility due to damage to water tanks and its associated piping and the lack of supply from outside the facility. Half of the oil storage tanks had damage ranging from complete collapse to warped plates and supports. In addition to the tank damage, there was structural damage to a fan unit which cools the gas before injecting it into the storage wells. 


\subsection{FREEWAY STRUCTURES}

Transportation was disrupted by the failure of bridges along four major highways: Interstate (I) 5 , State Route (SR) 14, I-10, and SR-118. Collapse (or partial collapse) of the bridges at these locations caused a large part of the severe impact on the lifelines infrastructure for Southern California due to the Northridge Earthquake.

Several of the bridges which had collapsed were demolished and replaced during extremely short construction schedules ranging from about 2.5 to 4.5 months after the main seismic event. On one bridge (SR-118 westbound direction at Mission-Gothic) which had some severely damaged columns, temporary wood timber and steel falsework was erected to shore up the superstructure. This was done so that the partially collapsed eastbound bridge next to it could be replaced while traffic in both directions was routed onto the westbound structure.

At the other locations where major highway bridges had collapsed, traffic had to be detoured onto city streets or via long alternate routes on other freeways. In at least one case, an alternate route was paved over an old dirt road to accommodate commercial shipping trucks and to enable commuters to get to work in a reasonable amount of time during bridge reconstruction.

\subsubsection{SR 14/I-5 Separation \& Overhead}

SR-14/I-5 Separation \& Overhead connects southbound SR-14 to southbound I-5 (see Figure 5.41a). As described in the following paragraphs, pier 3 is the column which remained standing after the spans collapsed on both sides of it (see Figure 5.4-1b). I-5 is the main artery connecting the San Joaquin Valley and Sacramento Valley (to the north) with the cities of Los Angeles and San Diego (to the south). SR-14 serves as a commute route for many who work in the Los Angeles area and live in north LA county.

SR-14/I-5 Separation \& Overhead is comprised of five frames with a total length of 1582 feet. There are ten spans which range in length from 103 feet to 206 feet. This bridge was under construction in 1971 and was damaged in the San Fernando Earthquake. At the time of the San Fernando Earthquake, all of the columns had been constructed. The bottom slab and stem concrete had been placed from abutment 1 to the hinge in span 3 . All concrete had been placed from the hinge in span 9 to abutment 11, but this frame had not yet been prestressed. Final construction of this bridge was completed in 1974 [ref 5.4-1].

The superstructure consists of alternating cast-in-place pre-stressed (CIP P/S) and reinforced concrete (RC) box girder frames with a structure depth of 7'-0". Hinge seat width is 14 inches. 


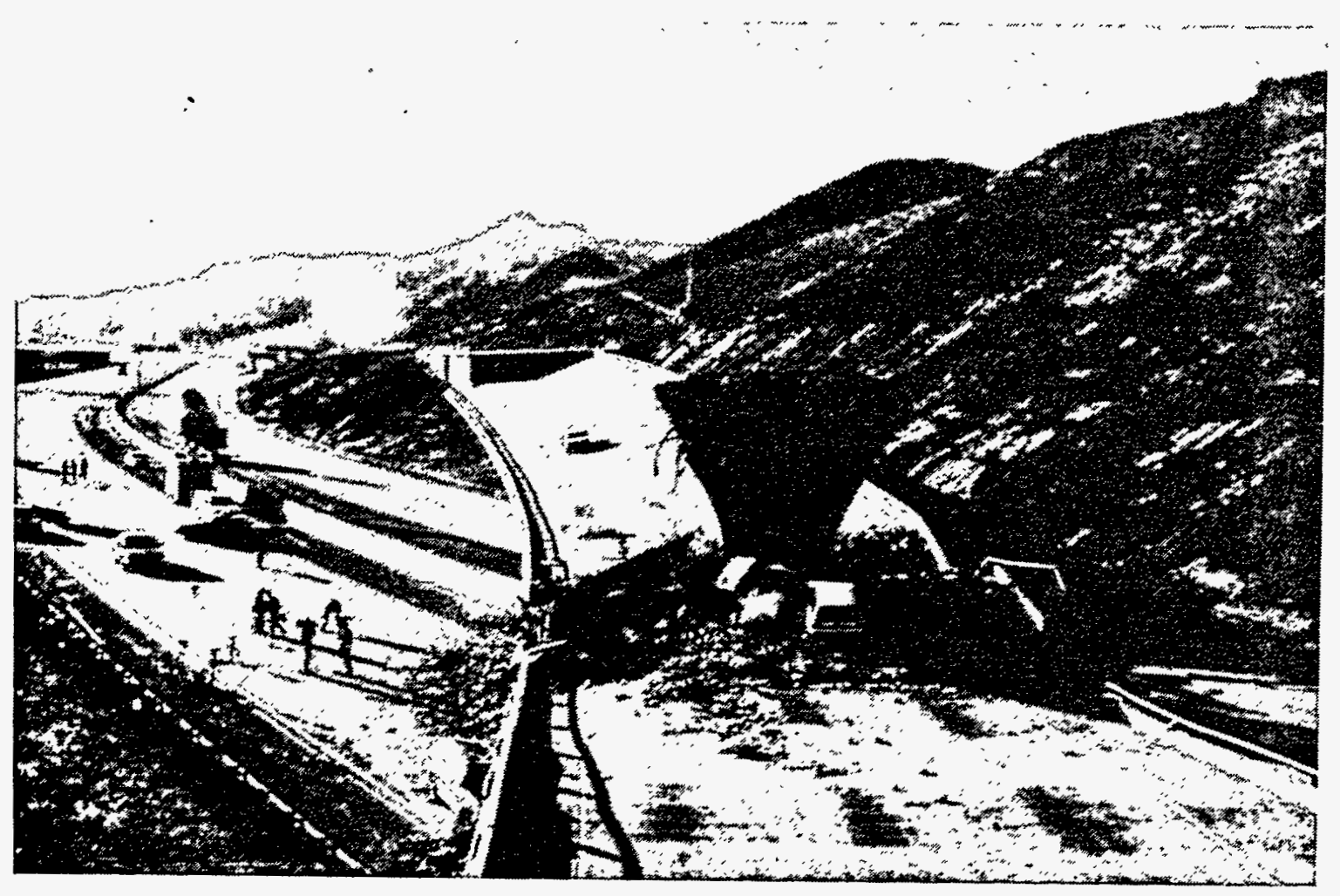

Figure 5.4-1a: SR-14/I-5 Separation \& Overhead connects southbound SR-14 to southbound I5. Pier 3 is the column which remained standing after the spans collapsed on both sides of it. This photo is looking in the southerly direction [ref 5.4-2]. 


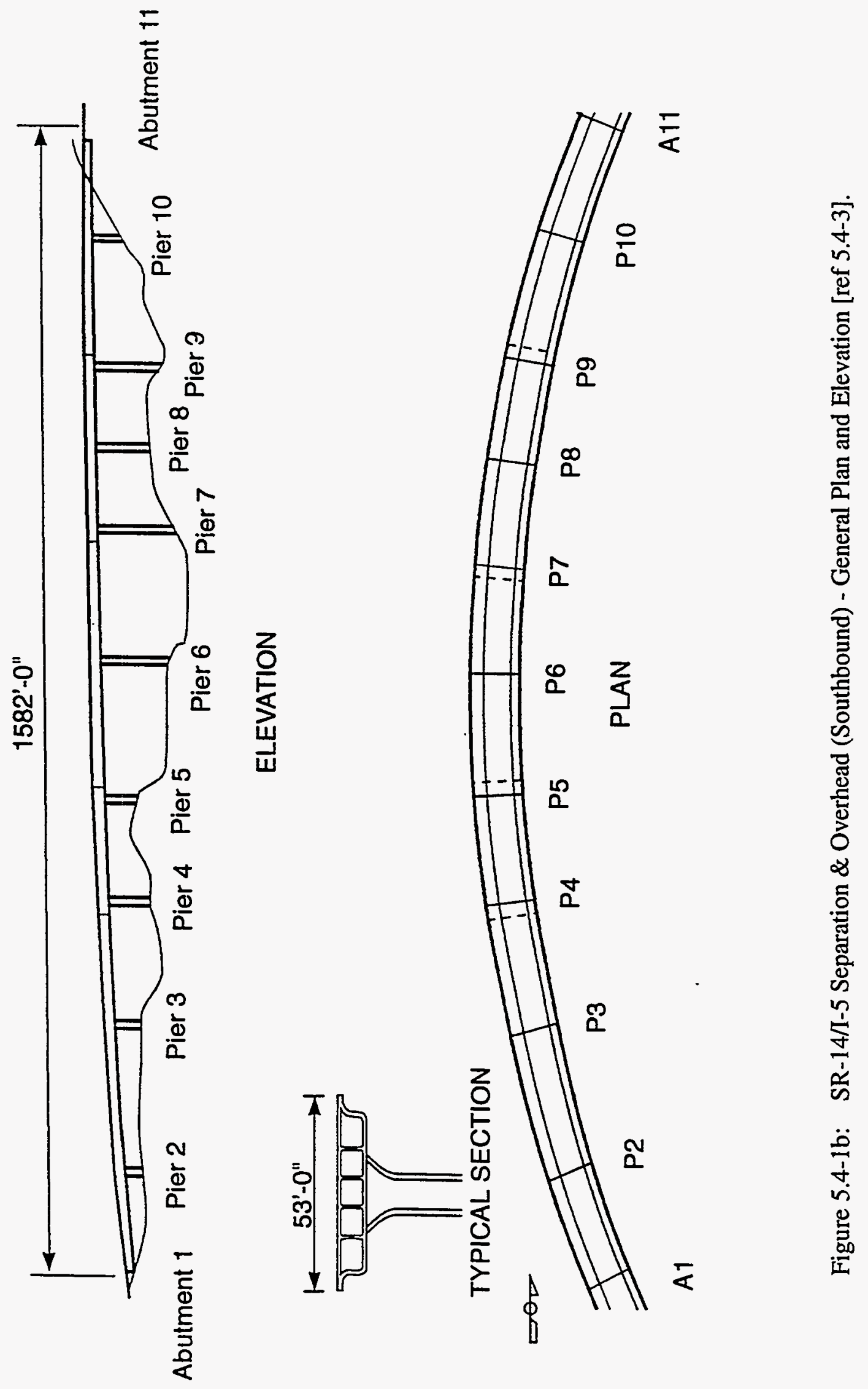


The superstructure is supported on elastomeric bearing pads on cantilevered seat type abutments which are founded on spread footings [ref 5.4-1].

The bents consist of single $12^{\prime} \times 4^{\prime}$ to $12^{\prime} \times 6^{\prime}$ octagonal columns that flare to a 26 -foot width at the soffit and extend into the ground as a pier shaft. The main longitudinal column reinforcement consists of 20 to $32 \# 18$ bars that follow the flare and extend into the bent cap. Lateral reinforcement is \#5 @ 12". The four hinges of this bridge were retrofitted with cable restrainers as part of the damage restoration contracts [ref 5.4-1].

The first frame of the structure collapsed. At the abutment, the diaphragm was found unseated and lying on the ground approximately 5 feet from the face of the abutment seat. The right exterior shear key failed completely, and the left exterior shear key appeared undamaged. The abutment seat had no internal shear keys. There was no evidence of any significant longitudinal movement in the backwall. The backwall remained intact, with no signs of cracking [ref 5.4-1].

At pier 2, the column failed completely. The main reinforcing steel in the column remained attached to the bent cap. The top of the column at pier 2 had translated several feet ahead of the base of the column (along the centerline of the bridge) toward pier 3 . The exterior girders on both sides of the bent cap had large vertical cracks at the face of the bent cap (looking in elevation) [ref 5.4-1].

Pier 3 remained standing. Pier 3 did not have cracking on the transverse face, while some vertical cracking ( $3 / 8^{\prime \prime}$ wide) was evident on the longitudinal face (looking in elevation). The superstructure on both sides of the pier was on the ground. The \#18 bars appeared undamaged, and all the concrete was cleaned from the bars. The \#5 stirrups in the bent cap had been ripped from the bent cap. Furthermore, there was no longitudinal, mild steel through the bent cap. When the prestressing was over-stressed and failed, the superstructure had almost no negative moment capacity [ref 5.4-1].

Hinge 1 had 4 7-cable restrainer units with an available seat width of 10 inches. The cable lengths were 5 feet and had been grouted. Both the restrainer units and equalizing bolts had failed in tension. Necking occurred in the equalizing bolts within the threaded portion. There was some localized damage at the face of the hinge, indicative of pounding [ref 5.4-1].

SR-14/I-5 Separation \& Overhead structure had many frames with columns of varying heights. The column at pier 2 was substantially shorter than most of the other columns in the structure. Also, all of the columns in the structure had column flares at the top. Longitudinal column reinforcement flared with the column and extended into the bent caps. In the very tall columns, the 
column flares did not affect the performance of the column, while in shorter columns such as pier 2 , the flares played a larger role. The shortness of the column at pier 2 combined with the flare, attracted significantly higher shears to pier 2 than those developed at the taller, and therefore more flexible, frames. The resulting loads at pier 2 overloaded and failed the column, contributing to the collapse of the frame [ref 5.4-1].

Looking at the overall structure, frame 1 was much stiffer than frame 2. Hinge 3 , the hinge between the two frames, did not have sufficient seat width to handle the difference in deflections between the two frames. Frame 2 appeared to move radially outward, as is typical for a long, curved connector. This outward motion can be seen in the soil displacement at pier 4 , which had a gap between the soil and column of approximately 6 inches. Frame 1, with its stiffer columns, was not able to deflect as much as frame 2. The contribution of an outward motion of the structure and the differences in stiffness between frames 1 and 2 led to the unseating of hinge 1 [ref 5.4-1].

The radially outward motion of frame 2 introduced a counter-clockwise rotation in frame 1 . This can be seen by the failed shear key at the abutment [ref 5.4-1]. Pier 3 had the problem of a column collapsing on one side and the long side of hinge 1 unseating on the other side. The superstructure was unable to carry the cantilevered loads from both sides and failed, not only taking the longitudinal steel from the superstructure with it, but also the top bent cap steel [ref 5.4-1]

Another contributing factor to the failure was that this structure was under construction along with the rest of the SR-14/I-5 Interchange during the 1971 Earthquake. Frame 1 was on falsework with the girder stems and soffit in place, but the top deck had not been placed. Photos from the 1971 Earthquake show that the falsework settled enough to induce cracks in the soffit and the girders at the face of the bent caps. A photo (that was taken from the Northridge Earthquake) showing the cracks at the faces of the bent cap resembles the photos from the 1971 Earthquake. This could account for the reason that the bent cap at pier 3 failed so completely [ref 5.4-1].

\subsubsection{I-5 at Gavin Canyon Undercrossing}

Gavin Canyon Undercrossing is located on I-5 approximately 2 miles north of the intersection of Routes 5 and 14 in Los Angeles County. I-5 is the main artery connecting the San Joaquin Valley and Sacramento Valley (to the north) with the cities of Los Angeles and San Diego (to the south). I-5 also serves as a commute route for many who work in the Los Angeles area and live in north LA county. 
At Gavin Canyon Undercrossing there are two separate bridges, right and left. As described in more detail in the following paragraphs, at least one span collapsed on each bridge (see Figure 5.42a). Both bridges are approximately 741 feet in length and 68 feet wide (see Figure 5.4-2b). They were built in 1955 and retrofitted in 1974 with restrainer cables and diaphragm bolsters at the hinges [ref 5.4-1].

The superstructure is a RC box girder from abutment 1 to the hinge in span 2, and from the hinge in span 4 to abutment 6 . It is a CIP P/S box girder from the hinge in span 2 to the hinge in span 4. The skew is $66^{\circ}$. The structure depth is $8^{\prime}-6^{\prime \prime}$. The hinge seats are 8 inches. There are equalizing bolts parallel to the structure at the center of each bay in the hinges (24 required) [ref 5.4-1].

The bents are multi-column, RC, fixed frame. The columns are 6'-3" $\times 10^{\prime}$ octagonal sections with a one-way flare over a transition length of 20 feet (see Figure 5.4-2c). Main longitudinal reinforcement along the octagon's 6 short sides are cut 10 feet below the soffit line, while the rest continue into the flare and bent. The flare is formed with smaller reinforcement (\#8 bars). All of the longitudinal reinforcement is confined with \#4 @ 12" ties. The main longitudinal reinforcement is lapped with the \#14 dowels at the footings. The footings have only a bottom mat of steel, and 100-ton driven piles [ref 5.4-1]. The abutments are diaphragm type on spread footing with a shear key. Type-1A retaining walls are on either side of the abutment [ref 5.4-1].

On the southbound bridge, the second span collapsed. The fourth span of the southbound bridge was near collapse with the top half of the hinge no longer seated. On the northbound bridge, both the second and the fourth spans collapsed. The center frame of both bridges appeared to be undamaged as did all of the columns. Minor damage was observed at the abutments [ref 5.4-1].

The collapse of the spans was due to the unseating of the hinges. Once the structure became unseated, the superstructure was unable to carry the cantilevered load and failed in flexure at the columns. There were several factors contributing to the failures. First, the hinges had only an 8inch seat width, and the bridges were on a $66^{\circ}$ skew. Also, the columns at the center frame were very tall allowing the structure to deflect and rotate substantially [ref 5.4-1].

The structure did have restrainers; however, the restrainers were placed parallel to the centerline of the bridge. This allowed the structure to rotate with minimal elongation of the restrainers. When the structure became unseated, the restrainers either failed or they pulled through the diaphragm. In some locations restrainer units, including plates and bolts, could be seen hanging from hinge diaphragms. In other locations, ruptured restrainer cable sections could be seen [ref 5.4-1]. 


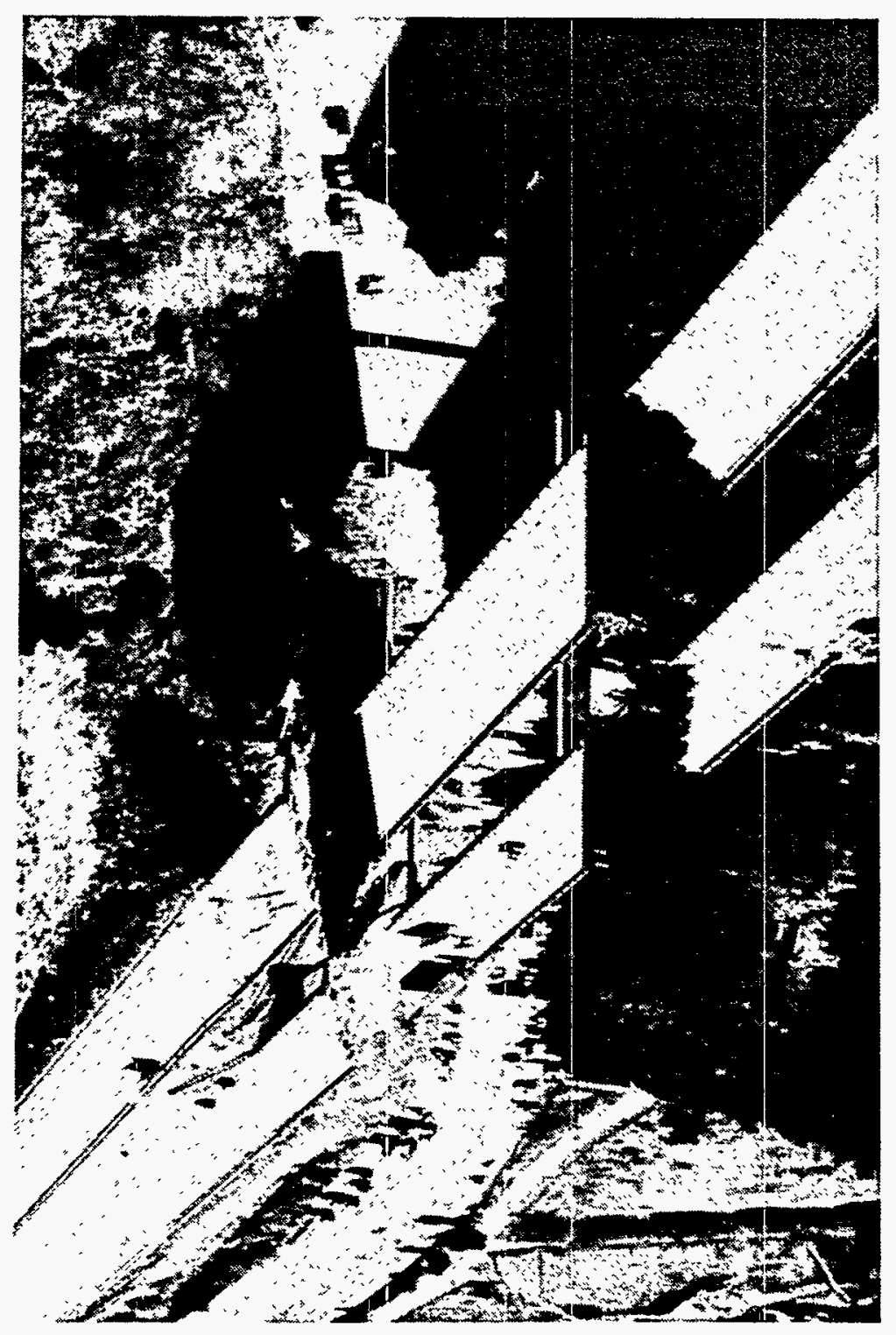




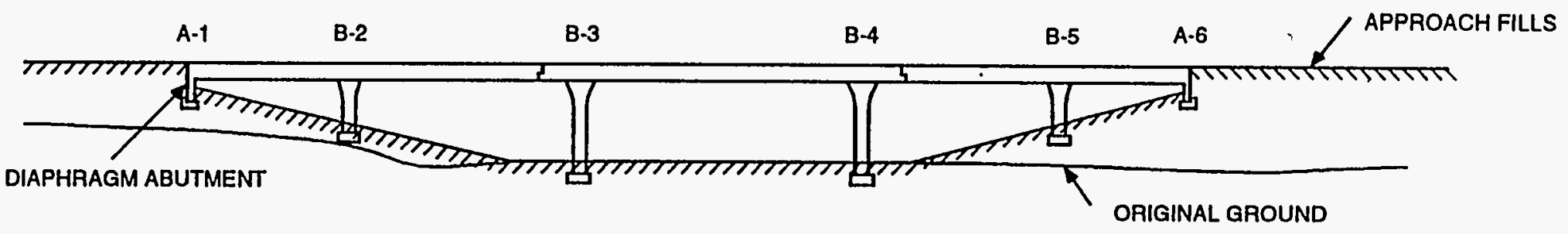

TYPICAL ELEVATION

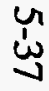

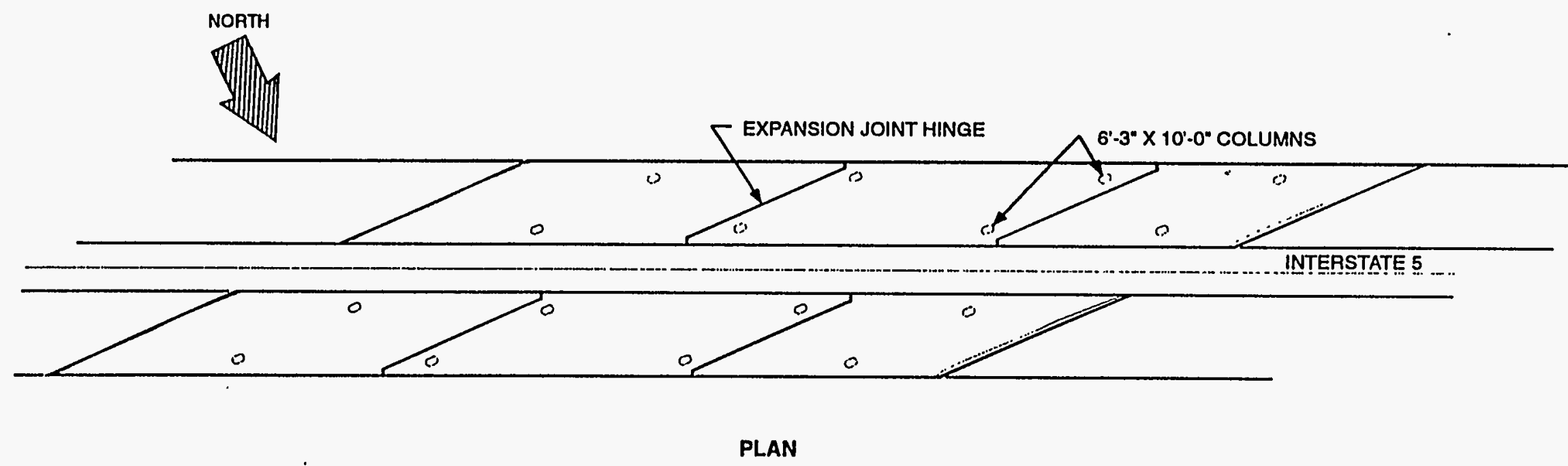

Figure 5.4-2b: I-5 at Gavin Canyon Undercrossing - General Plan and Elevation [ref 5.4-3]. 


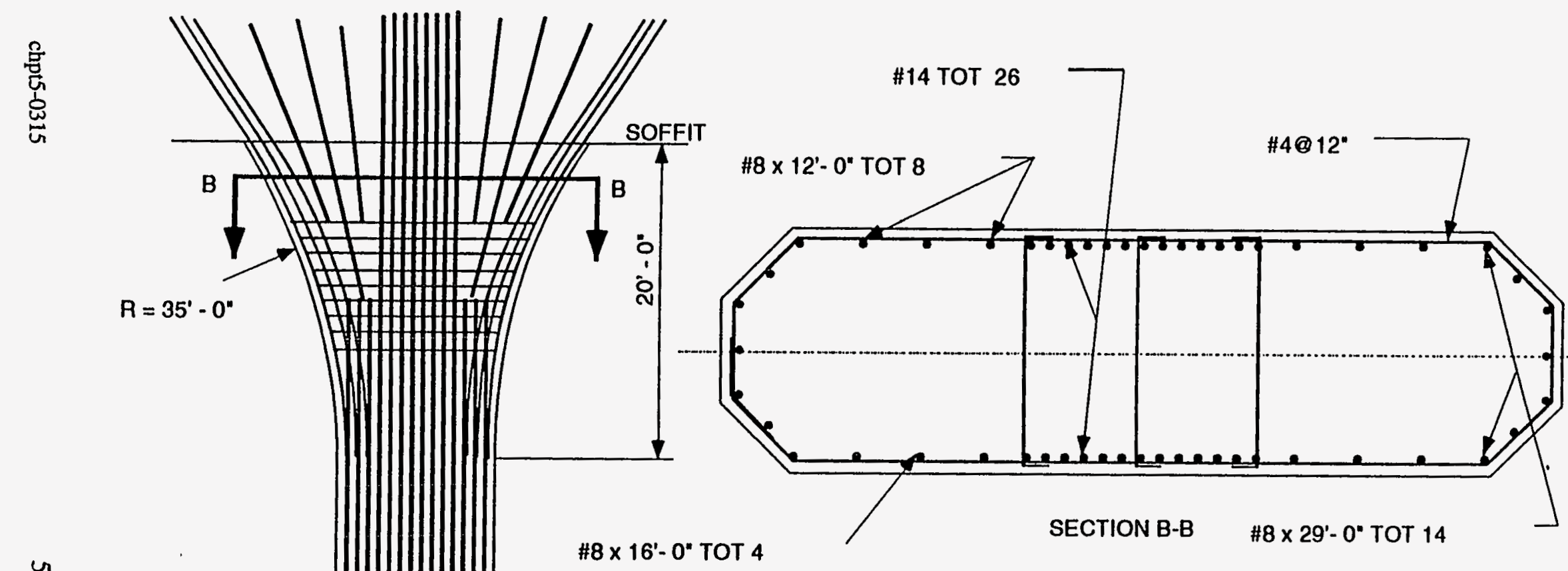

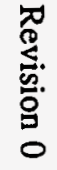

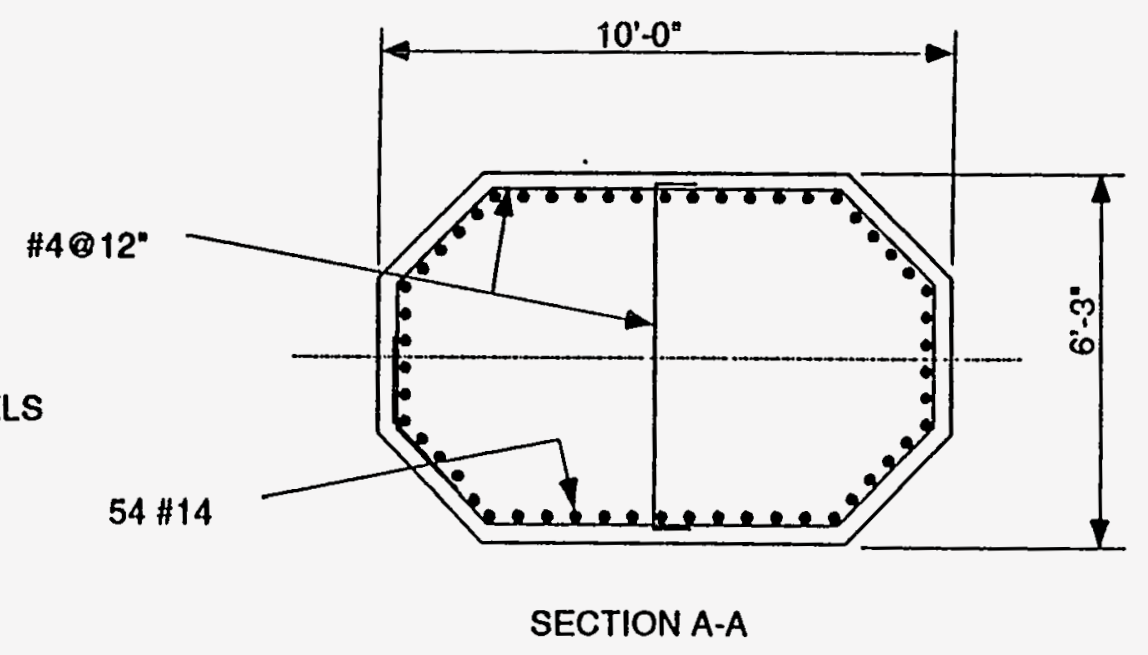

Figure 5.4-2c: I-5 at Gavin Canyon Undercrossing - Column Details [ref 5.4-3]. 


\subsubsection{SR-118 at Mission-Gothic Undercrossing}

SR-118 at Mission-Gothic Undercrossing consists of two parallel structures with skewed abutments (see Figure 5.4-3). The eastbound structure partially collapsed and was torn down soon after the main quake (see Figure 5.4-4). The columns have a flared region at the top which was intended to spall off but to not provide additional stiffness to the column. Instead, the flared top portion shortened the effective length of the column. As a result, the columns failed in shear near the mid-height of the columns (see Figures 5.4-5 through 5.4-9a).

Due to the configuration of the skewed abutments, the structures could move in only one direction which was to the southwest (see Figure 5.4-9b). Also, the orientation of some of the columns relative to the southwesterly direction of the large displacements contributed to failing of the columns about their weak axis.

The SR-118 eastbound structure which had partially collapsed was demolished and replaced in an extremely short construction schedule of about 4.5 to 5 months after the main seismic event. SR118 westbound structure at Mission-Gothic received wood timber and steel falsework that was erected to shore up the damaged structure. This was done so that the eastbound bridge next to it could be replaced while traffic in both directions was routed onto the westbound structure (see Figures 5.4-10 through 5.4-12).

\subsubsection{I-10 at La Cienega-Venice Undercrossing}

Interstate 10, the Santa Monica Freeway, is a heavily traveled artery that runs east-west from Santa Monica (on the west) through downtown Los Angeles (to the east). After that, I-10 continues east as the San Bernardino Freeway. The I-10 at La Cienega-Venice Undercrossing partially collapsed during the Northridge Earthquake. It is located about 17 miles southeast of the epicenter. The horizontal ground acceleration was about $0.25 \mathrm{~g}$ near this structure.

This bridge was constructed in 1964, and was retrofitted with cable restrainers in 1978. The bridge superstructure consists of cast-in-place, reinforced concrete box girders supported by multicolumn bents (see Figure 5.4-13). These columns lost core confinement of concrete due to shear failure. The typical shear reinforcement in the columns was \#4 bars @ 12 inches or \#4 spiral @ 12-inch pitch. The columns are each about 4 feet in diameter. 


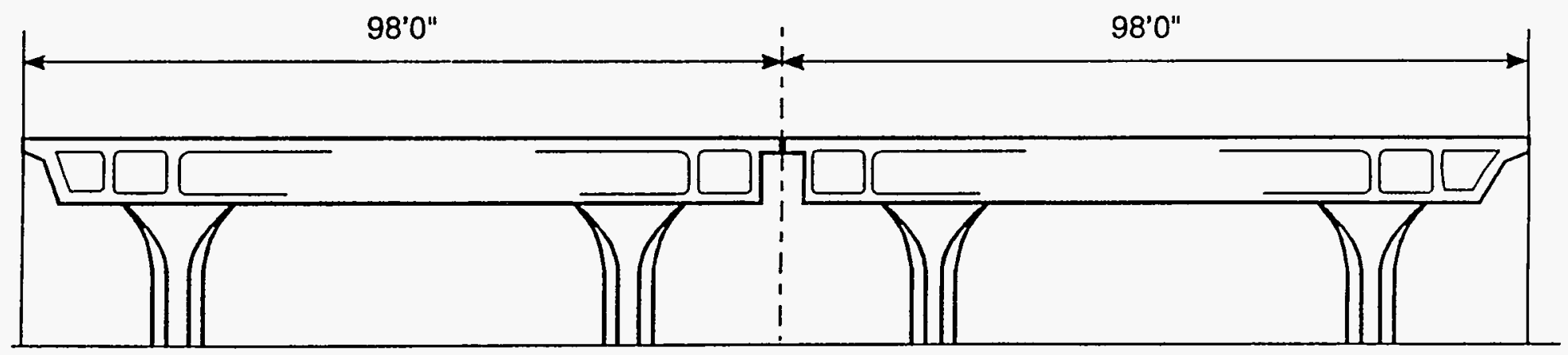

TYPICAL SECTIONS

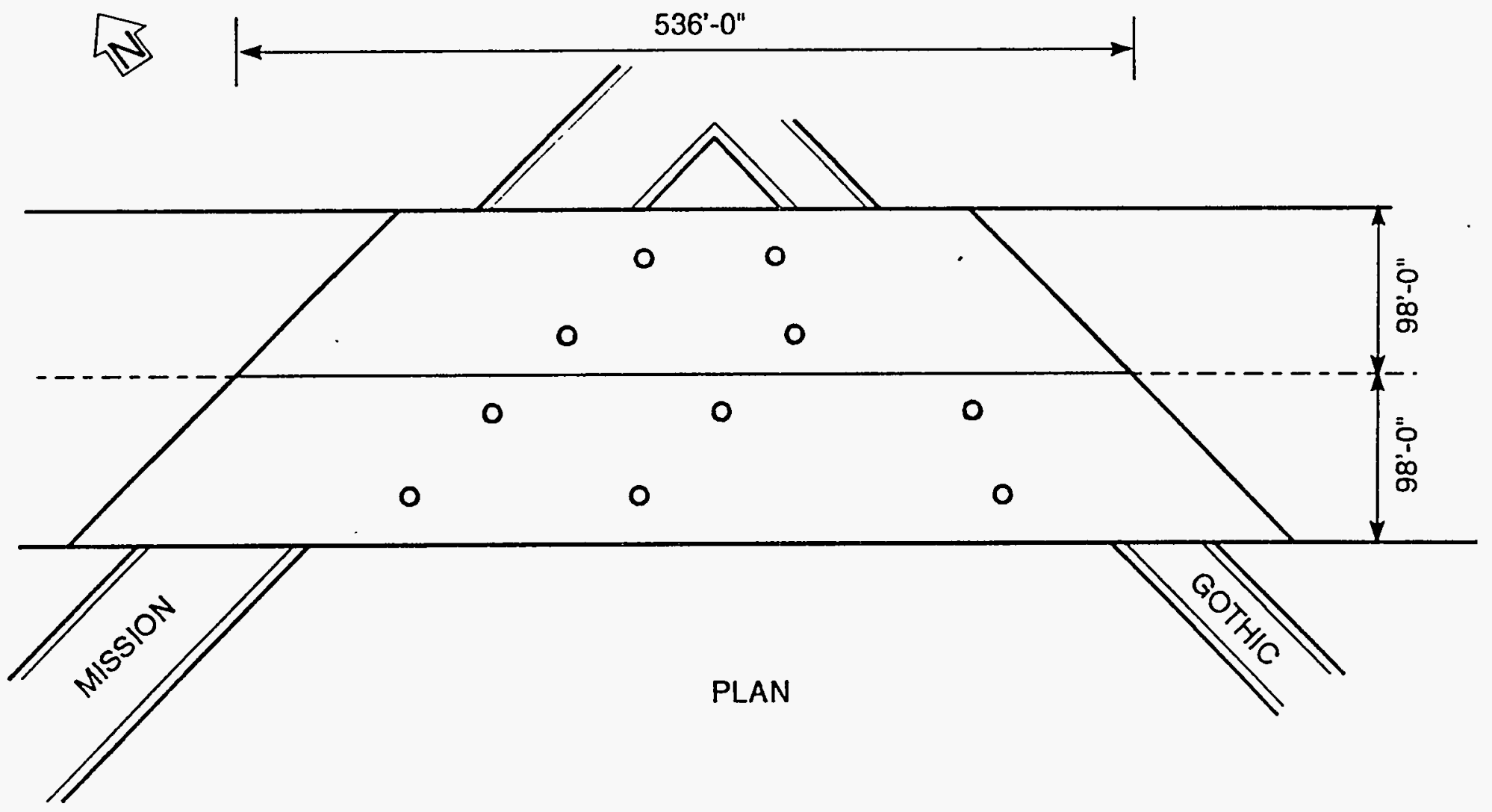

Figure 5.4-3: $\quad$ SR-118 at Mission-Gothic Undercrossing - General Plan and Elevation [ref 5.43]. 


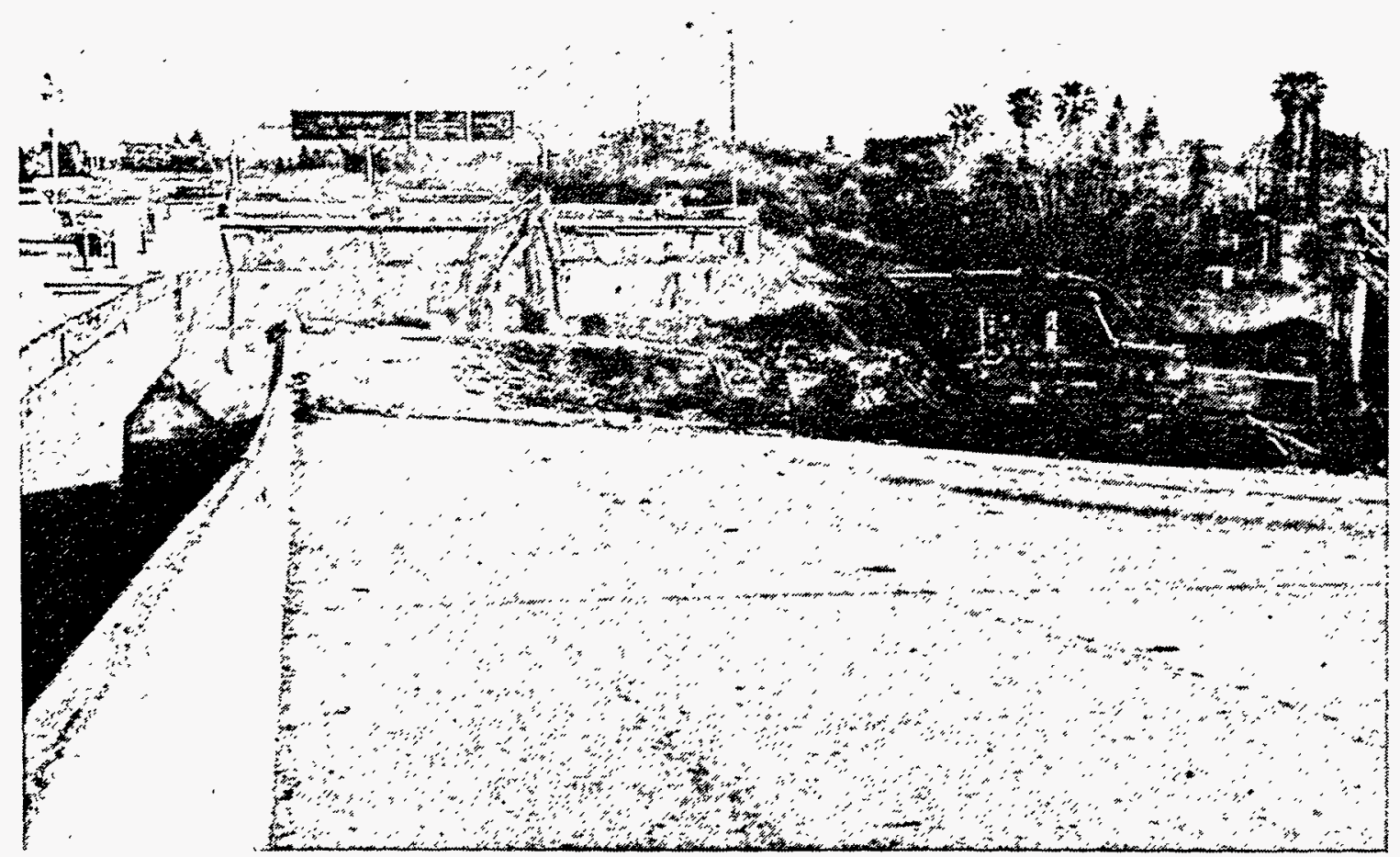

Figure 5.4-4: SR-118 at Mission-Gothic Undercrossing (looking southerly at the eastbound structure. The eastbound structure partially collapsed and was torn completely down several weeks after the main earthquake.

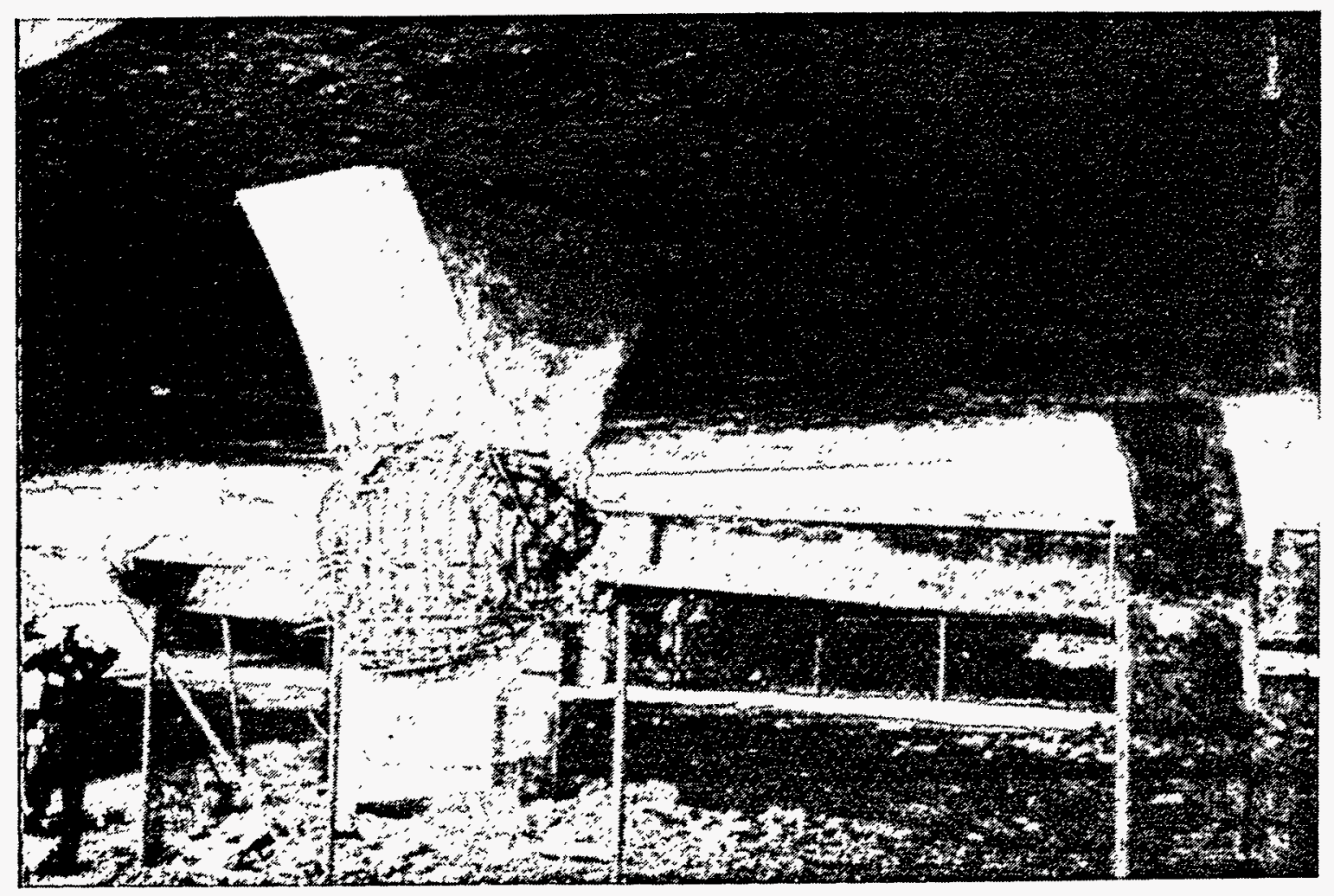

Figure 5.4-5: View of two of the columns on westbound structure of SR-118 at Mission-Gothic Undercrossing. Note failure of column is at mid-height just below flare. The partially collapsed eastbound structure is visible in the background. 


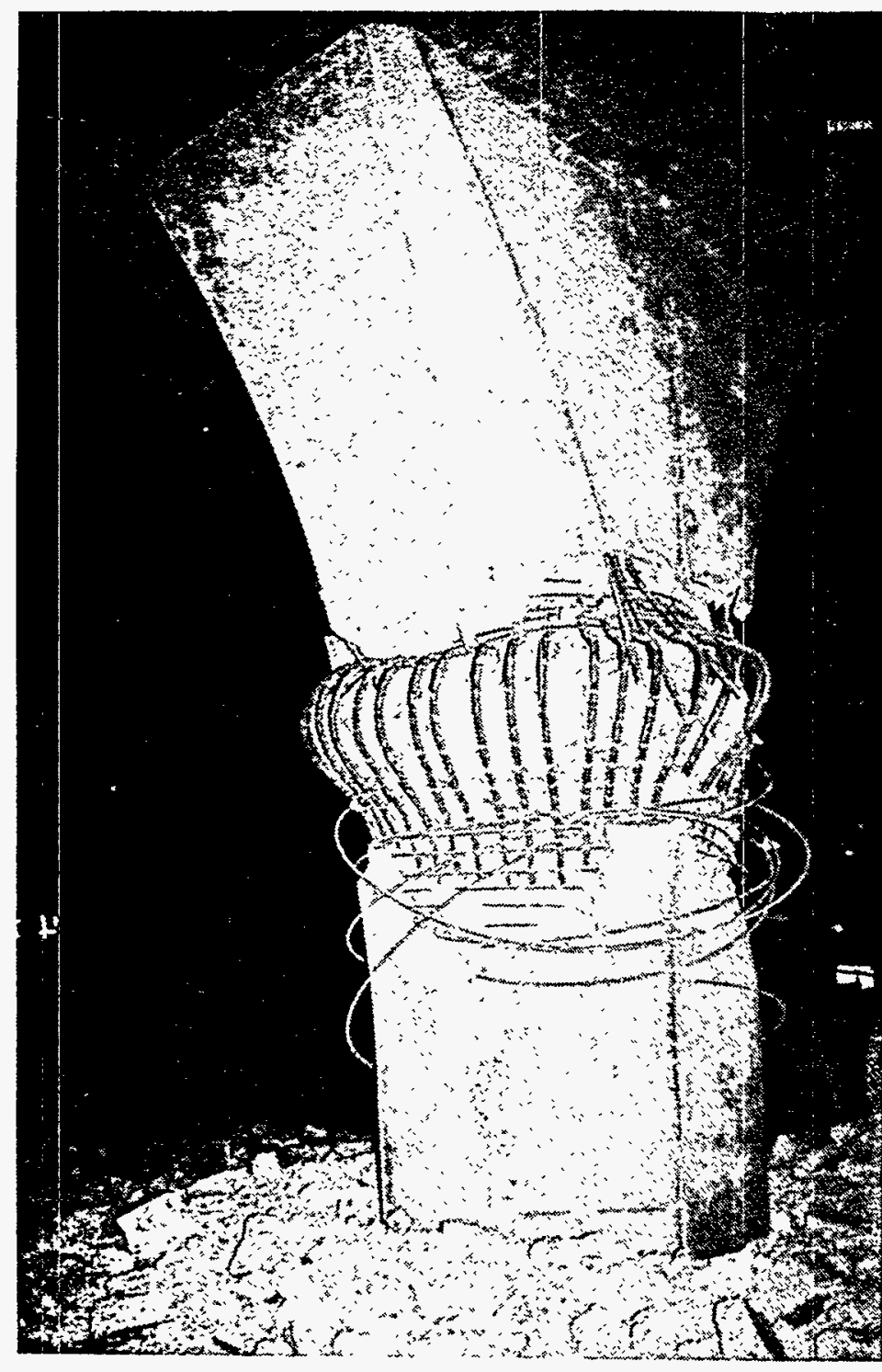

Figure 5.4-6: Close-up of column (failed in shear) on westbound structure of SR-118 at the Mission-Gothic Undercrossing. As core confinement of the column degraded, the vertical bars had very little axial compression load capacity.

Figure 5.4-7: Different close-up view of failed column on the westbound structure of SR-118 at Mission-Gothic Under-crossing. As core confinement of the column degraded, the vertical bars had very little axial compression load capacity.

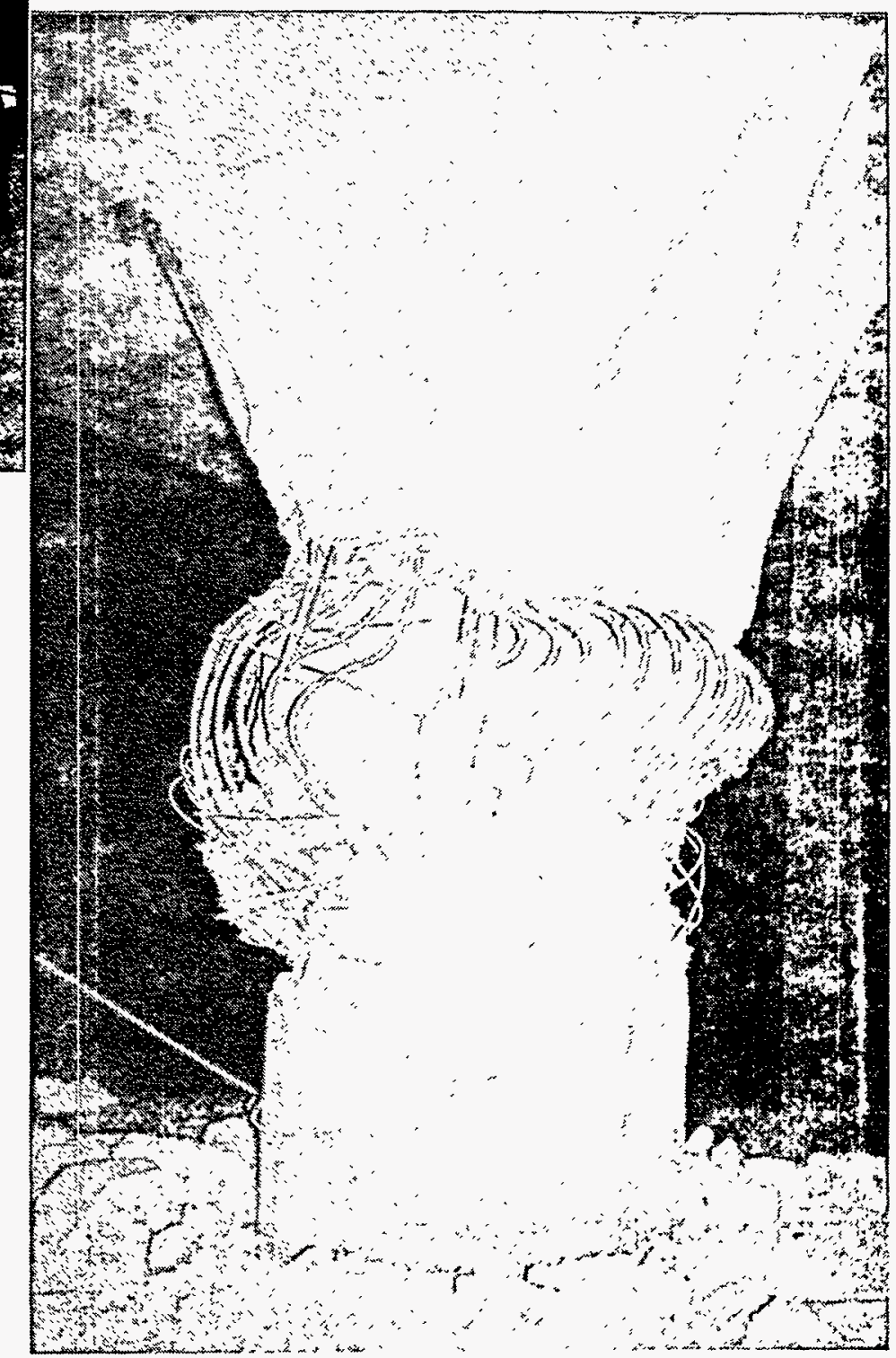




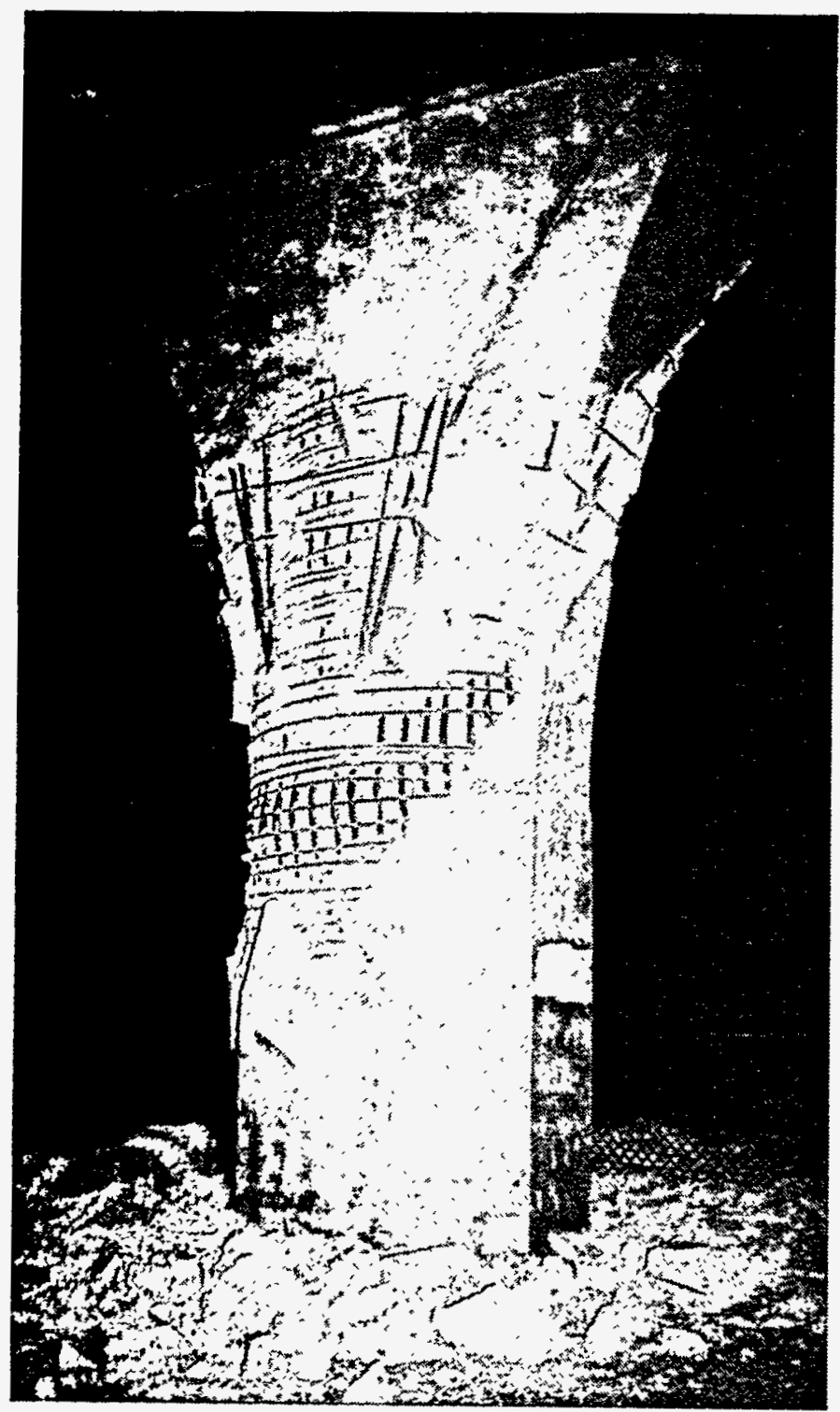

Figure 5.4-8: Close-up of column (on westbound structure of SR-118 at Mission-Gothic Undercrossing) with incipient structural damage.

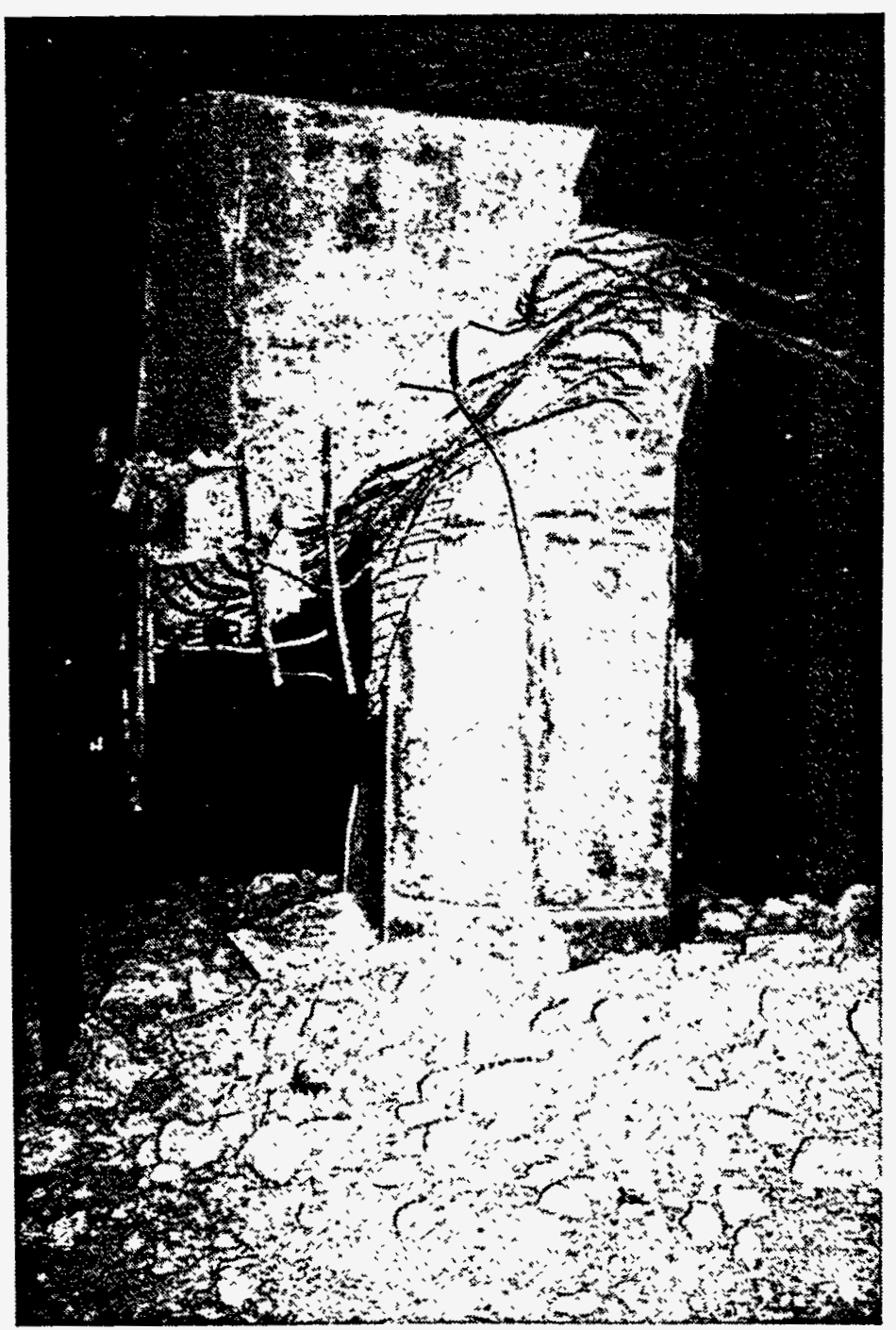


(a) EQ load to north and east bridge restrained by abutment backfills

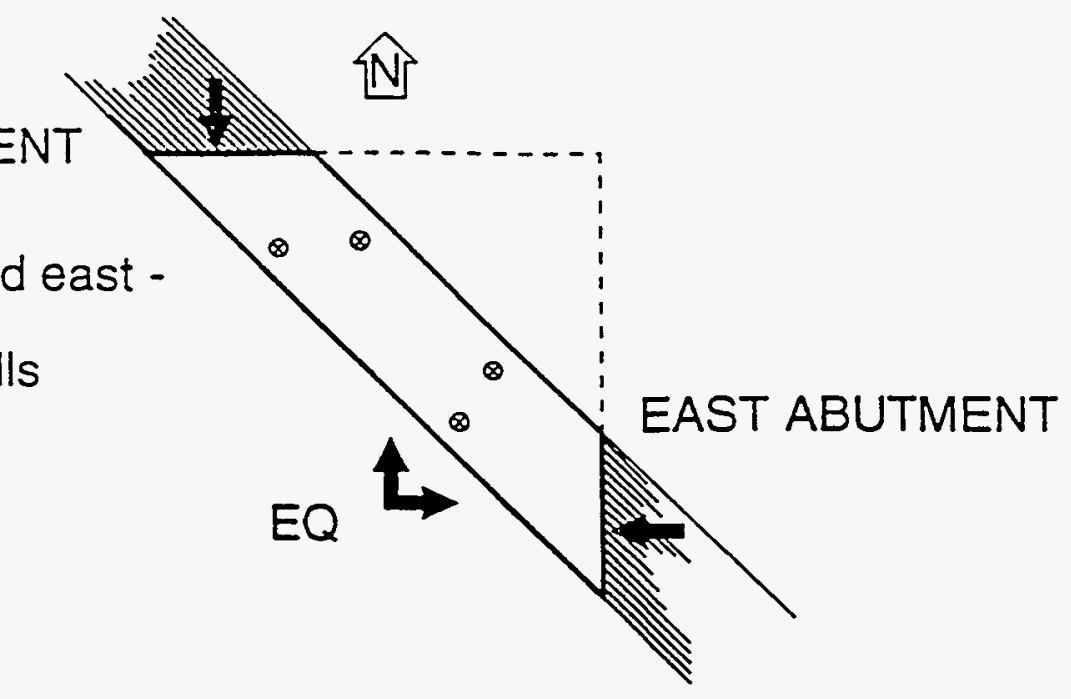

(b) EQ load to south and west bridge restrained by columns \& shear keys at each abutment

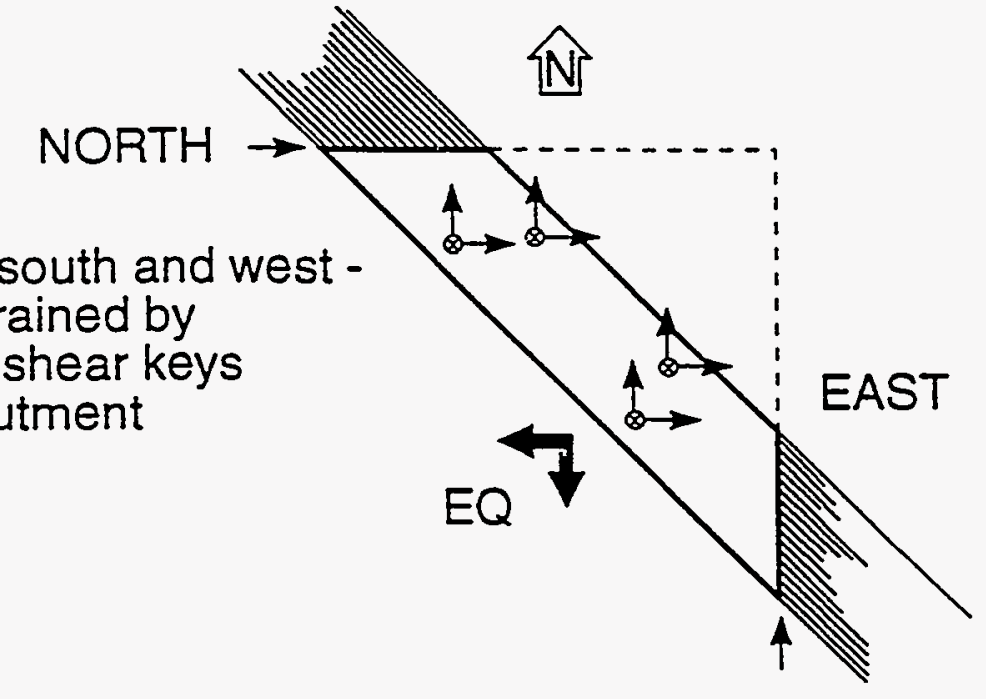

(c) EQ load to south and west shear keys fail and bridge rotates about north abutment

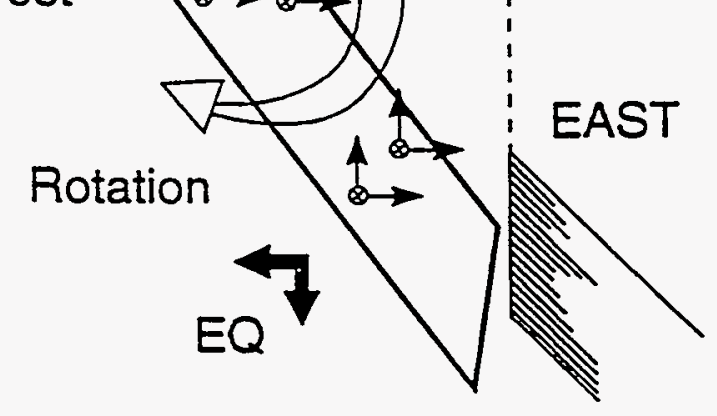

Figure 5.4-9b: SR-118 at Mission-Gothic Undercrossing (Eastbound Bridge) - Possible Load Distribution and Failure Sequence [ref 5.4-3] 


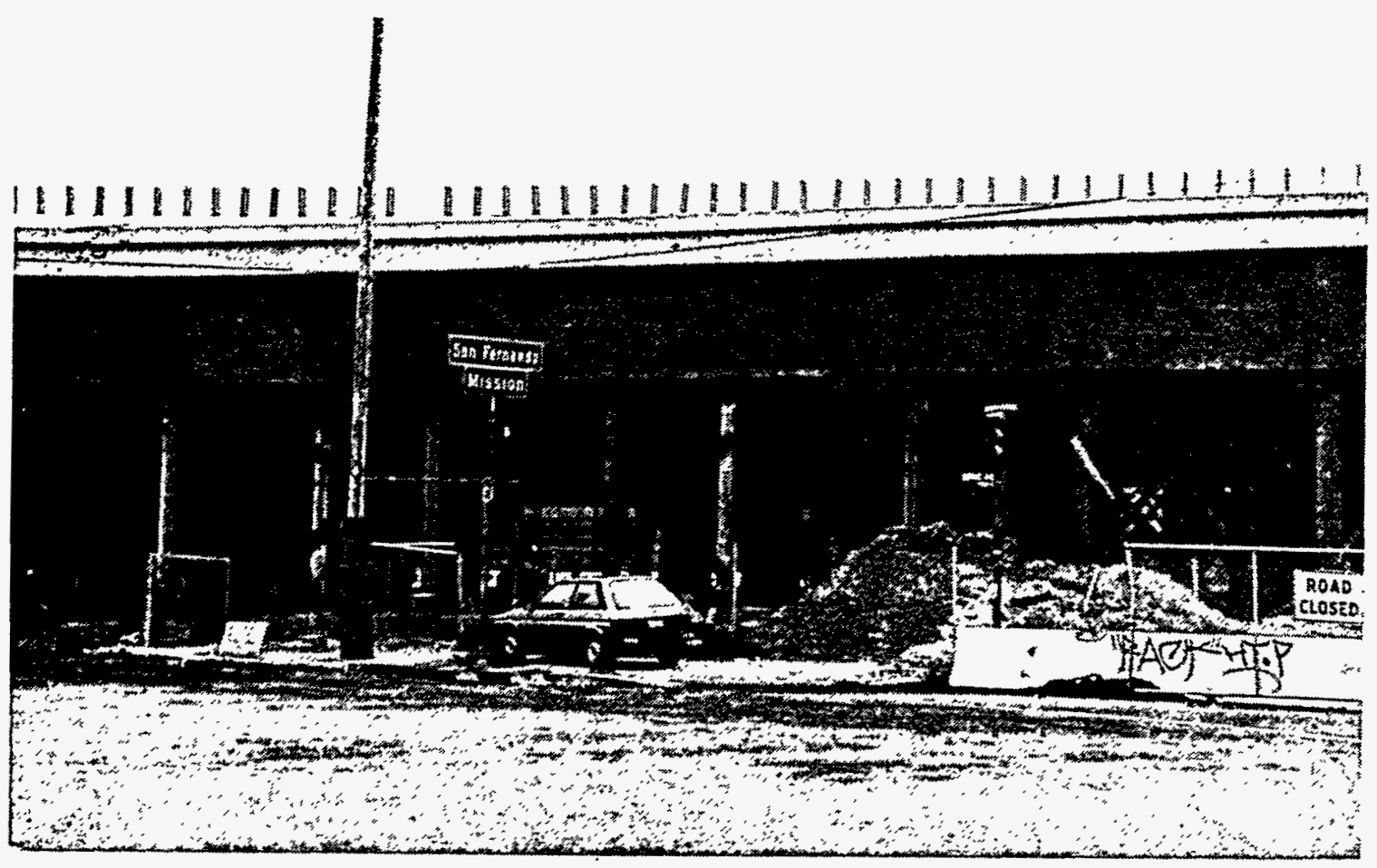

Figure 5.4-10: SR-118 westbound structure at Mission-Gothic Undercrossing received wood timber and steel falsework that was erected to shore up the damaged structure. This was executed so that the eastbound bridge next to it could be replaced while traffic in both directions was routed onto the westbound structure.

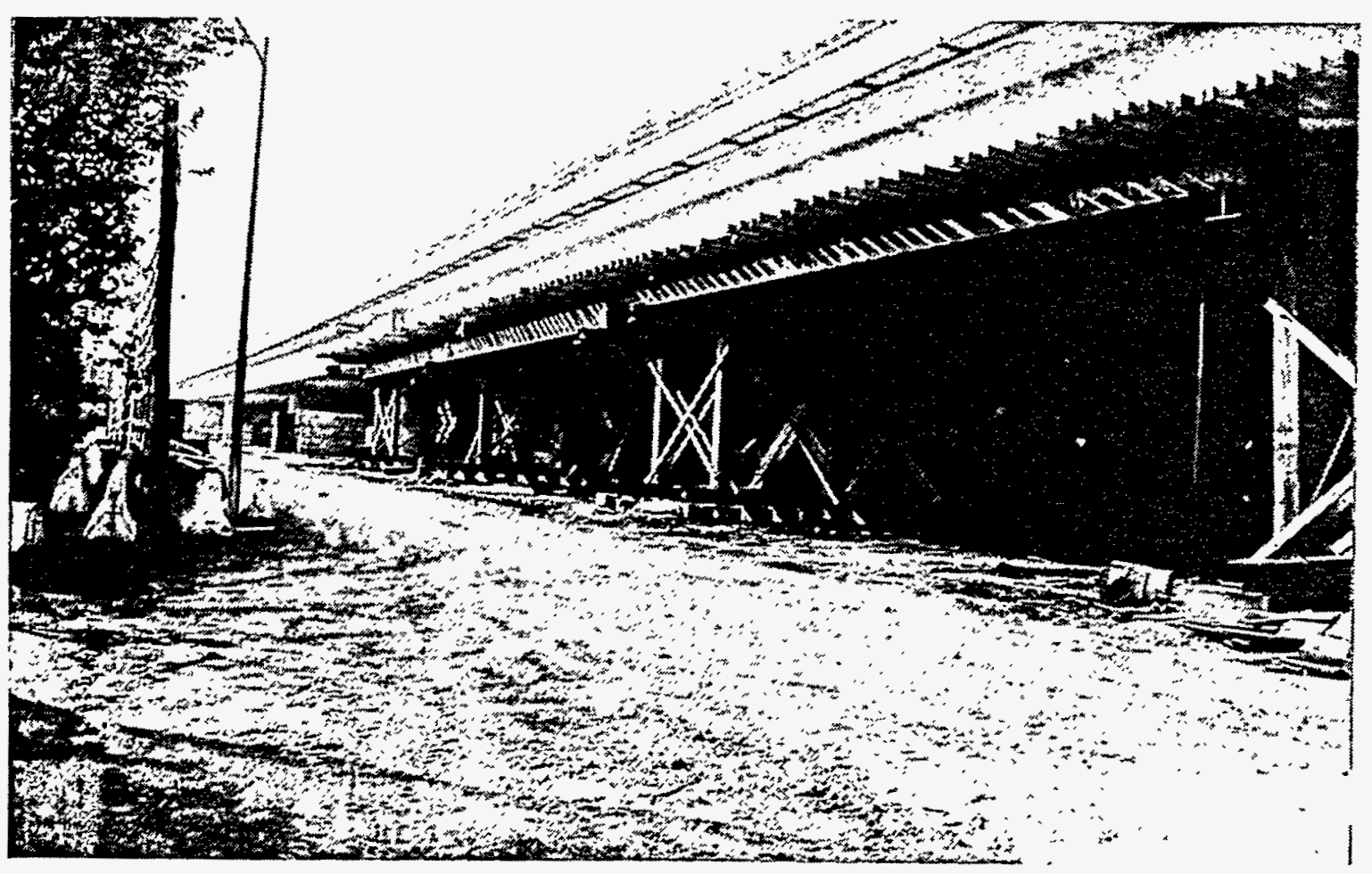

Figure 5.4-11: View looking north at replacement of SR-118 eastbound structure at MissionGothic U/C. In early May 1994, the forms and falsework were beginning to be removed from the new eastbound structure (SR-118 at Mission-Gothic). 


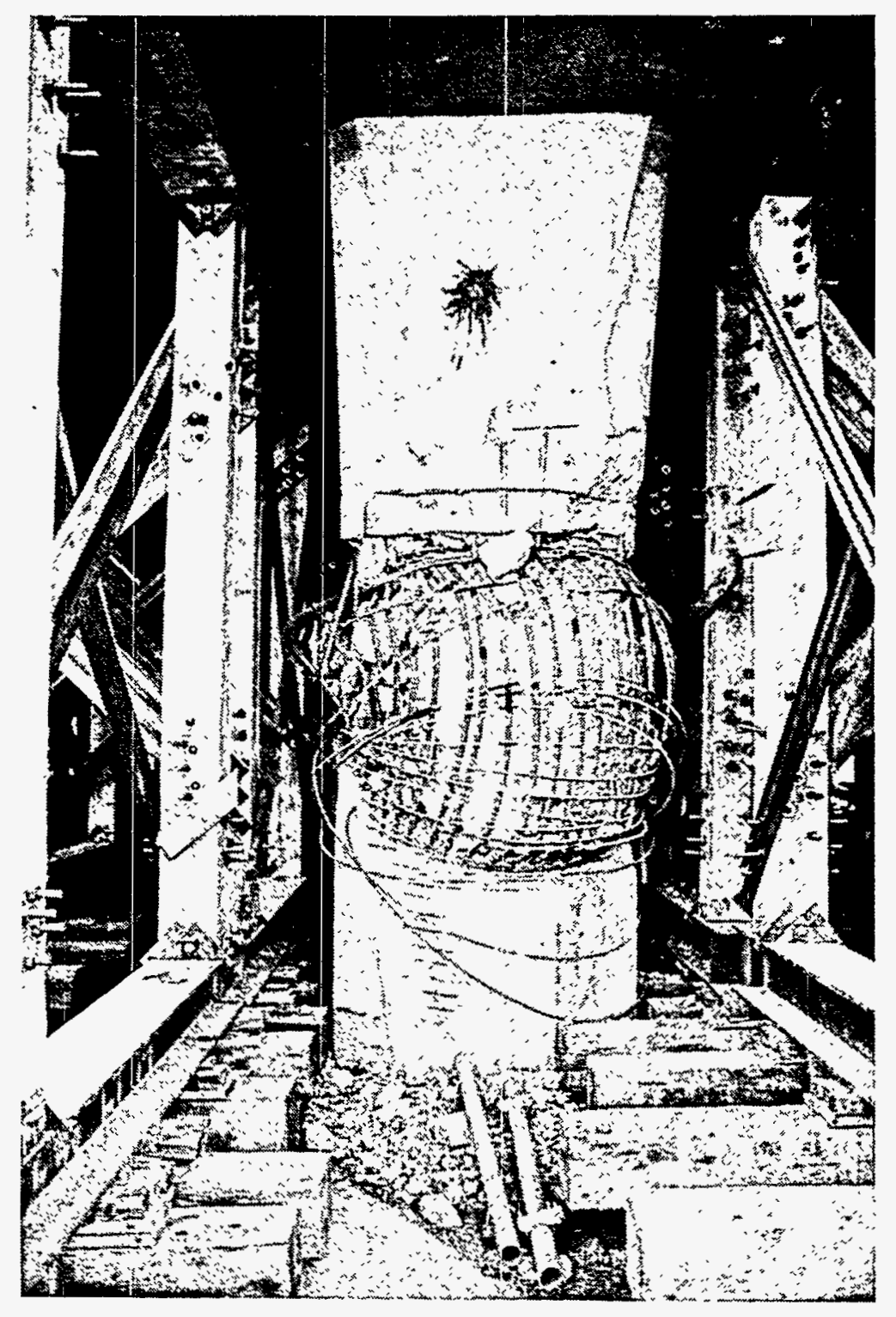

Figure 5.4-12: Close-up of temporary wood timber and steel falsework next to failed column on SR-118 westbound structure at Mission-Gothic Undercrossing. 

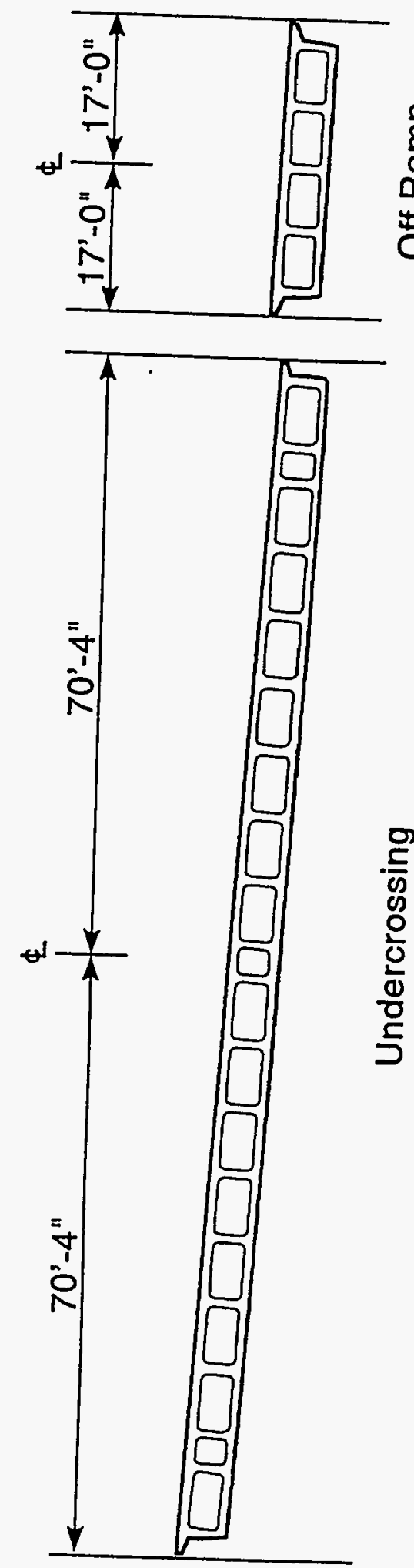
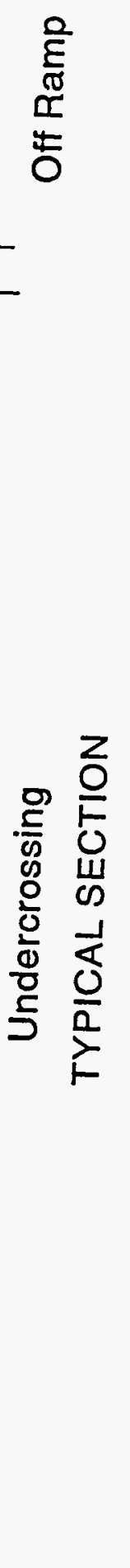

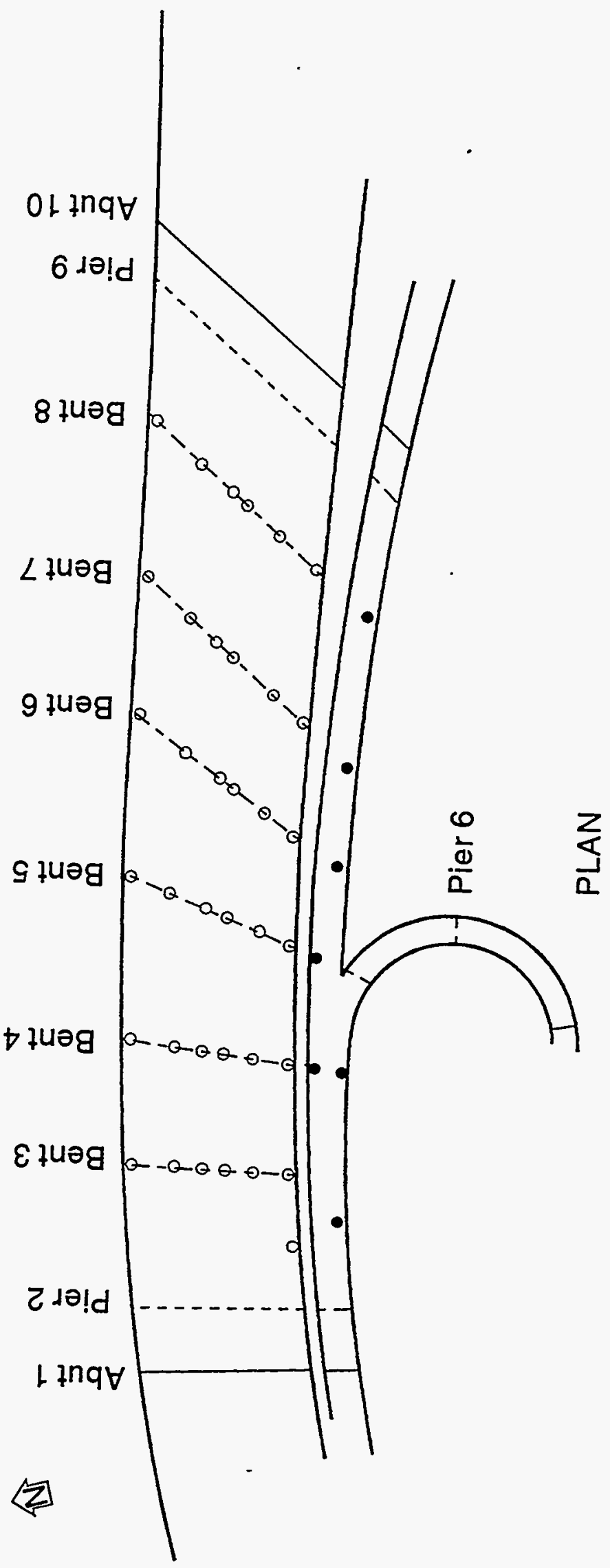

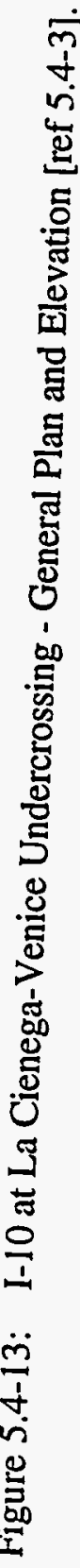




\subsubsection{Interaction of Lifelines at Highway Bridges}

The vulnerability of a lifeline that shares right-of-way with other lifelines is determined by the most fragile member; which may not necessarily be the lifeline under study [ref 5.4-3]. An example of this type of situation was demonstrated at the Balboa Boulevard Overcrossing at SR-118 during the Northridge Earthquake. As discussed in Section 5.1.1 of this report, water lines supported from the structure ruptured and subsequently washed out the soil beneath the approach and pile caps. This caused the collapse of approach pavement and undermining of the diaphragm abutment 1 and bent 2. Movement of the structure appeared to be primarily in the north-south direction, which is the longitudinal direction of the Balboa Boulevard Overcrossing (see Figure 5.4-14). Table 5.4-1 shows the utilities carried along the Balboa Boulevard Overcrossing [ref. 5.4-3].

Table 5.4-1: Utilities Carried by the Balboa Boulevard Overcrossing

\begin{tabular}{|l|c|l|}
\hline \multicolumn{1}{|c|}{ UTILITY } & SERVICE & \multicolumn{1}{c|}{ LIFELINES } \\
\hline Los Angeles Department of & Power & $6,5^{\prime \prime}$ ducts \\
Water and Power & Water & $1,12^{\prime \prime}$ pipeline \\
& Water & $1,8^{\prime \prime}$ pipeline \\
\hline Southern California & Gas & $22^{\prime \prime}$ line in $26^{\prime \prime}$ casing \\
Gas Company & Gas & $4^{\prime \prime}$ line in 8" casing \\
\hline General Telephone Company & Telephone & $4,4^{\prime \prime}$ ducts \\
AT\&T & Telephone & $6,4^{\prime \prime}$ ducts \\
\hline Unassigned & Unspecified & $4,3^{\prime \prime}$ ducts \\
\hline
\end{tabular}



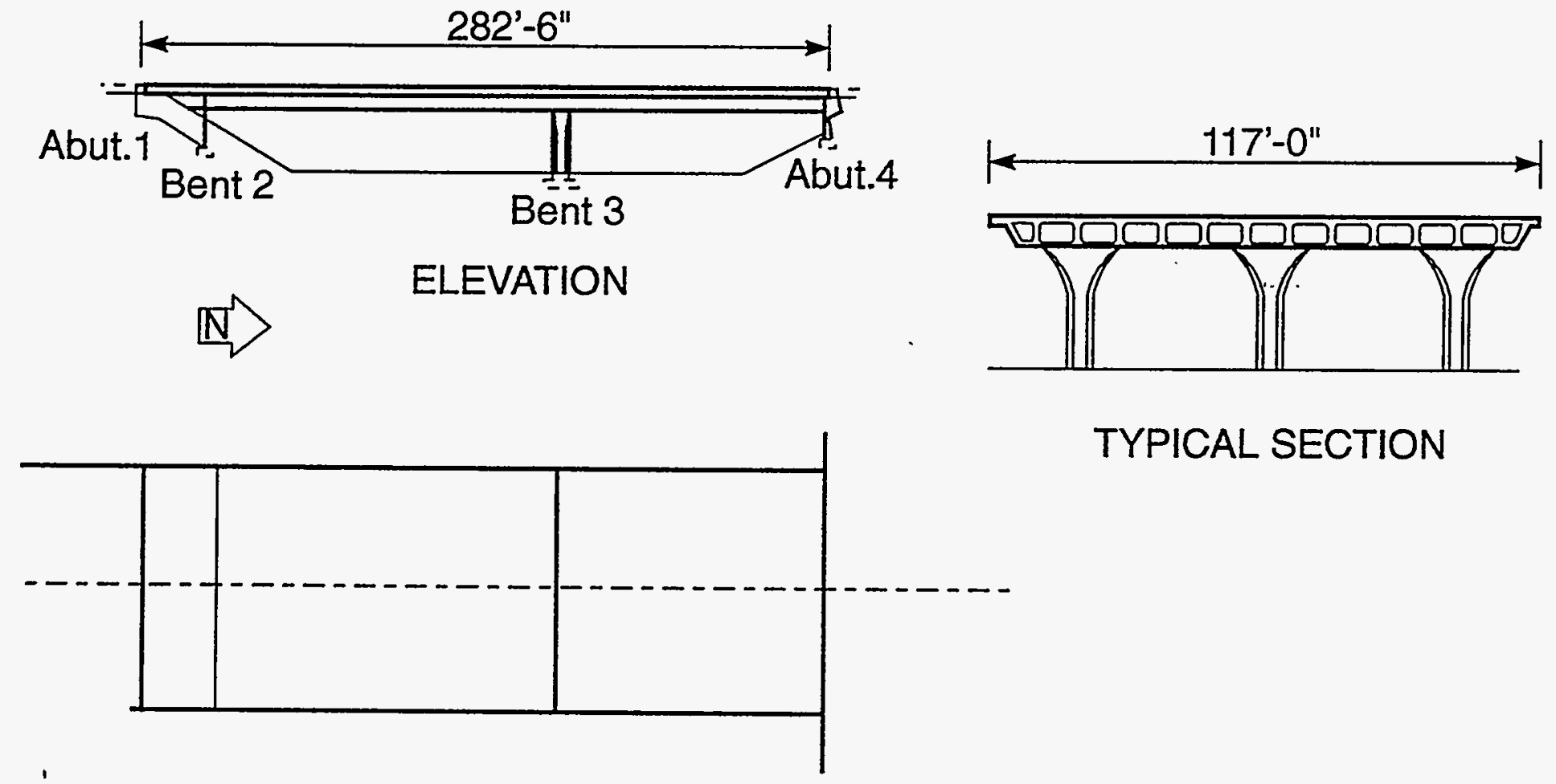

TYPICAL SECTION

\section{PLAN}

Figure 5.4-14: Balboa Boulevard Overcrossing at SR-118 - General Plan and Elevation [ref 5.43]. 


\subsection{REFERENCES}

5.1-1 Water for Los Angeles, Los Angeles Department of Water and Power, June 1991.

5.1-2 Buckle, I.G., The Northridge, California Earthquake of January 17, 1994: Performance of Highway Bridges, NCEER-94-008, State University of New York at Buffalo, March 24, 1994.

5.1-3 State of California Department of Conservation, Division of Mines and Geology, Third Quick Report on CSMIP Strong-Motion Data from the Northridge / San Fernando Valley Earthquake of January 17, 1994, Report OSMS 94-03, January 19, 1994.

5.1-4 Hall., J.F., Northridge Earthquake January 17, 1994 - Preliminary Reconnaissance Report, Earthquake Engineering Research Institute, 94-01, March 1994.

5.1-5 Todd, D., et. al., 1994 Northridge Earthquake - Performance of Structures, Lifelines, and Fire Protection Systems, NIST Special Publication 862, ICSSC TR14, United States Department of Commerce Technology Administration - National Institute of Standards and Technology, May 1994.

5.1-6 Lew, H.S., et. al., Engineering Aspects of the 1971 San Fernando Earthquake, Building Science Series 40, U.S. Department of Commerce - National Bureau of Standards, December 1971.

5.1-7 MWD Fact Sheet - 1993 Update, Metropolitan Water District of Southern California, April 1993.

5.1-8 Goltz, J.D., The Northridge, California Earthquake of January 17, 1994: General Reconnaissance Report, NCEER-94-0005, State University of New York at Buffalo, March 11, 1994.

5.1-9 Photograph provided by K. Salsman, Los Angeles Department of Water and Power.

5.2-1 Goltz, J.D. and Zadeh, Masoud, The Northridge, California Earthquake of January 17, 1994: General Reconnaissance Report, Section 4.1, Telecommunication, NCEER-940005, State University of New York at Buffalo, March 11, 1994. 
5.3-1 O'Rourke, T.D. and Palmer, M.C., The Northridge, California Earthquake of January 17, 1994: Performance of Gas Transmission Pipelines, NCEER-94-0011, State University of New York at Buffalo, May 16, 1994.

5.3-2 State of California Department of Conservation, Division of Mines and Geology, Fifth Quick Report on CSMIP Strong-Motion Data from the Northridge/San Fernando Valley Earthquake of January 17, 1994, Report OSMS 94-05, January 24, 1994.

5.4-1 California Department of Transportation - Division of Structures, "The Northridge Earthquake: Post-Earthquake Investigation Report".

5.4-2 Earthquake Engineering Research Institute, "Slides on the January 17, 1994 Northridge, CA Earthquake", Oakland, CA.

5.4-3 National Center for Earthquake Engineering Research, "The Northridge, California Earthquake of January 17, 1994: Performance of Highway Bridges", Technical Report NCEER-94-008, March 24, 1994, State University of New York at Buffalo, NY.

5.4-4 Earthquake Engineering Research Center, "Preliminary Report on the Seismological and Engineering Aspects of the January 17, 1994 Northridge Earthquake", College of Engineering, University of California at Berkeley, CA, Report UCB/EERC-94-01, January 1994. 


\section{OBSERVATIONS AND CONCLUSIONS}

\subsection{GENERAL}

The 1994 Northridge Earthquake was one of the largest earthquakes to occur within a major U.S. metropolitan area since the 1906 San Francisco Earthquake. A variety of engineered structures, systems, and components (SSCs) experienced strong seismic motions generated by the earthquake. The earthquake caused a considerable amount of damage including collapsed buildings, weld failures in steel moment-frame buildings, extensive loss of contents, loss of electric power and water to large portions of the epicentral region, and closure of major freeways. Due to the large number of recording stations for strong-motion accelerations within the epicentral region, there is a wealth of information about the seismic response of structures. The Northridge Earthquake exceeds all other earthquakes, including the 1989 Loma Prieta Earthquake, in terms of the number of strong-motion recordings from structures which were exposed to the earthquake. In many cases, these structures and their internal equipment experienced accelerations which significantly exceeded their seismic design bases.

Since the earthquake occurred in a highly populated and industrialized area, many types of SSCs experienced the event. To document and study the performance of some of these SSCs during the Northridge Earthquake, several industrial facilities, power plants, and lifeline facilities were investigated. In general, the investigated sites were those with larger facilities that experienced strong ground motions. The information gathered at these sites provides indications about good and poor design details for the seismic performance of SSCs.

Even with all the damage discussed in this report, many SSCs within the epicentral region survived the Northridge Earthquake with minimal or no damage. With the frequent occurrence of earthquakes in Southern California, there have been increased efforts to improve the seismic performance of structures and equipment. Much of these efforts were initiated following the damage to industrial facilities and lifelines during the 1971 San Fernando Earthquake. Many modern buildings and lifelines, which were designed and constructed with post-1980 seismic provisions, had minimal structural damage even though many of them experienced ground motion in excess of their design levels. This was due, in part, to enhanced seismic designs and detailing provisions. In addition, seismic mitigation efforts contributed to minimal damage during the earthquake at facilities such as the DOE Energy Technology Engineering Center. There was unexpected damage, though, in relatively new structures, including over 100 steel special-momentresisting-frames (SMRFs) and several parking garages. 
The ground motion at most of the investigated sites had moderate to strong amplitudes which were between $0.35 \mathrm{~g}$ and $1.0 \mathrm{~g}$ peak ground acceleration. In addition, several sites experienced vertical accelerations equal to or greater than the horizontal accelerations. Since for most structures the maximum seismic design value in building codes was $0.4 \mathrm{~g}$ horizontal, the Northridge Earthquake provided an opportunity to assess the performance of SSCs subjected to design level and beyonddesign level ground motion.

The relatively high accelerations were due to the type of faulting which caused the earthquake. It has been determined that the earthquake occurred on a blind thrust fault which had not been identified in many geologic maps. In the appropriate regions, seismic hazard determinations may need to be updated to reflect the presence of these types of faults. As is typical with many earthquakes, the frequency content was broadband between 1 and 10 Hertz. Most recordings of the earthquake motion indicate that the duration of strong shaking was about 10 seconds in the epicentral region. Interestingly, many recordings show several acceleration peaks or spikes within the duration of strong shaking. It is important to note that the seismic motion was not the strongest possible for most of the investigated sites. If a larger area of the blind thrust fault had fractured, if a fault with a larger seismic potential had moved, or if the duration of strong motion had been greater, there would have been more serious challenges to the SSCs within the epicentral region. In order to prepare for these inevitable scenarios, lessons should be learned from the response of SSCs during the Northridge and previous earthquakes.

The major observations and conclusions, or lessons learned, from the Northridge Earthquake are summarized in this chapter. In some cases, the lessons learned are actually lessons re-learned. Many of the SSCs discussed in this section are similar to those found in nuclear power plants and in DOE facilities. The lessons learned are divided into various categories of SSCs in order to organize the information. Information in this chapter was supplemented by summary data in References 6.1-1 through 6.1-5. For a pictorial summary of damage caused by the earthquake, Reference 6.1-6 contains a good selection of Associated Press photographs. Lessons learned from damage investigations of the Northridge Earthquake will greatly aid efforts by DOE, NRC, and EPRI to mitigate the effects of earthquakes on industrial facilities and lifelines, confirm design practices, and highlight new areas of further research. 


\subsection{STRUCTURES, SYSTEMS, AND COMPONENTS}

\subsubsection{Buildings}

In general, buildings designed and constructed using mid-1970s or later seismic requirements structurally performed well, except steel moment-frame buildings and parking garages.

While most buildings provided life safety as required by the building code, many of them were not functional or had significant nonstructural damage following the earthquake. An understanding of acceptable performance levels for buildings and other structures is needed.

In order to transmit earthquake-induced forces to the structural components designed to support the forces, appropriate connections for a complete and adequate load path and an adequate lateral forceresisting system are needed. Structures consisting of precast or tilt-up elements did not perform well when they lacked sufficient connections and load path development. The configuration of some parking garages with ramps, diaphragms, and short columns led to poor performance.

Buildings typically performed well when they were designed as integral systems without sudden changes in stiffness or strength so that the entire structure resisted the earthquake-induced forces. Important factors include continuity, rigidity, ductility, and stiffness.

Soft first stories below stiff upper stories were vulnerable to extensive distortion and damage due to a lack of sufficient shear capacity in the first story. The first story has insufficient shear capacity due to minimal shear walls, large openings, and architectural features.

The "short column" effect caused stiffer, shorter columns to attract the earthquake-induced forces, and those columns did not perform well if they had not been properly designed and constructed to have sufficient strength to resist these forces.

Structural components, which were not designed to be part of the earthquake-induced force resisting system, did not perform well if they were not detailed to accommodate drift.

Welded-flange, bolted-web connections of steel beams to steel columns suffered fractures and brittle failures in the joints due to cracks initiating at the welds with typical failure patterns of flange nugget pull-out, column fracture, and shear tab fracture. These failures were difficult to locate since most steel members were hidden behind fire proofing and architectural finishes. Prior to the Northridge Earthquake, steel SMRFs, which were designed according to the building code, were considered to behave in a ductile manner when subjected to seismic motion. 
Welded-flange, bolted-web connections in steel SMRFs had potential detailing problems such as stress concentrations at the connection, connection strength less than the member strength, prescribed connection detail with no rotation requirements, and a notch effect created by the backup bar. Since the issues concerning the damage to steel SMRFs are evolving, the relative contributions of the problems listed above are yet to be determined.

Cracks in the welds of flange-web connections of steel moment-frame buildings were, in some cases, due to poor weld quality contributing to a lack of fusion between the girder flange and the column. In addition, back-up and dam bars served as crack initiation sites.

Welded connections on steel SMRFs needed to have a redundant structural system to allow load redistribution upon damage to critical beam-to-column joints. Some steel moment-frame buildings had optimistic designs with few connections and large members such that there was little redundancy for load redistribution.

Potential repairs to connections in SMRFs include removal of the back-up bar, addition of fillet welds, and steel plate reinforcement. All of these are attempting to relieve stresses in the bottom girder flange to column connection.

Preliminary enhanced welding procedures are being specified for steel moment frames including the use of AWS D1.1 procedures, filler materials with increased toughness, and removal of backup bars and weld tabs.

Nonductile reinforced concrete buildings, which were known to be vulnerable to earthquake damage, lacked sufficient capacity to resist earthquake-induced motion and suffered collapse. Poor beam-to-column connection details contributed to the collapses.

Structural components constructed with unreinforced masonry (URM) performed poorly.

Rehabilitation of URM with parapet braces and bolts connecting the horizontal diaphragms to exterior walls provided improved performance as compared to complete collapse. URM, whether rehabilitated or not, presented a life safety concern due to falling brick.

When designed and constructed properly, seismic base isolated buildings performed well and reduced the earthquake-induced forces in the building. Base isolated buildings were functional during and immediately following the earthquake.

Impacts of base isolated buildings with nearby components occurred when the seismic gap around the building was not properly designed or constructed. 


\subsubsection{Nonstructural Components of Buildings}

Damage to nonstructural components caused many facilities, which had no or minimal structural damage, to be inoperational. A relatively large amount of critical facilities, such as hospitals, had degradation of service due to nonstructural damage. Damage to internal lifelines within a facility also contributed to those facilities being inoperational.

Nonstructural components, such as nonload bearing partition walls and raised floors, were damaged by the earthquake-induced motion, especially between adjacent structures. Damage to these components contributed to damage to internal lifeline systems, such as fire sprinklers and communications.

Damage to nonstructural components, such as light fixtures, storage cabinets, gas cylinders, and suspended ceilings, caused life safety and seismic interaction concerns.

If building contents were not secured from earthquake-induced motion, they were not available or caused other equipment to not be available for repair efforts following the earthquake. Many computer terminals were damaged from falling.

Storage rack systems were damaged due to excessive loading, poor anchorage, and nonredundant member design.

\subsubsection{Mechanical and Electrical Equipment}

Most equipment performed well when adequately anchored. In many cases, this equipment experienced ground motions which exceeded its design levels. Equipment, which had been seismically upgraded with additional supports or engineered anchorage systems, remained functional during the earthquake.

Vibration isolators on equipment performed well when designed for lateral loads, which typically involved using adequate seismic bumpers.

Damage to turbine bearings occurred when there is no back-up power to the lube oil pump.

The potential for seismic-induced relay chatter needs to be evaluated on electromechanical protective relays for critical electrical circuits. There were no reports of relay functional failures. 
Real-time earthquake monitoring systems experienced hardware and software problems, but did provide useful information for recovery efforts. Rapid post-earthquake loss assessment also aided recovery decision efforts.

\subsubsection{Electric Power Systems and Substation Components}

The largest contributor to the power outage was damage to transmission substations with the most significant vulnerability being the high voltage transformer bushings. Due to interconnections of the electric power grids, loss of power in the epicentral region caused power loss throughout a larger area.

Economic and societal recovery from the earthquake was very dependent on the operation of the lifeline systems, especially power and transportation. The vulnerability of lifelines needs to be reviewed for impact on continued operations or ability to restart after a major seismic event.

Redundancies and effective emergency response plans in the electric power system and water system allowed service to be restored relatively quickly.

Electric power was restored to some facilities that were structurally damaged which, in a few cases, caused concerns about fire hazards.

Electric power plants had minimal damage and provided power when the grid was restored.

The two nearest nuclear power plants experienced minimal ground motions which had no effect on plant operations. Located about 80 miles from the epicenter, the San Onofre Nuclear Power Plant had a measured peak ground acceleration of $0.02 \mathrm{~g}$. The Diablo Canyon Nuclear Power Plant, located 145 miles from the epicenter, had measured peak ground accelerations of about $0.002 \mathrm{~g}$ [ref 6.1-5].

Some substation components which were designed, tested, and constructed with post-1971 seismic provisions had good performance. Composite bushings generally performed better than porcelain bushings.

Dead tank circuit breakers performed well.

Most $115 \mathrm{kV}$ and lower voltage equipment performed well. An exception was at one facility where there was damage resulting from failure of cast aluminum connectors on $34.5 \mathrm{kV}$ bus structures. 
Porcelain-supported electric power components, such as transformer bushings, rigid bus, live tank circuit breakers, capacitor banks, disconnect switches, and lightning arresters, were vulnerable to earthquake-induced damage. Porcelain or ceramic elements for $230 \mathrm{kV}$ and $500 \mathrm{kV}$ were especially vulnerable due to brittle failure modes such as fracturing at the base of insulators.

Live tank circuit breakers were damaged at seismic accelerations as low as $0.15 \mathrm{~g}$. Live tank breakers were vulnerable since they had large masses supported on top of tall, porcelain supports.

Buswork performed well when there were slack and flexible connections between components to withstand the relative motions of the components. At one substation, a bus system was damaged since it did not have sufficient flexibility to accommodate earthquake-induced motions.

Substation components with tall, slender porcelain insulators, such as disconnect switches and lightning arresters, were damaged at seismic accelerations as low as $0.15 \mathrm{~g}$.

High voltage transformers had several types of damage including oil leaks at pipe connections of the radiator to the transformer body, collapsed surge arresters, and fractures and oil leaks in transformer bushings.

Substation components had seismic interaction issues due to damaged components falling on or pulling down other components.

A type of series capacitor bank was damaged.

Several lattice transmission towers in vulnerable locations, such as ridge tops, suffered foundation failures and were damaged.

\subsubsection{Water and Natural Gas Systems and Piping}

The differential movement of piping and ductwork at building separations needed to be accommodated, especially where adjacent buildings had a significant difference in natural frequency or where one building was on a spread footing and the adjacent building was on deep pile foundations.

At several facilities, inertial motion potentially caused damage to piping at transition regions of the pipe diameter. At one facility, there was failure of a 3-inch valve body on a 4-inch piping line. Breaks in the piping system at one facility occurred in the flange area of a 6-inch tee and near the 3inch end of a 6-inch to 3-inch reducer. 
Improperly installed or designed fire protection lines did not perform well. In many cases, these lines had numerous leaks and caused extensive water damage to computers and inventory. This water damage caused many facilities to be inoperational even though they had no structural damage.

Fire protection lines with threaded connections on elbows at branch lines experienced leaks due to interaction with suspended ceiling systems.

Pipelines designed and constructed with post-1971 seismic provisions performed well. Good performance was achieved with welded steel pipe with butt joints and ductile iron pipe with rubber gasket joints. For natural gas pipelines, polyethylene pipes and steel pipes with ductile connections, such as shielded or unshielded electric arc girth welds, performed well.

Redundancies and effective emergency response plans in the electric power system and water system allowed service to be restored relatively quickly.

Most damage to water system and natural gas pipelines occurred in distribution lines, not transmission lines. Repairs of water and gas pipelines were a time-consuming and expensive process. Tests of water quality also involved a relatively lengthy process.

Local ground instabilities and permanent ground deformations caused natural gas and large diameter water pipelines to shear, leak, or rupture.

Lifeline interaction occurred at several locations. At these locations, the failure of one lifeline system degraded the performance of the co-located systems such as pipelines. The vulnerability of a lifeline that shared right-of-way with other lifelines was determined by the most fragile member; which was not necessarily the lifeline under study.

Water treatment plants with post-1971 seismic provisions performed relatively well.

Water supply was significantly disrupted which caused concern since water was critical for emergency services such as fire fighting.

Dresser couplings in older-vintage water pipelines leaked because they could not withstand the earthquake-induced motion. In addition, cast iron pipe with rigid joints did not perform well.

Some water pipes had cracks in the change of curvature point in the bell section of the bell and spigot joints. 
Air and vacuum valves on water pipelines had damaged floats and toppled housings.

Corrosion decreased the capacity of older-vintage steel water pipelines to resist earthquake motion.

Natural gas pipelines with 1930 's-vintage oxyacetylene girth welds had nonductile performance at their connections and suffered failures, such as rupture or partial cracking.

In one location, natural gas pipelines with older-vintage, unshielded electric-arc girth welds had tension and compression failures.

Most fires were fueled by leaking natural gas pipelines and connected appliances.

Seismic shut-off valves for natural gas, which were predominantly in individual source lines, may have reduced the impact of fires.

\subsubsection{Tanks}

Welded steel tanks and prestressed concrete tanks designed and constructed to current seismic standards performed well.

Large tanks and attached piping performed well when there were flexible connections, such as an elastomeric flex connection, between the tanks and the rigidly anchored piping.

Attached piping did not perform well when the piping was fabricated from cast iron which typically had nonductile performance and could not accommodate the differential motion between the tank and rigidly attached piping.

Older-vintage steel tanks which were not designed and constructed for seismic motion and forces had damage, such as elephant foot buckling near the tank bottom and buckled shells near the top or middle of the tank.

Older-vintage water tanks had damaged roofs when they lacked sufficient capacity to withstand the earthquake-induced sloshing loads. Sloshing loads also damaged equipment at large water basins.

\subsubsection{Emergency Power}

The loss of offsite electric power emphasized the importance of sufficient emergency power, especially for essential operations. 
Most emergency generators were able to start on demand. If one of the supporting systems failed to function properly during the earthquake, there was no capability to distribute the emergency power to the critical SSCs.

Batteries were available for service when installed in anchored racks with spacers.

At one facility, the cable attached to the connecting bar for the battery terminals lacked sufficient slack to accommodate the seismic-induced motion of the batteries. In addition, the cable applied inertial loads to terminal connecting bar which transferred those loads to the terminals.

Emergency generators on engineered vibration isolators performed well when the startup batteries were restrained at top and bottom and there were flexible connections for fuel and electrical lines.

An automatic transfer switch from normal offsite power to emergency power failed to function properly at one facility. This switch had not previously been tested under full load. Emergency generators need to be regularly tested under load to ensure proper performance.

During the power loss, provisions were needed for adequate fuel supply and the ability to transfer fuel from the storage tank to the day tank since the electric pumps were inoperational.

Electrical shorts in distribution cabinets and switchgear due to water leaks from domestic water and fire sprinkler systems prevented some emergency power systems from operating.

Failure of controls to switch from the empty fuel day-tank to an auxiliary tank made an emergency generator inoperational.

\subsubsection{Transportation Systems and Freeway Structures}

Economic and societal recovery from the earthquake was very dependent on the operation of the lifeline systems, especially power and transportation. The vulnerability of lifelines needs to be reviewed for impact on continued operations or ability to restart after a major seismic event.

Lifeline interaction occurred at several locations. At these locations, the failure of freeway structures degraded the performance of the co-located systems such as pipelines. The vulnerability of a lifeline that shared right-of-way with other lifelines was determined by the most fragile member; which was not necessarily the lifeline under study. 
Toxic or hazardous materials conveyed on transportation systems presented health hazards when the systems were damaged.

Bridges designed and constructed using late-1970s or later seismic requirements performed structurally well. Large hinge seats allowed relatively large motions of some bridges.

High levels of confining steel were necessary in reinforced concrete bridge columns in order to provide adequate confinement of the core concrete.

The "short column" effect caused stiffer, shorter columns within a mixture of short and tall piers to attract the earthquake-induced forces. Those columns did not perform well if they lacked proper design and construction techniques to have sufficient strength to resist these forces.

Architectural flares at the top of some reinforced concrete bridge columns reduced the effective length of the columns and changed the location of the plastic hinge. This occurred when the rebar in the flares was integrally connected with the rebar in the rest of the columns causing a zone of increased stiffness. At other bridges, the columns were integrally connected with adjacent concrete walls. Columns with reduced effective lengths did not perform well.

Skewed or irregular alignment of a bridge increased its susceptibility to earthquake-induced damage due to relative motions of the bridge and its supporting structures.

Rehabilitation of nonductile reinforced concrete columns with steel reinforcing jackets provided increased seismic performance.

Steel rocker bridge bearings were vulnerable to earthquake-induced motion and were damaged leading to cracked girders and partial collapse of the bridge deck.

Bridge abutments had earthquake-induced damage ranging from shifting of entire abutment structures to impact damage, such as crushing due to pounding from adjacent girders. 


\subsection{ACTION ITEMS}

The effects of the 1994 Northridge Earthquake on industrial facilities and lifelines have reemphasized lessons learned from previous earthquakes and produced several new lessons. While most SSCs designed and constructed with post- 1980 seismic provisions survived the earthquake with minimal damage, there were many examples of older-vintage SSCs and SSCs with marginal seismic designs that experienced structural damage. The good and poor performance of SSCs during the Northridge Earthquake motivates the action items discussed in this section. By implementing these suggested action items at DOE facilities, mitigation efforts for the seismic design, retrofit, and construction of those facilities will be enhanced.

- Retrofit older-vintage facilities, such as those with nonductile designs.

- Retrofit SSCs identified as vulnerable to the effects of seismic strong motion, such as SSCs with brittle materials or with precast elements.

- Incorporate design, retrofit, and construction provisions that will be recommended by the structural engineering community to enhance the performance of steel special-moment-resistingframe buildings.

- Provide adequate seismic margin for SSCs through cost-effective design and retrofit by using ductile detailing, where appropriate.

- Use flexible connections, as appropriate, on piping systems at tank or equipment interfaces and at building separations.

- Evaluate the load path and anchorage of SSCs, especially those SSCs which are critical to the operation of the facility.

- Test emergency power systems to insure that the systems and their associated support equipment will function as intended upon demand.

- Review the performance of nonstructural items and their effects on the functionality of the facility.

- Incorporate redundancy in lifeline systems. 
- Study seismic interaction issues for safety-related SSCs located near nonsafety-related SSCs and review similar interaction issues for co-located lifeline systems.

- Address facility or SSC functionality by considering it as a system and by evaluating interactions of the system components.

The suggested action items discussed in this section can be summarized by a lesson learned following the 1994 Northridge Earthquake and previous earthquakes. Employing seismic mitigation efforts before an earthquake is a cost-effective means to provide life safety as well as to minimize damage, loss, and impact on facility operations. 


\subsection{REFERENCES}

6.1-1 Todd, D., et. al., 1994 Northridge Earthquake - Performance of Structures, Lifelines, and Fire Protection Systems, NIST Special Publication 862, ICSSC TR14, United States Department of Commerce Technology Administration, National Institute of Standards and Technology, Washington, D.C., May 1994.

6.1-2 Goltz, J.D., The Northridge, California Earthquake of January 17, 1994: General Reconnaissance Report, Technical Report NCEER-94-0005, State University of New York at Buffalo, March 11, 1994.

6.1-3 Draft of EERI Spectra on Northridge Earthquake, Chapter 5 - Lifelines, American Society of Civil Engineers, Technical Council of Lifeline Earthquake Engineering, August 19, 1994.

6.1-4 Eli, M.W. and Sommer, S.C., "Lessons Learned from the 1994 Northridge Earthquake", presented at the 22nd Water Reactor Safety Information Meeting, Bethesda, Maryland, October 24, 1994.

6.1-5 Taylor, J.M., "Magnitude 6.7 Northridge Earthquake of January 17, 1994", SECY-94077, United States Nuclear Regulatory Commission, March 23, 1994.

6.1-6 Shangle, R.D., Earthquake 6.8 - Los Angeles, January 17, 1994, American Productśs Corporation, Portland, Oregon, 1994. 